\title{
Precipitation of Neptunium Dioxide from Aqueous Solution
}

\author{
Kevin Edward Roberts \\ (Ph.D. Thesis)
}

December 1999 


\section{DISCLAIMER}

This document was prepared as an account of work sponsored by an agency of the United States Government. Neither the United States Government nor the University of California nor any of their employees, makes any warranty, express or implied, or assumes any legal liability or responsibility for the accuracy, completeness, or usefulness of any information, apparatus, product, or process disclosed, or represents that its use would not infringe privately owned rights. Reference herein to any specific commercial product, process, or service by trade name, trademark, manufacturer, or otherwise, does not necessarily constitute or imply its endorsement, recommendation, or favoring by the United States Government or the University of California. The views and opinions of authors expressed herein do not necessarily state or reflect those of the United States Government or the University of California, and shall not be used for advertising or product endorsement purposes.

Work performed under the auspices of the U. S. Department of Energy by the University of California Lawrence Livermore National Laboratory under Contract W-7405-Eng-48.

This report has been reproduced directly from the best available copy.

Available to DOE and DOE contractors from the

Office of Scientific and Technical Information

P.O. Box 62, Oak Ridge, TN 37831

Prices available from (423) 576-8401

http://apollo.osti.gov/bridge/

Available to the public from the National Technical Information Service

U.S. Department of Commerce 5285 Port Royal Rd., Springfield, VA 22161 http://www.ntis.gov/

OR Lawrence Livermore National Laboratory Technical Information Department's Digital Library http://www.llnl.gov/tid/Library.html 
UCRL-LR-137439

Distribution Category UC-40

\section{Precipitation of Neptunium Dioxide from Aqueous Solution}

Kevin Edward Roberts

(Ph.D. Thesis)

Manuscript date: December 1999

LAWRENCE LIVERMORE NATIONAL LABORATORY

University of California • Livermore, California • 94551 

PRECIPITATION OF NEPTUNIUM DIOXIDE FROM AQUEOUS SOLUTION

by

Kevin Edward Roberts

A Dissertation Submitted to the

Faculty of the Graduate School

In Partial Fulfillment of the

Requirements for the Degree of

DOCTOR OF PHILOSOPHY

School or Department: College of the Pacific

Major: Chemistry

University of the Pacific

Stockton, California

1999 



\title{
PRECIPITATION OF NEPTUNIUM DIOXIDE \\ FROM AQUEOUS SOLUTION
}

\author{
by
}

Kevin Edward Roberts

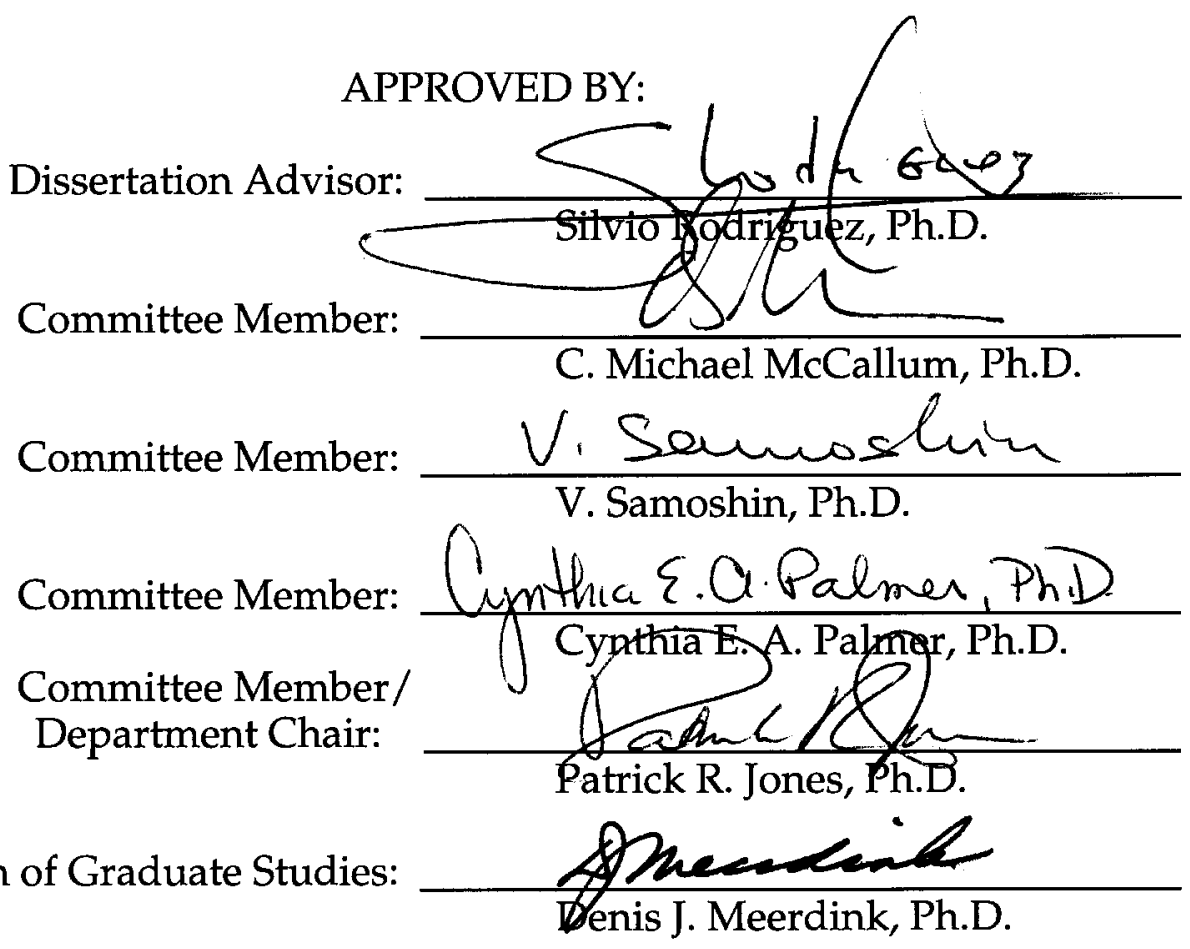





\section{DEDICATION}

For my mother and father, both of whom always knew I could do this. 



\section{ACKNOWLEDGMENTS}

Firstly, I would like to thank Cynthia E. A. Palmer and Thomas J. Wolery of the Lawrence Livermore National Laboratory for without their persistence this project would never have been started. Also, I would like to thank Jerome Bucher and David Shuh of the Lawrence Berkeley National Laboratory, Patrick Allen and Traudel Prussin of the Lawrence Livermore National Laboratory, and Robert Finch of Argonne National Laboratory for their contributions to this work.

I must thank my San Ramon Valley High School chemistry teacher, Judith Hunter, for showing me the beauty of chemistry for the first time. To Darleane Hoffman and Stanley Prussin of the University of California at Berkeley, thank you for introducing me to nuclear chemistry, a topic I truly love. To Heino Nitsche of the Lawrence Berkeley National Laboratory, thank you for giving me a chance when it seemed no one, myself included, had faith in my capabilities and for teaching me to do it the right way. To Silvio Rodriguez of the University of the Pacific, thank you for all of the helpful input toward making this an articulate body of work and for keeping me on track throughout all aspects of graduate school.

And last but not least, thank you Kathy for putting up with me through many long and often frustrating days over the last several years. For reminding me almost daily that I could do this, I am forever grateful. 



\title{
PRECIPITATION OF NEPTUNIUM DIOXIDE FROM AQUEOUS SOLUTION
}

\author{
Abstract \\ by Kevin Edward Roberts \\ University of the Pacific
}

1999

Tens of thousands of metric tons of highly radioactive, nuclear waste have been generated in the United States. Currently, there is no treatment or disposal facility for these wastes. Of the radioactive elements in high-level nuclear waste, neptunium $(\mathrm{Np})$ is of particular concern because it has a long half-life and may potentially be very mobile in groundwaters associated with a proposed underground disposal site at Yucca Mountain, Nevada.

Aqueous Np concentrations observed in previous, short-term solubility experiments led to calculated potential doses exceeding proposed long-term regulatory limits. However, thermodynamic data for $\mathrm{Np}$ at $25^{\circ} \mathrm{C}$ showed that these observed aqueous $\mathrm{Np}$ concentrations were supersaturated with respect to crystalline $\mathrm{NpO}_{2}$. It was hypothesized that $\mathrm{NpO}_{2}$ is the thermodynamically stable solid phase in aqueous solution, but it is slow to form in an aqueous solution of $\mathrm{NpO}_{2}^{+}$on the time scale of previous experiments. The precipitation of 
$\mathrm{NpO}_{2}$ would provide significantly lower aqueous $\mathrm{Np}$ concentrations leading to calculated doses below proposed regulatory limits.

To test this hypothesis, solubility experiments were performed at elevated temperature to accelerate any slow precipitation kinetics. Ionic $\mathrm{NpO}_{2}{ }^{+}(\mathrm{aq})$ was introduced into very dilute aqueous solutions of $\mathrm{NaCl}$ with initial $\mathrm{pH}$ values ranging from 6 to 10 . The reaction vessels were placed in an oven and allowed to react at $200^{\circ} \mathrm{C}$ until steady-state aqueous $\mathrm{Np}$ concentrations were observed. In all cases, aqueous $\mathrm{Np}$ concentrations decreased significantly from the initial value of $10^{-4} \mathrm{M}$. The solids that formed were analyzed by $\mathrm{x}$-ray powder diffraction, x-ray absorption spectroscopy, and scanning electron microscopy. The solids were determined to be high-purity crystals of $\mathrm{NpO}_{2}$. This is the first time that crystalline $\mathrm{NpO}_{2}$ has been observed to precipitate from $\mathrm{NpO}_{2}^{+}(\mathrm{aq})$ in near-neutral aqueous solutions. The results obtained demonstrate that $\mathrm{Np}$ will precipitate as $\mathrm{NpO}_{2}$ in aqueous solutions thereby leading to significantly lower aqueous Np concentrations. 


\section{TABLE OF CONTENTS}

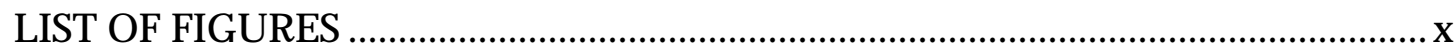

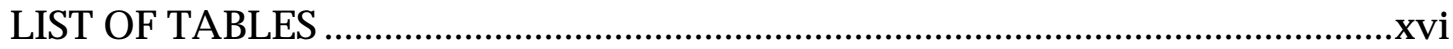

LIST OF ABBREVIATIONS .................................................................... xviii

\section{CHAPTER}

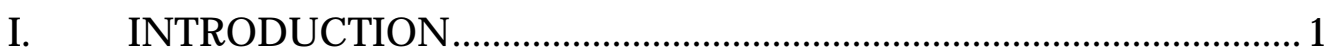

Radioactivity and Man's Splitting of the Atom - A brief history leading into Controlled Fission ......................................................... 1

Advancements in the Science of Nuclear Energy in the U.S. Military Driven Science ................................................................... 4

Advancements in the Peaceful Use of Nuclear Fission in the U.S. Commercial Nuclear Power Reactors........................................... 6

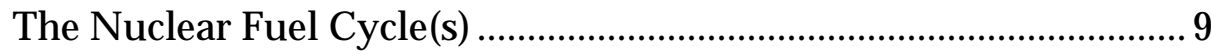

History of Nuclear Waste Disposal in the United States and Administrative Policies.

Current Disposal Plans ................................................................ 13

General Actinide Chemistry ......................................................... 14

Neptunium Chemistry.............................................................. 20

II. STATEMENT OF THE PROBLEM …............................................. 34

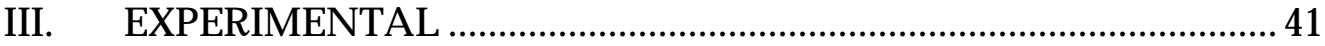

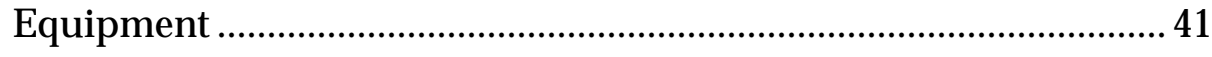

Controlled Atmosphere Glove Box........................................ 41

High-Temperature Safety Vacuum Oven ............................ 42

Reaction Vessels.................................................................... 46 
Balance 52

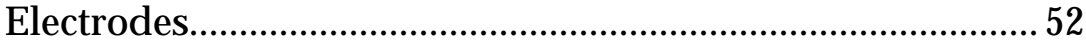

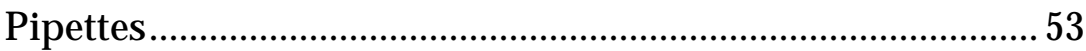

Filters /Centrifuge ….............................................................. 53

UV/VIS/NIR Absorption Spectrophotometer .....................54

Low-Energy Photon Spectrometer (LEPS)............................ 56

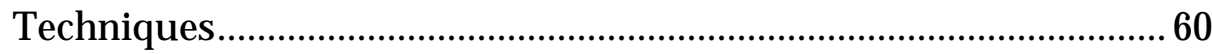

X-Ray Powder Diffraction .................................................... 60

X-ray Absorption Spectroscopy (XAS) - X-ray Absorption Near Edge Spectroscopy (XANES) and Extended X-ray Absorption Fine Structure (EXAFS)................................... 63

Scanning Electron Microscopy ............................................. 65

Solution Ion Determinations / Measurements .................................65

Hydrogen Ion Measurement ................................................6 65

Fluoride Ion Measurement....................................................6 66

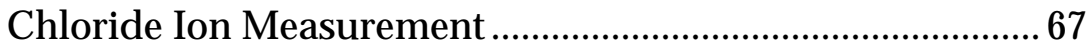

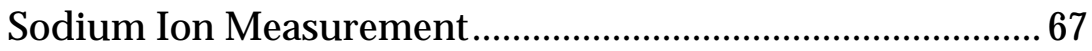

Neptunium Ion Determinations ............................................72

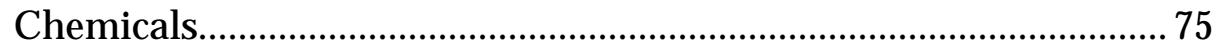

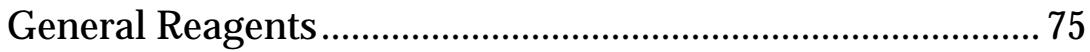

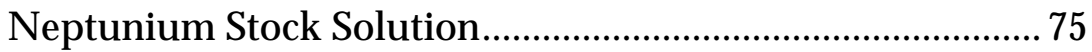

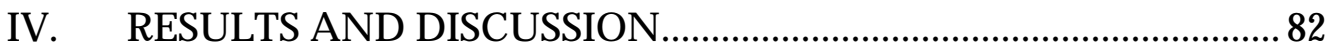

Neptunium Stock Solution: NpSS-A ….......................................... 82

Elevated Temperature Experiments ............................................... 84 
Initial Solubility Experiments in Teflon-Lined Reaction Vessels

Replicate Solubility Experiments in Titanium Reaction

Vessels.

Sodium Ion Concentration Measurements - Initial and

Replicate Experiments

X-ray Powder Diffraction of the Solids ..................................... 99

Larger Scale Experiments in Titanium Reaction Vessels.... 104

Neptunium Solubility ...................................................... 104

X-ray Powder Diffraction of the Solids Obtained in the Larger Scale Experiments ..................................114

X-ray Absorption Spectroscopy (XAS) ........................128

X-ray Absorption Near Edge Spectroscopy (XANES) ........................................................128

Extended X-ray Absorption Fine Structure (EXAFS)

Scanning Electron Microscopy

V. CONCLUSIONS

Neptunium Solubility ..................................................................... 149

Precipitated Neptunium Solids ....................................................... 152

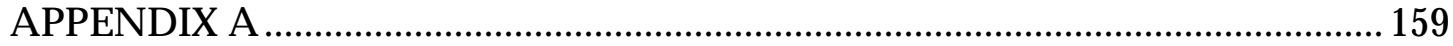

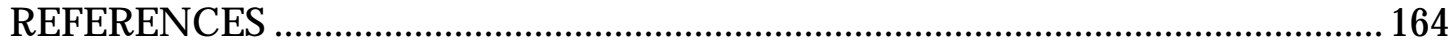




\section{LIST OF FIGURES}

Figure 1-1. Aqueous neptunium concentrations at standard state are plotted as a function of $\mathrm{pH}$ for the dissolution of $\mathrm{NpO}_{2}$ and the formation of aqueous neptunium hydrolysis species.

Figure 1-2. Aqueous neptunium concentrations at standard state are plotted as a function of $\mathrm{pH}$ for the dissolution of $\mathrm{NpO}_{2}(\mathrm{OH})$ and the formation of aqueous neptunium hydrolysis species.

Figure 1-3. Standard state total aqueous neptunium concentrations for the dissolution of $\mathrm{NpO}_{2}$ versus $\mathrm{NpO}_{2}(\mathrm{OH})$ solids as a function of $\mathrm{pH}$.

Figure 1-4. Standard state total aqueous neptunium concentrations for the dissolution of $\mathrm{NpO}_{2}$ versus $\mathrm{NpO}_{2}(\mathrm{OH})$ solids as a function of $\mathrm{pH}$. The dashed line in the center represents the dissolution of $\mathrm{NpO}_{2}$ under oxidizing conditions, 0.2 bar oxygen, in equilibrium with aqueous neptunium species in the 5+ oxidation state, both $\mathrm{NpO}_{2}^{+}$and $\mathrm{NpO}_{2}(\mathrm{OH})$, and at high $\mathrm{pH}$ the $4+$ oxidation state, $\mathrm{Np}(\mathrm{OH})_{5}^{-}(\mathrm{aq})$.

Figure 1-5. Upper and lower bounds to the total aqueous neptunium concentrations based on the dissolution of $\mathrm{NpO}_{2}$. The curves were calculated from the critically reviewed values listed by Lemire.

Figure 3-1. Controlled atmosphere glove box (Vacuum Atmospheres Company) used for the elevated temperature, neptunium solubility experiments.

Figure 3-2. High-temperature safety vacuum oven (Sheldon Manufacturing) on the inside left of the controlled atmosphere glove box. 
Figure 3-3. $\quad$ High Strength Acid Digestion Bombs model \# 4746 (Parr Instrument Company) made of T316 stainless steel and lined with a Teflon insert shown when closed.

Figure 3-4. High Strength Acid Digestion Bombs model \# 4746 made of T316 stainless steel and lined with a Teflon insert shown when disassembled.

Figure 3-5. General Purpose Pressure Vessel model \# 4750 (Parr Instrument Company) made of grade 2 titanium metal shown when closed.

Figure 3-6. General Purpose Pressure Vessel model \# 4750 made of grade 2 titanium metal shown when disassembled.

Figure 3-7. Digital photograph of the exterior of the LEPS counter. The $\mathrm{Pb}$ cave is shown at the top and the liquid nitrogen container is at the bottom

Figure 3-8. Digital photograph of the interior of the $\mathrm{Pb}$ cave. At the center of the cave is the encased germanium detector on top of which sits a sample contained in a liquid scintillation vial.

Figure 3-9. A graphical depiction of a Debye-Scherrer Camera, the Bragg Angle, and the Bragg equation for the interplanar spacing, d-spacing, relationship to the Bragg angle.

Figure 3-10. The negative log of the fluoride ion concentration as a function of millivolt reading. Each standard was diluted 1:1 with TISAB II with CDTA before measurement.

Figure 3-11. The negative log of the chloride ion concentration as a function of millivolt reading. To each $1000 \mu \mathrm{L}$ of standard, $20 \mu \mathrm{L}$ of ISA was added before measurement

Figure 3-12. The negative log of the sodium ion concentration as a function of millivolt reading. To each $1000 \mu \mathrm{L}$ of standard, $100 \mu \mathrm{L}$ of SISA was added before measurement.

Figure 3-13. Gamma spectrum from sample LDN70000 which contains 6054 alpha DPM of NIST traceable ${ }^{237} \mathrm{~Np}$. 
Figure 3-14. Absorption spectrum from 400 to $1300 \mathrm{~nm}$ of a ten $\mu \mathrm{L}$ sample of $\mathrm{Np}$ in $2 \mathrm{M} \mathrm{HNO}_{3}$ eluted from TEVA • Spec SPS diluted to $1 \mathrm{~mL}$ with $0.1 \mathrm{M} \mathrm{HClO}_{4}$.

Figure 3-15. Absorption spectrum from 400 to $1300 \mathrm{~nm}$ of a ten $\mu \mathrm{L}$ sample of $2 \mathrm{M} \mathrm{HNO}_{3}$ after heating at $90^{\circ} \mathrm{C}$ diluted to $1 \mathrm{~mL}$ with $0.1 \mathrm{M} \mathrm{HClO}_{4}$.

Figure 3-16. Absorption spectrum from 400 to $1300 \mathrm{~nm}$ of a ten $\mu \mathrm{L}$ sample of redissolved $\mathrm{Np}(\mathrm{V})$ diluted to $1 \mathrm{~mL}$ with $0.1 \mathrm{M}$ $\mathrm{HClO}_{4}$

Figure 4-1. Absorption spectrum from 900 to $1300 \mathrm{~nm}$ of the experimental solution at $\mathrm{pH} 6.09$ before reacting at $200^{\circ} \mathrm{C}$

Figure 4-2. Surface temperature of a cooling Parr reaction vessel as a function of time when removed from the oven at $200^{\circ} \mathrm{C}$.

Figure 4-3. Absorption spectrum from 900 to $1300 \mathrm{~nm}$ of the experimental solution at $25^{\circ} \mathrm{C}$ after reacting at $200^{\circ} \mathrm{C}$ for 13 days

Figure 4-4. X-ray powder diffraction film of sample "Np1" and plots showing digitized intensity as a function of diffraction angle, 2-theta.

Figure 4-5. Aqueous neptunium concentrations as a function of time for the initial, larger scale experiment.

Figure 4-6. Measured $\mathrm{pH}$ as a function of time for the initial, larger scale experiment.

Figure 4-7. Aqueous neptunium concentrations as a function of time for all of the larger scale solubility experiments

Figure 4-8. Measured $\mathrm{pH}$ as a function of time for all of the larger scale solubility experiments.

Figure 4-9. Steady-state aqueous neptunium concentrations plotted as a function of solution $\mathrm{pH}$. Uncertainties in both $\mathrm{pH}$ and neptunium concentration are shown as vertical and horizontal bars, respectively, on each of the four points. 
Figure 4-10. X-ray powder diffraction film and plots showing digitized intensity as a function of diffraction angle, 2-theta.

Figure 4-11. X-ray powder diffraction film and plots showing digitized intensity as a function of diffraction angle, 2-theta.

Figure 4-12. X-ray powder diffraction film and plots showing digitized intensity as a function of diffraction angle, 2-theta.

Figure 4-13. X-ray powder diffraction film and plots showing digitized intensity as a function of diffraction angle, 2-theta.

Figure 4-14. X-ray powder diffraction film and plots showing digitized intensity as a function of diffraction angle, 2-theta.

Figure 4-15. The neptunium $\mathrm{L}_{\mathrm{III}} \mathrm{x}$-ray absorption near edge structure for the aqueous dioxo-neptunium $(\mathrm{V})$ cation, $\mathrm{NpO}_{2}{ }^{+}$, (dashed line), crystalline neptunium(IV) dioxide, $\mathrm{NpO}_{2}$, (solid line), and the solid material obtained in the solubility experiment at $\mathrm{pH} 4$ (dotted line).

Figure 4-16. The neptunium $\mathrm{L}_{\mathrm{III}}$ extended x-ray absorption fine structure for crystalline neptunium(IV) dioxide, $\mathrm{NpO}_{2}$ (solid line) and the solid material from our experiment (dotted line) are shown at the top of the plot. Also shown in the plot (bottom, solid line) is the neptunium $\mathrm{L}_{\mathrm{III}}$ extended $\mathrm{x}$-ray absorption fine structure for the aqueous dioxo-neptunium $(\mathrm{V})$ cation, $\mathrm{NpO}_{2}^{+}$

Figure 4-17. Scanning electron micrograph of the solid Np4a from the larger scale experiment with a steady-state $\mathrm{pH}$ of 4 .

Figure 4-18. Scanning electron micrograph of the solid Np4a from the larger scale experiment with a steady-state $\mathrm{pH}$ of 4 .

Figure 4-19. Scanning electron micrograph of the solid Np3a from the larger scale experiment with a steady-state $\mathrm{pH}$ of 4 .

Figure 4-20. Scanning electron micrograph of the solid Np3a from the larger scale experiment with a steady-state $\mathrm{pH}$ of 4 . 
Figure 4-21. Scanning electron micrograph of the solid Np3a from the larger scale experiment with a steady-state $\mathrm{pH}$ of 4 .

Figure 4-22. Scanning electron micrograph of the solid Np3a from the larger scale experiment with a steady-state $\mathrm{pH}$ of 4 .

Figure 4-23. Scanning electron micrograph of the solid Np3a from the larger scale experiment with a steady-state $\mathrm{pH}$ of 4 .

Figure 4-24. Scanning electron micrograph of the solid Np3a from the larger scale experiment with a steady-state $\mathrm{pH}$ of 4 .

Figure 4-25. Scanning electron micrograph of the solid Np3a from the larger scale experiment with a steady-state $\mathrm{pH}$ of 4 .

Figure 4-26. Scanning electron micrograph of the solid Np3a from the larger scale experiment with a steady-state $\mathrm{pH}$ of 4 .

Figure 4-27. Scanning electron micrograph of the solid Np3a from the larger scale experiment with a steady-state $\mathrm{pH}$ of 4 .

Figure 4-28. Scanning electron micrograph of the solid Np3a from the larger scale experiment with a steady-state $\mathrm{pH}$ of 4 .

Figure 4-29. Scanning electron micrograph of the solid Np3a from the larger scale experiment with a steady-state $\mathrm{pH}$ of 4 .

Figure 4-30. Scanning electron micrograph of the solid Np3a from the larger scale experiment with a steady-state $\mathrm{pH}$ of 4 .

Figure 5-1. The solubility curves for the $\mathrm{Np}(\mathrm{IV}), \mathrm{Np}(\mathrm{V})$, and $\mathrm{Np}(\mathrm{IV}, \mathrm{V})$ system shown are the same as those shown in Figure 1-4. The solid circles are the steady-state aqueous neptunium concentrations obtained in the larger scale experiments.

Figure 5-2. X-ray powder diffraction pattern calculated for a face centered cubic unit cell with a experimentally determined lattice parameter of $5.426 \AA$. 
Figure 5-3. Fluorite structure for the unit cell of $\mathrm{NpO}_{2}$. The smaller black spheres are $\mathrm{Np}$ atoms, and the larger white spheres are oxygen atoms.

Figure 5-4. Oxygen centered fluorite structure of $\mathrm{NpO}_{2}$ limited to a spherical component with a radius of $3 \mathrm{~A}$. The smaller black spheres are $\mathrm{Np}$ atoms, and the larger white spheres are oxygen atoms. 157

Figure A-1. Reference powder diffraction pattern of $\mathrm{NpO}_{2} \ldots \ldots \ldots \ldots \ldots \ldots \ldots \ldots \ldots \ldots \ldots . . .160$

Figure A-2. Reference powder diffraction pattern of $\mathrm{NaNpO}_{2} \mathrm{CO}_{3} \ldots \ldots \ldots \ldots \ldots \ldots . . . .160$

Figure A-3. Reference powder diffraction pattern of $\mathrm{Np}_{3} \mathrm{O}_{8} \ldots \ldots \ldots \ldots \ldots \ldots \ldots \ldots \ldots \ldots \ldots . . . . . . . . . . . . .161$

Figure A-4. Reference powder diffraction pattern of $\mathrm{Np}_{2} \mathrm{O}_{5} \ldots \ldots \ldots \ldots \ldots \ldots \ldots \ldots \ldots \ldots \ldots . . . . . . . . . . . .161$

Figure A-5. Reference powder diffraction pattern of $\mathrm{NpF}_{3} \ldots \ldots \ldots \ldots \ldots \ldots \ldots \ldots \ldots \ldots \ldots \ldots . . .162$

Figure A-6. Reference powder diffraction pattern of $\mathrm{NpF}_{4} \ldots \ldots \ldots \ldots \ldots \ldots \ldots \ldots \ldots \ldots \ldots \ldots . . . . .162$

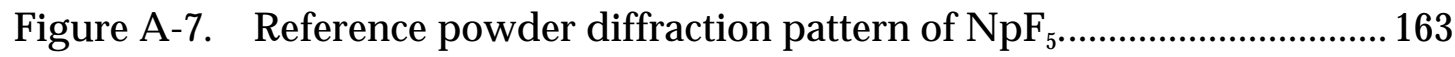

Figure A-8. Reference powder diffraction pattern of $\mathrm{NpF}_{6} \ldots \ldots \ldots \ldots \ldots \ldots \ldots \ldots \ldots \ldots \ldots \ldots . . . . . . . . . . . . . .163$ 


\section{LIST OF TABLES}

Table 1-1. Observed oxidation states for the actinide elements through Curium. Bold face indicates the most commonly observed oxidation states.

Table 1-2. Currently known isotopes of neptunium with the corresponding half-lives, modes of decay, and methods of production.

Table 2-1. Analyzed chemical composition of J-13 and UE-25p \# 1 well waters.

Table 4-1. Summary of results for initial Np solubility experiments at $200^{\circ} \mathrm{C}$

Table 4-2. Peak identification report obtained from Jade for sample "Np1", the solid obtained in the initial $200^{\circ} \mathrm{C}$ solubility experiment listed together with the published pattern for crystalline $\mathrm{NpO}_{2}$

Table 4-3. Values for the reaction time, solution $\mathrm{pH}$, and neptunium concentrations for the larger scale solubility experiments.

Table 4-4. Steady-state $\mathrm{pH}$ values and neptunium concentrations (uncertainties are one standard deviation of the averaged values).

Table 4-5. Peak identification report obtained from Jade for sample "Np3a", the solid obtained in the first larger volume $200^{\circ} \mathrm{C}$ solubility experiment, listed together with the published pattern for crystalline $\mathrm{NpO}_{2}$ and titanium metal. 
Table 4-6. Peak identification report obtained from Jade for sample "Np4", the solid obtained in the first larger volume $200^{\circ} \mathrm{C}$ solubility experiment by rubbing the sides of the reaction vessel, listed together with the published pattern for crystalline $\mathrm{NpO}_{2}$ and titanium metal.

Table 4-7. Peak identification report obtained from Jade for sample "992b", the solid obtained in the solubility experiment with a steady-state $\mathrm{pH}$ of 6 , listed together with the published pattern for crystalline $\mathrm{NpO}_{2}$

Table 4-8. Peak identification report obtained from Jade for sample "2140b", the solid obtained in the solubility experiment with a steady-state $\mathrm{pH}$ of 7 , listed together with the published pattern for crystalline $\mathrm{NpO}_{2}$

Table 4-9. Peak identification report obtained from Jade for sample "2141", the solid obtained in the solubility experiment with a steady-state $\mathrm{pH}$ of 9 , listed together with the published pattern for crystalline $\mathrm{NpO}_{2}$ 


\section{LIST OF ABBREVIATIONS}

$\begin{array}{ll}(a m) & \text { Amorphous } \\ (\mathrm{cr}) & \text { Crystalline } \\ \mu \mathrm{m} & \text { microliter } \\ \text { AEC } & \text { Atomic Energy Commission } \\ \text { ANL } & \text { Argonne National Laboratory } \\ \text { CDTA } & \text { 1,2-cyclohexane diaminetetraacetic acid } \\ \text { CPM } & \text { Counts per minute } \\ \text { DF } & \text { Dilution Factor } \\ \text { DOE } & \text { Department of Energy } \\ \text { DPM } & \text { Disintigrations per minute } \\ \text { EBR-1 } & \text { Experimental Breeder Reactor 1 } \\ \text { EDS } & \text { Energy Dispersive Spectrometer } \\ \text { EPA } & \text { Environmental Protection Agency } \\ \text { ERDA } & \text { Energy Research and Development Administration } \\ \text { EXAFS } & \text { Extended X-ray Absorption Fine Structure } \\ \text { HEPA } & \text { High Efficiency Particulate Air (filters) } \\ \text { ICDD } & \text { International Centre for Diffraction Data } \\ \text { IM } & \text { Isotopic Mass } \\ \text { ISA } & \text { Ionic strength adjustor } \\ \text { keV } & \text { kilo electron volt } \\ \text { kV } & \text { kilovolt } \\ \text { LBNL } & \text { Lawrence Berkeley National Laboratory } \\ \text { LEPS } & \text { Low energy photon spectrometer } \\ \text { LLNL } & \text { Lawrence Livermore National Laboratory } \\ \text { LSC } & \text { Liquid scintillation counting } \\ \text { M } & \text { Molar or Molarity } \\ \text { mg } & \text { milligram } \\ \text { mL } & \text { milliliter } \\ \text { MW } & \text { Megawatt } \\ \text { NIR } & \text { Near Infra red } \\ \text { NIST } & \text { National Institute for Standards and Technology } \\ & \end{array}$

xviii 


$\begin{array}{ll}\text { nm } & \text { nanometer } \\ \text { NRC } & \text { Nuclear Regulatory Commission } \\ \text { NWPA } & \text { Nuclear Waste Policy Act } \\ \text { PDF } & \text { Powder Diffraction File } \\ \text { SEM } & \text { Scanning Electron Microscopy } \\ \text { SISA } & \text { Sodium ionic strength adjustor } \\ \text { SRM } & \text { Standard Reference Material } \\ \text { SSRL } & \text { Stanford Synchrotron Radiation Laboratory } \\ \text { SV } & \text { Sample Volume } \\ \text { TISAB II } & \text { Total ionic strength adjustor buffer II } \\ \text { UV } & \text { Ultraviolet } \\ \text { VIS } & \text { Visible } \\ \text { XANES } & \text { X-ray Absorption Near-Edge Spectroscopy } \\ \text { XAS } & \text { X-ray Absorption Spectroscopy }\end{array}$





\section{INTRODUCTION}

Radioactivity and Man's Splitting of the Atom - A brief history leading into Controlled Fission

Mankind began to consciously realize the existence of radiation when Wilhelm Roentgen of the University of Würzburg discovered x-rays while experimenting with cathode ray tubes in 1895 . He had covered the cathode ray tubes with black cardboard, yet he still observed the fluorescence of materials that were outside of the cardboard away from the cathode ray tube itself. He observed that these penetrating rays would pass through certain materials like cardboard, wood, and flesh, but would not pass through harder materials like metal or bone. Within a few months he reported on his discovery of particle-less "x-ray radiation," and for this work, Wilhelm Roentgen received the Nobel Prize in 1901.

This discovery inspired others to investigate these new "x-rays," one of whom was Henri Becquerel, a French physicist who studied the effect of these x-rays on fluorescent materials. One such material was a salt of uranium. He would expose the salt to sunlight until it began to fluoresce visibly, and then he would place it onto a photographic plate and wrap it with black paper. The developed plate would blacken in the area where the salt had been. He eventually discovered that exposure to sunlight was unnecessary, and that uranium salts 
would themselves "expose" photographic plates regardless of what uranium compound was used.

The work of Becquerel inspired yet more scientists to investigate the phenomenon of radiation. Physicist Marie Curie, and her husband Pierre, worked with uranium in a fashion such that they were able to discover new radioactive elements that were associated with pitchblende, the natural, unpurified ore of uranium. These new elements were decay products of the uranium itself. Becquerel and the Curies both won the Nobel Prize for their works in 1903, just two years after Roentgen.

By now the scientific world had become increasingly more and more interested in this phenomenon of radioactivity, and research groups around the world were performing more and more experiments to increase the understanding of radioactivity and its possible usefulness.

By 1932, James Chadwick discovered the neutron, and soon after, this highenergy, charge-less particle was used to probe the nucleus of various elements. Italian scientist Enrico Fermi began to bombard the elements of the periodic table, and in 1934 he targeted the element uranium. The result, for which he was awarded the Nobel Prize in 1938, was thought to be the production of two new radioactive materials via neutron capture to a new "transuranic" element and the subsequent decay to radioactive daughter products. However, chemical isolation of the products could not confirm this result. 
In late 1938/early 1939, arguably one of the most important experiments in the history of nuclear science was performed. In Berlin, Otto Hahn and Fritz Strassman bombarded a target of uranium with a beam of neutrons, and the result mystified them. They found barium, a much lighter element, in the target after bombardment with neutrons. After discussions with Lise Meitner and Otto Frisch in Sweden, it was concluded that the bombardment of uranium by neutrons had split, or fissioned, the uranium atoms into two smaller atoms with a combined mass that was smaller than that of the original uranium atoms. What became of this difference in mass? It was released as energy. It was calculated that 150 million electron volts were released with the fissioning of a single atom. ${ }^{1}$

With Hitler having invaded Poland in 1939 and the resulting start of World War II, scientists with an understanding of the potential use of this newly found, seemingly limitless source of energy were frightened, and a great number of European scientists left their homelands for safety in the United States. Leo Szilárd and Eugene Wigner urged Albert Einstein to draft a letter, which he sent in August of 1939, to then U.S. President Franklin D. Roosevelt describing this new energy source and its potential use for the development of a weapon capable of unparalleled destruction. President Roosevelt's response was quick as he immediately created an Advisory Committee on Uranium, a committee that by mid-1940 became a subcommittee of the National Defense Research Committee. ${ }^{1}$ 
At this point in time, the science of nuclear fission in the United States had essentially become property of the Department of Defense of the United States government.

Advancements in the Science of Nuclear Energy in the U.S. - Military Driven $\underline{\text { Science }}$

By the early 1940's, the research efforts into fission had blossomed into many programs around the country. Work was being done to find efficient ways of separating the fissionable isotope ${ }^{235} \mathrm{U}(0.7 \%$ abundance in natural uranium ore $)$ from the non-fissile ${ }^{238} \mathrm{U}$ isotope (99.3\% abundance in natural uranium ore). As a part of this effort, scientists at the University of California at Berkeley, namely Edwin M. McMillan and Glenn T. Seaborg, discovered that when uranium was bombarded with neutrons, the nucleus of the ${ }^{238} \mathrm{U}$ isotope periodically absorbed a neutron to form the next heavier isotope of uranium, ${ }^{239}$ uranium. ${ }^{239} \mathrm{U}$ decayed with a very short half-life through beta emission (ejection of an electron from the nucleus as a result of conversion of a neutron to a proton) to form the next higher element with same atomic mass. This was mankind's first creation of ${ }^{239}$ neptunium, named after Neptune, the planet following Uranus. The isotope ${ }^{239} \mathrm{~Np}$ also decayed rapidly through beta emission to form the next higher element with the same atomic mass. This was mankind's first creation of ${ }^{239}$ plutonium, named after Pluto, the planet following Neptune. ${ }^{239} \mathrm{Pu}$ had a significantly longer half-life, so it could be chemically separated and characterized. Theoretical work predicted that ${ }^{239} \mathrm{Pu}$ should demonstrate the 
same fissionable behavior as the ${ }^{235} \mathrm{U}$ isotope, and the Berkeley researchers demonstrated this experimentally in 1941.

By the latter part of 1942, the U.S. Government placed this research effort under the control of the U.S. Army. Here began what was eventually termed the Manhattan Project headed by Brigadier General Leslie R. Groves. The four principal tasks for this new project were:

"procurement of uranium; production of the ${ }^{235} \mathrm{U}$ separated from natural uranium; production of plutonium; and the fashioning of these new kinds of explosives into practical, reliable, and deliverable weapons."1

So far, nuclear fission had been demonstrated by bombarding a fissile material, either ${ }^{235} \mathrm{U}$ or ${ }^{239} \mathrm{Pu}$, with a source of neutrons. Self-sustained nuclear fission, whereby the fissioning process produces more neutrons than were required to initiate the process (thus allowing for self-perpetuating fission within the fissile material) had been proposed, but not yet observed. In late 1942, beneath some grandstands at Chicago University's Stagg Field, Enrico Fermi and his colleagues initiated for the first time a controlled, self-sustaining nuclear fission reaction in a "pile" of carefully ordered uranium and graphite. This chain reaction (the term coined to describe self sustaining nuclear fission) that occurred in the pile of uranium, known as the "Chicago Pile," confirmed the previously theoretical work of Hahn and Strassman. ${ }^{1}$ 
All of the pieces of the puzzle were now available to the scientists of the Manhattan Project, and in the early morning hours of July $16^{\text {th }}, 1945$ the product desired by the military was demonstrated with the Trinity test shot near Alamogordo, New Mexico. The first atomic weapon had been detonated.

Several days later, similar devices were unleashed on the cities of Hiroshima and Nagasaki, Japan. The end of the war with Japan came almost immediately.

Advancements in the Peaceful Use of Nuclear Fission in the U.S. - Commercial Nuclear Power Reactors

The peaceful use of nuclear power for energy production purposes also dates back to the days prior to the detonation of the first nuclear weapon as well. True, the biggest driving force behind the advancement of nuclear fission science was the race to develop a weapon of mass destruction before the Germans could do so. To this end, scientists in America succeeded.

However, the prospect of using the energy produced by nuclear fission for nonmilitary purposes dates back to the late 1930's. When President Roosevelt created the Advisory Committee on Uranium, he appointed Lyman Briggs, then director of the National Bureau of Standards, as chairman of the committee, but he also appointed two military officers as well, one from the Army and one from the Navy. The Army's primary interest lay in the production of a weapon, but the Navy also showed interest in another idea, a submarine that did not have a 
conventional type propulsion system. In other words, would a nuclear power source produce a submarine that did not need to surface for extended periods of time?

Even Enrico Fermi, after successfully creating the Chicago pile, noted that he had "...hoped that with the end of the war, emphasis would be shifted decidedly from the weapon to the peaceful aspects of atomic energy."1 Before the end of the war, five different types of power reactors were being considered for development, and the first nuclear power reactor to produce electricity, Experimental Breeder Reactor 1 (EBR-1), did so on December 20 ${ }^{\text {th }}, 1951$. The Shippingport nuclear plant, on the $23^{\text {rd }}$ of December 1957, was the first commercial reactor to go fully online in the United States.

In 1946, President Truman's signing of the Atomic Energy Act created the Atomic Energy Commission (AEC). The Atomic Energy Act was established to begin the demilitarization of nuclear science. The topics were still deemed confidential by the U.S. Government, but it allowed for commercial industry to become contractors of the AEC. The AEC eventually took control of the wartime nuclear effort, the Manhattan Project. In 1949, the Soviet Union demonstrated their nuclear capabilities by detonating their first atomic bomb, which in turn increased the U.S. military effort; thermonuclear fusion devices were now the focus for the U.S. weapons program. ${ }^{2}$ 
President Eisenhower signed the Atomic Energy Act of 1954, superceding the Atomic Energy Act of 1946, in order to privatize the nuclear power industry even further. Now commercial enterprises could own nuclear power facilities for generation of electricity; however, the government, through the AEC, would retain ownership of all "special nuclear materials" that were used in the production of power. Then the Price-Anderson Act of 1957 provided an U.S. government funded policy to insure nuclear power plants in the event of a nuclear accident. What more could an industry need? By the early 1970's, electrical utility companies placed orders for roughly 160 nuclear power plants. The goal was to create an electricity generating capacity in excess of 150,000 MW.1,2

This proved to be a very optimistic outlook for the electricity generating future. In 1974, President Ford signed the Energy Reorganization Act that abolished the AEC and created the Energy Research and Development Administration (ERDA) and the Nuclear Regulatory Commission (NRC). ERDA, later renamed the Department of Energy (DOE), continued the work of the AEC in promoting the commercial nuclear power industry, whereas, the NRC became the regulatory body governing that industry.

By the late 1970's, a number of factors caused a great number of these nuclear power plant orders to be cancelled. Projections in the demand for power were overestimated, the supply of oil and natural gas was not decreasing as feared, the cost of building nuclear power plants rose extensively, and regulations 
governing the operation of such plants had become ever more strict. The demand for increased amounts of nuclear power no longer existed. These factors, when combined with the worst nuclear accident to occur in the U.S. (the 1979 meltdown of a reactor core at the Three Mile Island nuclear power plant and the subsequent release of radioactive materials to the environment), effectively halted the advancement of the commercial nuclear power industry in the U.S.

Currently, there are more than 100 commercial nuclear reactors operating in the United States. Together they produce about 100,000 MW which accounts for about $20 \%$ of the electricity produced in the United States, and nuclear waste disposal has become perhaps the largest problem associated with the nuclear power industry.

\section{The Nuclear Fuel Cycle(s)}

The term fuel cycle seems somewhat of a misnomer. Usually, a fuel is found, prepared, and used. The byproduct of this process usually becomes a waste; therefore, the process is not really a cycle but rather a series of steps. However, if a series of steps is repeated often, then the process could be considered a cycle.

With regard to the nuclear fuel cycle, a uranium fuel, usually found as $\mathrm{U}_{3} \mathrm{O}_{8}$, is mined from fairly abundant ore deposits. The fissile material is purified and prepared for use as fuel rods which are assemblies of several uranium dioxide 
pellets enriched in the ${ }^{235} \mathrm{U}$ isotope. The fuel rods are placed into a reactor core and are used to generate energy until their efficiency becomes compromised, usually after $\sim 3$ years, due to reaction byproducts that poison the reactivity of the fuel to the point that self-sustaining fission becomes ineffective. These used fuel assemblies usually consist of less than 10 percent of unusable, highly radioactive fission products and heavier fissile and non-fissile actinides with the balance being made up of unused uranium fuel. At this point, the fuel rod is removed from the reactor. In theory, this spent fuel assembly could be "reprocessed" in order to separate the contaminants and use the remaining uranium by reformulating a new fuel rod, supplemented with additional mined uranium, for further use in a nuclear power plant. By following this reprocessed fuel "cycle" the ultimate end product would be unusable fission products and non-fissile actinides to be disposed of as a high-level, nuclear waste. In its limit, this "cycle" becomes a series of repeated steps that takes a fuel and ultimately converts it all to a waste. This methodology is practiced in countries like Japan and France that depend highly on nuclear energy and have active reprocessing programs.

Current policy concerning nuclear fuels in the United States dates back to the late 1970 's which forbids the reprocessing of used nuclear fuel, thereby creating what is termed a "once-through nuclear fuel cycle." Once the nuclear fuel is used in a reactor to the point of becoming inefficient, but not necessarily exhausted, the fuel assembly is removed and becomes a nuclear waste, commonly called spent 
nuclear fuel. It is estimated that by the year 2030, the United States will own approximately 85,000 metric tons of spent nuclear fuel. ${ }^{3}$

History of Nuclear Waste Disposal in the United States and Administrative Policies

As a result of the Atomic Energy Act of 1954, it was implied that the AEC, the agency that eventually became the ERDA and is now the DOE, "owns" all nuclear materials outside of their residence time in a nuclear power reactor or in a nuclear weapon. ${ }^{1}$ Therefore, today, the DOE is ultimately responsible for all special nuclear materials from what is termed "cradle to grave," meaning the DOE is to maintain control of fissile radioactive elements from their being mined, or made as is the case for plutonium, to their ultimate disposition as a waste.

Permanent disposal of high-level nuclear waste was addressed by the United States government as early as 1957. At that time, a National Academy of Sciences Panel suggested pursuing a permanent, underground disposal facility in a geologic salt formation.1,3 From then up until the 1970's, a great amount of effort was put into a proposed disposal facility in Lyons, Kansas, and several other projects pursued the conversion of large volumes of radioactive liquid wastes to rather concentrated solids to be buried in the salt formation. Sometime in 1971/1972, the project at Lyons, Kansas was abandoned because of a "combination of possible technical difficulties and growing opposition"3 and the fact that commercial salt mining was still going on just a few miles away from the proposed site. ${ }^{1}$ 
Throughout the 1970's, concepts for nuclear waste disposal were numerous, yet, none ever came to fruition. In 1973, the AEC began plans for an above ground retrievable storage facility. This was abandoned two years later by the ERDA. ERDA in turn proposed a comprehensive national waste terminal storage program that would provide an underground repository in a geologic salt formation by the year 1985, and 5 more in a variety of other sites by the year 2000. ${ }^{1}$ This program was abandoned due to political issues. By the late 70 's, the DOE stated they would accept responsibility for commercial spent fuel, temporarily store the spent fuel above ground, and pursue a permanent, deep geological disposal site. ${ }^{1}$ But the first possible date of operation was postponed until 1988.

In 1980, after reaffirming the no reprocessing of spent fuel policy instituted by President Ford, President Carter made the commercial power utilities responsible for the storage of spent fuel until a permanent repository could be opened. President Carter also moved the first possible date of operation of a deep, geologic waste repository to the mid-1990's.

Because of the failure to find a solution for the ultimate disposition of nuclear waste for over 25 years, Congress decided to enact the Nuclear Waste Policy Act, and in 1983, President Reagan signed it into law. This act stated that the Secretary of Energy was to nominate five sites for potential study. By 1985, three sites were recommended for study by a process called "site characterization."3 It 
was also stated that the NRC would be called upon to approve or disapprove the selected site by 1989. However, by 1987 it was apparent that funding a full site characterization for three differnet sites was too costly, and that the time schedule outlined in 1983 could not be met. Therefore, Congress acted again by adopting in 1987 the Nuclear Waste Policy Amendments Act. This designated Yucca Mountain, Nevada, as the sole site to be fully characterized as a potential underground geologic repository for the permanent disposition of nuclear waste. In 1989, the Secretary of Energy announced that the new scheduled opening of the repository, following a successful licensing by the NRC, would be in the year 2010.

In the first part of the 1990's, the Environmental Protection Agency (EPA), the agency created to define safety limits, spent a great deal of time in litigation regarding the guidelines that were being developed for regulating nuclear waste disposal facilities. The EPA was tasked with setting the standards for acceptable release rates of radioactive materials to the environment that would be accessible by humans. By 1993, it was established that release rates of radionuclides from repositories had to conform to specified limits for a time period of 10,000 years after the closure of the facility. ${ }^{3}$

\section{Current Disposal Plans}

Since the Nuclear Waste Policy Amendments Act of 1987 designated Yucca Mountain, Nevada, as the sole, potential site for a high-level nuclear waste 
repository, the Yucca Mountain Site Characterization Project has been acquiring information as to whether or not the site is suitable for a potential nuclear waste repository. The Yucca Mountain Site Characterization Project is ongoing, but some recent experimental results have caused some concern with regard to the site's suitability. More specifically, experimentally measured neptunium $\left({ }^{237} \mathrm{~Np}\right.$ is a byproduct found in spent nuclear fuel) solubilities in groundwaters associated with the Yucca Mountain site were found to range as high as millimolar in total aqueous neptunium. 4,5 Should all barriers that are engineered to contain the high level nuclear waste in a potential underground repository at Yucca Mountain fail, the groundwater and mineral geochemistry of the site will most likely favor the potential migration of the radionuclides into the surrounding environment. If there is a significant flow of groundwater in and around the potential repository and if millimolar concentrations of soluble neptunium can be attained in those groundwaters, then there might be cause for alarm with regard to the potential migration of neptunium from the site to the surrounding environment over the course of thousands of years.

\section{General Actinide Chemistry}

The term "actinide series" can be traced back to 1944. A series of papers ${ }^{6-9}$ describing the evolution of the modern day periodic table was compiled by G.T. Seaborg. ${ }^{10}$ The first paper ${ }^{6}$, originally prepared in 1944, argued in favor of this new "series" of elements due to the fact that the recently discovered elements 93 (neptunium) and 94 (plutonium) exhibited behavior more like that of thorium 
and uranium than they did of their above, nearest neighbors ${ }_{75} \mathrm{Re}$ and ${ }_{76} \mathrm{Os}$. It was hypothesized then that another "series" of elements existed, a series similar to that of the lanthanides. This moved elements $90,91,92$, and so on from below elements $72,73,74$, and so on in what was the pre-World War II periodic table to a new series of their own, the actinide series. The actinides were thought to contain $5 \mathrm{f}$ orbitals similar to the $4 \mathrm{f}$ orbitals of the lanthanides. But, because of the increased shielding of the nucleus, the electrons in the $5 \mathrm{f}$ orbitals were expected to be bound less tightly when compared with the analogous lanthanide elements. Therefore, the actinides should exhibit a multitude of oxidation states; whereas, the lanthanides are typically limited to the 3+ oxidation state.

By 1949, it was shown that the actinides, at least through element 95 (americium), do exhibit a multitude of possible oxidation states for aqueous or solid state species. Table 1-1 lists observed oxidation states for the actinides from ${ }_{89} \mathrm{Ac}$ to ${ }_{96} \mathrm{Cm}$. The numbers that are in bold face type are the most common oxidation states observed for the listed elements. ${ }^{6,11-14}$ Elements beyond $\mathrm{Cm}$ are not listed here because they are not really relevant for long-term environmental considerations ${ }^{12}$ due to their relatively short half-lives and small abundance in nuclear waste. Plus, the heavier, transcurium actinides tend to resemble $\mathrm{Cm}$ in that they usually only exhibit the $3+$ oxidation state. ${ }^{13}$ 
Table 1-1. Observed oxidation states for the actinide elements through Curium. Bold face indicates the most commonly observed oxidation states. $6,11-14$

\begin{tabular}{|c|c|c|c|c|c|c|c|c|}
\hline Element & ${ }_{89} \mathrm{AC}$ & ${ }_{90} \mathrm{Th}$ & ${ }_{91} \mathrm{~Pa}$ & ${ }_{92} \mathrm{U}$ & ${ }_{93} \mathrm{~Np}$ & ${ }_{94} \mathrm{Pu}$ & ${ }_{95} \mathrm{Am}$ & ${ }_{96} \mathrm{Cm}$ \\
\hline $\begin{array}{l}\text { Oxidation } \\
\text { States }\end{array}$ & 3 & $\begin{array}{l}3 \\
4\end{array}$ & $\begin{array}{l}3 \\
4 \\
5\end{array}$ & $\begin{array}{l}3 \\
4 \\
5 \\
6\end{array}$ & $\begin{array}{l}3 \\
4 \\
5 \\
6\end{array}$ & $\begin{array}{l}3 \\
4 \\
5 \\
6\end{array}$ & $\begin{array}{l}2 \\
3 \\
4 \\
5\end{array}$ & $\begin{array}{l}3 \\
4\end{array}$ \\
\hline
\end{tabular}

Element 103, lawrencium, was discovered in 1961 and ended the identification of the actinides. The yet undiscovered element 104 then took the position below ${ }_{72} \mathrm{Hf}$ in the periodic table that is the position that ${ }_{90}$ Th once mistakenly occupied. Element 104 was eventually synthesized and chemically characterized. It was found that element 104 was chemically analogous to hafnium, ${ }^{9}$ the element directly above it in the modern periodic table that was first hypothesized by G.T. Seaborg in 1944. It seemed conclusive; the actinide elements were their own series.

The actinides in general are rather electropositive when in the metallic state and are usually quite reactive. In air, the actinide metals will eventually convert to oxides of varying stoichiometry depending on the number of stable oxidation states available to each actinide element. The metals dissolve easily in mineral acids such as nitric or hydrochloric acid. In addition to the observable oxidation states listed in Table 1-1, the 7+ oxidation state is attainable for $\mathrm{Np}$ and $\mathrm{Pu}$ in highly alkaline solutions. When in aqueous solution, the actinide ions in the $3+$ 
and $4+$ oxidation state are in the form of simple hydrated cations, $\mathrm{M}^{3+}$ and $\mathrm{M}^{4+}$ (where $\mathrm{M}=\mathrm{Th}, \mathrm{Pa}, \mathrm{U}, \mathrm{Np}$, etc.); whereas, the actinide ions in the $5+$ and $6+$ oxidation state form linear, "dioxoactinyl" ions, $\mathrm{MO}_{2}{ }^{1+}$ and $\mathrm{MO}_{2}{ }^{2+}$. The actinyl ions are very stable with respect to their bonding with the diaxial oxygen atoms, and the unit as a whole behaves very much like a single entity throughout many chemical operations such as precipitation or complexation. ${ }^{11}$ Because the lighter actinides exhibit several stable oxidation states in solution, it is not uncommon to observe more than one oxidation state of a given actinide under a single set of solution conditions, such as at a given ionic strength and $\mathrm{pH}$. For example, aqueous plutonium in the $3+, 4+, 5+$, and $6+$ oxidation states can coexist simultaneously in natural aquatic systems. ${ }^{12,13}$

The "oxidation state analogy" is commonly referred to in general actinide chemistry review articles, ${ }^{12-14}$ but it can be traced back to 1958 when G.T. Seaborg 11 first noted the similar chemical behavior of the various actinides when in the same oxidation state. In general, this means that $\mathrm{PuO}_{2}{ }^{2+}$ will behave chemically very much like $\mathrm{UO}_{2}{ }^{2+}$ just in the same way that $\mathrm{Np}^{4+}$ will behave chemically very much like $\mathrm{Th}^{4+}$. There are limits to this analogy such as when comparing the $3+$ oxidation state of all of the actinides, the ionic radii of the actinides decrease slightly when going from ${ }_{90}$ Th to ${ }_{103} \mathrm{Lr}$. This is the actinide contraction, a trait also observed in the lanthanide series. A similar contraction is generally evident for the $4+$ oxidation state as shown by the actinide dioxide solids, $\mathrm{MO}_{2}$. The lattice parameter, $\mathrm{a}_{0}$, for the fluorite structure of the actinide 
dioxides decreases from $5.586 \AA$ for $\mathrm{ThO}_{2}$ to $5.372 \AA$ for $\mathrm{CmO}_{2}$, with the only anomaly being the lattice parameter for $\mathrm{UO}_{2} \cdot 11$

Generally, the chemical reactivity, such as precipitation or complexation, of the actinides decreases in the order:

$$
\mathrm{M}^{4+}>\mathrm{M}^{3+} \approx \mathrm{MO}_{2}^{2+}>\mathrm{MO}_{2}^{+}
$$

In natural aquatic systems, the anionic ligands that dominate the complexation and/or precipitation chemistry of the actinides generally rank from strongest to weakest in the order:

$$
\mathrm{OH}^{-}, \mathrm{CO}_{3}^{2-}>\mathrm{F}^{-}, \mathrm{HPO}_{4}^{-}, \mathrm{SO}_{4}^{2-}>\mathrm{Cl}^{-}, \mathrm{NO}_{3}^{-} \text {. }
$$

Typical solids that precipitate from aqueous solutions of $3+$ actinides include hydroxides, hydroxycarbonates, and carbonates. Solids that precipitate from aqueous solutions of $4+$ actinides typically include the hydroxides or oxides. The $5+$ actinides tend to precipitate as hydroxides, oxides, and even the alkali salts of actinyl carbonates under certain solution conditions. Hydroxide and carbonate solids usually precipitate from solutions of the $6+$ actinides. In general, the hydroxide and carbonate ligands tend to dominate the solution chemistry of the actinides in natural aquatic systems. 
There is, however, a significant difference in solubility for the various oxidation states of the actinides under similar solution conditions. For example, in pH 7 solutions with a $\mathrm{Na}^{+}$concentration equal to $0.01 \mathrm{M}$ and in contact with atmospheric carbon dioxide, typical solubilities of the $4+, 3+, 6+$, and $5+$ actinides are on the order of $10^{-10}, 10^{-7}, 10^{-6}$, and $10^{-5} \mathrm{M}$ respectively. ${ }^{13}$ Generally, the $4+$ actinides tend to be the most insoluble; whereas, the 5+ actinides tend to be the most soluble.

Another interesting feature of these elements arises because the actinides contain $5 \mathrm{f}$ electrons. Electronic transitions within the $\mathrm{f}$ orbitals of these elements give rise to useful spectroscopic features for both ionic and solid state species in the UV/VIS/NIR part of the electromagnetic spectrum. These transitions are also responsible for the brilliant colors associated with various oxidation states of the concentrated actinide ions in solution. For example, the colors of $\mathrm{Pu}^{3+}, \mathrm{Pu}^{4+}$, $\mathrm{PuO}_{2}{ }^{+}$, and $\mathrm{PuO}_{2}{ }^{2+}$ in $1 \mathrm{M} \mathrm{HClO}_{4}$ are purple, orange, pink, and yellow, respectively. The various stable oxidation states of uranium, neptunium, and plutonium each have unique absorption spectra that fall between $\sim 250$ and 1300 $\mathrm{nm}$. Unfortunately, the molar extinction coefficients for the absorption peaks associated with these species are rather low. Molar extinction coefficients range from about $\sim 8 \mathrm{M}^{-1} \mathrm{~cm}^{-1}$ at $416 \mathrm{~nm}$ for $\mathrm{UO}_{2}{ }^{2+}$ in solutions of $1 \mathrm{M} \mathrm{HClO}_{4}$ to $\sim 550 \mathrm{M}^{-1} \mathrm{~cm}^{-1}$ at $830 \mathrm{~nm}$ for $\mathrm{PuO}_{2}{ }^{2+}$ in solutions of $1 \mathrm{M} \mathrm{HClO}_{4}$. The rather low molar extinction coefficients limit the detectable concentrations of these species in solution, depending on the actinide and its oxidation state, to concentrations at or above $10^{-4} \mathrm{M}$ when using spectrophotometric cells with a path length of $1 \mathrm{~cm}$ 
and a conventional absorption spectrophotometer. However, when examining aqueous actinides at relatively high concentrations in the presence of complexing ligands such as carbonate, formation constants, or reaction quotients, for the various complexed species can be determined from the changes in the position and intensity of the peak absorption of the uncomplexed, free cation. More modern techniques like laser induced photoacoustic spectroscopy have enhanced detection limits but only by one to two orders of magnitude. However, the gain in detection limits is usually offset by the relatively high price of the associated equipment.

The fact that these elements are radioactive allows for their quantification by nuclear counting methods. Great advances have been made in the low-level detection of alpha, beta, and gamma radiation thus facilitating the quantification of these elements at rather low concentrations. However, a possible negative side to these types of determinations includes the lack of information about speciation which is obtained when using spectroscopic techniques. Additionally, there is a physical hazard associated with the handling of these types of materials because of their radioactivity.

\section{Neptunium Chemistry}

Neptunium was first synthesized by E.M. McMillan and P.H. Abelson in 1940.15 The isotope discovered was ${ }^{239} \mathrm{~Np}$. When a thin foil of uranium was bombarded with slow moving neutrons, the abundant ${ }^{238} \mathrm{U}$ isotope occasionally absorbed a 
low-energy neutron into its nucleus resulting in the formation of the ${ }^{239} \mathrm{U}$ isotope. The ${ }^{239} \mathrm{U}$ isotope then de-excited by releasing a photon, or gamma ray. The following notation is used to describe this nuclear reaction:

$$
{ }^{238} \mathrm{U}(\mathrm{n}, \gamma){ }^{239} \mathrm{U} \text {. }
$$

The ${ }^{239} \mathrm{U}$ isotope decayed by beta emission with a half-life of 23 minutes, and the resulting daughter was ${ }^{239} \mathrm{~Np}$. The ${ }^{239} \mathrm{~Np}$ isotope also decayed by beta emission with a half-life of 2.3 days and resulted in the production of the first isotope of plutonium, ${ }^{239} \mathrm{Pu}$. L. B. Magnusson and T. J. LaChapelle, who determined the specific activity of the long-lived isotope ${ }^{237} \mathrm{~Np}$, obtained the first significant amount of neptunium in $1944^{16}$ after its discovery by A. C. Wahl and G. T. Seaborg in $1942 .{ }^{17}$

Table 1-2 lists the neptunium isotopes currently known together with their halflives, decay modes, and general methods of production. 18,19 
Table 1-2. Currently known isotopes of neptunium with the corresponding half-lives, modes of decay, and methods of production. ${ }^{18,19}$

\begin{tabular}{|c|c|c|c|}
\hline Isotope & Half-Life & Decay Mode(s) & Method of Production \\
\hline 227 & $0.51 \mathrm{~s}$ & $\mathrm{EC}, \alpha$ & $\left.{ }^{209} \mathrm{Bi}^{(22} \mathrm{Ne}, 4 \mathrm{n}\right)$ \\
\hline 228 & $58 \mathrm{~s}$ & SF & ${ }^{209} \mathrm{Bi}\left({ }^{22} \mathrm{Ne}, 3 \mathrm{n}\right)$ \\
\hline 229 & $4.0 \mathrm{~m}$ & $\mathrm{EC}, \alpha$ & ${ }^{233} \mathrm{U}(p, 5 n)$ \\
\hline 230 & $4.6 \mathrm{~m}$ & $\mathrm{EC}, \alpha$ & ${ }^{234} \mathrm{Am} \alpha$ decay \\
\hline 231 & $48.8 \mathrm{~m}$ & $\mathrm{EC}, \alpha$ & $\begin{array}{l}{ }^{233} \mathrm{U}(\mathrm{d}, 4 \mathrm{n}) \\
{ }^{235} \mathrm{U}(\mathrm{d}, 6 \mathrm{n}) \\
{ }^{238} \mathrm{U}(\mathrm{d}, 9 \mathrm{n})\end{array}$ \\
\hline 232 & $14.7 \mathrm{~m}$ & $\mathrm{EC}, \alpha$ & $\begin{array}{l}{ }^{232} \mathrm{Pu} \text { EC decay } \\
{ }^{235} \mathrm{U}(\mathrm{d}, 5 \mathrm{n})\end{array}$ \\
\hline 233 & $36.2 \mathrm{~m}$ & $\mathrm{EC}, \alpha$ & $\begin{array}{c}{ }^{233} \mathrm{Pu} \text { EC decay } \\
{ }^{237} \mathrm{Am} \alpha \text { decay } \\
{ }^{235} \mathrm{U}(\mathrm{d}, 4 \mathrm{n}) \\
{ }^{234} \mathrm{U}(\mathrm{d}, 3 \mathrm{n})\end{array}$ \\
\hline 234 & $4.4 \mathrm{~d}$ & $\mathrm{EC}$ & $\begin{array}{l}{ }^{234} \mathrm{Pu} \text { EC decay } \\
{ }^{238} \mathrm{Am} \alpha \text { decay } \\
{ }^{235} \mathrm{U}(\mathrm{d}, 3 \mathrm{n})\end{array}$ \\
\hline 235 & $396.1 \mathrm{~d}$ & $\mathrm{EC}, \alpha$ & $\begin{array}{c}{ }^{235} \mathrm{Pu} \text { EC decay } \\
{ }^{239} \mathrm{Am} \alpha \text { decay } \\
{ }^{234} \mathrm{U}\left({ }^{3} \mathrm{He}, \mathrm{d}\right) \\
{ }^{234} \mathrm{U}\left(\alpha,{ }^{3} \mathrm{H}\right) \\
{ }^{237} \mathrm{~Np}\left(\mathrm{p},{ }^{3} \mathrm{H}\right) \\
{ }^{235} \mathrm{U}(\mathrm{d}, 2 \mathrm{n})\end{array}$ \\
\hline 236 & $1.54 \mathrm{E}+5 \mathrm{y}$ & $\mathrm{EC}, \beta$ & $\begin{array}{c}{ }^{240} \mathrm{Am} \alpha \text { decay } \\
{ }^{235} \mathrm{U}(\mathrm{d}, \mathrm{n}) \\
{ }^{237} \mathrm{U}(\mathrm{n}, 2 \mathrm{n})\end{array}$ \\
\hline 237 & $2.14 \mathrm{E}+6 \mathrm{y}$ & $\alpha, \mathrm{SF}$ & $\begin{array}{c}{ }^{238} \mathrm{U}(\mathrm{n}, 2 \mathrm{n}) \\
{ }^{235} \mathrm{U}(\mathrm{n}, \gamma)^{2} \\
{ }^{236} \mathrm{U}\left({ }^{3} \mathrm{He}, \mathrm{d}\right) \\
{ }^{237} \mathrm{U} \beta \text { decay } \\
{ }^{237} \mathrm{Pu} \text { EC decay } \\
{ }^{241} \mathrm{Am} \alpha \text { decay }\end{array}$ \\
\hline 238 & $2.117 \mathrm{~d}$ & $\beta$ & $\begin{array}{c}{ }^{242} \mathrm{Am} \alpha \text { decay } \\
{ }^{237} \mathrm{~Np}(\mathrm{n}, \gamma) \\
{ }^{237} \mathrm{~Np}(\mathrm{~d}, \mathrm{p}) \\
{ }^{238} \mathrm{U}(\mathrm{d}, 2 \mathrm{n}) \\
{ }^{235} \mathrm{U}(\alpha, \mathrm{p})\end{array}$ \\
\hline 239 & $2.3565 \mathrm{~d}$ & $\beta$ & $\begin{array}{c}{ }^{239} \mathrm{U} \beta \text { decay } \\
{ }^{243} \mathrm{Am} \alpha \text { decay } \\
{ }^{238} \mathrm{U}(\mathrm{n}, \gamma) \\
{ }^{238} \mathrm{U}\left({ }^{3} \mathrm{He}, \mathrm{d}\right)\end{array}$ \\
\hline 240 & $61.9 \mathrm{~m}$ & $\beta$ & $\begin{array}{l}{ }^{240} \mathrm{U} \beta \text { decay } \\
{ }^{238} \mathrm{U}(\alpha, \mathrm{pn})\end{array}$ \\
\hline 241 & $13.9 \mathrm{~m}$ & $\beta, \alpha$ & ${ }^{238} \mathrm{U}(\alpha, \mathrm{p})$ \\
\hline 242 & $5.5 \mathrm{~m}$ & $\beta$ & ${ }^{242} \mathrm{U} \beta$ decay \\
\hline 243 & $1.8 \mathrm{~m}$ & $\beta$ & ${ }^{244} \mathrm{Pu}\left({ }^{3} \mathrm{H}, \alpha\right)$ \\
\hline
\end{tabular}

$\mathrm{EC}=$ electron capture, $\mathrm{SF}=$ spontaneous fission, $\alpha=$ alpha particle emission, $\beta=$ beta particle emission 
Of the 21 isotopes listed in Table 1-2, only two, ${ }^{236} \mathrm{~Np}$ and ${ }^{237} \mathrm{~Np}$, have half-lives in excess of a year or so thus making them potentially relevant to long-term environmental concerns. Of these two isotopes, ${ }^{237} \mathrm{~Np}$ is of primary environmental significance due to the fact that it is produced in significant quantities in nuclear fuel and has a half life in excess of 2 million years. In a nuclear power plant that utilizes uranium as its fuel, four of the six nuclear reactions listed in Table 1-2 for the production of ${ }^{237} \mathrm{~Np}$ occur in the fuel either when it is in the reactor, or after it has been removed and becomes spent fuel. The bombardment of both ${ }^{235} \mathrm{U}$ and ${ }^{238} \mathrm{U}$ by neutrons result in the production of ${ }^{237} \mathrm{~Np}$ directly; whereas, after the fuel has been removed from the neutron flux in the core of the reactor, the isotopes ${ }^{237} \mathrm{U}$ (6.75 day half-life) and ${ }^{241} \mathrm{Am}$ (432.2 year half-life) decay into ${ }^{237} \mathrm{~Np}$. Both ${ }^{237} \mathrm{U}$ and ${ }^{241} \mathrm{Am}$ are daughter products of the short-lived ${ }^{241} \mathrm{Pu}$ isotope, an isotope also produced in uranium fuel as it is used in a power reactor.

Because ${ }^{237} \mathrm{~Np}$ is produced in fairly significant quantities in nuclear fuel, it seems reasonable to assume that the chemical thermodynamics of neptunium compounds should be studied in order to better understand its potential behavior in the environment. For several decades this has been done; however, the thermodynamic data available for $\mathrm{Np}$ in natural aquatic systems are still somewhat scarce and subject to significant uncertainty. In natural aquatic systems, soluble neptunium is most stable in the 4+ and 5+ oxidation state depending upon the redox potential of the aqueous system. ${ }^{13}$ 
As stated earlier, actinides in the 4+ oxidation state tend to form very stable and insoluble dioxide solids. If precipitated with $\mathrm{OH}^{-}$from solutions of the aqueous $\mathrm{M}^{4+}$ cation, the actinides usually precipitate initially as an amorphous hydroxide, $\mathrm{M}(\mathrm{OH})_{4}$. However, the hydroxides can be considered hydrous forms of the 4+ actinide oxides. The synthesis of anhydrous neptunium dioxide, $\mathrm{NpO}_{2}$, is usually performed by the high temperature $\left(400^{\circ} \mathrm{C} \text { or higher }\right)^{18}$ decomposition of various neptunium precipitates such as hydroxides and oxalates. Neptunium dioxide is a very stable solid phase that leads to very low concentrations of soluble neptunium in aqueous solutions. Figure 1-1 shows the total aqueous neptunium concentration calculated at different $\mathrm{pH}$ values using the standardstate equilibrium constants available in a critical review of neptunium thermodynamic data for the dissolution of $\mathrm{NpO}_{2}$ solid and the formation of the first through fifth hydrolysis products of the aqueous $\mathrm{Np}^{4+}$ cation. ${ }^{20}$ The concentrations of the aqueous species were calculated using the following equations and equilibrium constants cited in the literature:

$$
\begin{array}{ll}
\mathrm{NpO}_{2}(\mathrm{~s})+4 \mathrm{H}^{+} \leftrightarrows \mathrm{Np}^{4+}(\mathrm{aq})+2 \mathrm{H}_{2} \mathrm{O} & \log \mathrm{K}_{\mathrm{sp}}=(-7.8 \pm 1.4) \\
\mathrm{Np}^{4+}(\mathrm{aq})+\mathrm{H} \mathrm{O} \leftrightarrows \mathrm{Np}(\mathrm{OH})^{3+}(\mathrm{aq})+\mathrm{H}^{+} & \log \mathrm{K}_{11}=(-1.0 \pm 1.0) \\
\mathrm{Np}^{4+}(\mathrm{aq})+2 \mathrm{H} \mathrm{O} \leftrightarrows \mathrm{Np}(\mathrm{OH})_{2}^{2+}(\mathrm{aq})+2 \mathrm{H}^{+} & \log \mathrm{K}_{12}=(-2.8 \pm 2.6) \\
\mathrm{Np}^{4+}(\mathrm{aq})+3 \mathrm{H} \mathrm{O} \leftrightarrows \mathrm{Np}(\mathrm{OH})_{3}^{+}(\mathrm{aq})+3 \mathrm{H} & \log \mathrm{K}_{13}=(-5.8 \pm 3.5) \\
\mathrm{Np}^{4+}(\mathrm{aq})+4 \mathrm{H}_{2} \mathrm{O} \leftrightarrows \mathrm{Np}(\mathrm{OH})_{4}^{0}(\mathrm{aq})+4 \mathrm{H}^{+} & \log \mathrm{K}_{14}=(-9.6 \pm 3.5) \\
\mathrm{Np}^{4+}(\mathrm{aq})+5 \mathrm{H}_{2} \mathrm{O} \leftrightarrows \mathrm{Np}(\mathrm{OH})_{5}^{-}(\mathrm{aq})+5 \mathrm{H}^{+} & \log \mathrm{K}_{15}=(-14.3+3.5 /-7.0)
\end{array}
$$




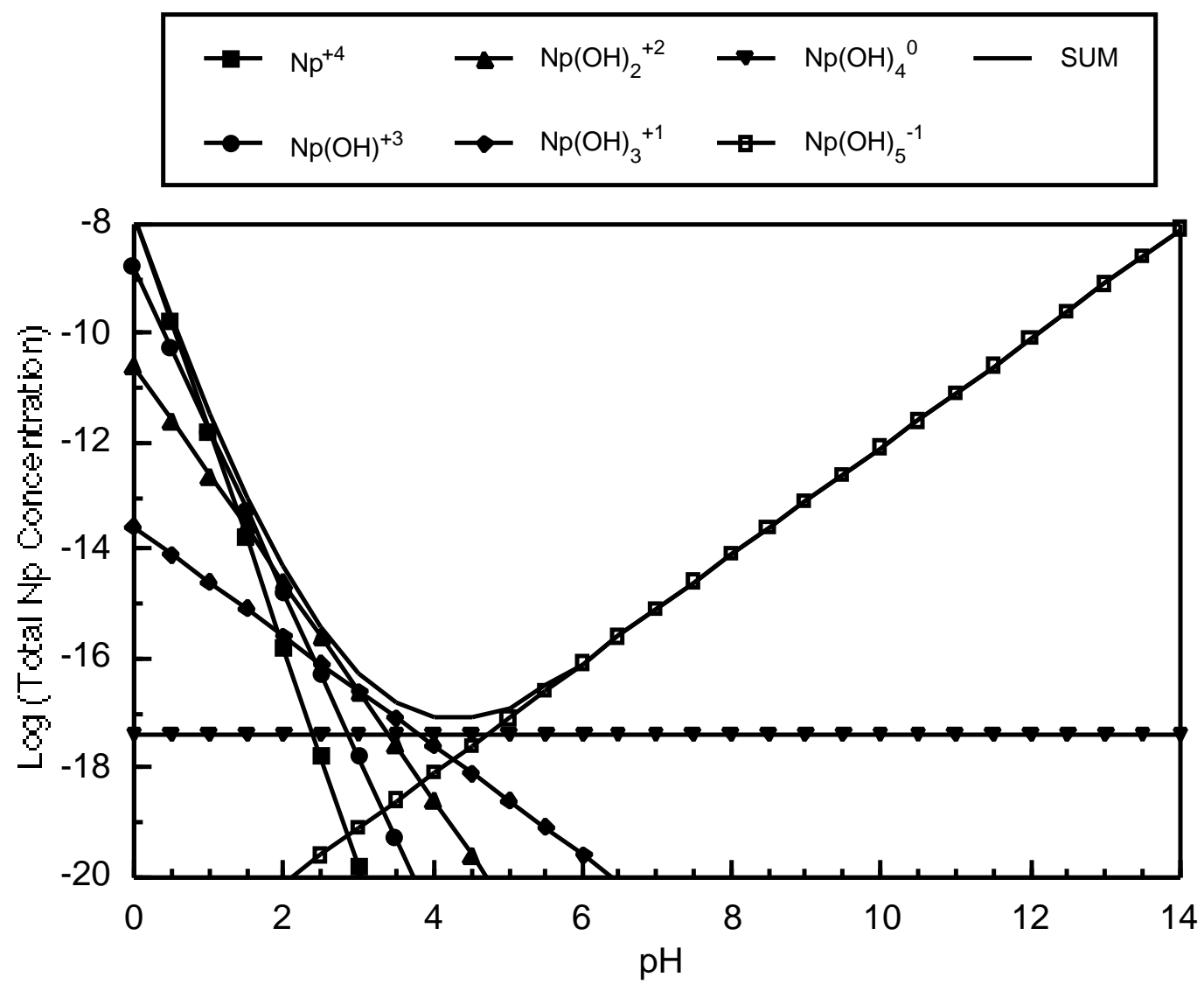

Figure 1-1. Aqueous neptunium concentrations at standard state are plotted as a function of $\mathrm{pH}$ for the dissolution of $\mathrm{NpO}_{2}$ and the formation of aqueous neptunium hydrolysis species.

Regardless of $\mathrm{pH}$, the equilibrium concentrations of aqueous neptunium in this system are rather low. The log of the concentration of each aqueous neptunium species, with the exception of $\mathrm{Np}(\mathrm{OH})_{4}{ }^{0}(\mathrm{aq})$, shows a linear dependence with $\mathrm{pH}$. As shown in the figure, the concentration of $\mathrm{Np}(\mathrm{OH})_{4}{ }^{0}(\mathrm{aq})$ is not a function of the $\mathrm{pH}$. The sum of the concentration of all the aqueous neptunium species is shown in Figure 1-1 with a bold line. A minimum total aqueous neptunium 
concentration of $\sim 10^{-17} \mathrm{M}$ is calculated for near $\mathrm{pH} 4$. As the $\mathrm{pH}$ increases or decreases from a value of 4 , the total aqueous neptunium concentration increases but never exceeds $10^{-8} \mathrm{M}$.

In contrast, actinides in the 5+ oxidation state tend to form relatively soluble compounds like hydroxides or di-actinide pentoxides (in the absence of carbonate). If precipitated with $\mathrm{OH}^{-}$from solutions of the aqueous $\mathrm{MO}_{2}{ }^{+}$cation, the actinides usually precipitate initially as an amorphous hydroxide, $\mathrm{MO}_{2}(\mathrm{OH})$. The hydroxide might be considered a non-crystalline, hydrous form of the diactinide pentoxide as stated by Lemire ${ }^{20}$ where he noted that amorphous $\mathrm{NpO}_{2}(\mathrm{OH})(\mathrm{s})$ has the same stoichiometry as crystalline $0.5 \mathrm{~Np}_{2} \mathrm{O}_{5} \cdot \mathrm{H}_{2} \mathrm{O}(\mathrm{s})$. The aqueous $\mathrm{NpO}_{2}{ }^{+}$cation does hydrolyze in solution, but there is debate as to whether or not a second, aqueous hydrolytic species forms. In work performed more recently than the review by Lemire, Neck et al. ${ }^{21}$ measured the solubility of amorphous $\mathrm{NpO}_{2}(\mathrm{OH})$ solid in aqueous solutions and determined formation constants at several ionic strengths for the aqueous species $\mathrm{NpO}_{2}(\mathrm{OH})_{2}^{-1}$ based on an observed increase in aqueous neptunium concentrations in solutions with $\mathrm{pH}$ values in excess of 12. However, Pan and Campbel122 did not observe a similar increase in aqueous neptunium concentrations at high $\mathrm{pH}$ when measuring the solubility of well-characterized, crystalline $\mathrm{Np}_{2} \mathrm{O}_{5}$. Contamination of an aqueous system by carbonate, presumably from exposure to even trace levels of carbon dioxide, may be responsible for observed increases in aqueous neptunium concentrations at high $\mathrm{pH}$. The aqueous carbonate anion, $\mathrm{CO}_{3}^{-2}$, is a very strong ligand and readily complexes the 5+ actinides in aqueous solution, especially at 
high $\mathrm{pH}$ values where the free carbonate concentrations are relatively high. However, in the work of Neck et al., great care was taken to avoid exposure to $\mathrm{CO}_{2}$ and currently there is no explanation as to why the work of Pan and Campbell did not provide similar results. Because of the uncertainty with regard to the existence of the second hydrolysis product, it will be omitted as a species in the following description as was the case in the review paper of Lemire.

Assuming that amorphous $\mathrm{NpO}_{2}(\mathrm{OH})$ is a less crystalline, less stable form of $\mathrm{Np}_{2} \mathrm{O}_{5}$, its solubility in aqueous systems of identical conditions should exceed that of $\mathrm{Np}_{2} \mathrm{O}_{5}$. In other words, aqueous concentrations of neptunium that result from the dissolution of $\mathrm{NpO}_{2}(\mathrm{OH})$ should provide an upper limit relative to the dissolution of other, more stable $\mathrm{NpO}_{2}^{+}$solids. Figure 1-2 shows the total aqueous neptunium concentration as a function of $\mathrm{pH}$ as calculated using the standard-state equilibrium constants determined by Neck et al. for the dissolution of $\mathrm{NpO}_{2}(\mathrm{OH})$ solid and the formation of the first hydrolysis product of the aqueous $\mathrm{NpO}_{2}{ }^{+}$cation. The concentrations of the aqueous species were calculated using the following equations and equilibrium constants cited in the literature:

$$
\begin{array}{ll}
\mathrm{NpO}_{2}(\mathrm{OH})(\mathrm{s})+\mathrm{H}^{+} \leftrightarrows \mathrm{NpO}_{2}^{+}(\mathrm{aq})+\mathrm{H}_{2} \mathrm{O} & \log \mathrm{K}_{\mathrm{sp}}=(5.24 \pm 0.05) \\
\mathrm{NpO}_{2}^{+}(\mathrm{aq})+\mathrm{H}_{2} \mathrm{O} \leftrightarrows \mathrm{NpO}_{2}(\mathrm{OH})^{0}(\mathrm{aq})+\mathrm{H} & \log \mathrm{K}_{11}=(-11.3 \pm 0.20)
\end{array}
$$




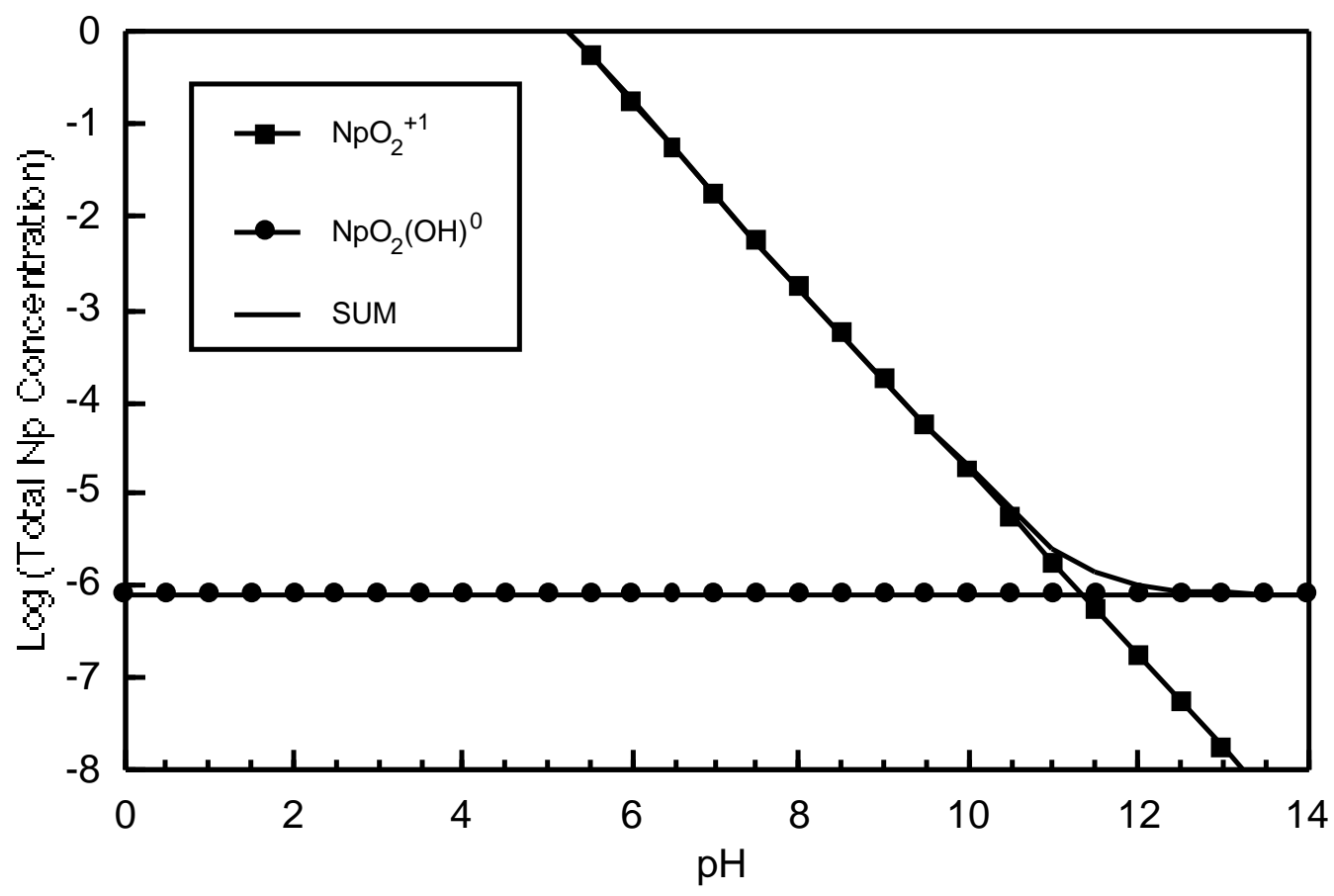

Figure 1-2. Aqueous neptunium concentrations at standard state are plotted as a function of $\mathrm{pH}$ for the dissolution of $\mathrm{NpO}_{2}(\mathrm{OH})$ and the formation of aqueous neptunium hydrolysis species.

The equilibrium constants listed above were adjusted from the original values using a value of -14 for the $\log$ of the ionization product of water at standard state conditions. The uncertainties listed are those reported by Neck et al. The relatively small uncertainties associated with the work of Neck et al. contrast with those listed for the equilibria involving the $4+$ species because the values from Lemire encompass a wider assortment of data that were critically reviewed. Therefore, the larger uncertainties listed by Lemire account for variations arising from the averaging of various data sources. 
In contrast to the low solubility of $\mathrm{NpO}_{2}$, total aqueous neptunium concentrations as a function of $\mathrm{pH}$ in equilibrium with amorphous $\mathrm{NpO}_{2}(\mathrm{OH})$ solid never fall below $10^{-7} \mathrm{M}$. If a second aqueous hydrolysis product does in fact exist, this will only increase the total aqueous neptunium concentrations between $\mathrm{pH}$ values of 12 and 14 because the concentration of $\mathrm{NpO}_{2}(\mathrm{OH})_{2}^{-1}(\mathrm{aq})$, on the logarithmic scale, as a function of $\mathrm{pH}$ has a positive slope similar to the fifth hydrolysis product in the neptunium $4+$ system.

Since the $4+$ and 5+ oxidation states dominate the solution chemistry of neptunium, it is interesting to directly compare their respective solubilities. Figure 1-3 shows a comparison of the total aqueous neptunium concentrations for the dissolution of $\mathrm{NpO}_{2}$ versus $\mathrm{NpO}_{2}(\mathrm{OH})$ solids as a function of $\mathrm{pH}$. These lines are the same as the bold lines in each of Figures 1-1 and 1-2. The dotted line shows the solubility curve for the $\mathrm{Np}(\mathrm{V})$ system, and the solid line shows the solubility curve for the $\mathrm{Np}(\mathrm{IV})$ system. At $\mathrm{pH} 14$, the difference between the two curves is at its minimum. There is only about a two order of magnitude difference in total aqueous neptunium. However, at near-neutral $\mathrm{pH}$ values, more likely to resemble environmental conditions, the difference between the two curves is much more significant. At $\mathrm{pH} 7$, there are approximately 13 orders of magnitude between the total aqueous neptunium concentrations when comparing the solubility of $\mathrm{NpO}_{2}$ and $\mathrm{NpO}_{2}(\mathrm{OH})$ solids. This is a rather significant result considering that the fundamental difference between the two systems is a single electron in the neptunium atom, going from $N p(I V)$ to $N p(V)$. 


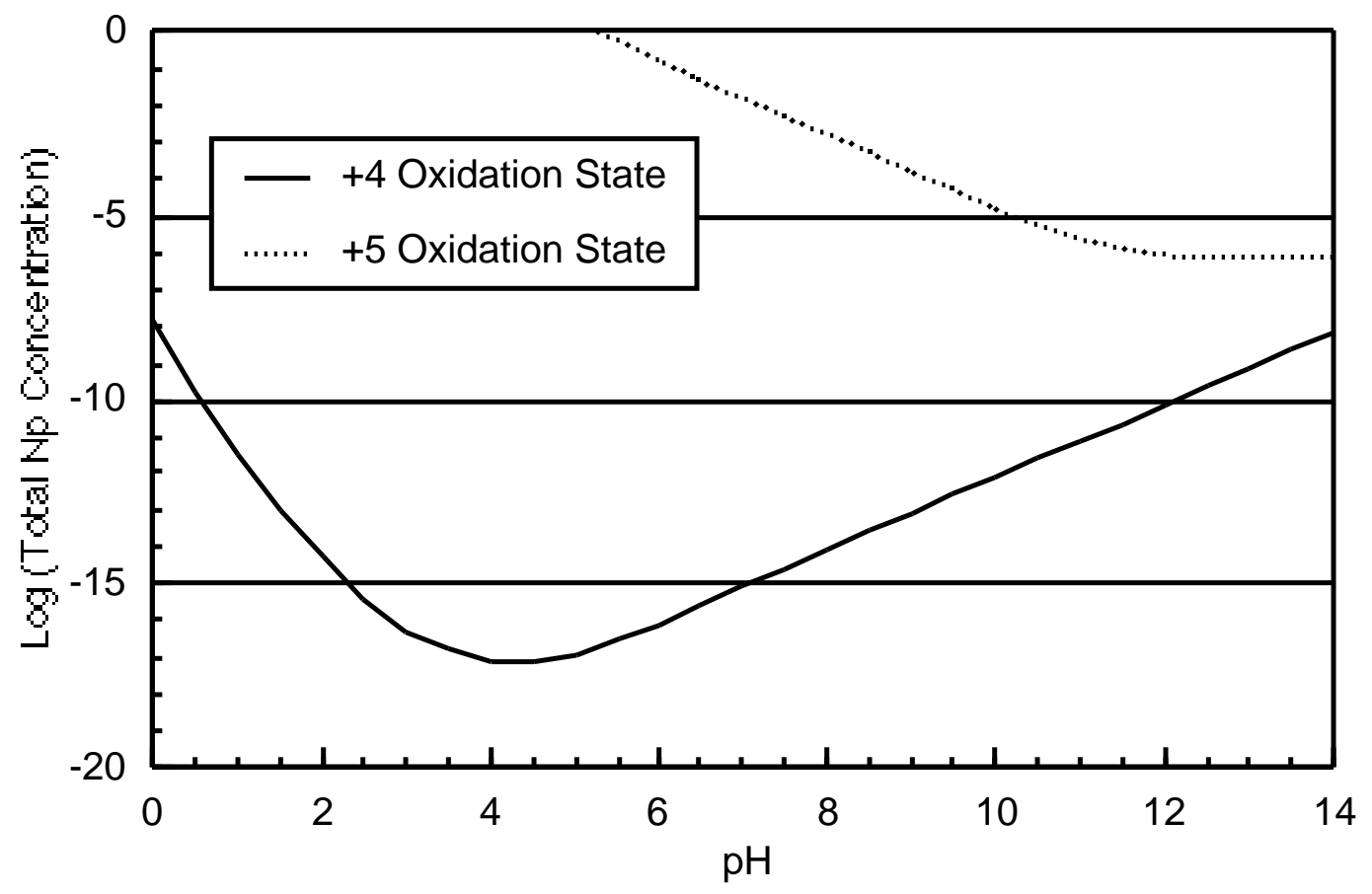

Figure 1-3. Standard state total aqueous neptunium concentrations for the dissolution of $\mathrm{NpO}_{2}$ versus $\mathrm{NpO}_{2}(\mathrm{OH})$ solids as a function of $\mathrm{pH}$.

The comparison of the $4+$ and $5+$ systems shown in Figure 1-3 is a somewhat simplified description because it neglects the oxidation/reduction reaction. The oxidation of $\mathrm{Np}^{4+}$ to $\mathrm{NpO}_{2}^{+}$involves oxygen and is described with the following equation:

$$
4 \mathrm{~Np}^{4+}(\mathrm{aq})+\mathrm{O}_{2}+6 \mathrm{H}_{2} \mathrm{O} \leftrightarrows 4 \mathrm{NpO}_{2}^{+}(\mathrm{aq})+12 \mathrm{~F} \quad \log \mathrm{K}_{\mathrm{ox}}=(39.5 \pm 6.1)
$$

The value for the equilibrium constant listed here is that published by Lemire. ${ }^{20}$ Air has an oxygen content of about 20 percent, or $\sim 0.2$ bar at standard state 
conditions. Assuming a stable solid phase of $\mathrm{NpO}_{2}$ in aqueous solutions exposed to air with an oxygen fugacity of 0.2 , the predominant oxidation state of the aqueous neptunium is $5+$. The oxidation of the aqueous neptunium significantly increases the total aqueous neptunium concentrations in equilibrium with $\mathrm{NpO}_{2}$ solid in solutions regardless of $\mathrm{pH}$. Figure 1-4 shows this effect. The middle curve, dashed line, represents the standard state total aqueous neptunium concentration in solutions containing $\mathrm{NpO}_{2}$ solid that are exposed to air. The speciation is predominantly the same as that for the dissolution of the $5+$ solids with the exception of the predominance of $\mathrm{Np}(\mathrm{OH})_{5}^{-}(\mathrm{aq})$ at very high $\mathrm{pH}$, but the total concentrations are somewhat lower when compared with the dissolution of $\mathrm{Np}(\mathrm{V})$ solid phases.

It might be expected that most groundwater systems would be exposed to oxygen partial pressures at most equal to and more often significantly lower that that in air. Therefore, the total aqueous neptunium concentrations from the dissolution of $\mathrm{NpO}_{2}$ under oxidizing conditions would be lower than the dashed line in Figure 1-4 so long as the oxygen partial pressure is lower than in air. Nonetheless, the concentration of neptunium in solutions containing $\mathrm{NpO}_{2}$ solid that are exposed to air remain 3 to 4 orders of magnitude lower than those calculated for the exclusively $\mathrm{Np}(\mathrm{V})$ system.

One additional note worth mentioning is that the critically reviewed values published by Lemire for the equilibrium constants in the Np(IV) system have rather significant uncertainties associated with them. To show the effect of these 


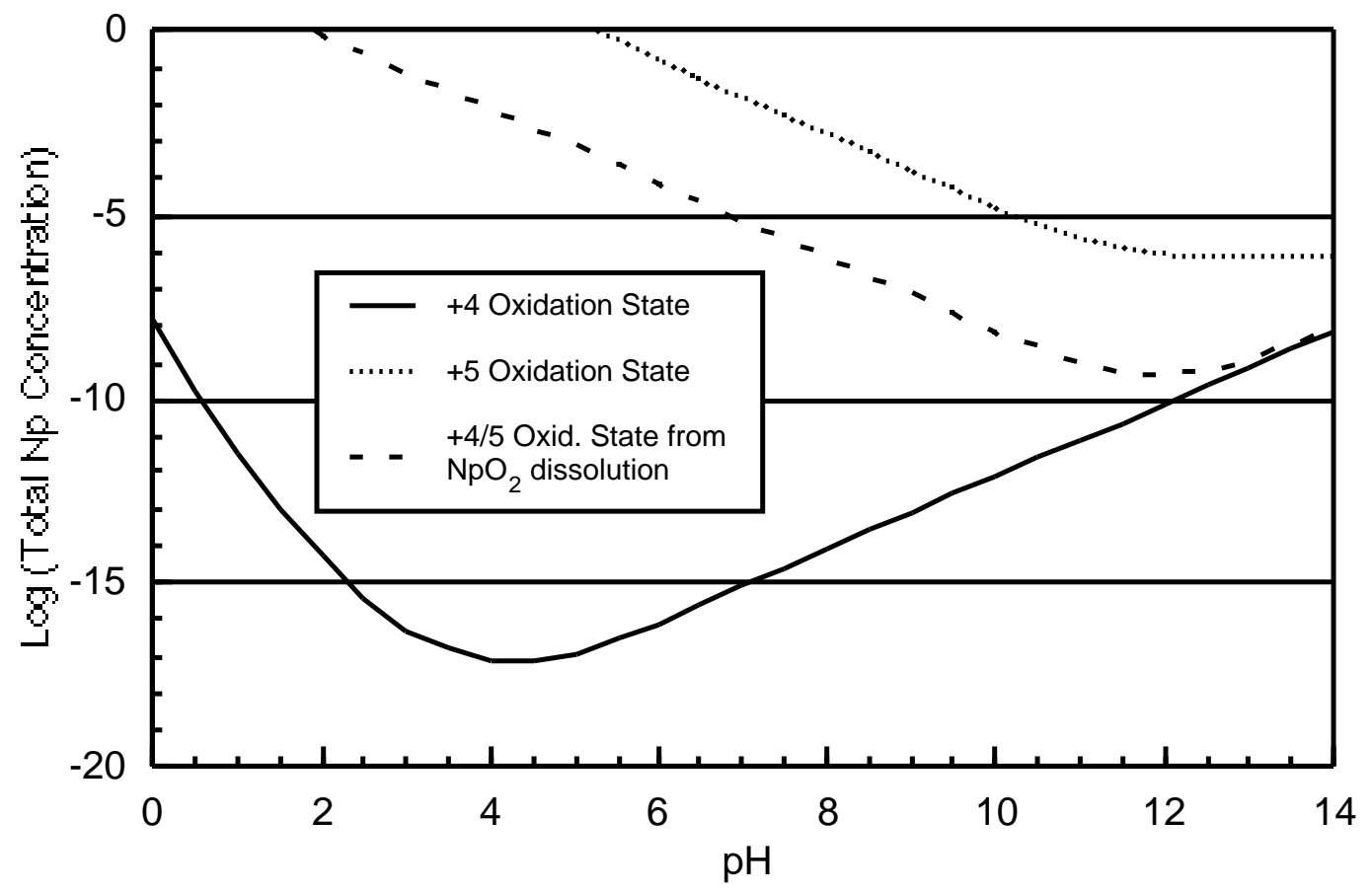

Figure 1-4. Standard state total aqueous neptunium concentrations for the dissolution of $\mathrm{NpO}_{2}$ versus $\mathrm{NpO}_{2}(\mathrm{OH})$ solids as a function of $\mathrm{pH}$. The dashed line in the center represents the dissolution of $\mathrm{NpO}_{2}$ under oxidizing conditions, 0.2 bar oxygen, in equilibrium with aqueous neptunium species in the $5+$ oxidation state, both $\mathrm{NpO}_{2}^{+}$ and $\mathrm{NpO}_{2}(\mathrm{OH})$, and at high $\mathrm{pH}$ the $4+$ oxidation state, $\mathrm{Np}(\mathrm{OH})_{5}{ }^{-}$ (aq).

uncertainties, boundary conditions can be calculated for the upper and lower limits of dissolved neptunium by using the smallest and largest possible equilibrium constants for the calculation of the concentrations of the aqueous species. These results can be seen in Figure 1-5. The bold line represents the total aqueous neptunium concentrations based on the recommended values in Lemire. The "upper bound" was calculated by using the largest values for each of the equilibrium constants, and the "lower bound" was calculated using the 
smallest values for each of the equilibrium constants. At $\mathrm{pH} 7$, the uncertainty associated with the dissolution of $\mathrm{NpO}_{2}$ and the subsequent formation of various hydrolysis products causes the calculated total aqueous neptunium concentration to vary over 12 orders of magnitude. Uncertainties of this magnitude certainly indicate that the thermodynamic data should be better evaluated.

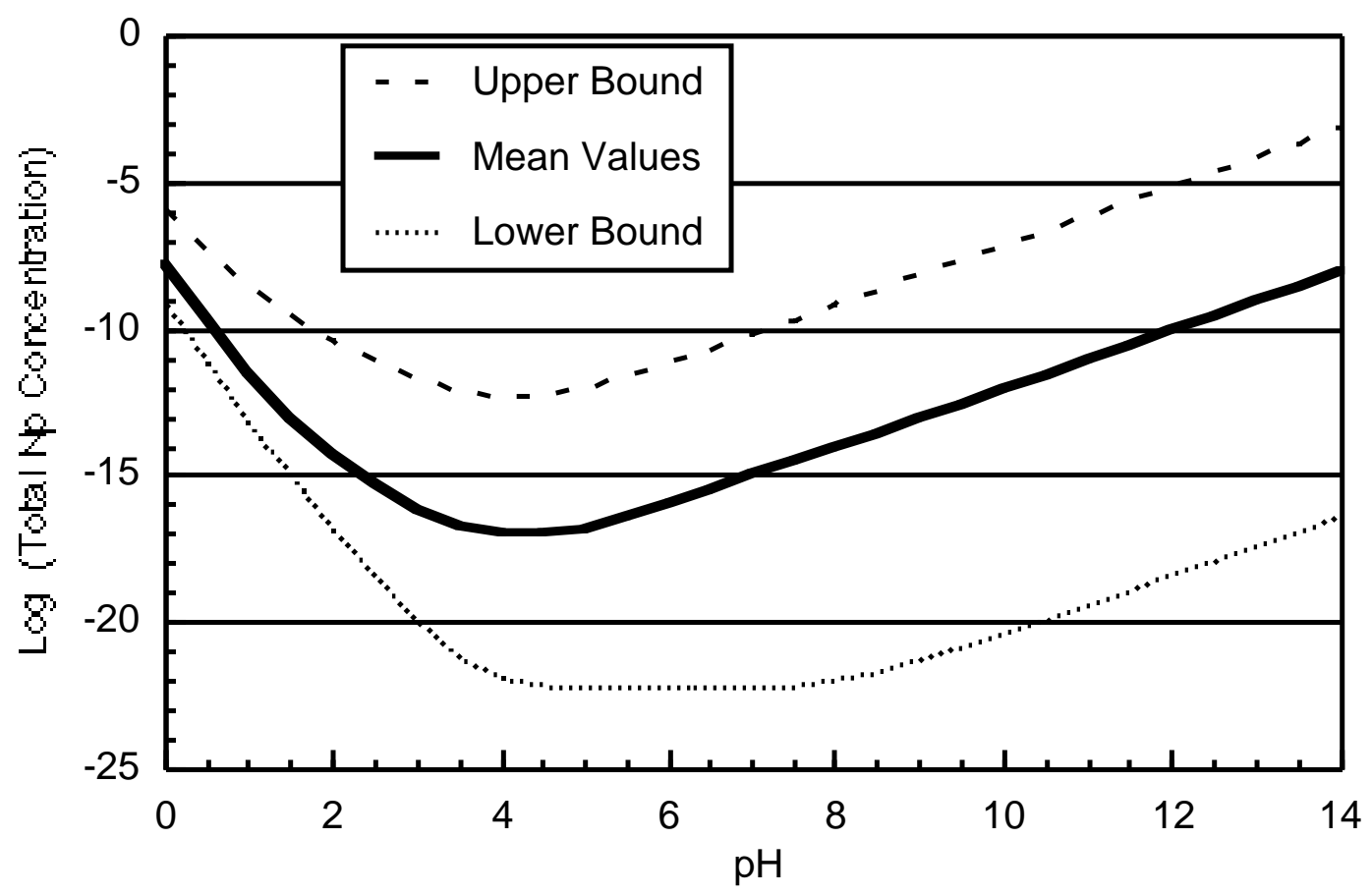

Figure 1-5. Upper and lower bounds to the total aqueous neptunium concentrations based on the dissolution of $\mathrm{NpO}_{2}$. The curves were calculated from the critically reviewed values listed by Lemire. 


\section{STATEMENT OF THE PROBLEM}

In order to help determine the suitability of Yucca Mountain as a site for a potential geologic nuclear waste repository, among other activities, the Yucca Mountain Project has engaged in an effort to understand and document the aqueous geochemistry of the site as well as the stability of various radionuclides that may be accessible to the environment should all barriers engineered to contain the high-level nuclear waste fail. As a part of this effort, a geochemical, thermodynamic modeling program, or computer code, called EQ3/6 has been under continual development. 23,24 This program, by including data pertaining to the site such as temperature and the composition of natural waters, can be used to calculate equilibrium amounts of dissolved metals, such as actinides and fission products, that would be released by the solids contained in the nuclear waste form. However, the geochemical modeling resulting from this computer code will only be accurate when the input parameters, the standard state thermodynamic properties of the elements and their compounds, are accurate. Thermodynamic properties include solubility products, complexation constants, sorption distribution coefficients, reduction-oxidation potentials, etc. all of which become a function of the solution conditions. Conditions that include the presence of inorganic and organic ligands, $\mathrm{pH}$, temperature, ionic strength, and Eh (reduction-oxidation potential). 
Excluding the formation of actinide colloids there are three fundamental processes that control the amount of an actinide in aqueous solution: 1.) precipitation/dissolution, 2.) complexation, and 3.) sorption/desorption. Of these three processes, precipitation/dissolution equilibria are arguably the most important because errors in those thermodynamic data can systematically raise or lower the amount of dissolved actinide available to other chemical processes.

Of the radioactive components in spent nuclear fuel, four actinides (uranium, neptunium, plutonium, and americium) are the most important because of the quantity contained within the spent fuel and the relatively long half lives associated with these radionuclides. ${ }^{13}$ Of these four actinides, the radioisotope ${ }^{237} \mathrm{~Np}$ is of particular concern. With its lengthy half-life of 2.14 million years, ${ }^{237} \mathrm{~Np}$ will be the major contributor to potential radiation doses in the accessible environment because it will be the predominant isotope in the repository inventory 10,000 to $1,000,000$ years after permanent closure of the repository. ${ }^{25}$

The potential radiological hazard for long disposal times associated with the long half-life of this isotope is compounded by the fact that neptunium most often is found in the $5+$ oxidation state when in aqueous solution. Actinides in the $5+$ oxidation state tend to be the most soluble in aqueous solution and the least sorbing on geologic media such as the volcanic Tuff in and around Yucca Mountain. Therefore, in evaluating the "worst-case-scenario" for an underground repository, where the man-made containment has been breached, or has ultimately failed, and the groundwater of the geologic medium controls 
the chemistry of the waste components, those actinides that exist in the $5+$ oxidation state will potentially be the most concentrated and the least retarded by sorption on the host rock. ${ }^{26}$

Values of neptunium release were initially based on the assumption that crystalline $\mathrm{NpO}_{2}$ would be the solubility-limiting solid phase in the repository environment. Based on thermodynamic data critically reviewed by R.J. Lemire, ${ }^{20}$ this leads to a calculated aqueous neptunium concentration that is well below $10^{-13} \mathrm{M}$ for conditions associated with Yucca Mountain

Other, long-term radiation dose estimates from the possible release of waste components into the environment were based upon the levels of neptunium found in solutions exposed to actinide-doped waste glasses. ${ }^{27}$ Neptuniumdoped borosilicate glass was used to simulate a potential waste form and was placed in contact with aqueous solutions to measure the dissolution of neptunium from the potential waste form. Steady-state aqueous concentrations of neptunium were attained after months of reaction time and found to be $\sim 10^{-6}$ $\mathrm{M}$ in solutions with $\mathrm{pH}$ values ranging from about 3 to 5 . Higher, near-neutral $\mathrm{pH}$ values would cause the precipitation of free neptunium from aqueous solution and thus lower aqueous $\mathrm{Np}$ concentrations even further. These results were consistent with aqueous $\mathrm{Np}(\mathrm{V})$ being in equilibrium with a neptunium(IV) oxide solid phase. 
An initial "Total System Performance Assessment" was prepared in 1992 for the Yucca Mountain Site Characterization Project in order to calculate the possible release of $\mathrm{Np}$ from the potential waste repository. ${ }^{28}$ The assessed $\mathrm{Np}$ release was determined to be on the order of $10^{-9}$ to $10^{-8} \mathrm{M}$ based on data obtained in several spent nuclear fuel dissolution studies. ${ }^{29-32}$

If studies like these were indicative of the potentially attainable levels of soluble neptunium in aqueous solution, then radiation dose calculations based on these levels in the environment would fall below safety limits proposed by the EPA. However, in an effort to supplement thermodynamic data in the database used by EQ3/6 for predictive modeling, neptunium solubility studies were performed by $\mathrm{H}$. Nitsche et al. at the Lawrence Berkeley National Laboratory in support of performance assessment for the proposed geological repository at Yucca Mountain. 4,5,33 Neptunium solubility studies were performed from oversaturation by introducing aqueous neptunium in the $5+$ oxidation state to groundwaters that range from the lowest to the highest ionic strengths expected to be found at Yucca Mountain. Table 2-1 lists the compositions of the two groundwaters, J-13 and UE-25p \# 1.34 Experiments were performed at 25 and $60^{\circ} \mathrm{C}$ in both waters and also at $90^{\circ} \mathrm{C}$ in $\mathrm{J}-13$ water. The ionic neptunium was introduced from a concentrated stock solution to the groundwaters at an initial concentration that was expected to exceed its solubility in the groundwaters. By doing this, the components of the groundwater determined the neptunium solid phase that precipitated. Aqueous neptunium concentrations were monitored, and steady state was demonstrated by achieving constant aqueous neptunium 
concentrations over time. Total aqueous neptunium concentration ranged from micromolar to millimolar in the $\mathrm{pH}$ and temperature ranges that were investigated ( $\mathrm{pH}$ values 6,7 , and 8.5 and temperatures of 25,60 , and $90^{\circ} \mathrm{C}$ ). The precipitated neptunium solid phases were characterized by $\mathrm{x}$-ray powder diffraction and were found to be, in almost all cases, sodium neptunium(V) carbonates, $\mathrm{Na}_{x} \mathrm{NpO}_{2}\left(\mathrm{CO}_{3}\right)_{y}$ where $\mathrm{x}$ and $\mathrm{y}$ varied. In one elevated temperature experiment, neptunium(V) oxide, $\mathrm{Np}_{2} \mathrm{O}_{5}$, was also observed to precipitate.

Table 2-1. Analyzed chemical composition of J-13 and UE-25p \# 1 well waters. ${ }^{34}$

\begin{tabular}{|lcc|}
\hline \multicolumn{1}{|c}{ Species } & $\begin{array}{c}\text { J-13 Well Water } \\
\text { Concentration (mM) }\end{array}$ & $\begin{array}{c}\text { UE-25p \#1 Well Water } \\
\text { Concentration (mM) }\end{array}$ \\
\hline \hline & & \\
$\mathrm{Na}^{+}$ & 1.96 & 7.43 \\
$\mathrm{~K}^{+}$ & 0.14 & 0.34 \\
$\mathrm{Ca}^{2+}$ & 0.29 & 2.19 \\
$\mathrm{Mg}^{2+}$ & 0.07 & 1.31 \\
$\mathrm{SiO}_{2}$ (aq) & 1.07 & 0.62 \\
$\mathrm{Cl}^{-}$ & 0.18 & 1.04 \\
$\mathrm{SO}_{4}^{2-}$ & 0.19 & 1.34 \\
$\mathrm{~F}^{-}$ & 0.11 & 0.18 \\
Total Carbonate & 2.81 & 15.31 \\
Ionic Strength & $\sim 3$ & $\sim 20$ \\
& & \\
& & \\
pH & 7.0 & 6.7 \\
Total Alkalinity & 2.34 mequiv./L & 11.44 mequiv./L \\
Eh & $700 \mathrm{mV}$ & $360 \mathrm{mV}$ \\
& & \\
\hline
\end{tabular}

The aqueous neptunium concentrations reported by Nitsche et al. posed a potentially serious problem with regard to the suitability of the proposed 
geological repository at Yucca Mountain. When using the relatively high solubilities reported by Nitsche et al. in a new set of performance assessment calculations for the potential release rates of radionuclides over extended periods of time, levels of neptunium release now yielded possible concentrations up to a level of $10^{-2} \mathrm{M} \cdot 35,36$

To address this potential issue, further modeling calculations using EQ3/6 were performed using existing thermodynamic data at $25^{\circ} \mathrm{C}$. The results showed that the experimentally observed $\sim 10^{-3} \mathrm{M}$ neptunium concentrations in $\mathrm{J}-13$ groundwater at near-neutral $\mathrm{pH}$ reported by Nitsche et al. were grossly supersaturated with respect to the formation of $\mathrm{NpO}_{2}$, yet these modeling efforts were unable to explain why $\mathrm{NpO}_{2}$ did not form. ${ }^{37}$ It was suggested that the formation of $\mathrm{NpO}_{2}$ was kinetically limited and therefore not observed because of the relatively short experimental duration of several months.

Since the work of Nitsche et al., additional solubility experiments of a very similar nature conducted for over a year at the Los Alamos National Laboratory by W. Efurd et al. resulted in slightly, but not significantly, lower neptunium solubilities for the same solution conditions. ${ }^{38}$ In this case, the investigators identified the solid phases as dineptunium pentoxide, $\mathrm{Np}_{2} \mathrm{O}_{5}$.

The solid phases observed in both the Nitsche et al. and Efurd et al. experiments were all $\mathrm{Np}(\mathrm{V})$ solid phases. If it could be demonstrated that $\mathrm{NpO}_{2}$ will precipitate, given time, from an aqueous solution of initially $\mathrm{Np}(\mathrm{V})$, then the 
solubility of neptunium at extended time periods may in fact be governed by the much more insoluble $\mathrm{Np}(\mathrm{IV})$ oxide solid phase. In other words, is the following reaction thermodynamically favorable:

$$
\mathrm{NpO}_{2}^{+}+0.5 \mathrm{H}_{2} \mathrm{O} \leftrightarrows \mathrm{NpO}_{2}(\mathrm{~s})+\mathrm{H}^{+}+0.25 \mathrm{O}_{2}
$$

It is the objective of this research project to determine if $\mathrm{NpO}_{2}$ solid will precipitate from an aqueous solution initially containing $\mathrm{Np}(\mathrm{V})$. If the currently accepted thermodynamic data are accurate, the formation of this phase should occur faster at elevated temperatures. Accordingly, the precipitation of $\mathrm{NpO}_{2}$ from aqueous $\mathrm{NpO}_{2}^{+}$at $200^{\circ} \mathrm{C}$ was studied.

If this precipitation could be observed experimentally, it would contribute to a better understanding of the ambient-temperature equilibrium distribution of the $\mathrm{Np}(\mathrm{IV})$ and $\mathrm{Np}(\mathrm{V})$ solution and solid species. 


\section{EXPERIMENTAL}

\section{Equipment}

\section{Controlled Atmosphere Glove Box}

A dual-stage, controlled-atmosphere glove box (Vacuum Atmospheres Company, Hawthorne, California) was used for all of the solubility experiments in order to 1.) contain the radiological hazard associated with the alpha decay of

${ }^{237}$ Neptunium and 2.) maintain a controlled atmosphere over the experimental solutions. The glove box was equipped with three separate gas intake lines: one line for pure argon gas (supplied from the laboratory), a second line for filtered, compressed air (supplied from the laboratory), and a third line to be connected to smaller cylinders of other gases such as pure $\mathrm{CO}_{2}$. This allowed solubility experiments to be run under different conditions such as an inert atmosphere, like argon, or under an oxidizing atmosphere, like air.

The glove box was run under slightly negative pressure with respect to atmospheric pressure as requested by the Health Physics department at LLNL. For these solubility experiments, a slow flow of air was allowed to continuously run through the glove box in order to maintain a constant and pure atmospheric composition. The continuous flow of gas also helped maintain an ambient 
temperature in the glove box; i.e., no continual heat build up from the oven being in continual use. The glove box exhaust was vented through two high efficiency particulate air (HEPA) filter units in series before venting into the building's exhaust system.

The glove box was equipped with an ante-chamber for use in transferring radioactive samples into secondary containment to prevent the unnecessary spread of contamination to other equipment. The anti-chamber also aids in maintaining the controlled atmosphere inside of the glove box by allowing the user to 'flush' items being transferred into the box with the gas inside of the box before they enter the box. Figure 3-1 shows a digital photograph of the dualstage, controlled atmosphere glove box used for the elevated-temperature, neptunium solubility experiments.

\section{High-Temperature Safety Vacuum Oven}

A high-temperature, safety vacuum oven, model \# 1410MS, made by Sheldon Manufacturing, Cornelius, Oregon, was obtained through VWR Scientific, San Francisco, California. The temperature set on the oven's digital display was calibrated by measuring the internal temperature at various settings with a thermometer placed through an insulated port on the back of the oven. The tip

of the external thermometer was centered in the oven's chamber. A constant shift from the digital readout of $-(6 \pm 1)^{\circ} \mathrm{C}$ was observed throughout the temperature range from 200 to $280^{\circ} \mathrm{C}$. The oven was then placed into the 
controlled-atmosphere glove box for the neptunium solubility experiments.

Figure 3-2 shows a digital photograph of the high-temperature, safety vacuum oven on the inside left of the controlled atmosphere glove box that was used for the elevated-temperature neptunium solubility experiments. 


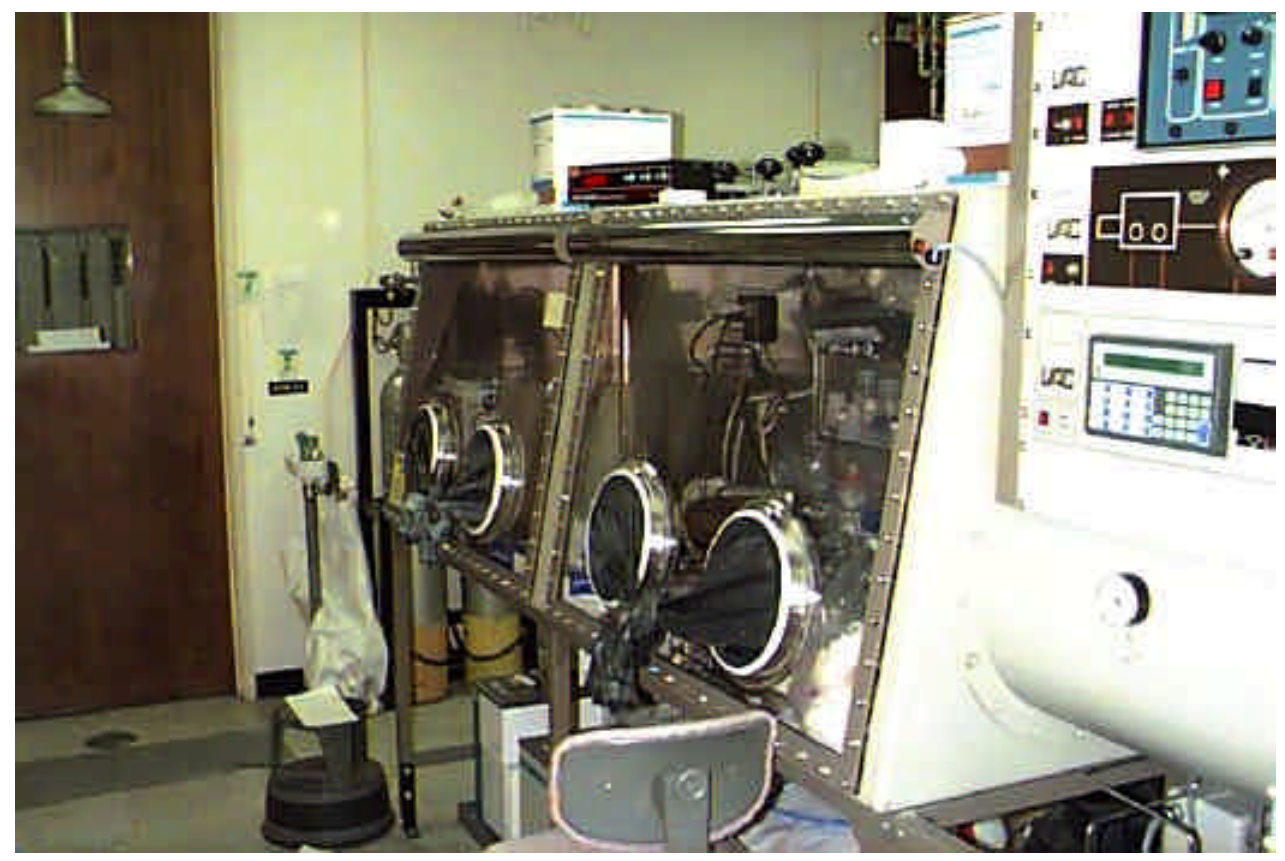

Figure 3-1. Controlled atmosphere glove box (Vacuum Atmospheres Company) used for the elevated temperature, neptunium solubility experiments. 


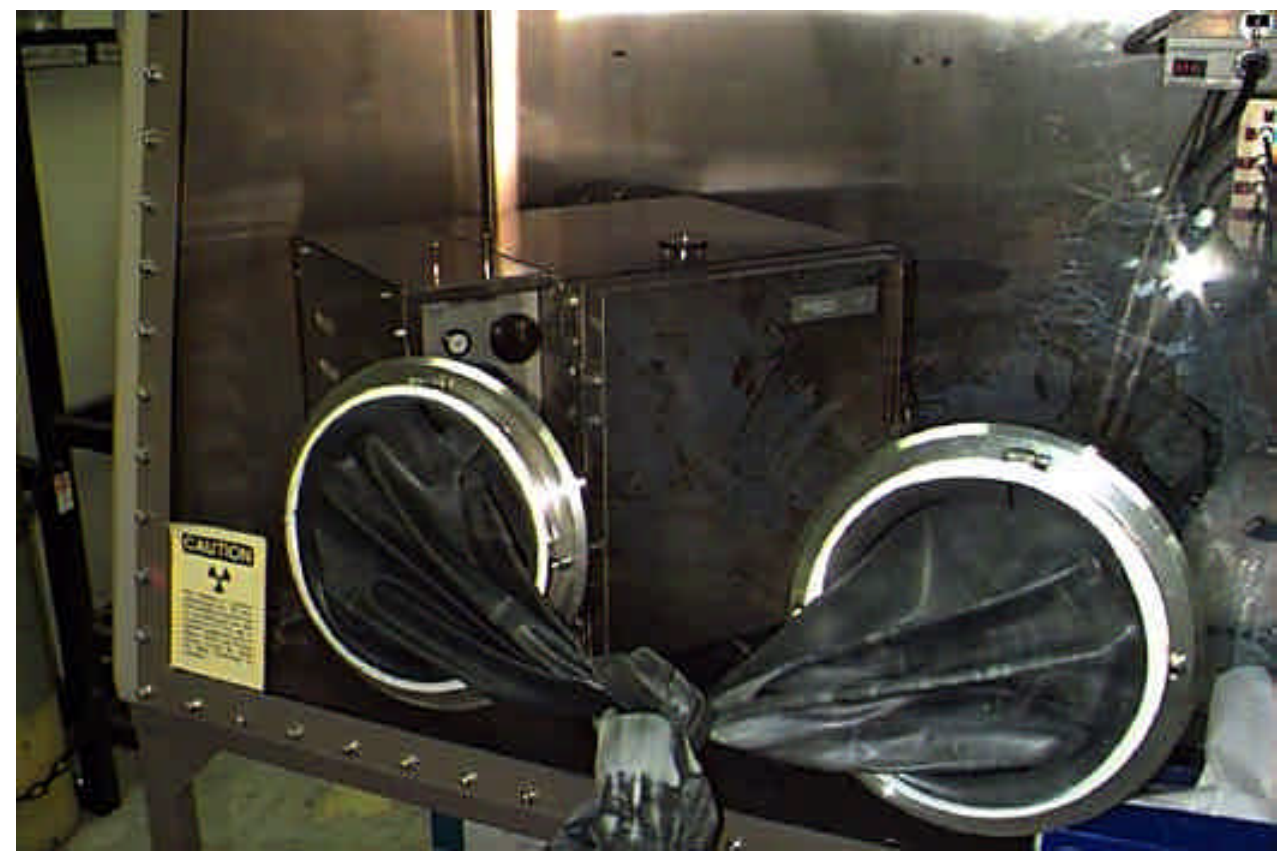

Figure 3-2. High-temperature safety vacuum oven (Sheldon Manufacturing) on the inside left of the controlled atmosphere glove box. 


\section{$\underline{\text { Reaction Vessels }}$}

The initial reaction vessels used in the elevated-temperature, neptunium solubility experiments, High Strength Acid Digestion Bombs model \# 4746, were obtained from Parr Instrument Company, Moline, Illinois. These reaction vessels consist of a T316 stainless steel exterior with a replaceable Teflon liner and cap that forms a tight seal when the spring loaded cap is hand tightened. The Teflon liners and caps were pretreated by first washing in $3 \mathrm{M} \mathrm{HCl}$ for $\sim 6$ hours at $\sim 90^{\circ}$ $\mathrm{C}$ and then in distilled, Milli-Q filtered water for the same time and temperature. Prior to use in a solubility experiment, each Teflon liner was loaded with $10 \mathrm{~mL}$ of distilled, Milli-Q filtered water, sealed in the stainless steel exterior, and heated in the oven overnight at $200^{\circ} \mathrm{C}$. This $200^{\circ} \mathrm{C}$ pretreatment was performed twice in order to remove any residual $\mathrm{HCl}$ and leachable fluoride from the liner. The $200^{\circ} \mathrm{C}$ pretreatment also mated the upper Teflon cap to the lower Teflon liner so the two pieces create a tight fitting seal prior to their use in actual experiments. This $200^{\circ} \mathrm{C}$ pretreatment process was performed as recommended by the manufacturer. The high-strength, acid digestion vessels have maximum working temperatures and pressures of $275^{\circ} \mathrm{C}$ and $5000 \mathrm{psi}$, respectively. Figures 3-3 and 3-4 show digital photographs of the stainless steel reaction vessels when sealed and open, respectively.

A second series of reaction vessels used, General Purpose Pressure Vessels model \# 4750, were also obtained from Parr Instrument Company, Moline, Illinois. These reaction vessels consist of a top and bottom made from grade 2 titanium 
metal. The top and bottom pieces are sealed by a Teflon flat ring (that is not in contact with the solution) and held closed by a split ring closure using six bolts that were tightened firmly by hand with a wrench. An outer sleeve then bolts around the circumference to hold the split rings together. These reaction vessels were treated with $6 \mathrm{M} \mathrm{HNO}_{3}$ at $\sim 90^{\circ} \mathrm{C}$, rinsed with water, and then baked in a $400^{\circ} \mathrm{C}$ oven. The titanium parts, initially of a dull gray color, exhibited a deep royal blue color after this treatment. Prior to their use in a solubility experiment, each titanium part was pretreated again by washing in $3 \mathrm{M} \mathrm{HNO}_{3}$ for $\sim 6$ hours at $\sim 90^{\circ} \mathrm{C}$ and then in distilled, Milli-Q filtered water for $\sim 6$ hours at $\sim 90^{\circ} \mathrm{C}$. The titanium parts were then baked in the oven overnight at $200^{\circ} \mathrm{C}$. These reaction vessels have maximum working temperatures and pressures of $350^{\circ} \mathrm{C}$ and 1250 psi, respectively. Figures 3-5 and 3-6 are digital photographs of the grade-2 titanium reaction vessels when sealed and open, respectively.

All reaction vessels were inspected and certified for use by the Pressure Safety Group at LLNL. No experiment in any of the above reaction vessels showed any measurable loss of solution. 


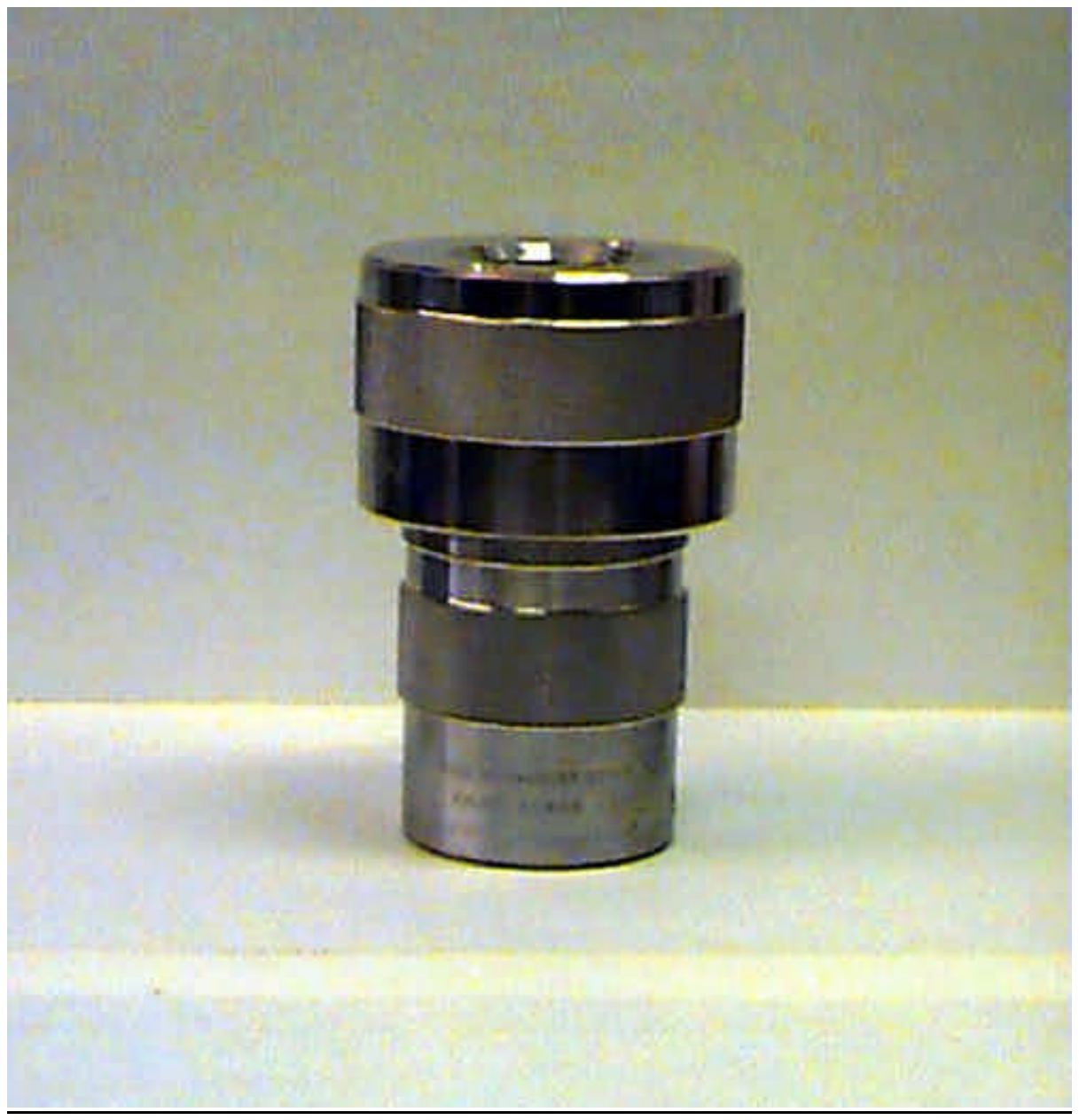

Figure 3-3. High Strength Acid Digestion Bombs model \# 4746 (Parr Instrument Company) made of T316 stainless steel and lined with a Teflon insert shown when closed. 


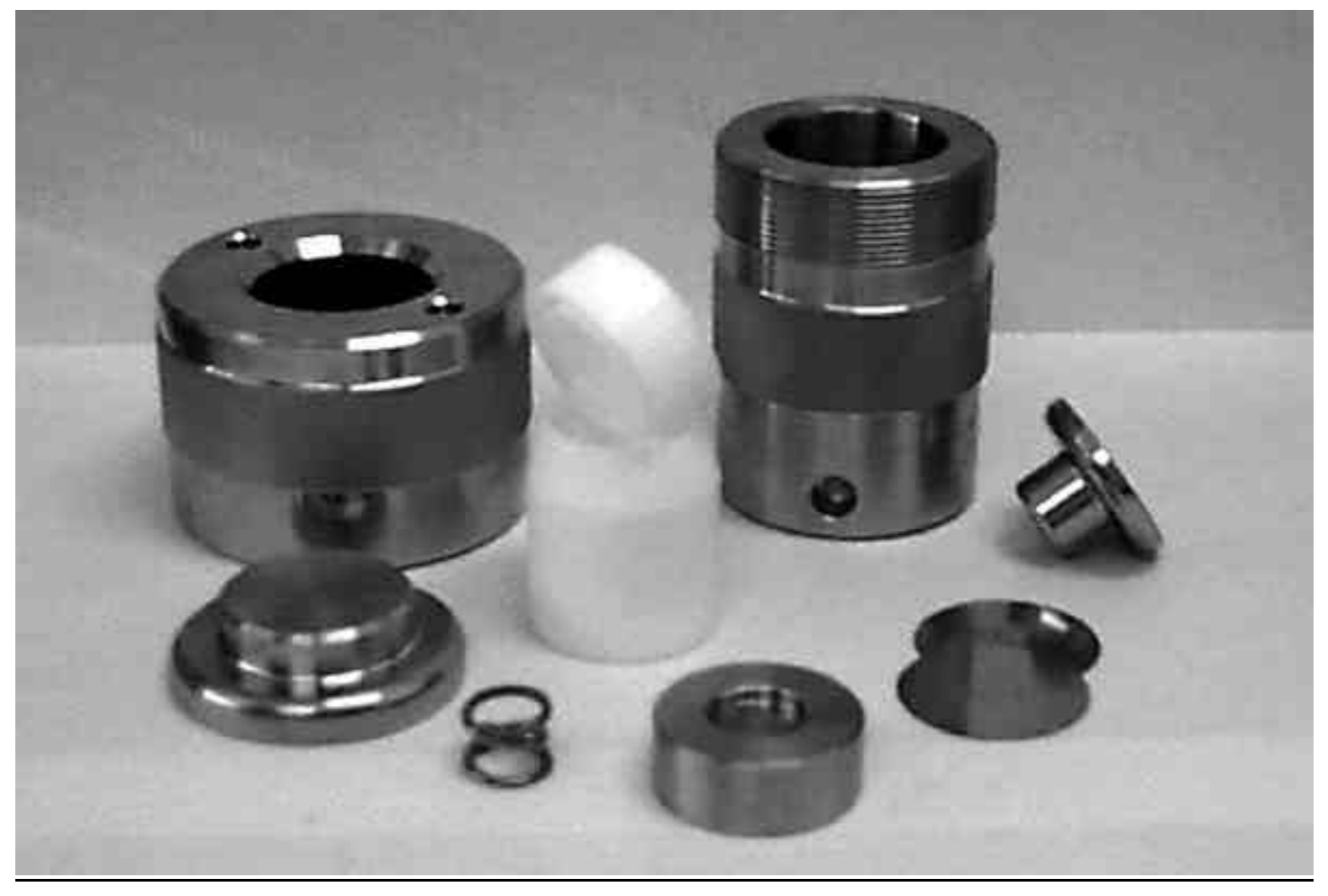

Figure 3-4. High Strength Acid Digestion Bombs model \# 4746 made of T316 stainless steel and lined with a Teflon insert shown when disassembled. 


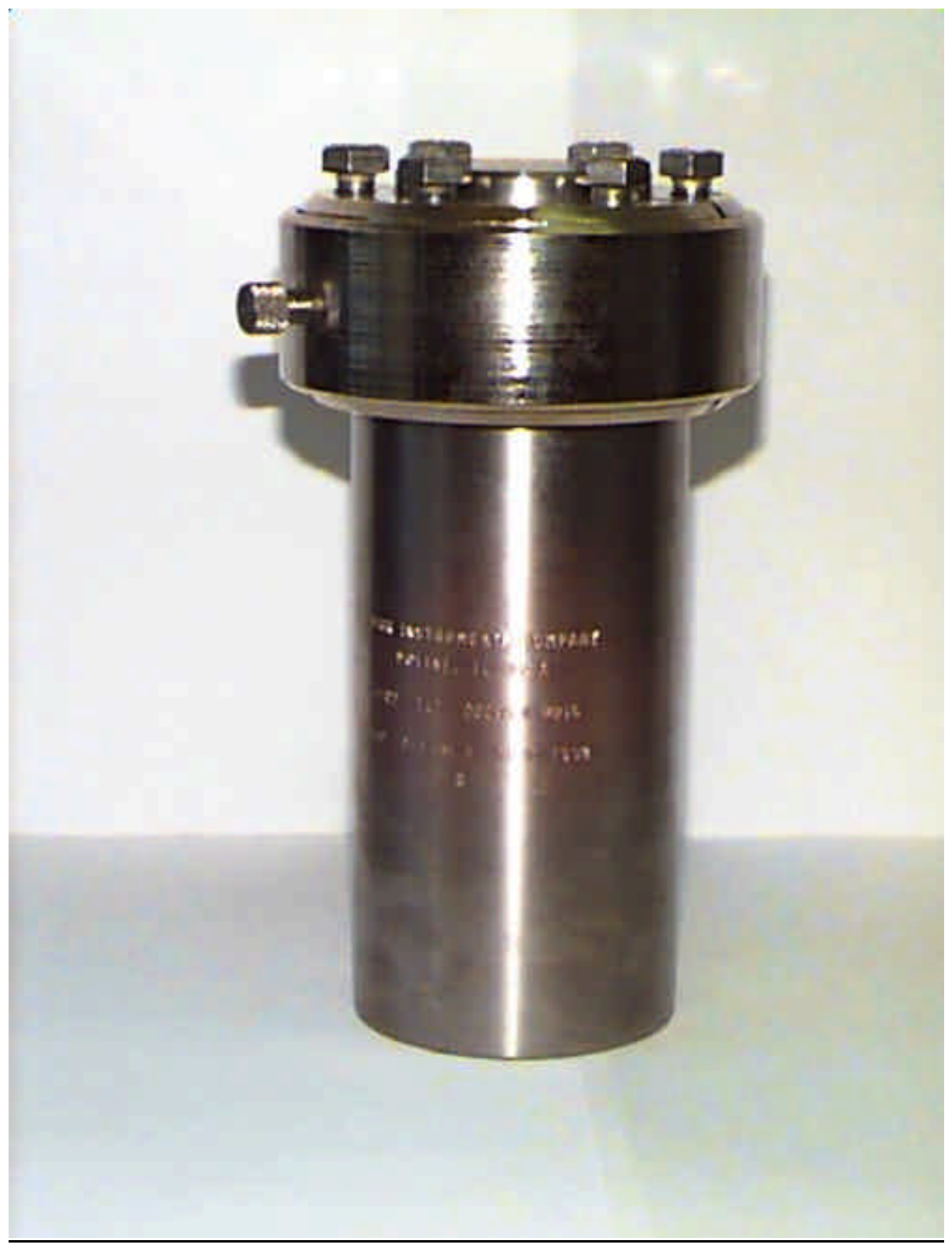

Figure 3-5. General Purpose Pressure Vessel model \# 4750 (Parr Instrument Company) made of grade 2 titanium metal shown when closed. 


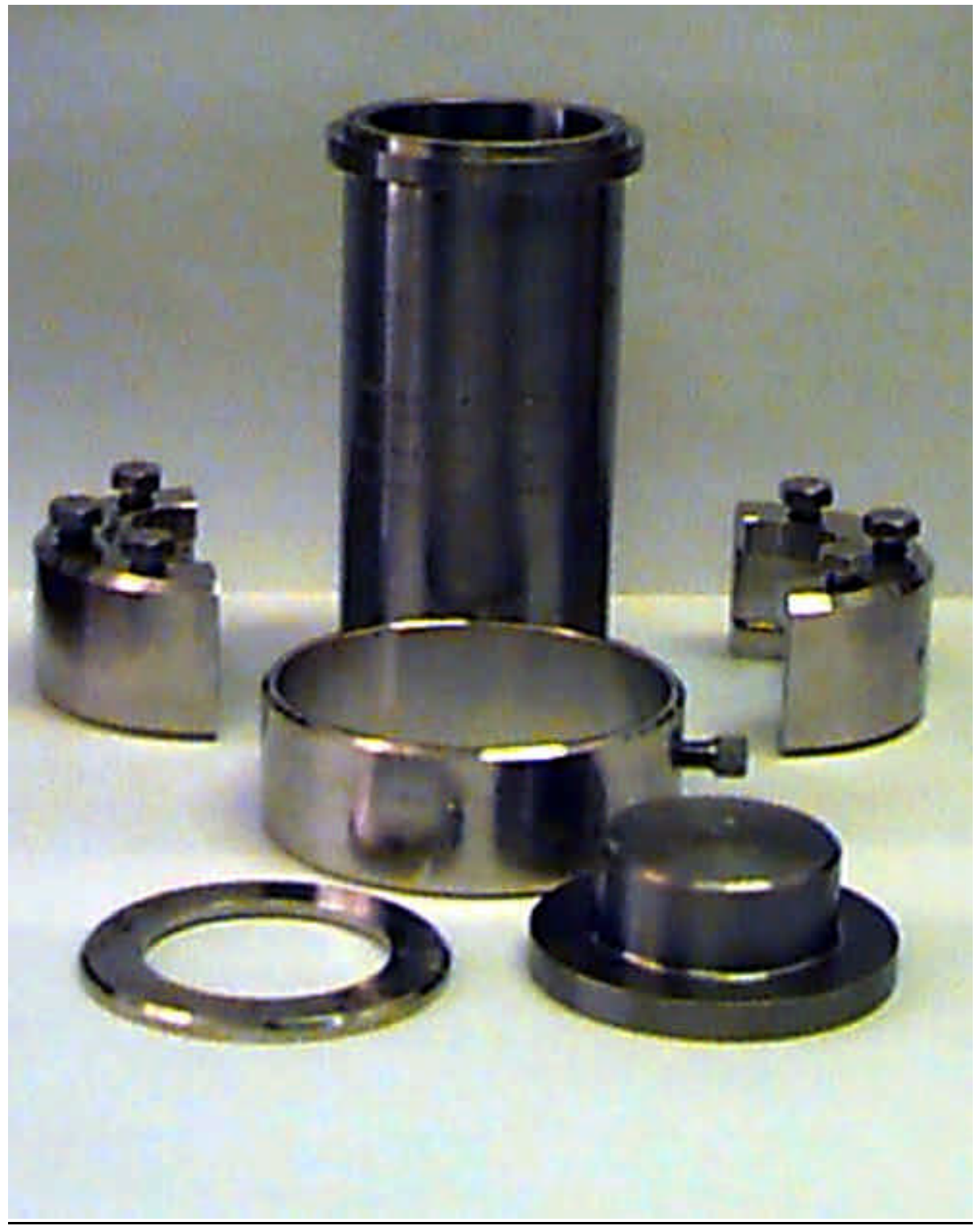

Figure 3-6. General Purpose Pressure Vessel model \# 4750 made of grade 2 titanium metal shown when disassembled. 
Balance

Masses were measured using a Mettler-Toledo model AG245 balance, Greifensee, Switzerland. The internal, NIST-traceable calibration weight was calibrated by Mettler-Toledo after installation in our laboratory on a balance table by a technician from Mettler-Toledo. Balance performance checks were made prior to use with a NIST-traceable weight set calibrated by Heusser Neuweigh, Clayton, California. The performance check consisted of measuring two NIST-traceable weights that bracket the mass to be measured as well as a stable reading with no mass on the balance. Each measurement of a traceable weight had to fall within the uncertainty of that weight provided on the Heusser Neuweigh NIST-traceable weight calibration certificate. If the balance failed a performance check, an automated, internal re-calibration of the balance was performed using the internal NIST-traceable weight. This internal re-calibration was performed until a satisfactory performance check was obtained.

\section{$\underline{\text { Electrodes }}$}

Solution $\mathrm{pH}$ was measured with an Orion semi-micro, Ross combination glass pH electrode, model \# 8103BN, and an Orion Research digital pH/millivolt meter model 611. Fluoride ion concentrations were measured with an Orion solid-state, ion selective combination electrode model \# 9609BN, and an Orion Research digital $\mathrm{pH} /$ millivolt meter model 611. Chloride ion concentrations were measured with an Orion solid-state, ion selective combination electrode model \# 9617BN, and an Orion Research digital pH/millivolt meter model 611. 
Sodium ion concentrations were measured with an Orion glass, ion selective combination electrode model \# 8611BN, and an Orion Research digital $\mathrm{pH} /$ millivolt meter model 611. All were products of Orion research Incorporated, Boston, Massachusetts.

\section{Pipettes}

Sample volumes of $1 \mathrm{~mL}$ or less were measured and dispensed using precision microliter pipettes manufactured by Rainin Instruments, Woburn, Massachusetts. For measuring and dispensing sample volumes in the range of 2 to 20 microliters, a P-20 pipette was used. For measuring and dispensing sample volumes in the range of 100 to 1000 microliters, a P-1000 pipette was used. Each pipette comes with a certificate of conformity stating that each pipette was performance tested under a manufacturer's quality assurance program. Each pipette is to successfully pass a performance check for accuracy and precision before being shipped. Pipettes were used as received.

\section{Filters/Centrifuge}

Solid and soluble phases were separated using microcentrifuge filtration devices, part \# 8505-00, obtained from Lida Manufacturing Corp., Kenosha, Wisconsin, and a Fisher Scientific Microcentrifuge model Micro V manufactured by Denver Instrument Company, Arvada, Colorado. 
The filtration units used contained a "nylon ${ }_{66}$ " (Lida Mfg. 'Data Sheet F-101') membrane with a $0.2 \mu \mathrm{m}$ pore size. The nylon membrane filter units are solvent resistant and hydrophilic and were recommended by the manufacturer for use with aqueous samples in general laboratory filtration. The maximum and recommended centrifugal force values for these filters are 10,000 and 3,000 g, respectively. Each filtration unit can filter up to $750 \mu \mathrm{L}$ per separation, and they have a hold-up volume (the volume of unfiltered solution retained on the membrane after centrifugation) of less than $20 \mu \mathrm{L}$.

Filtration units were used at 3,500 $\mathrm{g}$ for no more than 2-3 minutes. Errors arising from hold-up volumes were minimized by prefiltering and discarding a volume of experimental solution prior to filtering a volume through the same filter unit for analysis. This prefiltering treatment of the filter unit also aided in saturating any potential sorptive sites on the membrane surface or support, although no neptunium sorption behavior was ever detected.

\section{$\underline{\mathrm{UV} / \mathrm{VIS} / \mathrm{NIR} \text { Absorption Spectrophotometer }}$}

Absorption spectra were measured using a Guided Wave Model 260 conventional spectrophotometer, Guided Wave Inc., El Dorado Hills, California. This portable spectrophotometer was configured with a 800 lines per $\mathrm{mm}$ grating. In detector position number one, a germanium detector was used with a $1.0 \mathrm{~mm}$ slit and an $830 \mathrm{~nm}$ long-pass filter. In detector position number two, a silicon detector was used with a $0.25 \mathrm{~mm}$ slit and no filter. With this 
configuration, the spectrophotometer had a usable scanning range from 200 to $1300 \mathrm{~nm}$.

Remote measurements were made in the glove box by using two, 6-meter optic fibers with a 400 micron diameter obtained from Ocean Optics, Inc., Dunedin, Florida. One fiber carried light from the spectrophotometer into the glove box to a cuvette sample holder. A second fiber carried the light transmitted through the sample back out of the glove box and to the grating inside the spectrophotometer.

Because this instrument was not a conventional split-beam spectrophotometer, reference and sample spectra had to be taken sequentially. Reference spectra were taken first and stored by the Guided Wave operating software. The solutions used for measuring reference spectra were identical to the experimental solutions (i.e., $\mathrm{pH}$, background electrolyte, etc.) minus the element to be measured, in this case neptunium. The reference sample was then removed from the holder and the experimental solution was placed into the holder. The sample was then scanned and the Guided Wave operating software automatically removed the background spectrum from the sample spectrum before plotting the data.

The sample cuvettes used in all absorption measurements were disposable semimicro methyl acrylate cuvettes obtained from VWR Scientific, San Francisco, California, and had a cell path length of $10 \mathrm{~mm}$. Standard disposable 
polystyrene cuvettes are rated as having excellent light transmittance in the visible region from 340 to $800 \mathrm{~nm}$; whereas, disposable methyl acrylate cuvettes are recommended for measurements down to $275 \mathrm{~nm}$.

\section{Low-Energy Photon Spectrometer (LEPS)}

Samples containing neptunium were measured on a GLP Series HPGe (HighPurity Germanium) Low-Energy Photon Spectrometer, or LEPS counter, produced by EG\&G Ortec, Oak Ridge, Tennessee. The LEPS system consisted of a liquid-nitrogen cooled, high-purity germanium crystal with an active diameter of $16 \mathrm{~mm}$ and a sensitivity depth of $13 \mathrm{~mm}$. The germanium crystal, coupled to an integrated preamplifier, was operated in a vacuum housing with a $0.127 \mathrm{~mm}$ thick beryllium sample window. A Tennelec TC 950 5KV Bias Supply provided a 3000 volt bias to the HPGe crystal when cooled. The preamplifier signal was routed to a Canberra Spectroscopic Amplifier Model 2020 that used a shaping time constant of $4 \mu \mathrm{s}$. Spectral gamma emission data was collected on an IBM personal computer using a Canberra Multi-Channel Analyzer (MCA) and the associated Accuspec operating software. The system was configured to measure gamma energies ranging from 10 to $335 \mathrm{keV}$. The LEPS system was energy scale calibrated using a ${ }^{137}$ cesium source, and an energy scale calibration of 0.082 $\mathrm{keV}$ per channel was obtained. The germanium detector was housed inside of a two-foot cube of 2-inch thick $\mathrm{Pb}$ metal to shield the detector from both cosmogenic and facility external radiation sources. The inside of the $\mathrm{Pb}$ chamber was covered with layers of cadmium and copper in order to absorb $\mathrm{Pb}$ gamma 
emissions that result from activation by irradiation from the sample being counted inside the "cave". The efficiency of the LEPS counter is described in the "Neptunium Ion Determinations" section to follow. The outside and inside of the LEPS counting system used are shown in Figures 3-7 and 3-8, respectively. 


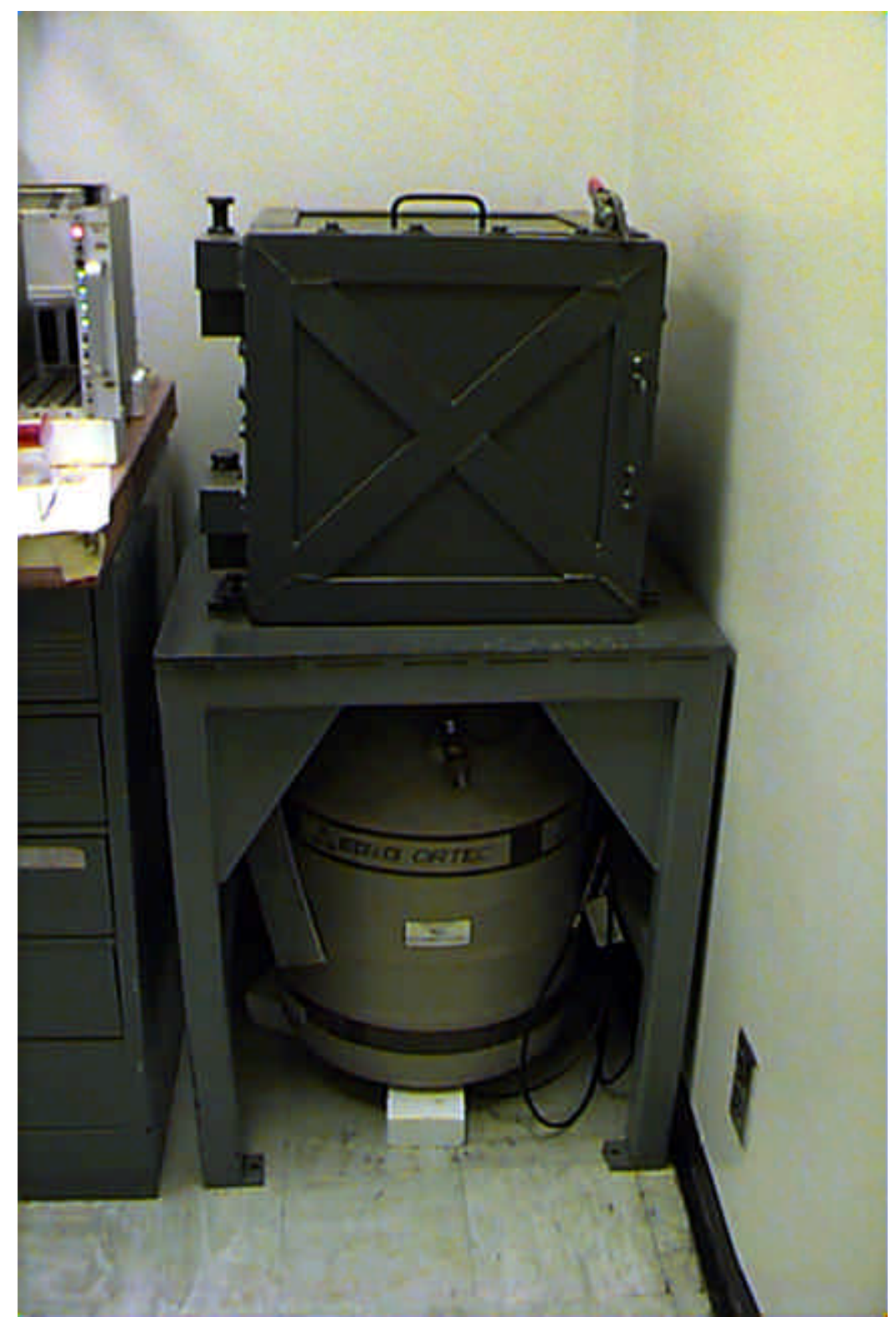

Figure 3-7. Digital photograph of the exterior of the LEPS counter. The Pb cave is shown at the top and the liquid nitrogen container is at the bottom. 


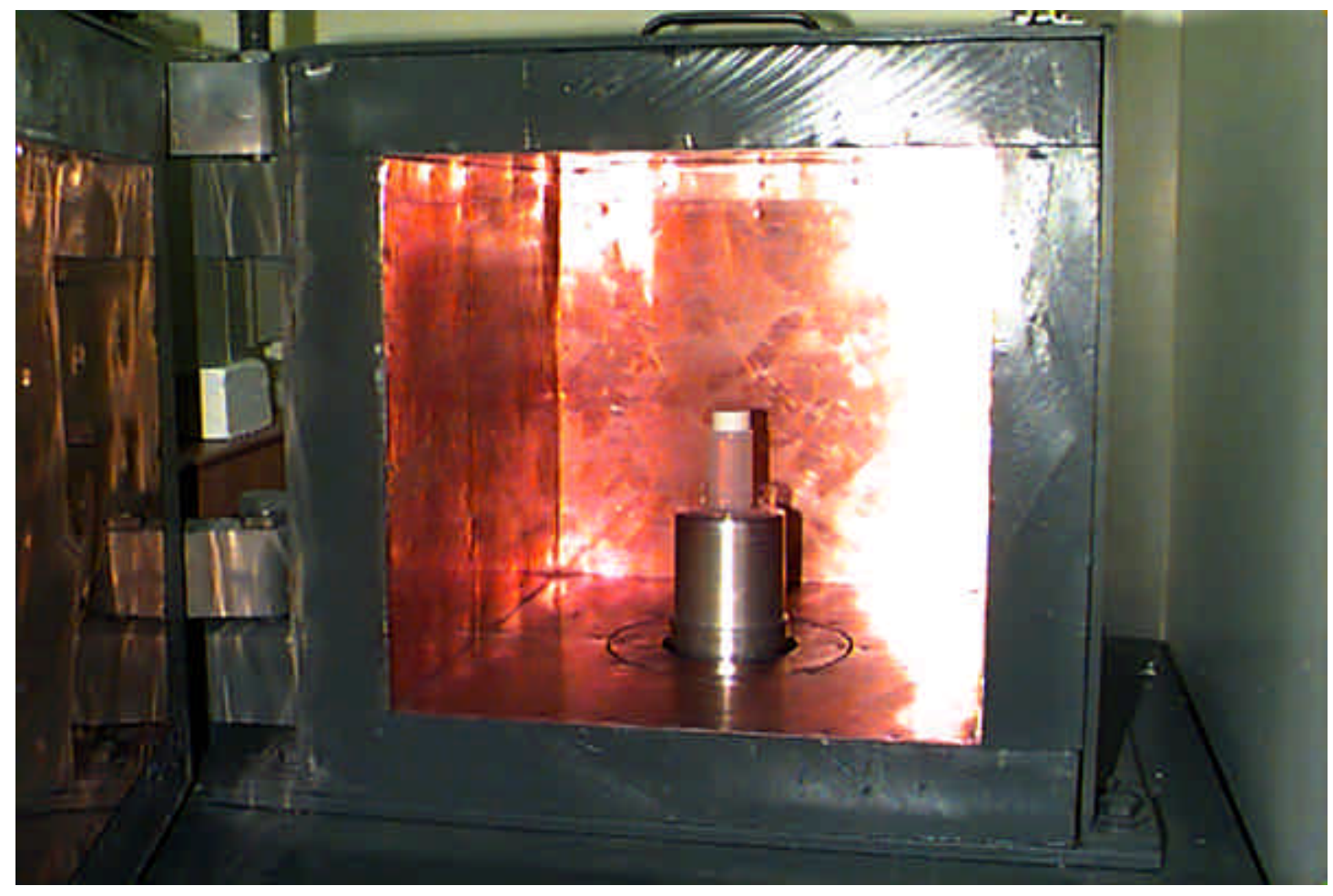

Figure 3-8. Digital photograph of the interior of the $\mathrm{Pb}$ cave. At the center of the cave is the encased germanium detector on top of which sits a sample contained in a liquid scintillation vial. 


\section{$\underline{\text { Techniques }}$}

\section{$\underline{\text { X-Ray Powder Diffraction }}$}

The solids obtained in the elevated-temperature, neptunium solubility experiments were analyzed by x-ray powder diffraction in collaboration with Traudel G. Prussin of the Lawrence Livermore National Laboratory and Jerome Bucher of the Lawrence Berkeley National Laboratory in order to characterize them by comparing them with referenced powder patterns of known solids. Approximately 50 micrograms of each precipitate was placed in a $0.33-\mathrm{mm}$ outside diameter quartz capillary tube produced by the Charles Supper Company, Natick, Massachusettes. The capillary tubes were sealed about one half of an inch above the base that contained the solid, placed into a glass liquid scintillation vial for temporary storage, and then sent to LBNL for analysis. At LBNL, the capillary was removed from the vial, mounted in 114.6-mm diameter Debye-Scherrer cameras, and then irradiated with x-rays from a Norelco III XRay Generator (Philips Electronics, Inc.). Copper $\mathrm{K}_{\alpha}$ radiation filtered through nickel was used.

The Lawrence Berkeley National Laboratory is equipped to perform x-ray powder diffraction measurements on radioactive materials like neptunium. The $\mathrm{x}$-ray tube and mounting assembly for a pair of Debye-Scherrer cameras is contained in a plexiglass case that can be sealed and is exhausted through a HEPA filtered ventilation system. The camera is loaded in a small, HEPA filtered glove box dedicated for this function. This glove box resides in a dark 
room in one of LBNL's radioactive material handling laboratories. Quartz capillaries are extremely fragile, and in the event that one is broken upon loading a camera, the glove box performs as a secondary containment system for the now dispersed radioactive material. If this happens, as it has occasionally in the past, works stops immediately and the inside of the glove box and the camera in use are decontaminated.

A small brass holder is placed in the rotating center of the Debye-Scherrer camera. Modelers' clay is used to hold the small quartz capillary in the center of the brass mount. With all of the necessary equipment (camera, undeveloped film, clay, capillary, tweezers and tape) placed inside the uncontaminated mounting glove box, the glass scintillation vial containing the quartz capillary is opened. A small pair of tweezers, coated on the ends with silicone or epoxy to soften the tips slightly, is used to carefully place the empty side of the capillary firmly into the clay in the center of the camera. A precut and punched piece of undeveloped film is then placed into the camera. The camera's lid is replaced and taped to the camera. Then the sealed camera is carried out of the loading glove box and transferred to the camera mount on the x-ray generator. The plexiglass windows around the generator are closed, the instrument is powered up, and the sample is exposed to the x-ray beam for a preset amount of time.

At the end of this preset amount of time, the generator shuts down. The user then removes the camera and returns it to the glove box in the dark room. The film is removed from the camera in the glove box in the darkroom and 
developed. The film is developed for 5 minutes in Kodak GBX developer diluted with water at 3.6 parts water to 1 part developer. The developed film is rinsed in water for a minute, and then it is placed into Kodak GBX fixer also diluted with water at 3.6 parts water to 1 part fixer for 10 minutes. The film is then allowed to stand in a water bath for 30 minutes before being hung to dry in air.

After drying, the resulting film is then scanned into a personal computer using Adobe Photoshop 4.0LE and a Umax Mirage II scanner in transmission mode in order to create a pixel by pixel, digital image. The full scale image exported from Photoshop is imported into Filmscan software, Materials Data Incorporated, Livermore, California. The Filmscan software allows for linear integration of the gray scale image as a function of 2 -theta space. The result is an intensity versus 2-theta data set (plot) similar to that obtained using a modern, digital diffractometer. This data set is then imported into Jade software, Materials Data Incorporated, Livermore, California, for background subtraction and subsequent comparison with powder diffraction files published in the ICDD-PDF database. ${ }^{39}$

Figure 3-9 shows a graphical depiction of the film within the circumference of a Debye-Scherrer camera as viewed perpendicular to the incident $\mathrm{x}$-ray beam with the capillary at the center of the camera. The Bragg angle is shown in Figure 3-9 as $\Theta$, and the Bragg equation that relates the interplanar spacings in Angstroms ( $\mathrm{A})$, or d-spacings, to the Bragg angle is listed below the diagram. 


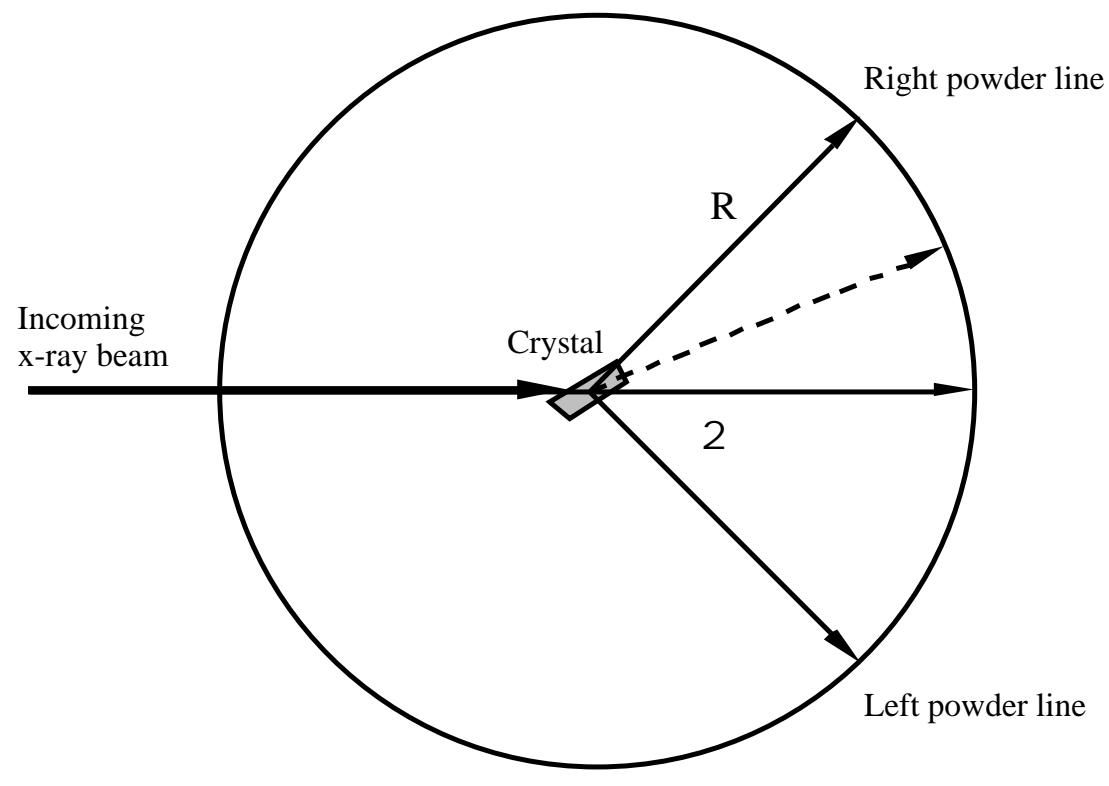

$\frac{1}{d^{2}}=\left(\frac{2 \cdot \sin \Theta}{\lambda}\right)^{2}, d=\frac{\lambda}{2 \cdot \sin \Theta} \quad(\AA), \quad \lambda=1.5418 \AA$

Figure 3-9. A graphical depiction of a Debye-Scherrer Camera, the Bragg Angle, and the Bragg equation for the interplanar spacing, $\mathrm{d}-$ spacing, relationship to the Bragg angle.

X-ray Absorption Spectroscopy (XAS) - X-ray Absorption Near Edge Spectroscopy (XANES) and Extended X-ray Absorption Fine Structure (EXAFS)

X-ray absorption spectroscopy (XAS) measurements were made in collaboration with Patrick G. Allen of the Lawrence Livermore National Laboratory and Jerome J. Bucher and David K. Shuh both of the Lawrence Berkeley National Laboratory. Safety protocols were already in place at the Stanford Synchrotron 
Radiation Laboratory (SSRL) for the measurement of radioactive solids and solutions.

The sealed, externally decontaminated quartz capillaries containing the solids obtained in the elevated-temperature, neptunium solubility experiments were double bagged by heat sealing the quartz capillary in two layers of polyethylene plastic and then sent to SSRL after successful measurement by x-ray powder diffraction at LBNL. The double bagging of the decontaminated quartz capillary provided triple containment of the radioactive material as called for in the safety protocols required by SSRL. Measurements of the precipitated solids were performed together with reference samples of both solid $\mathrm{NpO}_{2}$ and the aqueous dioxo-neptunium(V) cation, $\mathrm{NpO}_{2}^{+}$.

Neptunium $\mathrm{L}_{\mathrm{III}}$ edge absorption spectra were obtained on wiggler beamline 4-1 at SSRL. The polychromatic x-ray beam obtained from the electron ring was energy tuned to monochromatic x-rays using a $\mathrm{Si}(220)$ double-crystal monochromator. The flux of the x-ray beam was reduced to 50 percent by detuning the crystals in the monochromator in order to reduce the higher order harmonic content of the beam. The neptunium samples were measured in fluorescence mode using a portable germanium solid-state detector developed and built by LBNL. 40 Patrick Allen, using standard methods as described by Konisberger and Prins ${ }^{41}$ and software called EXAFSPAK developed by G. George of SSRL, performed the data analysis of the neptunium samples. 


\section{Scanning Electron Microscopy}

Scanning electron microscopy (SEM) measurements were made in collaboration with Robert J. Finch of Argonne National Laboratory (ANL). Because neptunium is an alpha emitting radionuclide, most owners/users of SEM instruments are reluctant to examine or are prohibited from examining solids containing neptunium because of safety considerations and/or fear of equipment contamination. Given that ANL is equipped with a SEM instrument for use with radioactive materials, the solids obtained in our experiments were sent to ANL for SEM analysis.

The micrographs were obtained by Robert Finch using a Topcon ABS 60 SEM equipped with a $\mathrm{Si}(\mathrm{Li})$ EDS detector and Vantage software. The images were obtained by using an accelerating voltage of $15 \mathrm{kV}$, and EDS data were obtained at $30 \mathrm{kV}$.

\section{$\underline{\text { Solution Ion Determinations/Measurements }}$}

\section{$\underline{\text { Hydrogen Ion Measurement }}$}

For solutions with ionic strengths below $0.01 \mathrm{M}$, hydrogen ion activity measurements were made with Orion glass combination $\mathrm{pH}$ electrodes after calibration with $\mathrm{pH} 4$ and 7 buffer solutions. The $\mathrm{pH} 7$ buffer was a sodium and potassium phosphate buffer obtained from VWR Scientific, San Francisco, California. The $\mathrm{pH} 4$ buffer was a potassium hydrogen phthalate buffer also 
obtained from VWR Scientific, San Francisco, California. Both buffer solutions were traceable to National Institute of Standards and Technology (NIST) Standard Reference Materials (SRMs) and were used before the listed expiration dates.

\section{Fluoride Ion Measurement}

Fluoride ion concentrations were measured using an Orion Research ion selective electrode. The electrode was first calibrated with standards made from NIST traceable $(0.1000 \pm 0.0005) \mathrm{M} \mathrm{NaF}$, part \# 940906, Orion Research, Inc., as outlined by the electrode's instruction manual. Dilutions of the $0.1 \mathrm{M} \mathrm{NaF}$ were made with distilled, Milli-Q filtered water to cover fluoride concentrations ranging from $5 \times 10^{-7}$ to $5 \times 10^{-2} \mathrm{M}$. The calibration standards were mixed with equal volumes of Total Ionic Strength Adjustment Buffer II (TISAB II) with 1,2-

cyclohexane diaminetetraacetic acid (CDTA), part \# 940909, Orion Research, Inc., before being measured with the solid-state electrode. The TISAB II with CDTA solution brings a fluoride sample of low ionic strength to a higher, constant background ionic strength, decomplexes fluoride ions, and buffers the solution's $\mathrm{pH}$. The standards were measured without being stirred and with the calibration knob on the Orion model 611 millivolt meter turned completely counterclockwise. Figure 3-10 shows the calibration curve obtained for the fluoride ion, solid-state electrode. The closed circles were fit with a simple linear regression; whereas, the open circles were with fit with a second-order 
polynomial regression. Both curves were fit using Deltagraph Professional version 4.0.4 on a Macintosh computer.

\section{Chloride Ion Measurement}

Chloride ion concentrations were measured using an Orion Research ion selective electrode. The electrode was first calibrated with standards made from NIST traceable (1000 \pm 5) PPM NaCl, part \# 841108, Orion Research, Inc., as outlined by the electrode's instruction manual. Dilutions of the $1000 \mathrm{PPM} \mathrm{NaCl}$ were made with distilled, Milli-Q filtered water to cover concentrations ranging from $4.35 \times 10^{-5}$ to $4.35 \times 10^{-2} \mathrm{M}$. (1000 PPM NaCl equals $0.0435 \mathrm{M} \mathrm{NaCl}$.) The calibration standards were mixed with Ionic Strength Adjuster (ISA), part \# 940011, Orion Research, Inc. To $1000 \mu \mathrm{L}$ of standard, $20 \mu \mathrm{L}$ of ISA ( $2 \%$ of the sample volume) was added in order to give the calibration standard a higher, constant ionic strength background. The standards were measured without being stirred and with the calibration knob on the Orion model 611 millivolt meter turned completely counterclockwise. Figure 3-11 shows the calibration curve obtained for the chloride ion, solid-state electrode. The closed circles were fit with a simple linear regression using Deltagraph Professional version 4.0.4 on a Macintosh computer.

\section{$\underline{\text { Sodium Ion Measurement }}$}

Sodium ion concentrations were measured using an Orion Research ion selective electrode. The electrode was first calibrated with standards made from NIST 
traceable (1000 \pm 5) PPM NaCl, part \# 841108, Orion Research, Inc., as outlined by the electrode's instruction manual. Dilutions of the 1000 PPM NaCl were made with distilled, Milli-Q filtered water to cover concentrations ranging from $4.35 \times 10^{-5}$ to $4.35 \times 10^{-2} \mathrm{M}$. The calibration standards were mixed with Sodium Ionic Strength Adjuster (SISA), part \# 841111, Orion Research, Inc. To $1000 \mu \mathrm{L}$ of standard, $100 \mu \mathrm{L}$ of SISA was added in order to give the calibration standard a higher, constant ionic strength background and to raise the solutions $\mathrm{pH}$ to a value where free protons do not interfere with low level sodium determinations. The standards were measured without being stirred and with the calibration knob on the Orion model 611 millivolt meter turned completely clockwise. Figure 3-12 shows the calibration curve obtained for the sodium ion, glass combination electrode. The closed circles were fit with a simple linear regression using Deltagraph Professional version 4.0.4 on a Macintosh computer. 


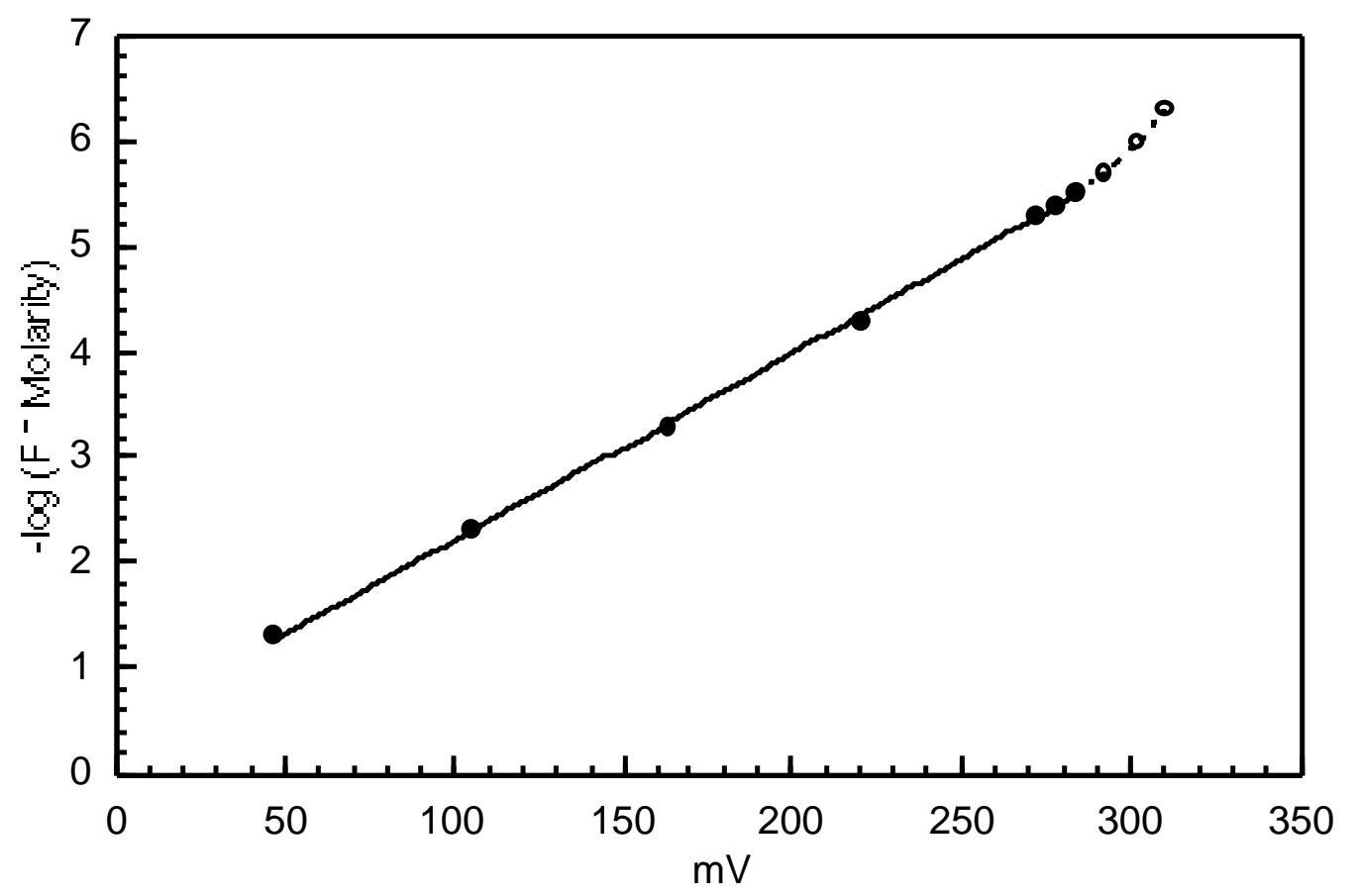

Figure 3-10. The negative log of the fluoride ion concentration as a function of millivolt reading. Each standard was diluted 1:1 with TISAB II with CDTA before measurement. 


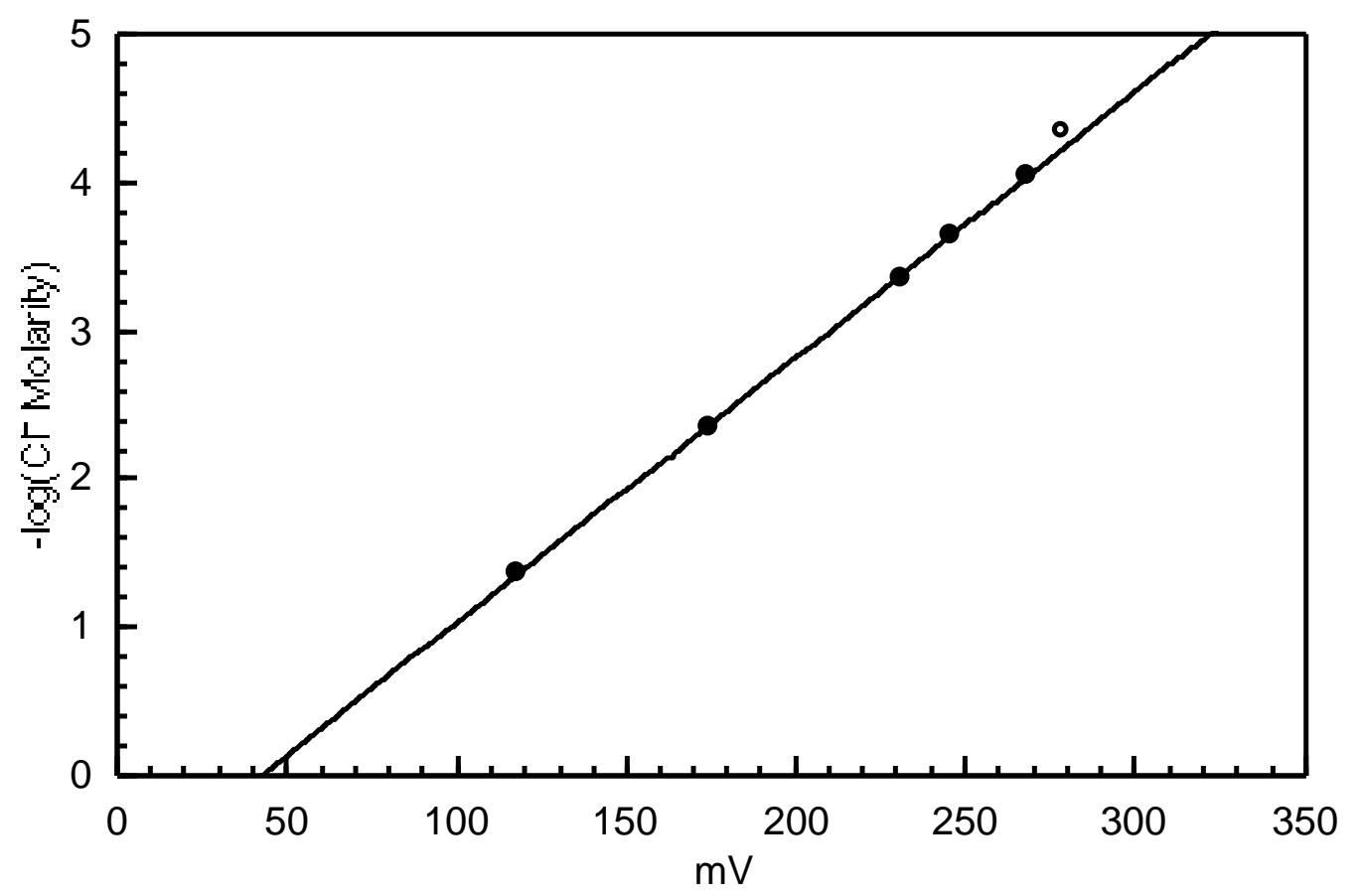

Figure 3-11. The negative log of the chloride ion concentration as a function of millivolt reading. To each $1000 \mu \mathrm{L}$ of standard, $20 \mu \mathrm{L}$ of ISA was added before measurement. 




Figure 3-12. The negative log of the sodium ion concentration as a function of millivolt reading. To each $1000 \mu \mathrm{L}$ of standard, $100 \mu \mathrm{L}$ of SISA was added before measurement. 


\section{$\underline{\text { Neptunium Ion Determinations }}$}

Aqueous ${ }^{237} \mathrm{~Np}$ concentrations were determined by nuclear counting. The 29.374 $\mathrm{keV}$ gamma ray emitted from the excited state ${ }^{233} \mathrm{~Pa}$ daughter resulting from the nuclear decay of the ${ }^{237} \mathrm{~Np}$ parent atom was measured on the LEPS counter. The LEPS counter was efficiency calibrated with a NIST traceable ${ }^{237} \mathrm{~Np}$ sample made with the same chemical and physical composition as samples obtained from solubility experiments to ensure the same counting efficiency.

The ${ }^{237} \mathrm{~Np}$ gamma calibration standard was prepared by pipetting $1000 \mu \mathrm{L}$ of NIST SRM 4341 (a standardized sample of neptunium in $2 \mathrm{M} \mathrm{HNO}_{3}$ ) into a $23 \mathrm{~mL}$ plastic liquid scintillation vial. The vial was weighed before and after adding the $1000 \mu \mathrm{L}$ of SRM 4341. To the 1.0403 grams of SRM 4341 solution, $20 \mathrm{~mL}$ of Ecolite $(+)^{\mathrm{TM}}$ Liquid Scintillation Cocktail, ICN Biomedicals, Inc., Costa Mesa, California, was added and the sample vial numbered LDN70000. According to the NIST certificate for SRM 4341, the ${ }^{237} \mathrm{~Np}$ standard has an activity of $97.0 \mathrm{~Bq}$ per gram of solution; therefore, sample LDN70000 has an activity of $6.054 \times 10^{3} \alpha$ DPM from ${ }^{237} \mathrm{~Np}$. The eighth edition of the Table of Isotopes ${ }^{19}$ lists the branch ratio for the emission of the $29.374 \mathrm{keV}$ gamma as $0.15 \gamma \mathrm{DPM}$ per $\alpha \mathrm{DPM}$; therefore, sample LDN70000 contains $908.2 \gamma$ DPM at $29.374 \mathrm{keV}$ from the decay of the ${ }^{237} \mathrm{~Np}$.

The daughter of ${ }^{237} \mathrm{~Np},{ }^{233} \mathrm{~Pa}$, decays very rapidly due to its relatively short half life (26.967 days), and its excited state daughter, ${ }^{233} \mathrm{U}$, emits a gamma photon with 
an energy of $28.375 \mathrm{keV}$. These photons are too close in energy to those emitted by ${ }^{233} \mathrm{~Pa}$, that result from the ${ }^{237} \mathrm{~Np}$ alpha decay, to be resolved by our LEPS counting system, so they are integrated with the photons emitted by ${ }^{233} \mathrm{~Pa}$ at $28.374 \mathrm{keV}$. A small correction was made to the overall count rate at $29 \mathrm{keV}$ to account for the contribution from ${ }^{233} \mathrm{U}$ at $\sim 29 \mathrm{keV}$. Because the parent, ${ }^{237} \mathrm{~Np}$, and daughter, ${ }^{233} \mathrm{~Pa}$, were in secular equilibrium, the beta decay rate of the daughter is equal to the alpha decay rate of the parent isotope. The Table of Isotopes lists the branch ratio for the emission of the $28.375 \mathrm{keV}$ gamma from ${ }^{233} \mathrm{U}$ as $0.0011 \gamma$ DPM per $\beta$ DPM of ${ }^{233} \mathrm{~Pa}$. This resulted in ${ }^{233} \mathrm{~Pa}$ contributing an additional $6.66 \gamma$ DPM (or $0.73 \%$ ) at $29 \mathrm{keV}$ in sample LDN70000. When combined, sample LDN70000 had a photon emission rate of $914.8 \gamma$ DPM at $\sim 29 \mathrm{keV}$. Sample LDN70000 was measured in the LEPS counting system for more than 64 hours and provided a count rate at $29 \mathrm{keV}$ of $(9.1717 \pm 0.0457) \gamma \mathrm{CPM}$. The LEPS counting system has a measured counting efficiency at $29 \mathrm{keV}$ of $0.010025 \gamma$ $\mathrm{CPM} / \gamma \mathrm{DPM}$ (or $1.0025 \%$ ) when an aqueous sample is suspended in $20 \mathrm{~mL}$ of Ecolite $(+)^{\mathrm{TM}}$ liquid scintillation cocktail in a plastic liquid scintillation vial. Figure 3-13 shows the gamma spectrum obtained for sample LDN70000 after being counted for more than 64 hours.

The smaller plot in Figure 3-13 shows an expanded scale of the emission peak at $\sim 29 \mathrm{keV}$ for sample LDN7000. The two filled circles on the spectrum indicate the background subtraction points used in the quantification of the $29 \mathrm{keV}$ emission from the samples. For background subtraction, a line is drawn between the two filled circles, and the number of integrated counts below the non-vertical line and 
within the two vertical lines are subtracted from the total integrated counts within the total area of the $29 \mathrm{keV}$ peak. The resulting "net" counts were used in determining the counting efficiency for the $29 \mathrm{keV}$ gamma associated with the alpha decay of ${ }^{237} \mathrm{~Np}$.

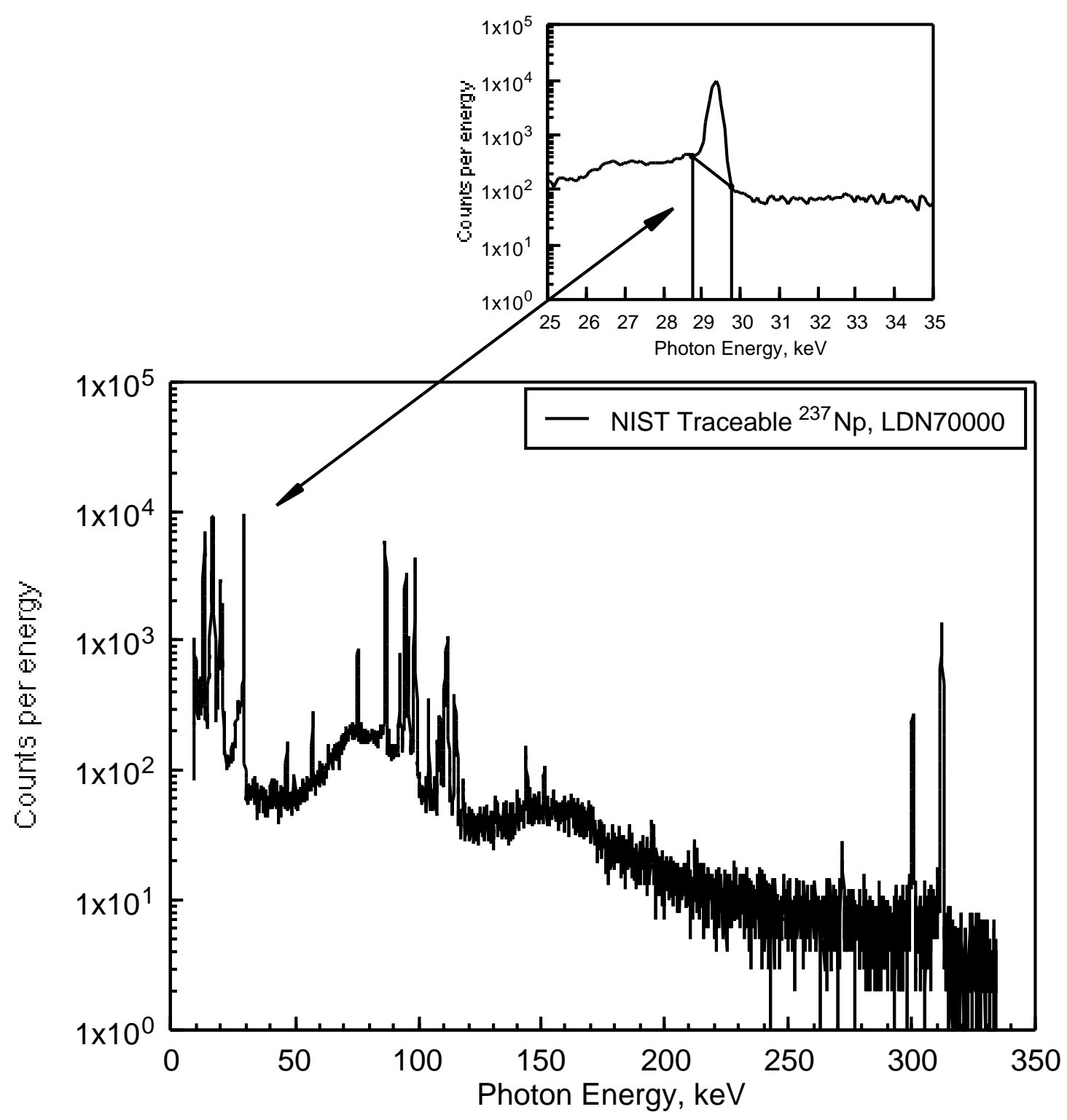

Figure 3-13. Gamma spectrum from sample LDN70000 which contains 6054 alpha DPM of NIST traceable ${ }^{237} \mathrm{~Np}$. 


\section{$\underline{\text { Chemicals }}$}

\section{General Reagents}

Water used in all experiments was first distilled then passed through a Milli-Q Water Plus System, Millipore Corporation, Medford, Oregon. Water used in carbonate free experiments was first distilled, then passed through a Milli-Q Water Plus System, and distilled and collected under a flow of argon gas. Carbonate free water was immediately placed into the controlled atmosphere glove box.

Nitric and hydrochloric acids used were "double sub-boiling distilled in quartz" grade from Seastar Chemicals Inc., Sidney, British Columbia, Canada. Sodium Hydroxide pellets used was reagent grade from J.T. Baker. Sodium Chloride used was Ultrex ultrapure reagent grade from J.T. Baker. TEVA•Spec SPS chromatography resin was obtained from EIChroM Industries, Inc., Darien Illinois.

\section{Neptunium Stock Solution}

A few milliliters of dissolved ${ }^{237} \mathrm{~Np}$ ( $\sim 20 \mathrm{mg}$ of $\mathrm{Np}$ per $\mathrm{mL}$ of solution) was obtained from LLNL as $\mathrm{Np}(\mathrm{V})$ in $6 \mathrm{M} \mathrm{HCl}$. This stock solution was possibly contaminated with thorium and iron. Because this experimental effort was going to be investigating possible redox reactions between $\mathrm{Np}(\mathrm{V})$ and $\mathrm{Np}(\mathrm{IV})$, it was desirable to have the iron contamination removed. Thorium contamination 
would have interfered with neptunium quantification by alpha pulse height spectroscopy because the two common isotopes of neptunium and thorium have similar alpha particle emission energies, so it was also desirable to have it removed.

As a quick test to see if in fact there was iron in the stock, a small aliquot of the LLNL stock was placed into a centrifuge tube. To this deep green solution, small portions of $1 \mathrm{M}$ sodium hydroxide were slowly added until a precipitate formed. The precipitation of $\mathrm{Np}(\mathrm{V})$ hydroxide results in the formation of a pale-green solid that readily flocculates out of solution. In this case, the solid that formed had a reddish-brown color identical to that of iron(III) hydroxide. This seemed to indicate iron contamination. No test was performed to verify thorium contamination; it was assumed to be there in trace amounts.

Anion exchange chromatography is commonly used to separate contaminants from actinides. Recently, I have used a relatively modern chromatography resin produced by EiChrom Industries to purify uranium(VI) from thorium(IV) contamination. The U/TEVA $\bullet$ Spec SPS resin proved to be very efficient and reusable for several separations. The name "U/TEVA" was derived from uranium/tetravalent actinide separation. The U/TEVA • spec resin retained the $\mathrm{U}(\mathrm{VI})$ from a solution of $6 \mathrm{M} \mathrm{HCl}$; whereas, the Th(IV) flowed right through the column. The $\mathrm{U}(\mathrm{VI})$ was then easily eluted with $0.1 \mathrm{M} \mathrm{HCl}$, a desirable medium for the work that followed. 
I chose to use another resin from EiChrom Industries to purify the Np stock I received from LLNL. TEVA • Spec SPS resin was developed for the separation of various actinides in the $4+$ oxidation state. Thorium(IV) and neptunium(IV) could be separated from one another if the aqueous medium was $6 \mathrm{M} \mathrm{HCl}$. A column of TEVA $\bullet$ Spec resin, when washed with $6 \mathrm{M}$ HCL will retain $\mathrm{Np}(\mathrm{IV})$; whereas, Th(IV) will flow through. I chose this approach because iron, in the 2+ oxidation state, will also flow through the column and be separated from the Np.

An aliquot was removed from the LLNL stock solution and the $\mathrm{Np}(\mathrm{V})$ was reduced to $\mathrm{Np}(\mathrm{IV})$ by addition of $\mathrm{KI}$ in $6 \mathrm{M} \mathrm{HCl}$ and heating the solution at $\sim 90^{\circ}$ C for about an hour. Portions of the $\mathrm{Np}(\mathrm{IV})$ stock solution $(\sim 5 \mathrm{mg}$ of $\mathrm{Np}$ per column) were then loaded onto a $2.5 \mathrm{~mL}$ column of TEVA • Spec SPS chromatography resin. In $6 \mathrm{M} \mathrm{HCl}$, the presumably anionic $\mathrm{Np}(\mathrm{IV})-\mathrm{Cl}$ complex will adhere to the column while the Th(IV) and Fe(II) ion complexes will not. Any Fe(III) present in the original stock was reduced to Fe(II) by the addition of KI. ${ }^{42}$ The columns were washed with a minimum of ten free column volumes using $6 \mathrm{M} \mathrm{HCl}$. The $\mathrm{Np}(\mathrm{IV})$ was then eluted with $2 \mathrm{M} \mathrm{HNO}_{3}$ and collected in a 5 mL volumetric flask. A ten $\mu \mathrm{L}$ sample of eluant was diluted to $1000 \mu \mathrm{L}$ with 0.1 $\mathrm{M} \mathrm{HClO}_{4}$ and scanned using the Guided Wave 260 spectrophotometer from 400 to $1300 \mathrm{~nm}$ using $0.1 \mathrm{M} \mathrm{HClO}_{4}$ as a reference solution. Figure 3-14 is a sample spectrum of the eluted $\mathrm{Np}$ and shows the characteristic $\mathrm{Np}(\mathrm{IV})$ absorption peaks at 723 and $960 \mathrm{~nm} \cdot{ }^{43}$ 
The eluant was then heated gently to $\sim 90^{\circ} \mathrm{C}$. After approximately 15 minutes at $90^{\circ} \mathrm{C}$, the yellow-green solution darkened to a deep brown and red fumes began to emanate from the surface. After an additional 10-15 minutes, the dark color and the red fumes both dissipated leaving a solution that was deep green in color indicative of $\mathrm{Np}(\mathrm{V})$. Heating $\mathrm{Np}(\mathrm{IV})$ in nitric acid is a simple method of preparing $\mathrm{Np}(\mathrm{V}){ }^{18}$ After cooling to room temperature, a ten $\mu \mathrm{L}$ sample of this solution was diluted to $1000 \mu \mathrm{L}$ with $0.1 \mathrm{M} \mathrm{HClO}_{4}$ and scanned using the Guided Wave 260 spectrophotometer from 400 to $1300 \mathrm{~nm}$ using $0.1 \mathrm{M} \mathrm{HClO}_{4}$ as a reference solution. Figure 3-15 is a sample spectrum of the oxidized neptunium and shows the characteristic $\mathrm{Np}(\mathrm{V})$ absorption peaks at 617 and $980 \mathrm{~nm} .{ }^{43}$ Evidence of $\mathrm{Np}(\mathrm{VI})$ would be apparent by an absorption peak at $1223 \mathrm{~nm} .{ }^{43}$

The ionic $\mathrm{Np}(\mathrm{V})$ was then precipitated as $\mathrm{NpO}_{2} \mathrm{OH}(\mathrm{am})$ by addition of $0.1 \mathrm{M}$ $\mathrm{NaOH}$ until a green suspension formed in solution. ${ }^{21,44}$ The green precipitate was collected by centrifugation in a $5 \mathrm{~mL}$ pyrex centrifuge tube. The supernatant was removed and the precipitate suspended in distilled, Milli-Q filtered water to remove any residual amount of ionic sodium and/or nitrate. The washing and centrifuging was repeated two additional times. The resulting precipitate was then dissolved with the smallest volume of $0.1 \mathrm{M} \mathrm{HCl}$ needed to dissolve the precipitate. Again, a ten $\mu \mathrm{L}$ sample was removed from the centrifuge tube, diluted to $1000 \mu \mathrm{L}$, and examined by absorption spectrophotometry. Figure 3-16 is a sample spectrum of the re-dissolved $\mathrm{Np}$ and again shows the characteristic $\mathrm{Np}(\mathrm{V})$ absorption peaks. 


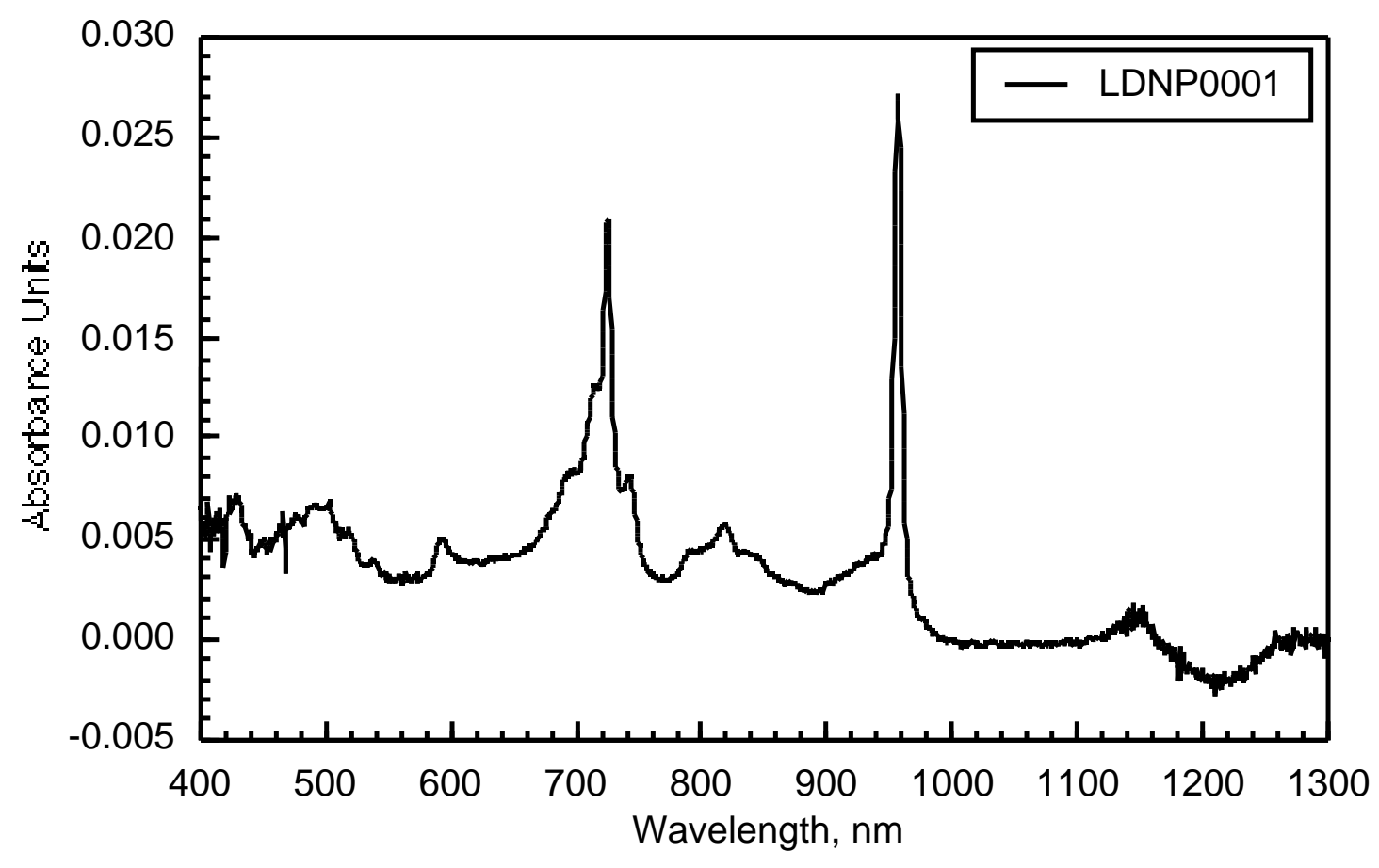

Figure 3-14. Absorption spectrum from 400 to $1300 \mathrm{~nm}$ of a ten $\mu \mathrm{L}$ sample of $\mathrm{Np}$ in $2 \mathrm{M} \mathrm{HNO}_{3}$ eluted from TEVA • Spec SPS diluted to $1 \mathrm{~mL}$ with 0.1 $\mathrm{M} \mathrm{HClO}_{4}$. 


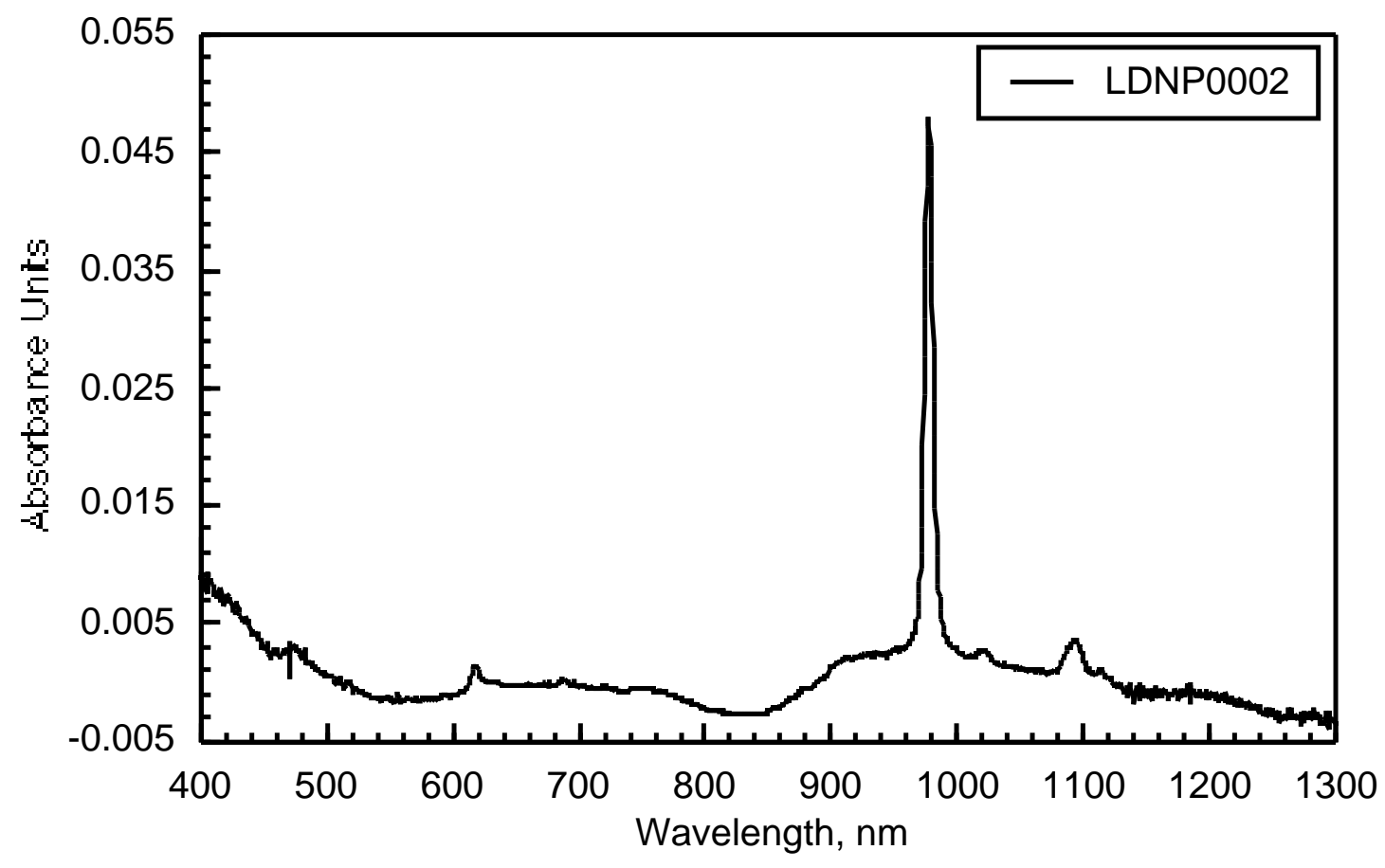

Figure 3-15. Absorption spectrum from 400 to $1300 \mathrm{~nm}$ of a ten $\mu \mathrm{L}$ sample of 2 $\mathrm{M} \mathrm{HNO}_{3}$ after heating at $90^{\circ} \mathrm{C}$ diluted to $1 \mathrm{~mL}$ with $0.1 \mathrm{M} \mathrm{HClO}_{4}$. 


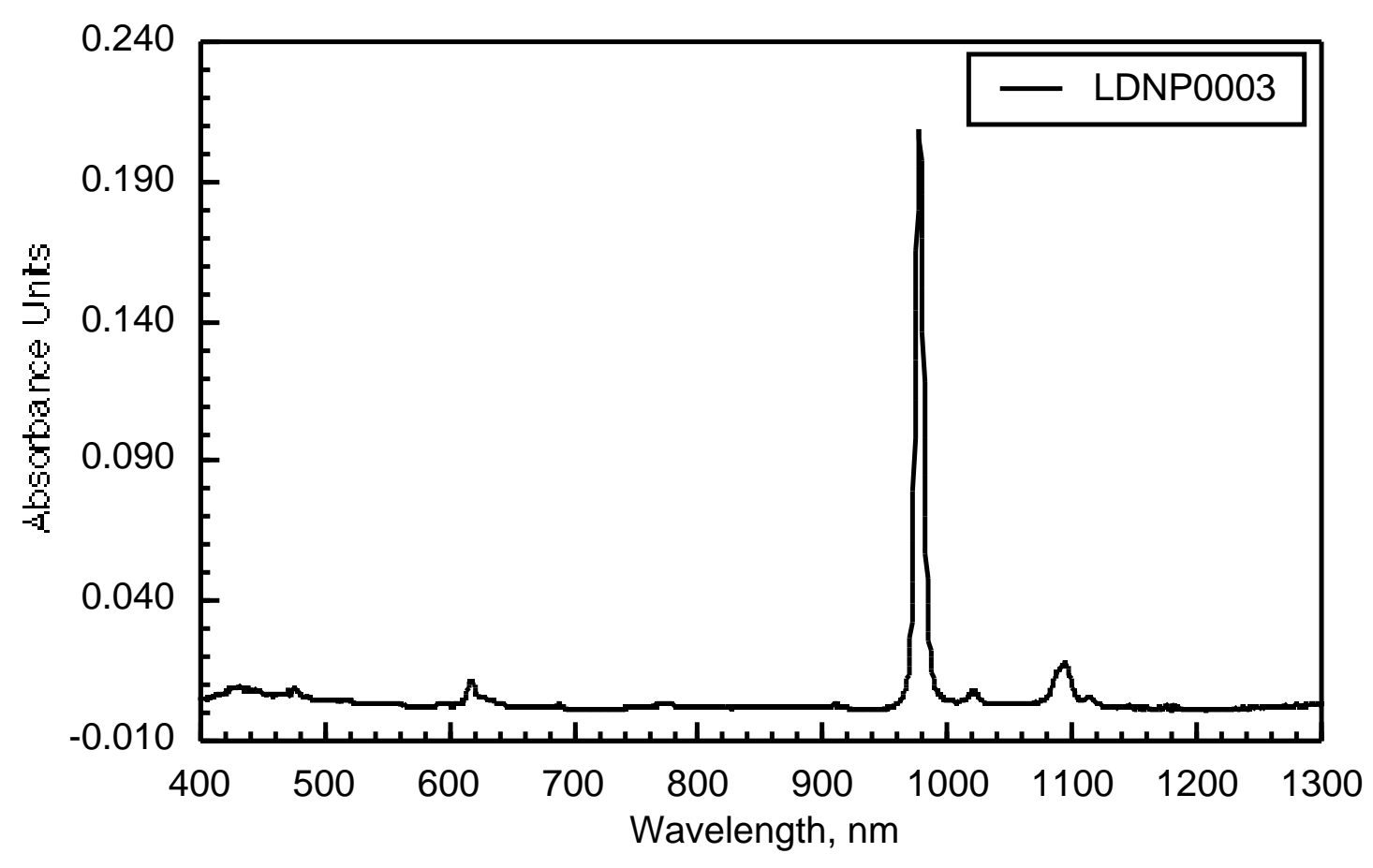

Figure 3-16. Absorption spectrum from 400 to $1300 \mathrm{~nm}$ of a ten $\mu \mathrm{L}$ sample of redissolved $\mathrm{Np}(\mathrm{V})$ diluted to $1 \mathrm{~mL}$ with $0.1 \mathrm{M} \mathrm{HClO}_{4}$. 


\section{RESULTS AND DISCUSSION}

\section{Neptunium Stock Solution: NpSS-A}

Neptunium stock solution "NpSS-A" was prepared by purifying $12 \mathrm{mg}$ of the ${ }^{237} \mathrm{~Np}$ from the $20 \mathrm{mg} / \mathrm{mL}$ LLNL stock using TEVA • Spec SPS chromatography resin as described in the Experimental section. (A "stock solution" is a concentrated solution of a dissolved actinide, $\sim 0.1 \mathrm{M}$, with a $\mathrm{pH}$ near 0 .) Following the Np oxidation in nitric acid, precipitation with sodium hydroxide, and re-dissolution with dilute hydrochloric acid and water, a $10 \mu \mathrm{L}$ sample was removed and diluted with $1000 \mu \mathrm{L}$ of $0.1 \mathrm{M}$ perchloric acid. Perchloric acid is commonly used as a non-complexing aqueous medium, and the resulting absorption spectrum could be compared directly with a reference spectrum form the literature. ${ }^{43}$ An absorption spectrum, number LDNP0003, of this sample was acquired with the Guided Wave 260 absorption spectrophotometer using $0.1 \mathrm{M}$ perchloric acid as a reference solution in order to verify the $\mathrm{Np}$ oxidation state in solution. Spectrum number LDNP0003 was shown in Figure 3-18. The sample was then placed into $20 \mathrm{~mL}$ of Ecolite(+) liquid scintillation cocktail in a plastic liquid scintillation counting (LSC) vial and numbered LDN70008. Sample LDN70008 was placed into the LEPS counter, and the count rate of the $29 \mathrm{keV}$ gamma peak was measured to determine the total Np concentration. A count 
rate of $(314.4474 \pm 0.2819) \gamma \mathrm{CPM}$ was obtained. The total Np concentration in molarity units was calculated according to the following equation:

$$
[N p]=\frac{(\gamma C P M)(D F)}{\left(0.010025^{\gamma C P M} / \gamma D P M\right)\left(0.15^{\gamma D P M} / \alpha D P M\right)(S p A)(I M)(S V)} ;
$$

where DF is the dilution factor, SpA is the specific activity (alpha) for ${ }^{237} \mathrm{~Np}$, IM is the isotopic mass of ${ }^{237} \mathrm{~Np}$, and SV is the sample volume in $\mathrm{mL}$. For sample $\mathrm{LDN70008}, \mathrm{DF}=((1000 \mu \mathrm{L}+10 \mu \mathrm{L}) / 10 \mu \mathrm{L})=101, \mathrm{SpA}=1.566 \times 10^{6} \alpha \mathrm{DPM} / \mathrm{mg}$, $\mathrm{IM}=237.0482 \mathrm{mg} / \mathrm{mn}$, and SV $=1.010 \mathrm{~mL}$. The Np concentration in stock solution "NpSS-A" was determined to be $0.05633 \mathrm{M}$. There was approximately $900 \mu \mathrm{L}$ of stock solution "NpSS-A" for a total of $\sim 12.0 \mathrm{mg}$.

In analyzing the absorption spectrum LDNP0003, data points from 950.5 to 960.0 and 1000.5 to $1010.0 \mathrm{~nm}$ were averaged and this average was used as a background value for the $\mathrm{Np}(\mathrm{V})$ absorption peak observed at $979 \mathrm{~nm}$. This resulted in a net absorbance of 0.20610 in $0.1 \mathrm{M}$ perchloric acid. According to Beer's Law,

$$
A=\varepsilon l c,
$$

the absorbance, $\mathrm{A}$, is equal to the molar extinction coefficient of a particular species, $\varepsilon$, times the length of path the light travels through in the sample, 1 , times the concentration of that species, c. Using the determined values for the net 
absorbance and total $\mathrm{Np}$ concentration list above together with a path length of 1 $\mathrm{cm}$ as was the case with our cuvette, the molar extinction coefficient for the $\mathrm{Np}(\mathrm{V})$ absorbance peak observed at $979 \mathrm{~nm}$ was calulated to be $369.5 \mathrm{~cm}^{-1} \mathrm{M}^{-1}$. This result agrees fairly well (<7\% difference) with the value of $395 \mathrm{~cm}^{-1} \mathrm{M}^{-1}$ reported in the literature. ${ }^{43}$

\section{Elevated Temperature Experiments}

\section{$\underline{\text { Initial Solubility Experiments in Teflon-Lined Reaction Vessels }}$}

The initial Np solubility experiment was performed at $200^{\circ} \mathrm{C}$ for 13 days. A calculated volume, $53.4 \mu \mathrm{L}$, of stock solution "NpSS-A" was added to $30 \mathrm{~mL}$ of Milli-Q filtered, distilled water in a polycarbonate Oak Ridge centrifuge tube (VWR Scientific, San Francisco, California) to give an initial Np concentration of $1 \times 10^{-4} \mathrm{M}$. This concentration was chosen because it was below the measured solubility of $\mathrm{NaNpO}_{2} \mathrm{CO}_{3}(\mathrm{~s})$ at pH 6 and 7 as observed by Nitsche et al. in J-13 well water. ${ }^{4}$ Small volumes $(\sim 22 \mu \mathrm{L}$ total $)$ of $0.1 \mathrm{M} \mathrm{NaOH}$ were added to the experimental solution to neutralize the small amount of $\mathrm{HCl}$ introduced from the "NpSS-A" stock solution and to bring the overall solution to a $\mathrm{pH}$ of about 6 . The solution was then allowed to stand overnight. The next day, the measured $\mathrm{pH}$ was 6.09. Twelve $\mathrm{mL}$ of solution were placed into a stainless steel, Teflonlined Parr Instruments reaction vessel which was then placed into the oven that had been preheated to $200^{\circ} \mathrm{C}$ over night. Twelve $\mathrm{mL}$ of solution were placed into a second stainless steel, Teflon-lined Parr Instruments reaction vessel which was allowed to stand at $25^{\circ} \mathrm{C}$. From the remaining solution, $1000 \mu \mathrm{L}$ was 
examined by UV/VIS spectrophotometry, $500 \mu \mathrm{l}$ was used for an unfiltered assay, $500 \mu \mathrm{L}$ was used to presaturate a $0.2 \mu \mathrm{m}$ filter unit, and $500 \mu \mathrm{L}$ was used to prepare a filtered assay. The $1 \mathrm{~mL}$ sample was scanned with the absorption spectrophotometer from 400 to $1400 \mathrm{~nm}$ (LDNP0004) to verify that $\mathrm{Np}(\mathrm{V})$ was the only observable oxidation state in solution. The sample was then re-scanned from 900 to $1300 \mathrm{~nm}$ (LDNP0005) with a smaller step size of $0.2 \mathrm{~nm} 5$ times and then averaged. Figure 4-1 shows the spectrum from 900 to $1300 \mathrm{~nm}$ of the experimental solution at $\mathrm{pH}$ 6.09. Data points from 950.2 to 960.0 and 1000.2 to 1010.0 nm were averaged and the resulting average was used as a background value for the $\mathrm{Np}(\mathrm{V})$ absorption peak observed at $978.6 \mathrm{~nm}$. This resulted in a net absorbance of 0.037413 at $978.6 \mathrm{~nm}$ in a dilute aqueous solution at $\mathrm{pH} 6.09$.

The $500 \mu \mathrm{L}$ unfiltered aliquot was placed into $20 \mathrm{~mL}$ of Ecolite(+) in a LSC vial for nuclear counting (sample LDN70009). The $500 \mu \mathrm{L}$ prefiltered volume was discarded and the second $500 \mu \mathrm{L}$ filtered volume was placed into $20 \mathrm{~mL}$ of Ecolite(+) for nuclear counting (sample LDN70012). Each of the two samples were measured, and using equation 1 with DF and SV being equal to 1 and 0.5 $\mathrm{mL}$, respectively, $\mathrm{Np}$ concentrations were determined. The unfiltered fraction and the filtered fraction provided concentrations of $9.854 \times 10^{-5}$ and $1.007 \times 10^{-4}$ $\mathrm{M}$, respectively. The ratio of the count rates at the $29 \mathrm{keV}$ gamma line was $(27.5032 \pm 0.3084) /(28.1116 \pm 0.1669)=\left(97.8 \pm 2.5_{2 \sigma}\right) \%$ which means that statistically all of the $\mathrm{Np}$ in solution is smaller than $0.2 \mu \mathrm{m}$ and most likely remained ionic $\mathrm{Np}(\mathrm{V})$. 


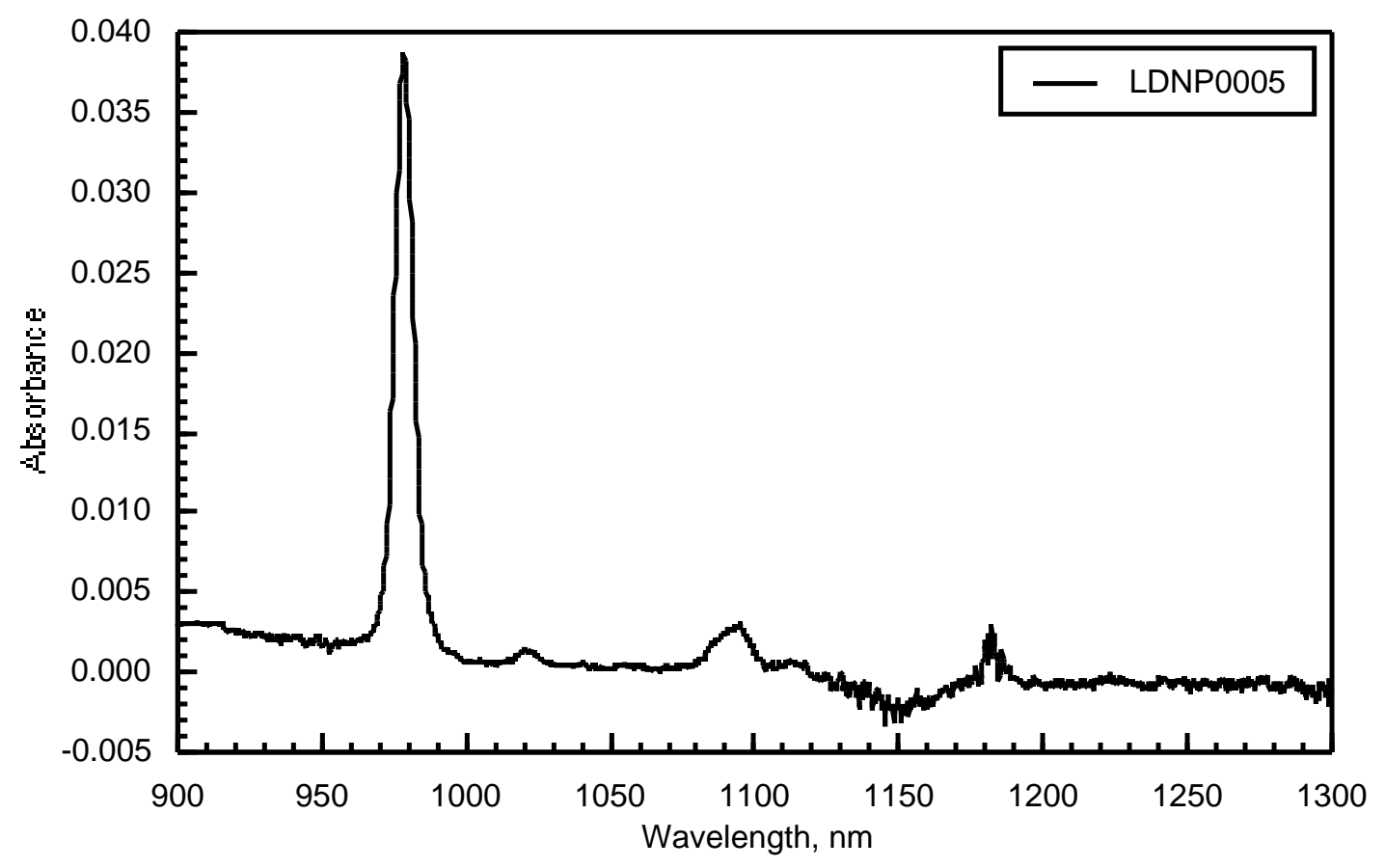

Figure 4-1. Absorption spectrum from 900 to $1300 \mathrm{~nm}$ of the experimental solution at $\mathrm{pH} 6.09$ before reacting at $200^{\circ} \mathrm{C}$. 
Based on Beer's Law, equation 2, the average of the two Np concentration determinations, and the measured absorbance at $\mathrm{pH}$ 6, the molar extinction coefficient for the peak at $980 \mathrm{~nm}$ at pH 6 was calculated to be $375.6 \mathrm{~cm}^{-1} \mathrm{M}^{-1}$.

After 13 days of reacting at $200^{\circ} \mathrm{C}$ the reaction vessel was removed and allowed to cool to $25^{\circ} \mathrm{C}$ in the glove box. The surface temperature of the reaction vessel was measured using a Dual Magnet Surface Thermometer Model 314C (PTC Instruments, Los Angeles, California) over time and those results can be seen in Figure 4-2. After four hours of cooling, the surface temperature reached $25^{\circ} \mathrm{C}$ and the reaction vessel was opened. No evaporative loss was observed. Two 500 $\mu \mathrm{L}$ filtered aliquots were combined and scanned with the spectrophotometer from 900 to $1300 \mathrm{~nm}$ (LDNP0007). Figure 4-3 shows the spectrum from 900 to $1300 \mathrm{~nm}$ of the experimental solution after reacting for 13 days at $200^{\circ} \mathrm{C}$. As before, data points from 950.2 to 960.0 and 1000.2 to $1010.0 \mathrm{~nm}$ were averaged and the resulting average was used as a background value for the $\mathrm{Np}(\mathrm{V})$ absorption peak observed at $978.6 \mathrm{~nm}$. This resulted in a net absorbance of 0.009434. Using the value of $375.6 \mathrm{~cm}^{-1} \mathrm{M}^{-1}$ for the molar extinction coefficient, an aqueous $\mathrm{Np}$ concentration of $2.51 \times 10^{-5} \mathrm{M}$ was obtained. This result means only 25 percent of the initial aqueous $\mathrm{Np}$ remained as $\mathrm{Np}(\mathrm{V})$ in solution.

One $\mathrm{mL}$ of unfiltered solution was placed, after shaking the experimental solution, into $20 \mathrm{~mL}$ of Ecolite(+) in a LSC vial for nuclear counting (LDN70013). Two $500 \mu \mathrm{L}$ prefilter samples were discarded. Two subsequent $500 \mu \mathrm{L}$ samples were passed through the presaturated filter units and combined into $20 \mathrm{~mL}$ of 
Ecolite(+) in a LSC vial for nuclear counting (LDN70014). The filtered sample $(\mathrm{LDN70014}, \mathrm{DF}=1, \mathrm{SV}=1)$ provided a Np concentration of $2.45 \times 10^{-5} \mathrm{M}$ which agreed very well ( $<3 \%$ difference) with the result obtained from absorption spectrophotometry. Therefore, the Np small enough to pass through the $0.2 \mu \mathrm{m}$ filter unit must in fact have been aqueous $\mathrm{Np}(\mathrm{V})$. The unfiltered sample (LDN70013, DF $=1, \mathrm{SV}=1$ ) provided a Np concentration of $1.34 \times 10^{-4} \mathrm{M}$ which was in excess of the initial $\mathrm{Np}$ concentration, meaning that some particulate matter that included $\mathrm{Np}$ was able to preconcentrate in the unfiltered sample. This may have occurred if a Np precipitate had settled to the bottom of the vessel and the pipette tip used to remove $1000 \mu \mathrm{L}$ sucked up some of this Np precipitate thus placing more Np into sample LDN70013.

The measured $\mathrm{pH}$ after the 13 days of reaction time was 4.05 . This was a decrease from the initial value by two $\mathrm{pH}$ units.

In the base of the Teflon cup was a visually observable amount of very finely divided solid. In order to collect this material, the remaining $8 \mathrm{~mL}$ of solution was gently agitated and split equally using disposable plastic transfer pipettes into two $10 \mathrm{~mL}$ pyrex centrifuge tubes and centrifuged mildly for 30 minutes. The supernatants were removed and the solids were allowed to dry in air for a couple of days. Using methanol, the very small amount of precipitate, which was barely observable at the base of the centrifuge tubes with a 7x magnifying glass, was combined and transferred to the open neck of a quartz capillary tube. 
The solid was brownish or dark olive green in color; it was difficult to visually tell from the very small amount of precipitate collected.

The solubility experiment had an initial solution volume of $12 \mathrm{~mL}$ and neptunium concentration of $10^{-4} \mathrm{M}$. This is a total of $0.284 \mathrm{mg}$ of neptunium of which $75 \%$ precipitated. Therefore, the solid material collected and transferred to the capillary contained at most $0.215 \mathrm{mg}$ of neptunium.

In order to move the solids to the bottom, sealed end of the capillary, a $10 \mathrm{~mL}$ pyrex centrifuge tube was fitted with a cork that had a hole drilled through its length. The quartz capillary tube was placed through the hole in the cork and into the centrifuge tube until the wider, open end of the quartz capillary tube barely protruded from the top of the cork. A small amount of epoxy was used to hold the capillary tube in place in the cork. The centrifuge tube containing the capillary tube was then centrifuged very mildly for 30 minutes, and the precipitate was found visually at the sealed end (bottom) of the capillary tube. The methanol was allowed to evaporate before the quartz capillary was sealed about one half of an inch from the base with a Microflame Gas Torch, Minnetonka, Minnesota. The sealed capillary was decontaminated in the glove box by washing repeatedly with dilute, uncontaminated $\mathrm{HCl}$ and passed out of the glove box into a glass liquid scintillation vial. The capillary was visually inspected under a microscope to verify that the capillary was sealed at both ends. The liquid scintillation vial containing the capillary was labeled "Np1" and was set aside for shipment to LBNL for an x-ray powder diffraction measurement. 




Figure 4-2. Surface temperature of a cooling Parr reaction vessel as a function of time when removed from the oven at $200^{\circ} \mathrm{C}$. 


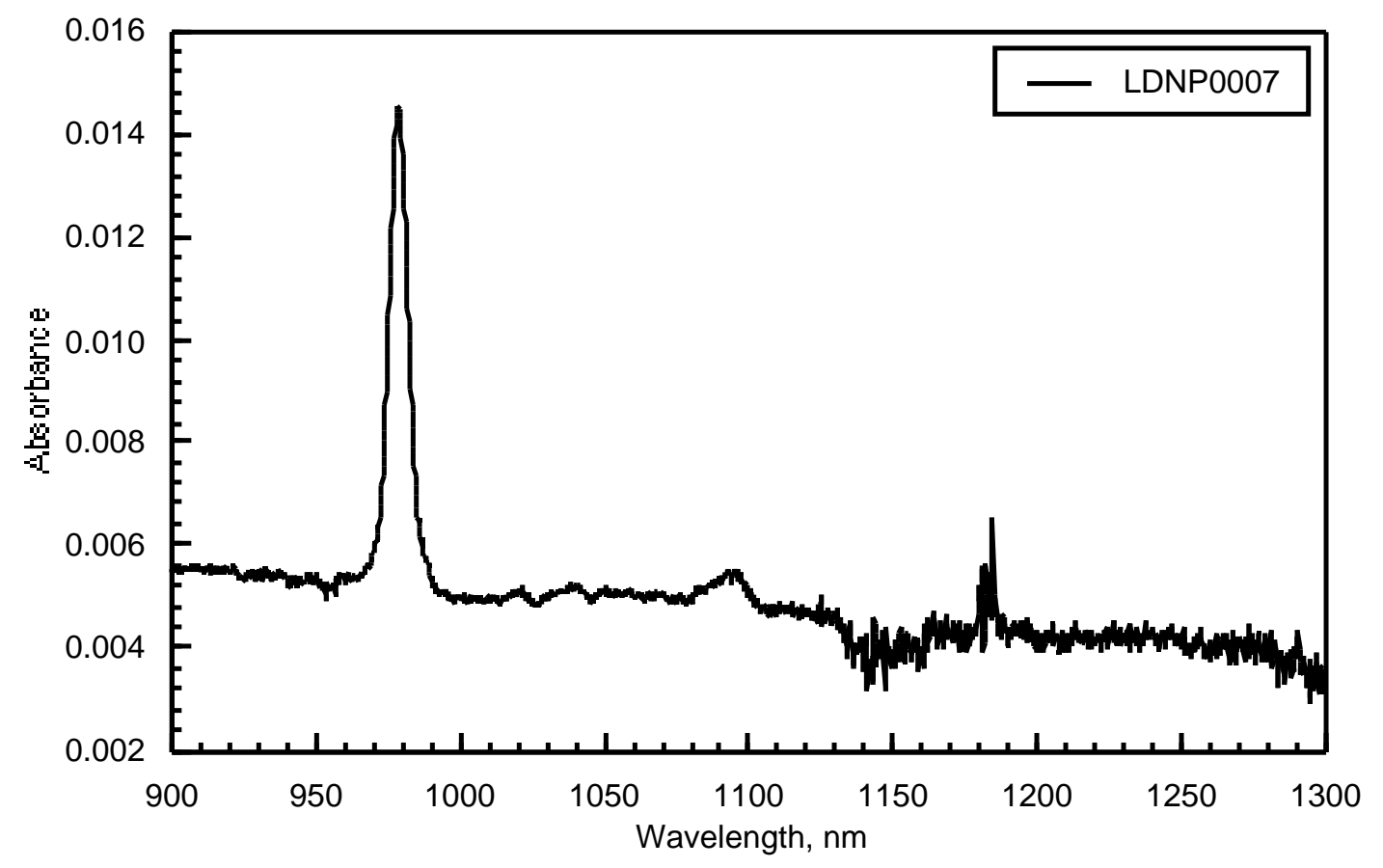

Figure 4-3. Absorption spectrum from 900 to $1300 \mathrm{~nm}$ of the experimental solution at $25^{\circ} \mathrm{C}$ after reacting at $200^{\circ} \mathrm{C}$ for 13 days. 
The following day, after 14 days of reaction time, the ambient temperature duplicate experiment was opened and a sample removed for nuclear counting. Two $500 \mu \mathrm{L}$ samples were passed through $0.2 \mu \mathrm{m}$ filter units to presaturate any sorptive sites. A second volume of $500 \mu \mathrm{L}$ was passed through each of the same two filter units and then combined into $20 \mathrm{~mL}$ of Ecolite(+) in a LSC vial for nuclear counting (LDN70015). The resulting aqueous Np concentration was found to be $1.01 \times 10^{-4} \mathrm{M}(\mathrm{DF}=1, \mathrm{SV}=1)$ which was equal to the initial aqueous $\mathrm{Np}$ concentration. The $\mathrm{pH}$ in the $25^{\circ} \mathrm{C}$ experiment after 14 days of reaction time was 6.00, virtually unchanged from the initial $\mathrm{pH}$ of 6.09 .

Aqueous samples were removed from both experiments for measurements of the sodium ion concentration. The ion selective electrode was calibrated as described in the experimental section prior to measuring the two unknown samples. The sodium ion concentrations in the 13 and 28 day solubility experiments in Teflon-lined vessels were found to be $3.58 \times 10^{-4}$ and $3.43 \times 10^{-4} \mathrm{M}$, respectively.

In summary, after 14 days of reacting at $25^{\circ} \mathrm{C}$, no $\mathrm{Np}$ precipitation was observed from $1.0 \times 10^{-4} \mathrm{M} \mathrm{Np}$ at $\mathrm{pH}$. However, after 13 days at $200^{\circ} \mathrm{C}$, the $\mathrm{Np}$ solubility experiment in the Teflon reaction vessel showed a $75 \%$ decrease in the solubility of $\mathrm{Np}$ when compared with the identical experiment performed at $25^{\circ} \mathrm{C}$. A precipitate formed and was collected. 
The remaining ten $\mathrm{mL}$ from the $25^{\circ} \mathrm{C}$ experiment was placed back into its Teflonlined reaction vessel, and the vessel was placed into the oven that was kept at $200^{\circ} \mathrm{C}$. This time the reaction vessel remained in the oven for 28 days in order to investigate the time dependence on the precipitation of $\mathrm{Np}$ at $200^{\circ} \mathrm{C}$. The solution had a measured $\mathrm{pH}$ of 6.00 when the experiment was started.

After 28 days of reaction time, the vessel was removed from the oven and allowed to cool to $25^{\circ} \mathrm{C}$ for four hours. Two filter units were presaturated by passing through $500 \mu \mathrm{L}$ of solution through each unit. The filtrates were discarded and a second volume of $500 \mu \mathrm{L}$ was passed through each of the units. The secondary filtrates were combined and placed into a LSC vial containing 20 mL of Ecolite(+) for nuclear counting (LDN70016). The resulting aqueous Np concentration was found to be $9.46 \times 10^{-7} \mathrm{M}(\mathrm{DF}=1, \mathrm{SV}=1)$. This was a decrease in soluble $\mathrm{Np}$ of two orders of magnitude after the 28 days of reaction time at $200^{\circ}$ C. A $1 \mathrm{~mL}$ sample was then scanned with the absorption spectrophotometer from 900 to $1300 \mathrm{~nm}$ by $0.2 \mathrm{~nm} 5$ times. These spectra were then averaged. No absorption peaks were observed in the wavelength range examined. With the detection limit for the Guided Wave 260 absorption spectrophotometer being on the order of 0.001 absorbance units, concentrations of aqueous $\mathrm{Np}(\mathrm{V})$ below $2.7 \mathrm{x}$ $10^{-6} \mathrm{M}$ will not be observable with this instrument.

The measured $\mathrm{pH}$ in the solution after the 28 days of reaction time was 3.97, again two $\mathrm{pH}$ units below the starting $\mathrm{pH}$ of the solubility experiment. 
Again a finely divided precipitate was observed in the base of the Teflon cup. This material was collected in the same manner as was done in the first experiment. The resulting capillary was decontaminated, passed out of the glove box, and visually inspected under a microscope. The liquid scintillation vial containing the capillary was labeled "Np2" and was set aside for shipment to LBNL for an x-ray powder diffraction measurement.

Before the precipitated solids were analyzed by x-ray powder diffraction, the inert characteristic of the Teflon reaction vessels in experiments at elevated temperatures was questioned. Teflon has a tendency to slowly release fluoride ions into solutions that are in contact with the Teflon. At ambient temperatures this release of fluoride is rather slow, but with the high temperatures of these experiments, that release rate may have been significantly increased. Also, Teflon has a tendency to adsorb or absorb ions from solutions and then release those ions into subsequent solutions. The fact that these Teflon liners were treated in $3 \mathrm{M}$ hydrochloric acid to remove any possible metal contaminants may have lead to the adsorption/absorption of protons and/or chloride ions which may then be released in the subsequent low ionic strength solubility experiments. In order to measure possible fluoride and chloride ion contamination, fluoride and chloride ion selective electrodes were procured and calibrated as outlined in the Experimental section.

Fluoride contamination was found in the previous experiments. The 13 and 28 day experiments had measured fluoride ion concentrations of $9.29 \times 10^{-5}$ and 
$1.34 \times 10^{-4} \mathrm{M}$, respectively. Based on the amount of $\mathrm{HCl}$ introduced to the experiment from the slightly acidic stock "NpSS-A" solution, an estimated chloride ion concentration was calculated to be on the order of $1.3 \times 10^{-4} \mathrm{M}$. However, the 13 and 28 day experiments had measured chloride ion concentrations of $6.26 \times 10^{-3}$ and $6.80 \times 10^{-3} \mathrm{M}$, respectively. This is more than an order of magnitude greater than the estimated value based on what was introduced with the Np stock, thus indicating that some chloride contamination took place.

The problem associated with chloride ion contamination is not critical because it only increases the ionic strength of the experimental solutions. This is not necessarily a severe problem other than it defeats our objective to investigate $\mathrm{Np}$ solubility in solutions of very low ionic strength. By very low ionic strength, it is meant solutions near, or if possible below, millimolar in total ionic strength.

The problem associated with fluoride ion contamination is somewhat more significant because of the rather low solubility of actinide-fluoride solids in general. Historically, fluoride ion has been used in quantitative actinide separations schemes to remove actinides from solution by precipitation. Therefore, if significant fluoride ion concentrations are reached, Np precipitation may be governed by the fluoride ion in solution and not by any expected hydrolytic reactions. 
In an attempt to avoid both of these problems these experiments were repeated using titanium vessels. The vessels were pretreated with hot concentrated nitric acid and then baked (dry) at $400^{\circ} \mathrm{C}$.

\section{$\underline{\text { Replicate Solubility Experiments in Titanium Reaction Vessels }}$}

The first experiment performed in a titanium vessel was a duplicate of the first experiment performed in a Teflon-lined reaction vessel. The initial $\mathrm{Np}$ concentration in the $20 \mathrm{~mL}$ experiment was $1 \times 10^{-4} \mathrm{M}$. The starting $\mathrm{pH}$ was 6.65 . The titanium vessel was allowed to react in the oven at $200^{\circ} \mathrm{C}$ for 12 days. The vessel was then removed and allowed to cool for four hours as was done in the previous experiments. No evaporative loss was observed.

Two $500 \mu \mathrm{L}$ samples were passed through $0.2 \mu \mathrm{m}$ filter units to presaturate any sorptive sites. A second volume of $500 \mu \mathrm{L}$ was passed through each of the same two filter units and then combined into $20 \mathrm{~mL}$ of Ecolite(+) in a LSC vial for nuclear counting (LDN70017). The resulting aqueous Np concentration was found to be $1.54 \times 10^{-5} \mathrm{M}(\mathrm{DF}=1, \mathrm{SV}=1)$. The measured $\mathrm{pH}$ after the 12 days of reaction time was 4.44 . The fluoride ion concentration was measured and found to be at the detection limit of the ion selective electrode. The potential read by the electrode was the same as the potential found for Milli-Q filtered, distilled water. Therefore, it was concluded that no ionic fluoride was present in this experiment. The chloride ion concentration was measured and found to be $2.97 \mathrm{x}$ $10^{-4} \mathrm{M}$. This is on the order of 20 times lower than that measured at the 
conclusion of the 13 day experiment performed in Teflon and much closer to the value estimated based on calculating the amount introduced from the Np stock solution.

Another experiment performed in a titanium vessel was a duplicate of the 28 day experiment performed in a Teflon-lined reaction vessel. Again, the initial Np concentration in this $20 \mathrm{~mL}$ experiment was $1 \times 10^{-4} \mathrm{M}$, and the starting $\mathrm{pH}$ was 6.65. The titanium vessel was allowed to react in the oven at $200^{\circ} \mathrm{C}$ for 28 days. The vessel was then removed and allowed to cool for four hours as was done in the previous experiments. No evaporative loss was observed.

Two $500 \mu \mathrm{L}$ samples were passed through $0.2 \mu \mathrm{m}$ filter units to presaturate any sorptive sites. A second volume of $500 \mu \mathrm{L}$ was passed through each of the same two filter units and then combined into $20 \mathrm{~mL}$ of Ecolite(+) in a LSC vial for nuclear counting (LDN70019). The resulting aqueous Np concentration was found to be $1.09 \times 10^{-5} \mathrm{M}(\mathrm{DF}=1, \mathrm{SV}=1)$. The measured $\mathrm{pH}$ after the 28 days of reaction time was 4.39. The fluoride ion concentration was not measured because none was detected in the first experiment in titanium. The chloride ion concentration was measured and found to be $5.08 \times 10^{-4} \mathrm{M}$.

Sodium Ion Concentration Measurements - Initial and Replicate Experiments

Aqueous samples were removed from all experiments for measurements of the sodium ion concentration. The ion selective electrode was calibrated as 
described in the experimental section prior to measuring the two unknown samples. The sodium ion concentrations in the 13 and 28 day solubility experiments in the Teflon-lined vessels were found to be $3.58 \times 10^{-4}$ and $3.43 \times 10^{-4}$ $\mathrm{M}$, respectively. The sodium ion concentrations in the 12 and 28 day solubility experiments in the titanium vessels were found to be $2.02 \times 10^{-4}$ and $1.79 \times 10^{-4} \mathrm{M}$, respectively. Concentrations of sodium were expected to be slightly lower in the two titanium solubility experiments because less $0.1 \mathrm{M} \mathrm{NaOH}$ was introduced at the start of the experiments. Regardless, the amount of sodium in all four solutions was on the order of what was expected based on what was introduced at the start of the experiments in adjusting the initial $\mathrm{pH}$.

Table 4-1 summarizes initial values for the $\mathrm{pH}$ and neptunium concentrations as well as the final values for the $\mathrm{pH}$, neptunium, fluoride, chloride and sodium ion concentrations that were measured in the Teflon and titanium vessel experiments.

Table 4-1. Summary of results for initial Np solubility experiments at $200^{\circ} \mathrm{C}$.

\begin{tabular}{|c|c|c|c|c|c|c|c|c|c|}
\hline $\begin{array}{c}\text { Reaction } \\
\text { Vessel }\end{array}$ & $\begin{array}{c}\text { Initial Np } \\
\text { Conc. (M) }\end{array}$ & $\begin{array}{c}\text { Initial } \\
\mathrm{pH}\end{array}$ & $\begin{array}{c}\text { Initial } \\
\text { Vol. (mL) }\end{array}$ & $\begin{array}{c}\text { Reaction } \\
\text { Time (days) }\end{array}$ & $\begin{array}{c}\text { Final } \\
\mathrm{pH}\end{array}$ & $\begin{array}{c}\text { Final Np } \\
\text { Conc. (M) }\end{array}$ & $\begin{array}{c}\text { Fluoride } \\
\text { Conc. (M) }\end{array}$ & $\begin{array}{c}\text { Chloride } \\
\text { Conc. (M) }\end{array}$ & $\begin{array}{c}\text { Sodium } \\
\text { Conc. (M) }\end{array}$ \\
\hline Teflon & $1.01 \mathrm{E}-04$ & 6.09 & 12 & 13 & 4.05 & $2.51 \mathrm{E}-05$ & $9.29 \mathrm{E}-05$ & $6.26 \mathrm{E}-03$ & $3.58 \mathrm{E}-04$ \\
\hline Teflon & $1.01 \mathrm{E}-04$ & 6.09 & 10 & 28 & 3.97 & $9.46 \mathrm{E}-07$ & $1.34 \mathrm{E}-04$ & $6.80 \mathrm{E}-03$ & $3.43 \mathrm{E}-04$ \\
\hline $\mathrm{Ti}$ & $1.00 \mathrm{E}-04$ & 6.65 & 20 & 12 & 4.44 & $1.54 \mathrm{E}-05$ & BDL & $2.97 \mathrm{E}-04$ & $2.02 \mathrm{E}-04$ \\
\hline $\mathrm{Ti}$ & $1.00 \mathrm{E}-04$ & 6.65 & 20 & 28 & 4.39 & $1.09 \mathrm{E}-05$ & NM & $5.08 \mathrm{E}-04$ & $1.79 \mathrm{E}-04$ \\
\hline
\end{tabular}

BDL - Below Detection Limit, NM - Not Measured 


\section{$\underline{\text { X-ray Powder Diffraction of the Solids }}$}

The quartz capillaries containing the solids obtained from the two experiments performed in Teflon-lined reaction vessels were shipped from LLNL to LBNL. Sample Np1 was loaded into a Debye-Scherrer camera and x-rayed for 24 hours. The film was removed, developed and processed as described in the Experimental section. The results are shown in Figure 4-4. The vertical image of the film shown on the left in Figure 4-4 was reduced from 14 to 8 inches in length in Adobe Photoshop in order for it to fit a single page here. A second measurement was made for 46 hours in order to hopefully provide better resolution of the higher 2-theta peaks, but the subsequent film had a significantly darker background that hindered its conversion to a digital image. The 24 hour film proved to be a better image.

The plot on the top right shows the raw intensity data as a function of the diffraction angle 2 theta. The Jade software has a manual background subtraction tool that was used to prepare the center plot which reveals only the powder diffraction peak intensities. The bottom plot is a "stick" plot representation of the powder diffraction pattern for crystalline $\mathrm{NpO}_{2}$ solid as published in the ICDD-PDF database. ${ }^{39}$ Clearly, the powder diffraction pattern for the solid obtained in the first elevated temperature experiment matches that for crystalline neptunium(IV) dioxide published in the literature. 
The peak intensities in the plots were normalized to the peak at $33^{\circ}$ instead of the peak at $28^{\circ}$. The highest intensity peak is not quantitative because the film reached an exposure saturation that cannot be accurately integrated, relative to the other peaks, by the Filmscan software. This saturation effect can be reduced by exposing films for shorter amounts of time; however, the peaks at higher diffraction angles would have lower intensities and their quantification would become less accurate.

Table 4-2 lists the output from the peak identification tool produced by the Jade software in order to numerically compare the results (both peak position and relative intensity) from sample $\mathrm{Np} 1$ with the reference material in the ICDD-PDF database. The data on the left-hand side is that of sample Np1 whereas, the data to the right is that for the ICDD-PDF file for crystalline $\mathrm{NpO}_{2}$. Each peak observed in the pattern obtained from sample Np1 corresponded with a peak in the reference pattern for crystalline $\mathrm{NpO}_{2}$. The final right-hand column lists the difference in peak positions between the two patterns as a "delta 2-theta". The largest difference in peak position was 0.36 degrees 2-theta, and the average difference in peak position for all diffraction lines was 0.205 degrees 2-theta. Each peak value listed for the experimental sample was determined as the centroid of the peak. Relative intensities were determined from integration of each peak. Absolute peak height at the centroid value is reduced by line broadening, especially at the higher values of 2-theta; therefore, relative intensities were more accurately calculated by integrating the total peak area. 
After obtaining a quality powder pattern for the Np1 sample, the capillary was removed from the camera and the $\mathrm{Np} 2$ sample was prepared for loading into the camera for a powder diffraction measurement. Unfortunately, the capillary was destroyed while trying to place it into the clay holder. The tweezers pinched the capillary hard enough to shatter the quartz and disperse the contents inside of the glove box for loading cameras. No visible sign of either the precipitate or the capillary were found in the glove box; however, a handheld alpha particle Geiger counter was able to measure alpha radiation inside the surfaces of the glove box and on the camera itself. Both the glove box and camera were immediately decontaminated, and the subsequent radioactive waste was disposed of at LBNL.

This was the only solid sample collected from the second experiment, so no characterization of the solid was performed. 

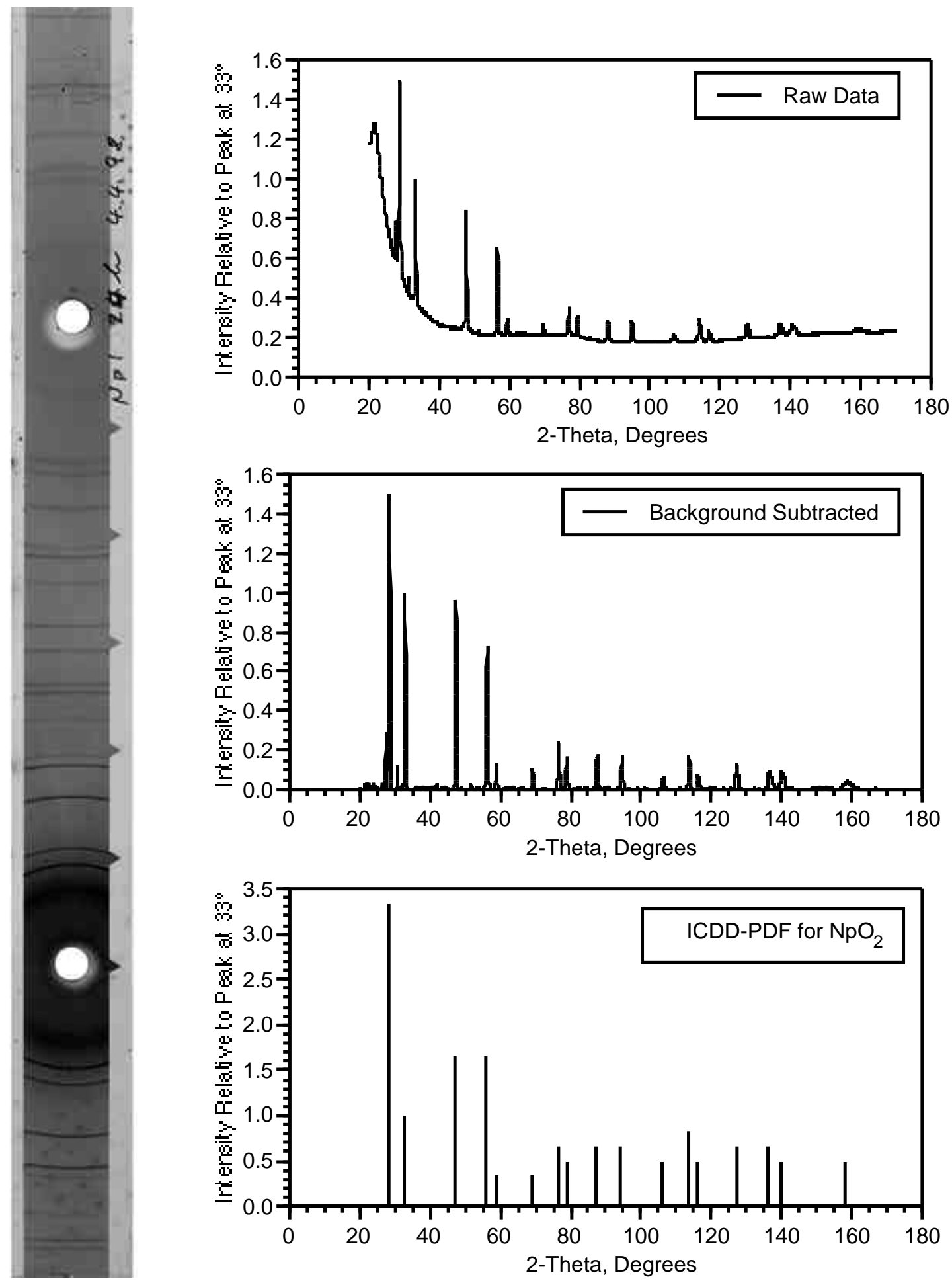

Figure 4-4. X-ray powder diffraction film of sample "Np1" and plots showing digitized intensity as a function of diffraction angle, 2-theta. 
Table 4-2. Peak identification report obtained from Jade for sample "Np1", the solid obtained in the initial $200^{\circ} \mathrm{C}$ solubility experiment listed together with the published pattern for crystalline $\mathrm{NpO}_{2}$.

USER: GENERAL

JADE: Peak ID Report

DATE: Friday, 12-04-98 @10:53a

FILE: NP2.MDI

IDEN: NP2.PCX <Camera Diameter $=114.6 \mathrm{~mm}>$

SCAN: Range=20.0008-169.9981/0.02117, Dwell=1(sec), Anode=CU, 12-04-98@10:44

FIND: Filter $=99 p$, Threshold $=3.0 \mathrm{~s}$, Cutoff $=0.01 \%, 2$-Theta $=$ Centroid

Data Generated from Sample "Np1" ICDD-PDF file for $\mathrm{NpO}_{2}(\mathrm{cr})$

\begin{tabular}{|c|c|c|c|c|c|c|c|c|}
\hline 2-Theta & $d(A)$ & $1 \%$ & FWHM & Phase-ID & $\mathrm{d}(\mathrm{A})$ & $1 \%$ & 2-Theta & $\begin{array}{c}\text { Delta } \\
\text { 2-Theta }\end{array}$ \\
\hline 28.504 & 3.129 & 100 & 0.38 & $\mathrm{NpO}_{2}$ & 3.14 & 100 & 28.401 & -0.104 \\
\hline 33.016 & 2.711 & 47.5 & 0.272 & $\mathrm{NpO}_{2}$ & 2.717 & 30 & 32.939 & -0.077 \\
\hline 47.414 & 1.916 & 53.4 & 0.313 & $\mathrm{NpO}_{2}$ & 1.921 & 50 & 47.279 & -0.135 \\
\hline 56.266 & 1.634 & 43 & 0.334 & $\mathrm{NpO}_{2}$ & 1.638 & 50 & 56.102 & -0.164 \\
\hline 58.995 & 1.564 & 8.3 & 0.368 & $\mathrm{NpO}_{2}$ & 1.568 & 10 & 58.85 & -0.146 \\
\hline 69.259 & 1.355 & 5.7 & 0.369 & $\mathrm{NpO}_{2}$ & 1.358 & 10 & 69.113 & -0.146 \\
\hline 76.542 & 1.244 & 16.6 & 0.426 & $\mathrm{NpO}_{2}$ & 1.247 & 20 & 76.305 & -0.237 \\
\hline 78.892 & 1.212 & 11.1 & 0.393 & $\mathrm{NpO}_{2}$ & 1.215 & 15 & 78.688 & -0.204 \\
\hline 88.188 & 1.107 & 12.9 & 0.461 & $\mathrm{NpO}_{2}$ & 1.109 & 20 & 87.996 & -0.192 \\
\hline 95.134 & 1.044 & 13 & 0.461 & $\mathrm{NpO}_{2}$ & 1.046 & 20 & 94.852 & -0.282 \\
\hline 106.896 & 0.959 & 4 & 0.43 & $\mathrm{NpO}_{2}$ & 0.961 & 15 & 106.555 & -0.341 \\
\hline 114.296 & 0.917 & 15.9 & 0.514 & $\mathrm{NpO}_{2}$ & 0.918 & 25 & 114.107 & -0.189 \\
\hline 116.827 & 0.904 & 7 & 0.497 & $\mathrm{NpO}_{2}$ & 0.906 & 15 & 116.467 & -0.36 \\
\hline 127.733 & 0.858 & 10.3 & 0.543 & $\mathrm{NpO}_{2}$ & 0.859 & 20 & 127.46 & -0.273 \\
\hline 136.951 & 0.828 & 6.4 & 0.54 & $\mathrm{NpO}_{2}$ & 0.829 & 20 & 136.646 & -0.305 \\
\hline 140.476 & 0.818 & 5.8 & 0.552 & $\mathrm{NpO}_{2}$ & 0.819 & 15 & 140.276 & -0.2 \\
\hline 158.74 & 0.784 & 2.1 & 0.183 & $\mathrm{NpO}_{2}$ & 0.784 & 15 & 158.608 & -0.131 \\
\hline
\end{tabular}

@End-Of-List!

Average Delta 2-Theta $=0.205$ 


\section{Larger Scale Experiments in Titanium Reaction Vessels}

\section{Neptunium Solubility}

Because the initial elevated temperature experiments demonstrated that crystalline $\mathrm{NpO}_{2}(\mathrm{~s})$ can form from an aqueous solution of initially $\mathrm{Np}(\mathrm{V})$, experiments were continued on a larger scale so that a significant amount of precipitate could be collected for analysis. The replicate experiments in the titanium vessels were of nearly the same starting volume $(\sim 20 \mathrm{~mL})$ as the initial Teflon-lined vessel experiments and were conducted primarily to determine whether or not the halide ion (fluoride and/or chloride) contamination was responsible for the decrease in the aqueous $\mathrm{Np}$ concentrations. Both of the relatively short-term experiments conducted in the titanium reaction vessels exhibited similar behavior in that the concentration of aqueous neptunium did in fact decrease in time when the solutions were allowed to react at $200^{\circ} \mathrm{C}$. Attempts were made to collect the solids that formed in these experiments; however, efforts were diverted from the characterization of these solids to newer, larger scale experiments that could be monitored as a function of time and that would result in larger amounts of precipitate being formed.

The initial larger scale solubility experiment performed in titanium was a duplicate of the previous experiments with one exception. The total starting volume of solution was increased to $80 \mathrm{~mL}$ in order to be able to collect a significant amount of precipitated neptunium for analysis. The larger starting 
volume also allowed for periodic sample removal for aqueous neptunium concentration determinations as a function of time. A $1 \mathrm{~mL}$ unfiltered assay was taken at the start of the experiment to measure the initial aqueous $\mathrm{Np}$ concentration. The resulting aqueous $\mathrm{Np}$ concentration was determined to be $1.01 \times 10^{-4} \mathrm{M}$, and the starting $\mathrm{pH}$ was 6.5 .

The vessel was placed into the preheated oven and allowed to stand for a week at $200^{\circ} \mathrm{C}$. On day seven, the vessel was removed from the oven, allowed to cool for four hours as was done in the previous experiments, and then assayed for soluble neptunium. As was done in the past, two $500 \mu \mathrm{L}$ aliquots were passed through two separate $0.2 \mu \mathrm{m}$ filter units and the subsequent filtrate was discarded. Another two $500 \mu \mathrm{L}$ aliquots of solution were filtered through the pretreated filter units. These two filtrates were combined and placed into a LSC vial containing $20 \mathrm{~mL}$ of Ecolite(+). This sampling provided a dilution factor and sample volume of one. The sample was then analyzed by gamma pulse height analysis, and the resulting aqueous $\mathrm{Np}$ concentration was found to be $6.15 \times 10^{-5}$ M. The measured solution $\mathrm{pH}$ was 4.64 .

The larger scale experiment was demonstrating behavior similar to the previous experiments that were started at $\mathrm{pH}$ values of 6 to 6.5 , so the vessel was returned to the oven and the experiment continued.

The titanium vessel was removed from the oven periodically. Each time, it was allowed to cool for four hours, the solution's $\mathrm{pH}$ was then measured, and an 
aliquot removed for an aqueous neptunium concentration determination. Each time a $1 \mathrm{~mL}$ assay was prepared as was done on day seven providing each assay a dilution factor and a sample volume of one. This continued over time until steady-state aqueous neptunium concentrations were observed. Steady-state conditions were defined when the changes in aqueous neptunium concentrations from sample to sample were not significant. Steady state was reached after approximately 100 days of reaction time, and the experiment was terminated on day 102.

Figure 4-5 shows the aqueous neptunium concentrations as a function of time for this experiment. Figure 4-6 shows the measured $\mathrm{pH}$ values as a function of time for the same experiment.

Because this larger scale experiment at an initial $\mathrm{pH}$ of 6 demonstrated behavior similar to the previous, smaller scale experiments, three more $\sim 80 \mathrm{~mL}$ solubility experiments were started. For this series of experiments, the changing variable was solution $\mathrm{pH}$. These experiments were started just as the initial, larger scale experiment was started, but at time zero more dilute sodium hydroxide was added to increase the solution's initial $\mathrm{pH}$ value.

Periodically, each of these experiments was removed from the oven so the solution's pH could be measured. Each showed a significant decrease in $\mathrm{pH}$ when allowed to react at $200^{\circ} \mathrm{C}$, so they were each adjusted by periodically adding small volumes of dilute sodium hydroxide $(0.1 \mathrm{M})$ to again increase the 
solutions' $\mathrm{pH}$ values. Assays were not taken in order to conserve as much of the working solution as possible. Once the $\mathrm{pH}$ of each of the experiments began to demonstrate steady-state characteristics, assays were taken for aqueous neptunium concentration determinations.

Figure 4-7 shows the aqueous neptunium concentrations as a function of time for all of the $80 \mathrm{~mL}$ neptunium solubility experiments. Figure $4-8$ shows the measured $\mathrm{pH}$ values as a function of time for the same experiments.

Table 4-3 lists the values for the reaction time, solution $\mathrm{pH}$, and neptunium concentrations for the larger scale solubility experiments. Steady-state values for $\mathrm{pH}$ and aqueous neptunium concentrations listed in Table 4-4, were calculated by averaging the last $4,3,3$, and 2 data points in the experiments that had steadystate $\mathrm{pH}$ values near 4, 6, 7, and 9, respectively. Figure 4-9 shows the steadystate aqueous neptunium concentrations as a function of solution $\mathrm{pH}$.

Upon reaching steady-state conditions in each of the $80 \mathrm{~mL}$ solubility experiments, the solids that precipitated in each of the experiments were again collected for analysis by x-ray powder diffraction. 


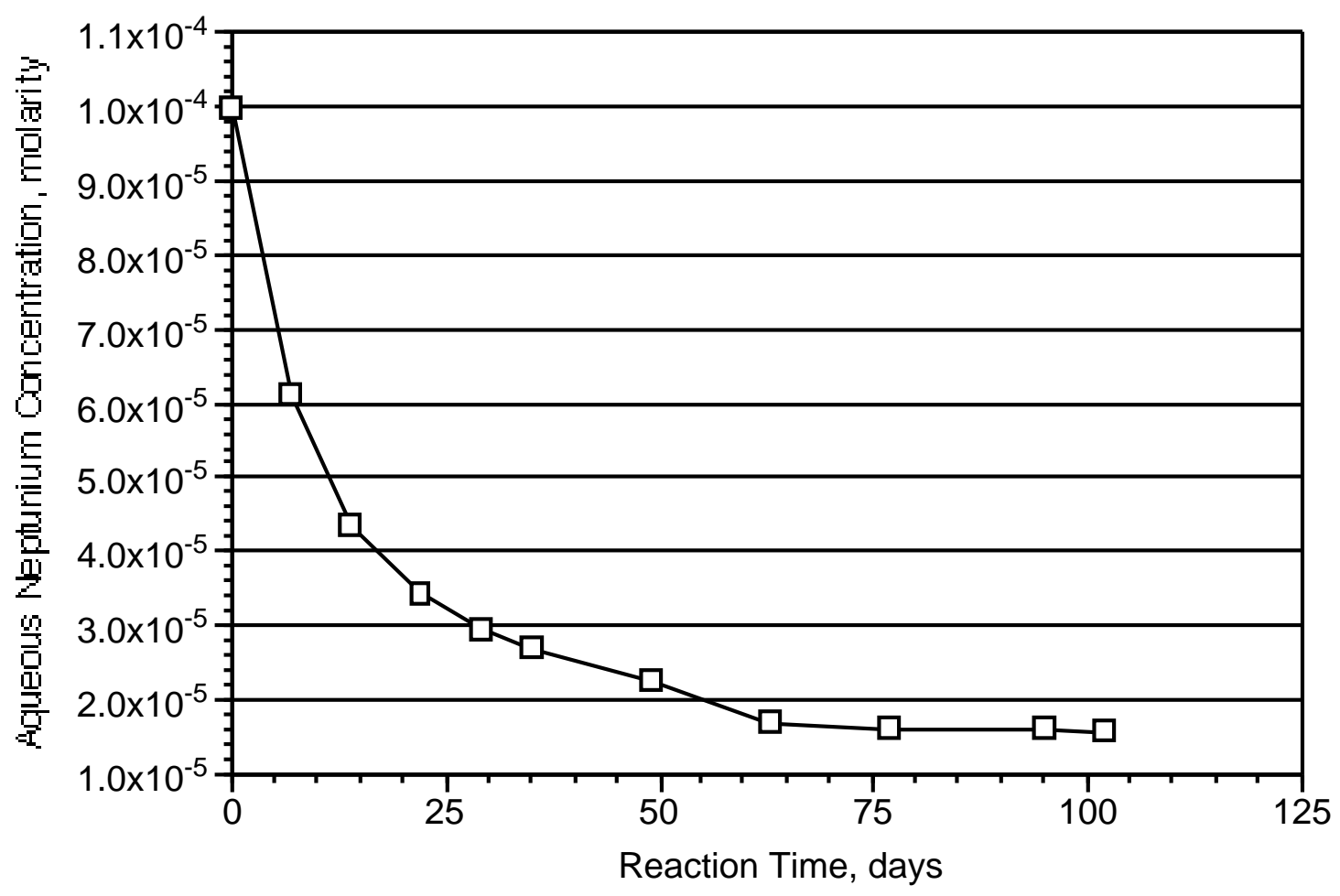

Figure 4-5. Aqueous neptunium concentrations as a function of time for the initial, larger scale experiment. 


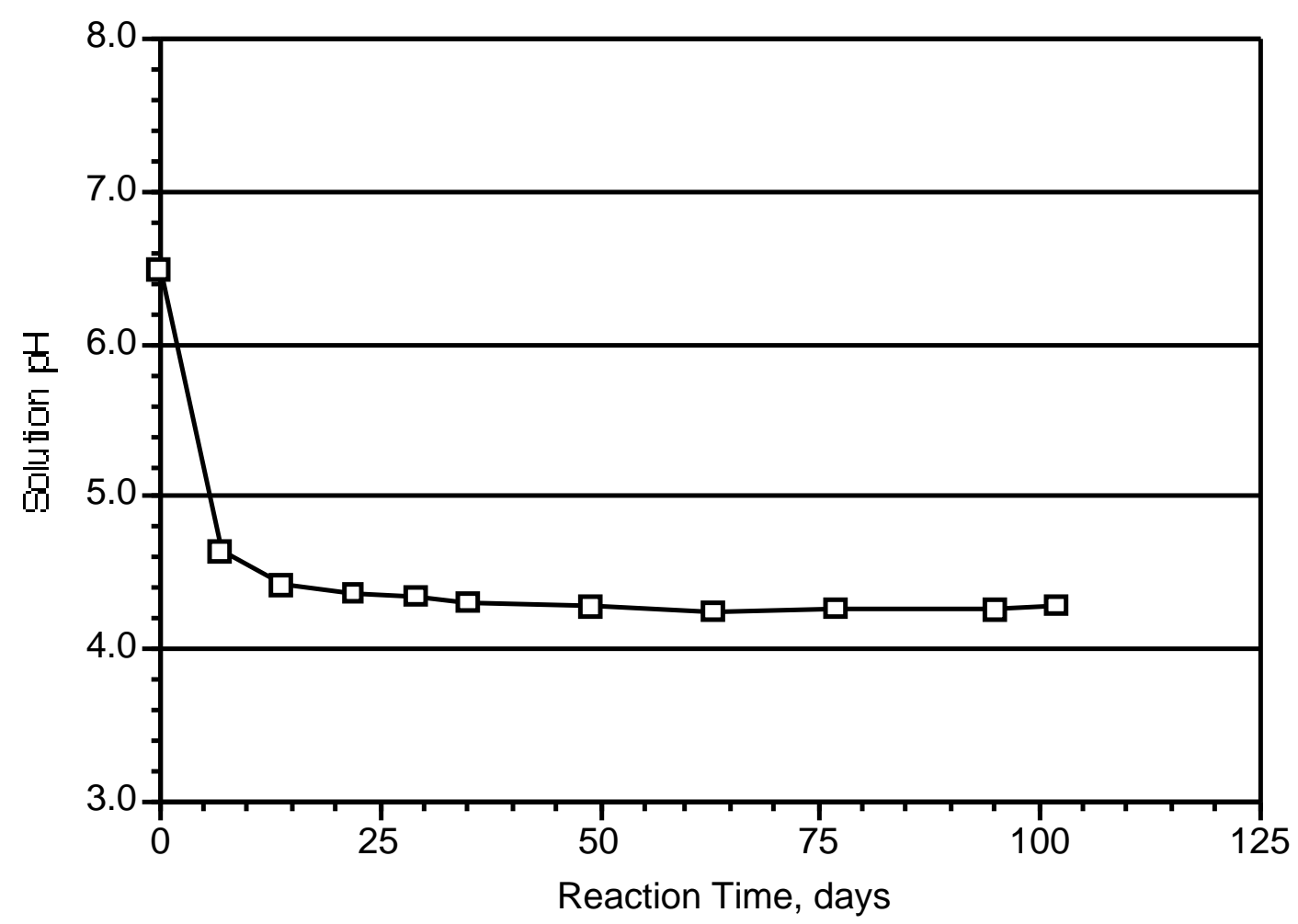

Figure 4-6. Measured $\mathrm{pH}$ as a function of time for the initial, larger scale experiment. 


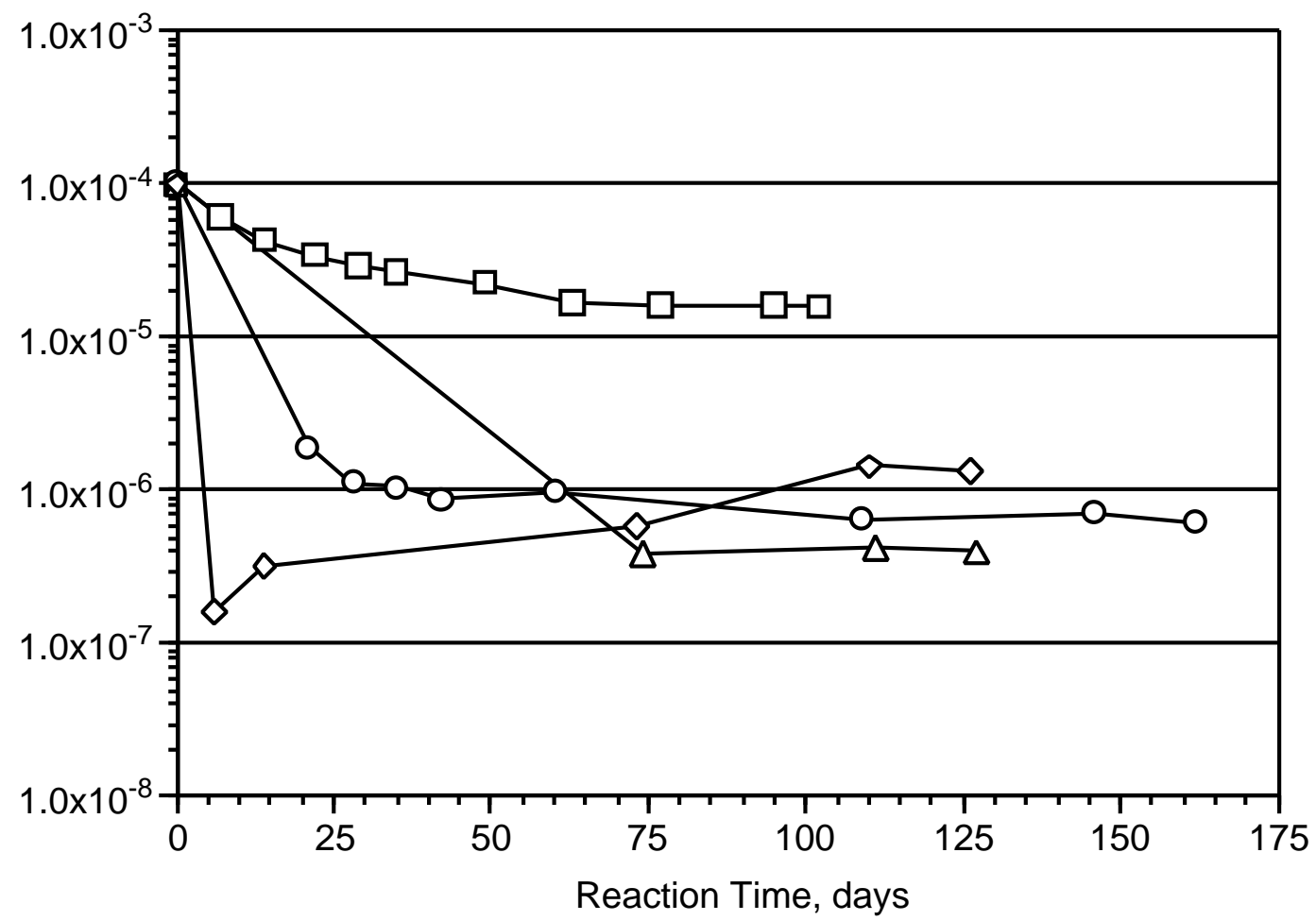

\begin{tabular}{|ll|}
\hline$\square$ & Steady state $\mathrm{pH} 4$ \\
-0 & Steady state $\mathrm{pH} 6$ \\
$-\checkmark$ & Steady state $\mathrm{pH} 7$ \\
$\multimap$ & Steady state $\mathrm{pH} 9$ \\
\hline
\end{tabular}

Figure 4-7. Aqueous neptunium concentrations as a function of time for all of the larger scale solubility experiments. 


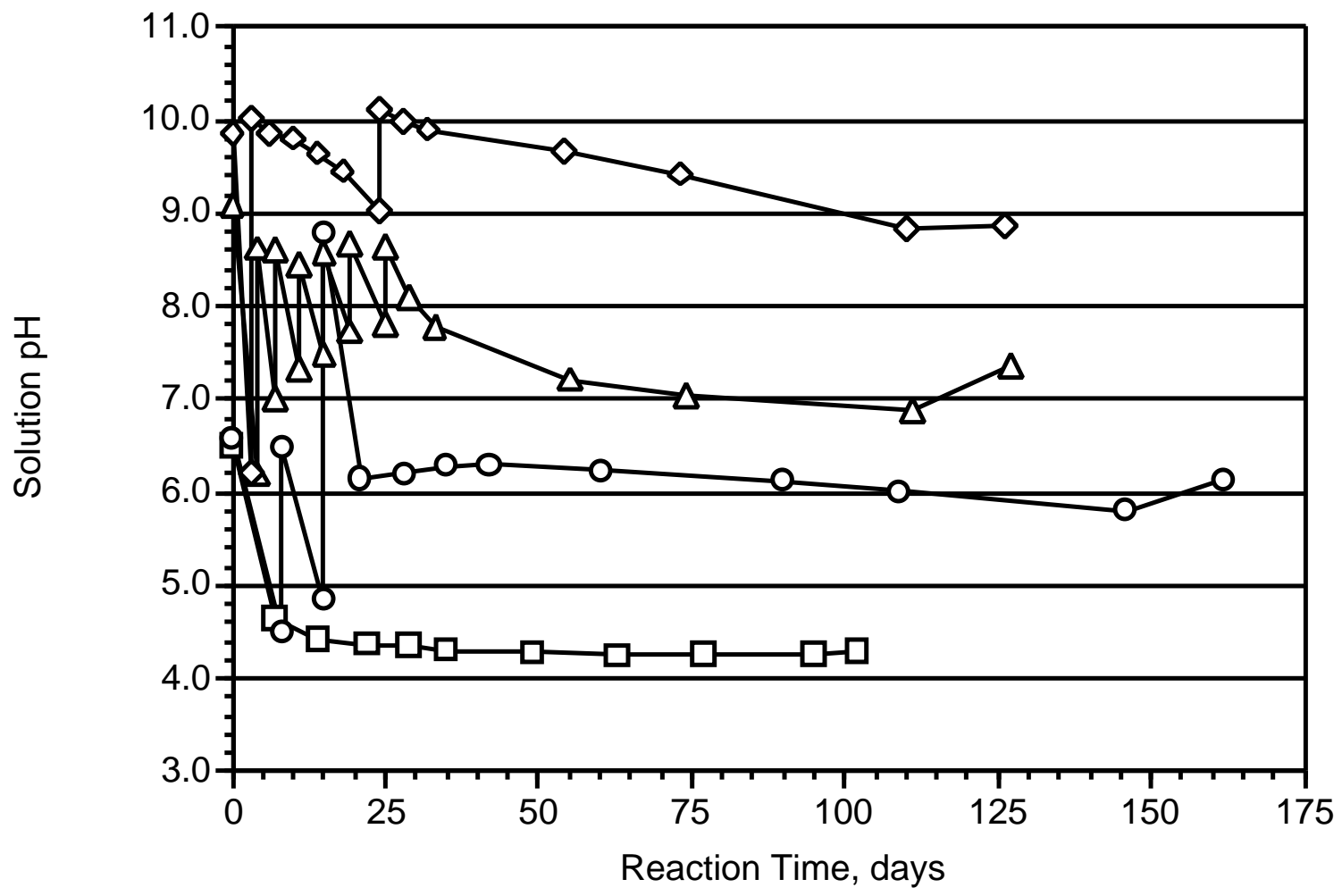

\begin{tabular}{ll}
$-\square-$ & Steady state $\mathrm{pH} 4$ \\
-0 & Steady state $\mathrm{pH} 6$ \\
$-\Delta$ & Steady state $\mathrm{pH} 7$ \\
- & Steady state $\mathrm{pH} 9$ \\
\hline
\end{tabular}

Figure 4-8. Measured $\mathrm{pH}$ as a function of time for all of the larger scale solubility experiments. 
Table 4-3. Values for the reaction time, solution $\mathrm{pH}$, and neptunium concentrations for the larger scale solubility experiments.

\begin{tabular}{|ccc|ccc|}
\hline Days & $\mathrm{pH}$ & $\begin{array}{c}\text { Np Conc. } \\
(\mathrm{M})\end{array}$ & Days & $\mathrm{pH}$ & $\begin{array}{c}\text { Np Conc. } \\
(\mathrm{M})\end{array}$ \\
\hline 0 & 6.50 & $1.000 \mathrm{E}-04$ & 0 & 6.58 & $1.045 \mathrm{E}-04$ \\
7 & 4.64 & $6.153 \mathrm{E}-05$ & 8 & 4.51 & \\
14 & 4.42 & $4.342 \mathrm{E}-05$ & 8 & 6.49 & \\
22 & 4.37 & $3.440 \mathrm{E}-05$ & 15 & 4.84 & \\
29 & 4.35 & $2.959 \mathrm{E}-05$ & 15 & 8.80 & \\
35 & 4.31 & $2.701 \mathrm{E}-05$ & 21 & 6.15 & $1.941 \mathrm{E}-06$ \\
49 & 4.28 & $2.271 \mathrm{E}-05$ & 28 & 6.20 & $1.141 \mathrm{E}-06$ \\
63 & 4.25 & $1.705 \mathrm{E}-05$ & 35 & 6.29 & $1.064 \mathrm{E}-06$ \\
77 & 4.27 & $1.634 \mathrm{E}-05$ & 42 & 6.30 & $8.761 \mathrm{E}-07$ \\
95 & 4.26 & $1.634 \mathrm{E}-05$ & 60 & 6.24 & $9.833 \mathrm{E}-07$ \\
102 & 4.29 & $1.583 \mathrm{E}-05$ & 90 & 6.12 & \\
& & & 109 & 6.01 & $6.481 \mathrm{E}-07$ \\
& & & 146 & 5.80 & $7.166 \mathrm{E}-07$ \\
& & & 162 & 6.14 & $6.255 \mathrm{E}-07$ \\
\hline
\end{tabular}

\begin{tabular}{|ccc|ccc|}
\hline Days & $\mathrm{pH}$ & $\begin{array}{c}\mathrm{Np} \text { Conc. } \\
(\mathrm{M})\end{array}$ & Days & $\mathrm{pH}$ & $\begin{array}{c}\mathrm{Np} \text { Conc. } \\
(\mathrm{M})\end{array}$ \\
\hline 0 & 9.09 & $1.000 \mathrm{E}-04$ & 0 & 9.87 & $1.000 \mathrm{E}-04$ \\
4 & 6.20 & & 3 & 6.21 & \\
4 & 8.63 & & 3 & 10.03 & \\
7 & 7.02 & & 6 & 9.86 & $1.605 \mathrm{E}-07$ \\
7 & 8.61 & & 10 & 9.81 & \\
11 & 7.34 & & 14 & 9.65 & $3.230 \mathrm{E}-07$ \\
11 & 8.45 & & 18 & 9.46 & \\
15 & 7.50 & & 24 & 9.04 & \\
15 & 8.58 & & 24 & 10.11 & \\
19 & 7.74 & & 28 & 9.99 & \\
19 & 8.67 & & 32 & 9.91 & \\
25 & 7.82 & & 54 & 9.68 & \\
25 & 8.65 & & 73 & 9.43 & $5.900 \mathrm{E}-07$ \\
29 & 8.10 & & 110 & 8.83 & $1.444 \mathrm{E}-06$ \\
33 & 7.79 & & 126 & 8.88 & $1.344 \mathrm{E}-06$ \\
55 & 7.22 & & & & \\
74 & 7.04 & $3.922 \mathrm{E}-07$ & & & \\
111 & 6.88 & $4.262 \mathrm{E}-07$ & & & \\
127 & 7.36 & $3.989 \mathrm{E}-07$ & & & \\
\hline
\end{tabular}


Table 4-4. Steady-state $\mathrm{pH}$ values and neptunium concentrations (uncertainties are one standard deviation of the averaged values).

\begin{tabular}{|cc|}
\hline$\underline{\mathrm{pH}}$ & $\underline{\text { Aqueous Np Concentration }}$ \\
$4.27 \pm 0.02$ & $(1.639 \pm 0.050) \mathrm{E}-5 \mathrm{M}$ \\
$5.98 \pm 0.17$ & $(6.634 \pm 0.474) \mathrm{E}-7 \mathrm{M}$ \\
$7.09 \pm 0.24$ & $(4.058 \pm 0.180) \mathrm{E}-7 \mathrm{M}$ \\
$8.86 \pm 0.04$ & $(1.394 \pm 0.071) \mathrm{E}-6 \mathrm{M}$ \\
\hline
\end{tabular}

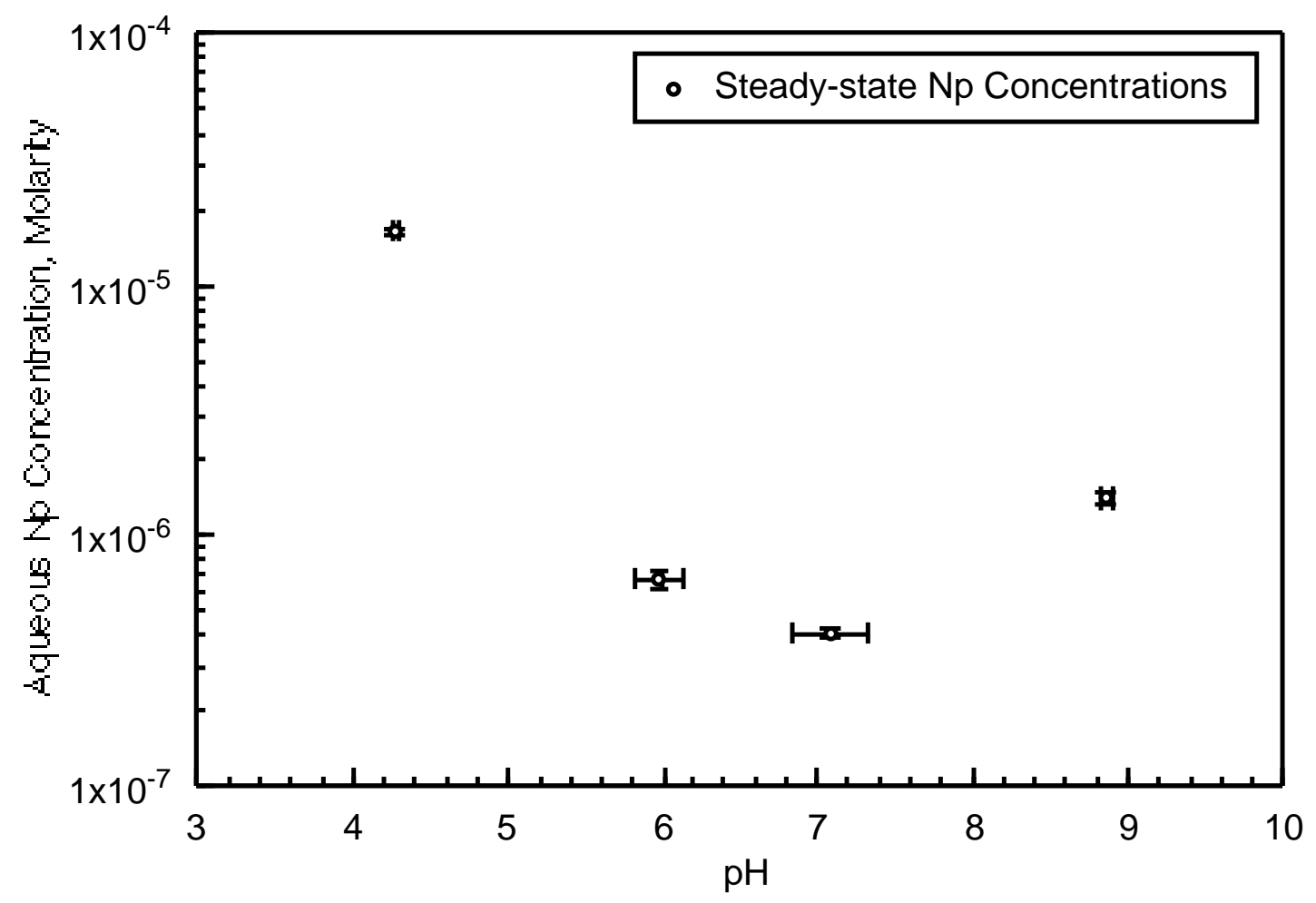

Figure 4-9. Steady-state aqueous neptunium concentrations plotted as a function of solution $\mathrm{pH}$. Uncertainties in both $\mathrm{pH}$ and neptunium concentration are shown as vertical and horizontal bars, respectively, on each of the four points. 
X-ray Powder Diffraction of the Solids Obtained in the Larger Scale Experiments

The solids that precipitated from the steady state $\mathrm{pH} 4$ experiment were the first to be collected. Again, the solution in the reaction vessel was agitated to suspend any solids before aliquots from the vessel were transferred to two $2 \mathrm{~mL}$ centrifuge tubes using disposable, plastic transfer pipettes. The tubes were centrifuged for 30 minutes, and the resulting supernatant solutions were transferred to a $40 \mathrm{~mL}$ oak ridge tube. The $2 \mathrm{~mL}$ centrifuge tubes were then filled with more of the experimental solution and again centrifuged. This was continued until all of the working solution was centrifuged. The total of the supernatant was now isolated and returned to its original titanium reaction vessel. The solids in the two centrifuge tubes were allowed to dry. The solids from both tubes were transferred to two separate quartz capillary tubes using methanol. They were allowed to dry, and each was sealed with a torch. The capillaries were decontaminated, passed out of the box into glass vials, and labeled as samples Np3 and Np3a. The solids obtained were not combined into a single capillary because there was a sufficient amount in each of the centrifuge tubes. This allowed for the preparation of two capillary samples in case one was to break upon mounting in the Debye-Scherrer camera.

Upon returning the supernatant to its titanium reaction vessel, it was noted that a brownish material was adhering to the sides of the titanium reaction vessel near where the meniscus touched the sides of the vessel. A stainless steel spatula was used to gently rub (short of scraping) the sides of the vessel while a transfer 
pipette was used to wash down the side being rubbed with working solution. Following this procedure, the total of the working solution was again sequentially centrifuged to collect more of a solid material. The solids collected in each of two centrifuge tubes were allowed to dry and were also transferred to two quartz capillary tubes using methanol. They were allowed to dry, and each was sealed with a torch. The capillaries were decontaminated, passed out of the box into glass vials, and labeled as samples Np4 and Np4a. They were then shipped to LBNL for analysis by $\mathrm{x}$-ray powder diffraction. Two capillaries were prepared because again there was enough solid material collected to do so.

A total of four solid samples, Np3, Np3a, Np4, and Np4a, were produced from the solids obtained in the solubility experiment that ended with a solution $\mathrm{pH}$ of 4. The loading of the camera was successful for samples Np3a and Np4a, so samples Np3 and Np4 were not used. The resulting powder patterns obtained for samples Np3a and Np4a can be seen in Figures 4-10 and 4-11, respectively. The films obtained had a fairly dark background, so each capillary was measured a couple of times using different preset exposure times. The results shown here were the best obtained.

Both Np3a and Np4a were measured by x-ray powder diffraction prior to the collection of any solids obtained in the three higher $\mathrm{pH}$ experiments. This was fortunate because the solid material collected from the $\mathrm{pH} 4$ experiment showed an interesting feature. Additional diffraction lines were evident that could not be attributed to crystalline neptunium dioxide. A quick search of the ICDD 
database showed that metallic titanium produced a x-ray powder diffraction pattern that accounts for the unknown lines seen in sample Np3a. Together, the patterns for $\mathrm{NpO}_{2}$ and Ti metal account for all of the diffraction lines obtained from sample Np3a. The diffraction lines associated with Ti metal were much less prominent in intensity than those produced by the $\mathrm{NpO}_{2}$ component in the solid. Therefore, the Ti component in the solid phase must be significantly smaller in abundance than the $\mathrm{NpO}_{2}$ component. The powder diffraction pattern for sample Np4a contained the same diffraction lines as those in sample Np3a. Both $\mathrm{NpO}_{2}$ and Ti metal solid phases were present. However, the intensity of the diffraction lines associated with Ti metal were significantly stronger than those for the $\mathrm{NpO}_{2}$ component in sample $\mathrm{Np} 4$ a thus indicating that Ti metal was the predominant solid material. The conclusion drawn here was that the stainless steel spatula used to gently rub down the sides of the titanium reaction vessel was a significantly harder material than the titanium itself. Thus by scraping the sides of the vessel, titanium metal was dislodged from the surface and subsequently collected with any $\mathrm{NpO}_{2}$ that was adhering to the sides.

Because the gentle rubbing of the titanium vessel with a stainless steel spatula dislodged a significant amount of the vessel itself, solid samples prepared from the three higher $\mathrm{pH}$ experiments were collected again in pairs by centrifuging the working solution (after agitating it) only. The capillaries containing the solids from the experiment with a steady-state $\mathrm{pH}$ value of 6 were labeled 992 and 992b. The capillaries containing the solids from the experiment with a steadystate $\mathrm{pH}$ value of 7 were labeled 2140 and $2140 \mathrm{~b}$. The capillaries containing the 
solids from the experiment with a steady-state $\mathrm{pH}$ value of 9 were labeled 2141 and $2141 \mathrm{~b}$. All six of the sealed capillaries were decontaminated, inspected, and shipped to LBNL. The results from the x-ray powder diffraction analysis of the solids obtained from sample 992b, sample 2140b, and sample 2141 are shown in Figures 4-12, 4-13, and 4-14, respectively.

As was the case in the previous solubility experiments, the solid material that precipitated was crystalline $\mathrm{NpO}_{2}$. In addition, no evidence of titanium metal was observed in any of the three precipitates.

As a general note, difficulties in analyzing the x-ray powder diffraction films were eliminated by using a batch of freshly obtained Kodak film. Several films obtained, even as a function of x-ray exposure time, had rather dark background levels. These high background levels are prominent in the powder diffraction films obtained for samples Np3a and especially Np4a. The unexposed film used for those measurements was several months old, and even though it had been stored wrapped and in a drawer in the darkroom, it aged such that the film developed with a significant background. New film was purchased and used for the measurement of the samples from the last three experiments. The powder diffraction films obtained had a marked improvement in the contrast between the diffraction lines and the background of the film. This can be seen clearly in the films for samples 992b, 2140b, and 2141 and the resulting intensity versus 2theta plots. 

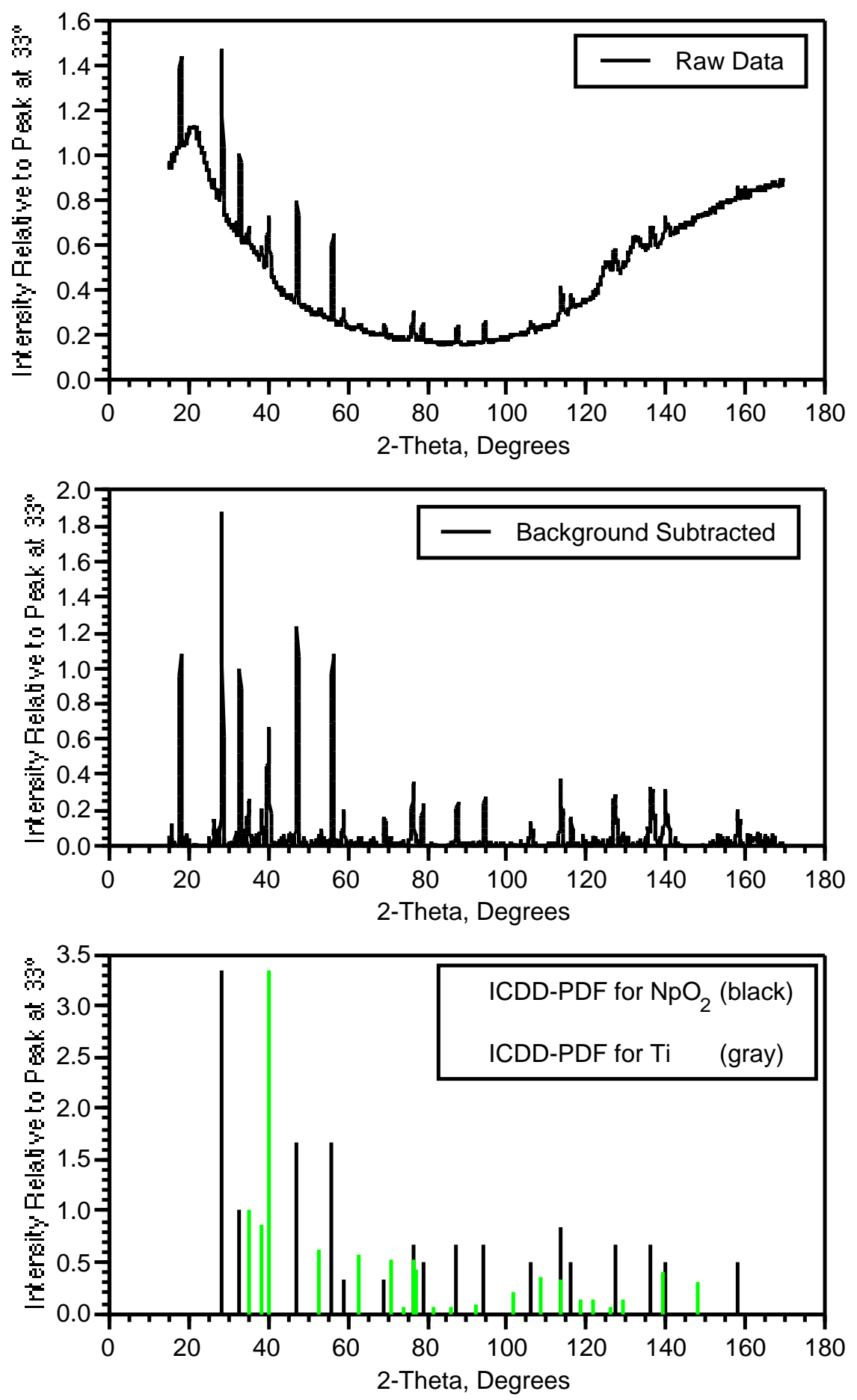

Figure 4-10. X-ray powder diffraction film and plots showing digitized intensity as a function of diffraction angle, 2-theta. 
Table 4-5. Peak identification report obtained from Jade for sample "Np3a", the solid obtained in the first larger volume $200^{\circ} \mathrm{C}$ solubility experiment, listed together with the published pattern for crystalline $\mathrm{NpO}_{2}$ and titanium metal.

USER: GENERAL

JADE: Peak ID Report

DATE: Friday, 12-04-98 @12:42p

FILE: 3A_2_2.MDI

IDEN: 3A_2_2.PCX <Camera Diameter $=114.6 \mathrm{~mm}>$

SCAN: Range=14.9848-169.9982/0.02117, Dwell=1(sec), Anode=CU, 12-04-98@12:26

FIND: Filter $=99 p$, Threshold $=3.0 \mathrm{~s}$, Cutoff $=0.01 \%, 2-$ Theta $=$ Centroid

Data Generated from Sample "Np3a"

ICDD-PDF files for $\mathrm{NpO}_{2}(\mathrm{cr})$ and Ti metal (in italics)

\begin{tabular}{|ccrl|l|lll|c|}
\hline 2-Theta & $\mathrm{d}(\mathrm{A})$ & \multicolumn{1}{l}{ I\% } & FWHM & Phase-ID & $\mathrm{d}(\mathrm{A})$ & I\% & 2-Theta & $\begin{array}{c}\text { Delta } \\
\text { 2-Theta }\end{array}$ \\
\hline & & & & & & & & \\
28.48 & 3.131 & 100 & 0.366 & $\mathrm{NpO}_{2}$ & 3.14 & 100 & 28.401 & -0.079 \\
33.012 & 2.711 & 43.2 & 0.301 & $\mathrm{NpO}_{2}$ & 2.717 & 30 & 32.939 & -0.073 \\
35.128 & 2.553 & 12.2 & 0.418 & Titanium & 2.557 & 30 & 35.066 & -0.061 \\
38.394 & 2.343 & 8.3 & 0.336 & Titanium & 2.342 & 26 & 38.404 & 0.01 \\
40.172 & 2.243 & 51.8 & 0.522 & Titanium & 2.244 & 100 & 40.153 & -0.018 \\
47.353 & 1.918 & 65.2 & 0.353 & $\mathrm{NpO}_{2}$ & 1.921 & 50 & 47.279 & -0.074 \\
52.934 & 1.728 & 4.2 & 0.366 & Titanium & 1.726 & 19 & 53.014 & 0.08 \\
56.238 & 1.634 & 56.9 & 0.368 & $\mathrm{NpO}_{2}$ & 1.638 & 50 & 56.102 & -0.136 \\
58.971 & 1.565 & 10.5 & 0.383 & $\mathrm{NpO}_{2}$ & 1.568 & 10 & 58.85 & -0.121 \\
62.903 & 1.476 & 2 & 0.274 & Titanium & 1.475 & 17 & 62.963 & 0.06 \\
69.254 & 1.356 & 7.1 & 0.351 & $\mathrm{NpO}_{2}$ & 1.358 & 10 & 69.113 & -0.142 \\
76.422 & 1.245 & 21.8 & 0.465 & Titanium & 1.247 & 16 & 76.305 & -0.117 \\
78.804 & 1.214 & 13.3 & 0.437 & $\mathrm{NpO}_{2}$ & 1.215 & 15 & 78.688 & -0.116 \\
88.132 & 1.108 & 14.9 & 0.458 & $\mathrm{NpO}_{2}$ & 1.109 & 20 & 87.996 & -0.136 \\
95.001 & 1.045 & 17.2 & 0.478 & $\mathrm{NpO}_{2}$ & 1.046 & 20 & 94.852 & -0.149 \\
106.708 & 0.96 & 8.7 & 0.516 & $\mathrm{NpO}_{2}$ & 0.961 & 15 & 106.555 & -0.153 \\
114.188 & 0.917 & 29.9 & 0.567 & Titanium & 0.918 & 10 & 114.184 & -0.005 \\
116.747 & 0.905 & 13.4 & 0.541 & $\mathrm{NpO}_{2}$ & 0.906 & 15 & 116.467 & -0.281 \\
125.473 & 0.867 & 10.5 & 0.681 & Titanium & 0.863 & 2 & 126.315 & 0.843 \\
127.516 & 0.859 & 12.8 & 0.39 & $\mathrm{NpO}_{2}$ & 0.859 & 20 & 127.46 & -0.056 \\
136.764 & 0.829 & 12.1 & 0.409 & $\mathrm{NpO}_{2}$ & 0.829 & 20 & 136.646 & -0.118 \\
140.299 & 0.819 & 12.3 & 0.394 & Titanium $^{2}$ & 0.821 & 12 & 139.51 & -0.788 \\
158.567 & 0.784 & 2.5 & 0.152 & $\mathrm{NpO}_{2}$ & 0.784 & 15 & 158.608 & 0.041 \\
& & & & & & & & \\
\hline
\end{tabular}

@End-Of-List

Average Delta 2-Theta $=0.159$ 

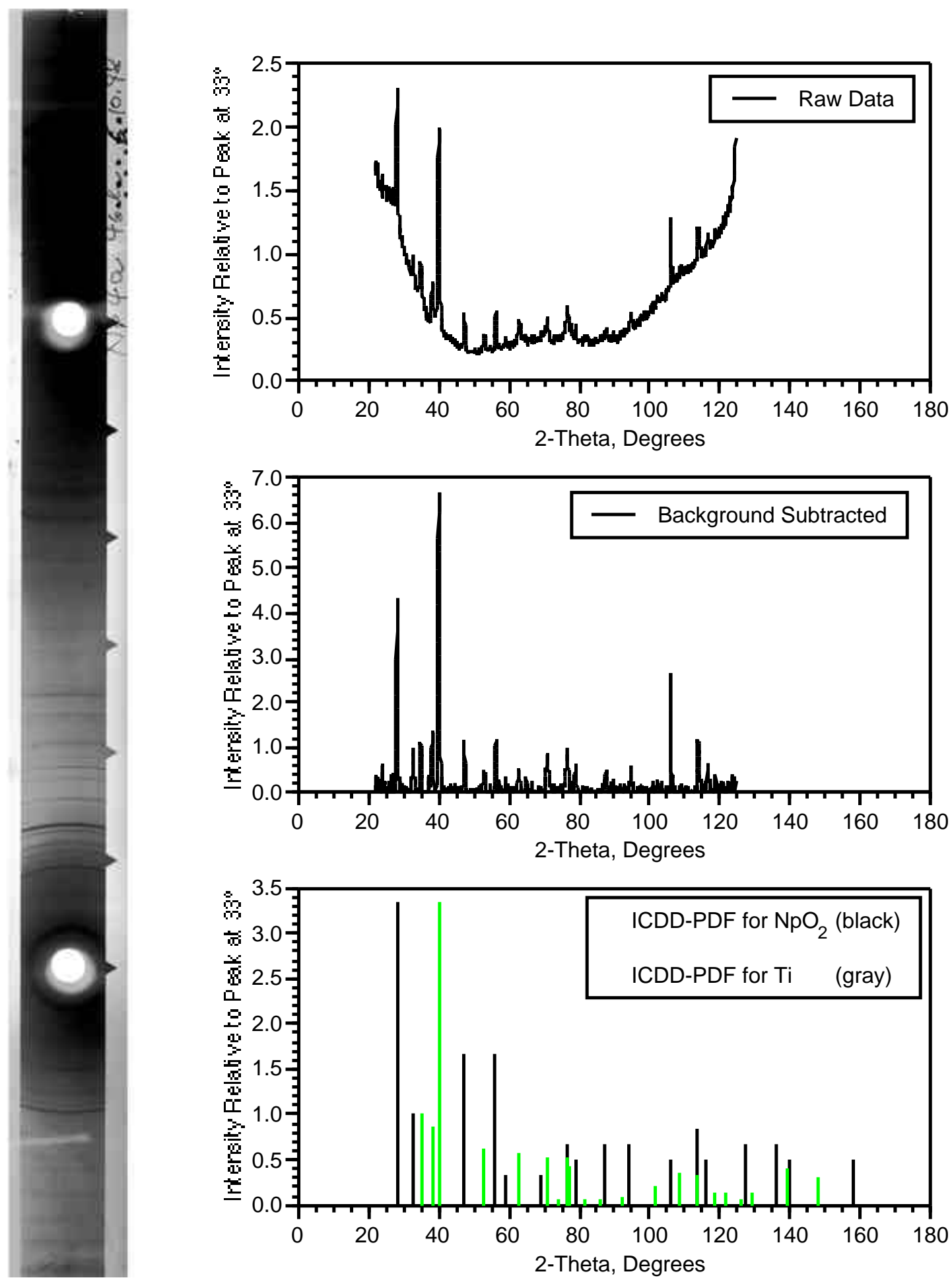

Figure 4-11. X-ray powder diffraction film and plots showing digitized intensity as a function of diffraction angle, 2-theta. 
Table 4-6. Peak identification report obtained from Jade for sample "Np4", the solid obtained in the first larger volume $200^{\circ} \mathrm{C}$ solubility experiment by rubbing the sides of the reaction vessel, listed together with the published pattern for crystalline $\mathrm{NpO}_{2}$ and titanium metal.

USER: GENERAL

JADE: Peak ID Report

DATE: Friday, 12-04-98 @02:13p

FILE: 4A_1.MDI

IDEN: 4A_1.PCX <Camera Diameter $=114.6 \mathrm{~mm}>$

SCAN: Range=21.9905-124.98/0.02117, Dwell=1(sec), Anode=CU, 12-04-98@14:00

FIND: Filter $=99 \mathrm{p}$, Threshold=3.0s, Cutoff $=1.0 \%, 2$-Theta $=$ Centroid

Data Generated from Sample "Np4a"

ICDD-PDF files for $\mathrm{NpO}_{2}(\mathrm{cr})$ and Ti metal (in italics)

\begin{tabular}{|clcl|l|lrl|c|}
\hline 2-Theta & $\mathrm{d}(\mathrm{A})$ & $\mathrm{I} \%$ & FWHM & Phase-ID & $\mathrm{d}(\mathrm{A})$ & $1 \%$ & 2-Theta & \multicolumn{1}{c|}{$\begin{array}{l}\text { Delta } \\
\text { 2-Theta }\end{array}$} \\
\hline & & & & & & & & \\
28.222 & 3.16 & 43 & 0.327 & $\mathrm{NpO}_{2}$ & 3.14 & 100 & 28.401 & 0.179 \\
32.789 & 2.729 & 9.2 & 0.362 & $\mathrm{NpO}_{2}$ & 2.717 & 30 & 32.939 & 0.15 \\
34.918 & 2.567 & 16.8 & 0.445 & Titanium & 2.557 & 30 & 35.065 & 0.147 \\
38.263 & 2.35 & 16.9 & 0.46 & Titanium & 2.342 & 26 & 38.404 & 0.141 \\
40.037 & 2.25 & 100 & 0.459 & Titanium & 2.244 & 100 & 40.152 & 0.114 \\
47.294 & 1.92 & 12.7 & 0.325 & $\mathrm{NpO}_{2}$ & 1.921 & 50 & 47.279 & -0.016 \\
52.951 & 1.728 & 8.7 & 0.509 & Titanium & 1.726 & 19 & 53.011 & 0.059 \\
56.227 & 1.635 & 14.7 & 0.382 & $\mathrm{NpO}_{2}$ & 1.638 & 50 & 56.102 & -0.125 \\
58.976 & 1.565 & 3 & 0.251 & $\mathrm{NpO}_{2}$ & 1.568 & 10 & 58.846 & -0.13 \\
62.912 & 1.476 & 10.4 & 0.529 & Titanium & 1.475 & 17 & 62.963 & 0.051 \\
70.781 & 1.33 & 12.2 & 0.535 & Titanium & 1.332 & 16 & 70.661 & -0.12 \\
76.467 & 1.245 & 12.6 & 0.486 & Titanium & 1.247 & 16 & 76.298 & -0.169 \\
77.528 & 1.23 & 10.2 & 0.247 & Titanium & 1.233 & 13 & 77.323 & -0.204 \\
78.903 & 1.212 & 4.9 & 0.306 & $\mathrm{NpO}_{2}$ & 1.215 & 15 & 78.688 & -0.214 \\
88.274 & 1.106 & 4.6 & 0.38 & $\mathrm{NpO}_{2}$ & 1.109 & 20 & 87.986 & -0.288 \\
95.142 & 1.044 & 4.4 & 0.327 & $\mathrm{NpO}_{2}$ & 1.046 & 20 & 94.852 & -0.29 \\
106.509 & 0.961 & 17.1 & 0.222 & $\mathrm{NpO}_{2}$ & 0.961 & 15 & 106.555 & 0.046 \\
114.316 & 0.917 & 14.5 & 0.457 & Titanium & 0.918 & 10 & 114.184 & -0.133 \\
116.92 & 0.904 & 3 & 0.22 & $\mathrm{NpO}_{2}$ & 0.906 & 15 & 116.467 & -0.453 \\
& & & & & & & & \\
\hline
\end{tabular}

@End-Of-List!

Average Delta 2-Theta $=0.159$ 

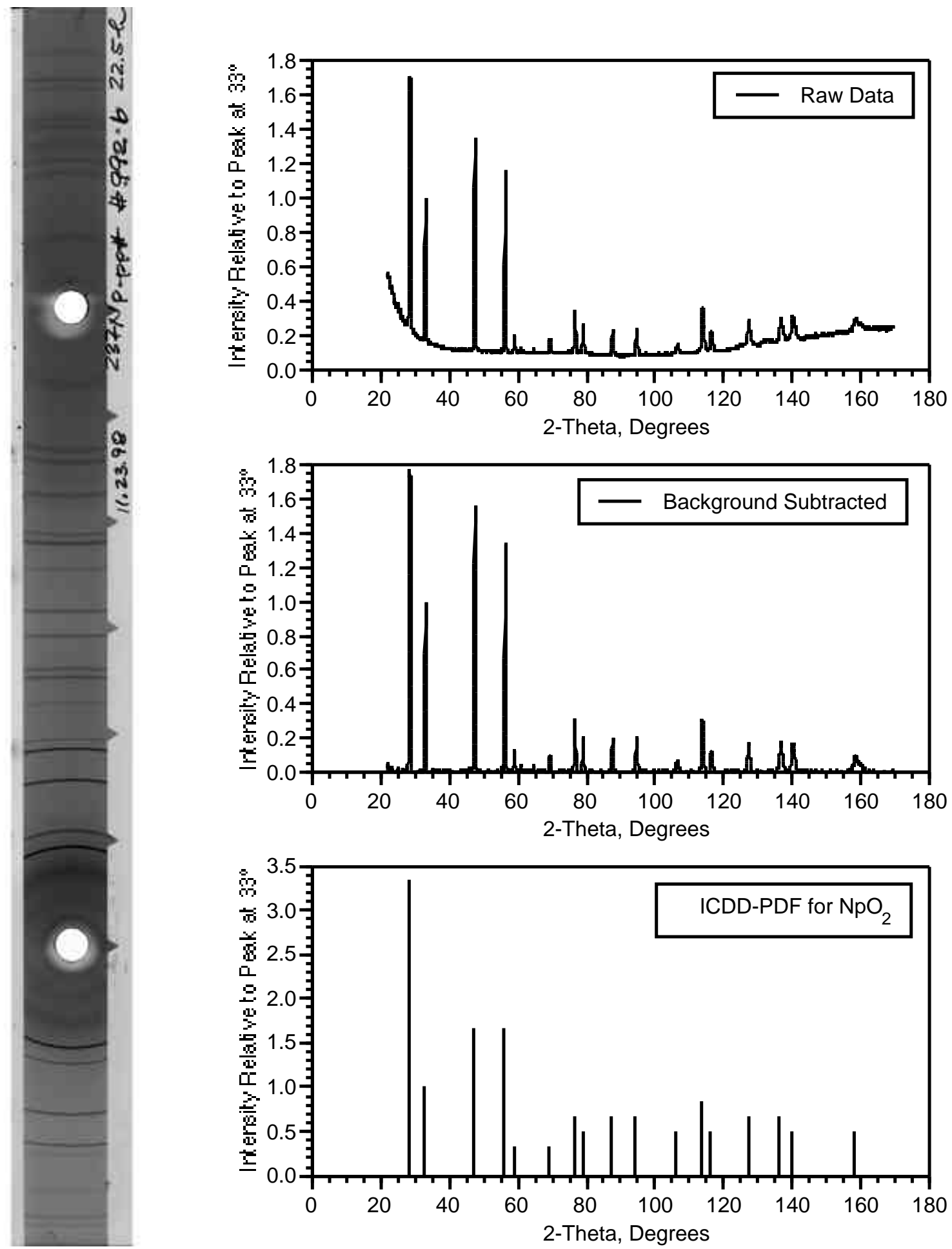

Figure 4-12. X-ray powder diffraction film and plots showing digitized intensity as a function of diffraction angle, 2-theta. 
Table 4-7. Peak identification report obtained from Jade for sample "992b", the solid obtained in the solubility experiment with a steady-state $\mathrm{pH}$ of 6 , listed together with the published pattern for crystalline $\mathrm{NpO}_{2}$.

USER: GENERAL

JADE: Peak ID Report

DATE: Friday, 12-04-98 @02:54p

FILE: SOLID2.MDI

IDEN: SOLID2.PCX <Camera Diameter $=114.6 \mathrm{~mm}>$

SCAN: Range=22.0006-169.9872/0.02117, Dwell=1(sec), Anode=CU, 12-04-98@14:46

FIND: Filter $=99 \mathrm{p}$, Threshold $=3.0 \mathrm{~s}$, Cutoff $=1.0 \%, 2$-Theta $=$ Centroid

Data Generated from Sample 992b ICDD-PDF file for $\mathrm{NpO}_{2}(\mathrm{cr})$

\begin{tabular}{|rrrl|l|lll|c|}
\hline 2-Theta & $\mathrm{d}(\mathrm{A})$ & \multicolumn{1}{l}{$\%$} & $\mathrm{FWHM}$ & Phase-ID & $\mathrm{d}(\mathrm{A})$ & $1 \%$ & 2-Theta & $\begin{array}{c}\text { Delta } \\
\text { 2-Theta }\end{array}$ \\
\hline & & & & & & & & \\
28.581 & 3.121 & 100 & 0.411 & $\mathrm{NpO}_{2}$ & 3.14 & 100 & 28.401 & -0.181 \\
33.124 & 2.702 & 35.3 & 0.264 & $\mathrm{NpO}_{2}$ & 2.717 & 30 & 32.939 & -0.185 \\
47.492 & 1.913 & 56.1 & 0.277 & $\mathrm{NpO}_{2}$ & 1.921 & 50 & 47.279 & -0.213 \\
56.332 & 1.632 & 48.6 & 0.287 & $\mathrm{NpO}_{2}$ & 1.638 & 50 & 56.102 & -0.231 \\
59.069 & 1.563 & 5.3 & 0.346 & $\mathrm{NpO}_{2}$ & 1.568 & 10 & 58.846 & -0.223 \\
69.327 & 1.354 & 4.3 & 0.34 & $\mathrm{NpO}_{2}$ & 1.358 & 10 & 69.113 & -0.215 \\
76.605 & 1.243 & 15.1 & 0.372 & $\mathrm{NpO}_{2}$ & 1.247 & 20 & 76.298 & -0.307 \\
78.979 & 1.211 & 10.3 & 0.387 & $\mathrm{NpO}_{2}$ & 1.215 & 15 & 78.688 & -0.291 \\
88.234 & 1.107 & 10.7 & 0.429 & $\mathrm{NpO}_{2}$ & 1.109 & 20 & 87.986 & -0.248 \\
95.182 & 1.043 & 10.9 & 0.437 & $\mathrm{NpO}_{2}$ & 1.046 & 20 & 94.852 & -0.329 \\
106.964 & 0.958 & 3.4 & 0.428 & $\mathrm{NpO}_{2}$ & 0.961 & 15 & 106.555 & -0.409 \\
114.395 & 0.916 & 22.4 & 0.552 & $\mathrm{NpO}_{2}$ & 0.918 & 25 & 114.087 & -0.308 \\
116.895 & 0.904 & 8.4 & 0.465 & $\mathrm{NpO}_{2}$ & 0.906 & 15 & 116.467 & -0.429 \\
127.742 & 0.858 & 10.4 & 0.518 & $\mathrm{NpO}_{2}$ & 0.859 & 20 & 127.46 & -0.282 \\
137.181 & 0.827 & 11.6 & 0.629 & $\mathrm{NpO}_{2}$ & 0.829 & 20 & 136.611 & -0.57 \\
140.57 & 0.818 & 9.7 & 0.58 & $\mathrm{NpO}_{2}$ & 0.819 & 15 & 140.276 & -0.294 \\
158.876 & 0.784 & 1.9 & 0.295 & $\mathrm{NpO}_{2}$ & 0.784 & 15 & 158.531 & -0.345 \\
& & & & & & & & \\
\hline
\end{tabular}

@End-Of-List

Average Delta 2-Theta $=0.298$ 

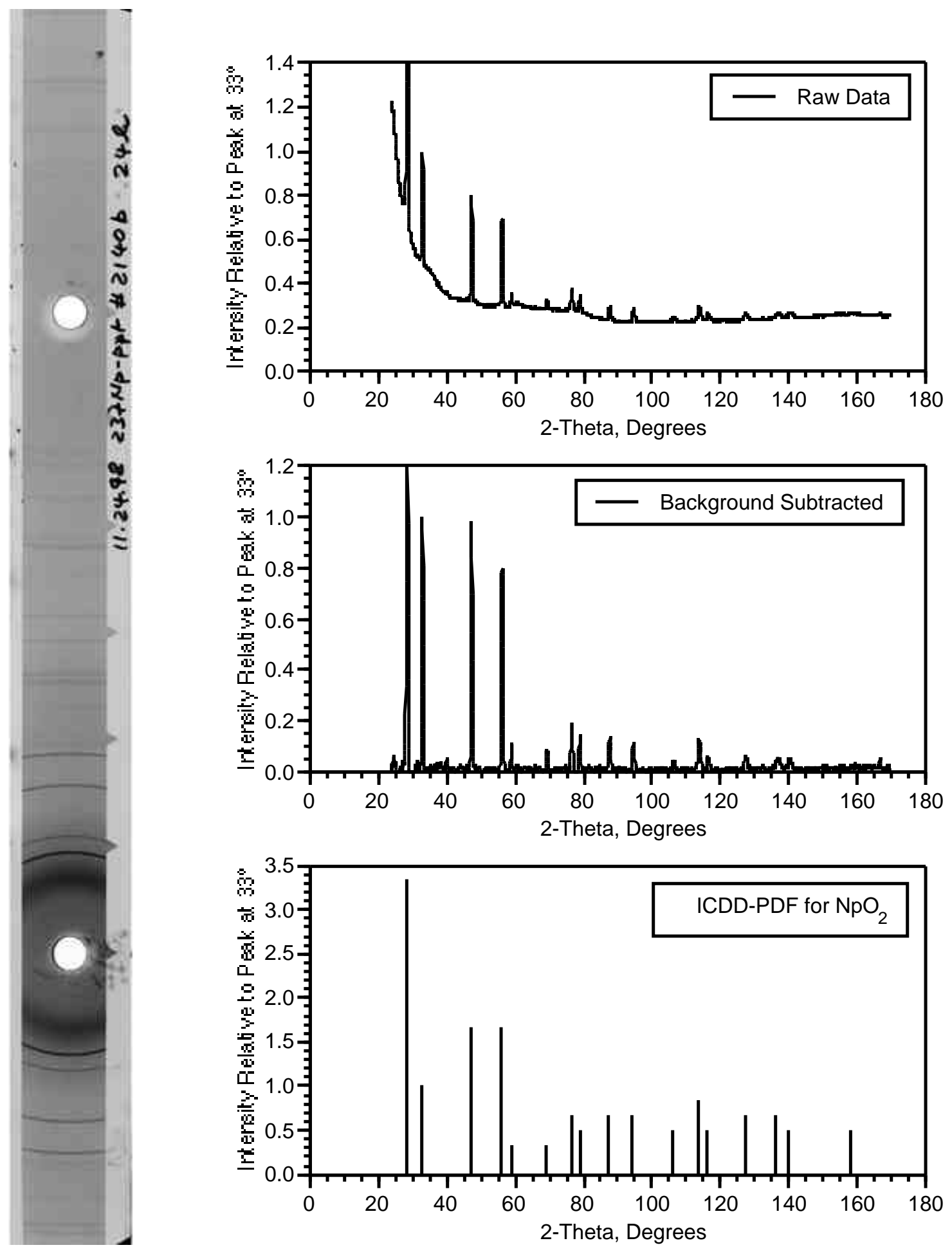

Figure 4-13. X-ray powder diffraction film and plots showing digitized intensity as a function of diffraction angle, 2-theta. 
Table 4-8. Peak identification report obtained from Jade for sample "2140b", the solid obtained in the solubility experiment with a steady-state $\mathrm{pH}$ of 7 , listed together with the published pattern for crystalline $\mathrm{NpO}_{2}$.

USER: GENERAL

JADE: Peak ID Report

DATE: Friday, 12-04-98 @03:34p

FILE: SOLID2.MDI

IDEN: SOLID2.PCX <Camera Diameter $=114.6 \mathrm{~mm}>$

SCAN: Range=23.9905-169.9876/0.02117, Dwell=1(sec), Anode=CU, 12-04-98@15:32

FIND: Filter $=99 p$, Threshold=3.0s, Cutoff $=1.0 \%$, 2-Theta $=$ Centroid

Data Generated from Sample Np2140b ICDD-PDF file for $\mathrm{NpO}_{2}(\mathrm{cr})$

\begin{tabular}{|cccl|l|lll|l|}
\hline 2-Theta & $\mathrm{d}(\mathrm{A})$ & $\mathrm{I} \%$ & FWHM & Phase-ID & $\mathrm{d}(\mathrm{A})$ & I\% & 2-Theta & $\begin{array}{c}\text { Delta } \\
\text { 2-Theta }\end{array}$ \\
\hline & & & & & & & & \\
28.459 & 3.134 & 100 & 0.291 & $\mathrm{NpO}_{2}$ & 3.14 & 100 & 28.401 & -0.058 \\
32.982 & 2.714 & 18.9 & 0.32 & $\mathrm{NpO}_{2}$ & 2.717 & 30 & 32.939 & -0.043 \\
47.348 & 1.918 & 20.5 & 0.365 & $\mathrm{NpO}_{2}$ & 1.921 & 50 & 47.279 & -0.07 \\
56.231 & 1.635 & 18.5 & 0.4 & $\mathrm{NpO}_{2}$ & 1.638 & 50 & 56.102 & -0.129 \\
59.017 & 1.564 & 1.7 & 0.281 & $\mathrm{NpO}_{2}$ & 1.568 & 10 & 58.846 & -0.171 \\
69.282 & 1.355 & 1.7 & 0.374 & $\mathrm{NpO}_{2}$ & 1.358 & 10 & 69.113 & -0.169 \\
76.5 & 1.244 & 5 & 0.469 & $\mathrm{NpO}_{2}$ & 1.247 & 20 & 76.298 & -0.202 \\
78.865 & 1.213 & 3.3 & 0.399 & $\mathrm{NpO}_{2}$ & 1.215 & 15 & 78.688 & -0.176 \\
88.182 & 1.107 & 3 & 0.456 & $\mathrm{NpO}_{2}$ & 1.109 & 20 & 87.986 & -0.196 \\
95.123 & 1.044 & 3.3 & 0.547 & $\mathrm{NpO}_{2}$ & 1.046 & 20 & 94.852 & -0.271 \\
106.871 & 0.959 & 2.7 & 0.387 & $\mathrm{NpO}_{2}$ & 0.961 & 15 & 106.555 & -0.316 \\
114.268 & 0.917 & 3 & 0.49 & $\mathrm{NpO}_{2}$ & 0.918 & 25 & 114.087 & -0.181 \\
116.773 & 0.905 & 4.9 & 0.395 & $\mathrm{NpO}_{2}$ & 0.906 & 15 & 116.467 & -0.307 \\
127.718 & 0.858 & 6.2 & 0.465 & $\mathrm{NpO}_{2}$ & 0.859 & 20 & 127.46 & -0.258 \\
136.902 & 0.828 & 0.7 & 0.13 & $\mathrm{NpO}_{2}$ & 0.829 & 20 & 136.611 & -0.29 \\
140.429 & 0.819 & 2.2 & 0.355 & $\mathrm{NpO}_{2}$ & 0.819 & 15 & 140.276 & -0.153 \\
158.622 & 0.784 & 0.1 & 0.1 & $\mathrm{NpO}_{2}$ & 0.784 & 15 & 158.531 & -0.091 \\
& & & & & & & \\
\hline
\end{tabular}

@End-Of-List!

Average Delta 2-Theta $=0.181$ 

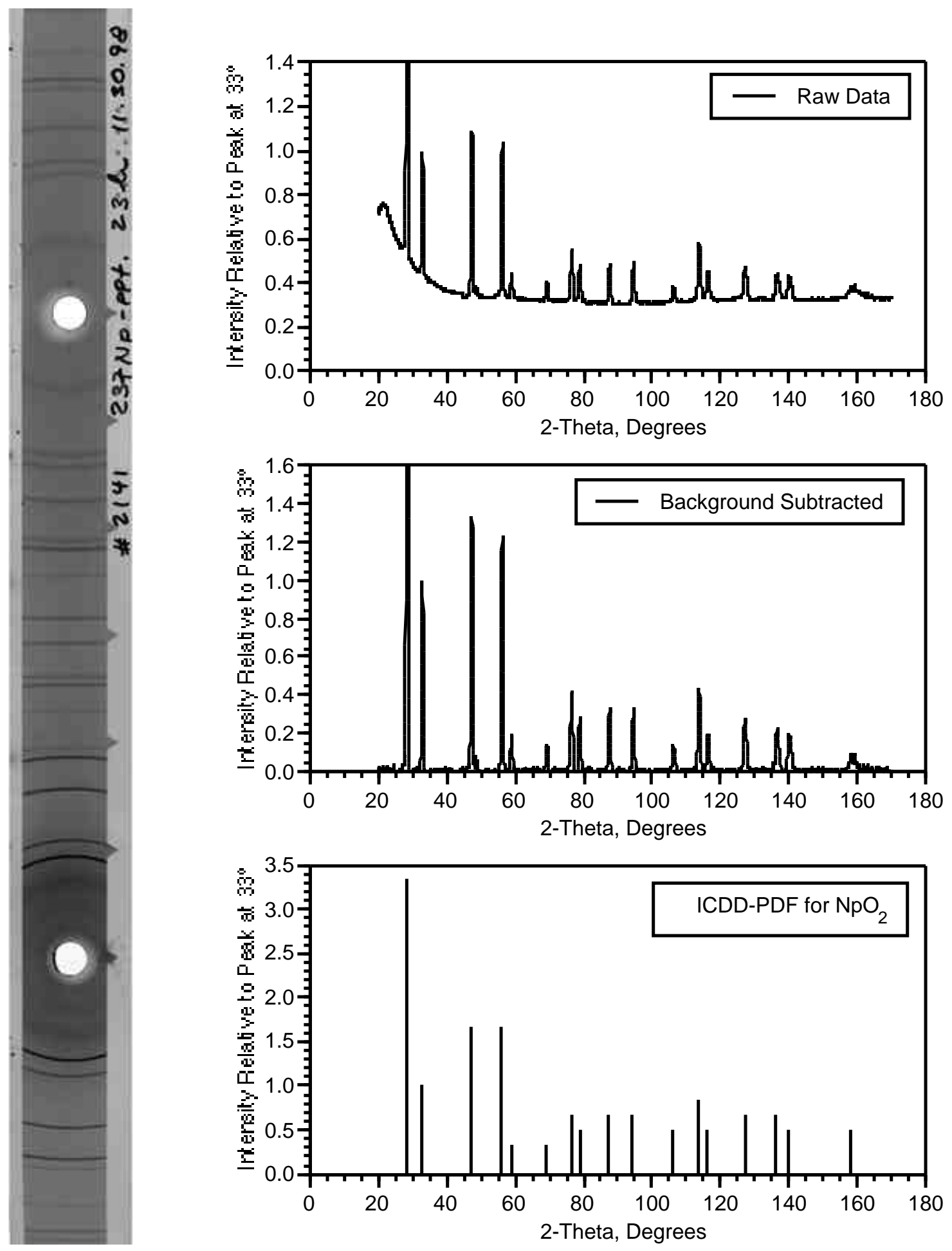

Figure 4-14. X-ray powder diffraction film and plots showing digitized intensity as a function of diffraction angle, 2-theta. 
Table 4-9. Peak identification report obtained from Jade for sample "2141", the solid obtained in the solubility experiment with a steady-state $\mathrm{pH}$ of 9 , listed together with the published pattern for crystalline $\mathrm{NpO}_{2}$.

USER: GENERAL

JADE: Peak ID Report

DATE: Friday, 12-04-98 @03:51p

FILE: 8SOLID2.MDI

IDEN: 8SOLID2.PCX <Camera Diameter $=114.6 \mathrm{~mm}>$

SCAN: Range=20.001-169.9983/0.02117, Dwell=1(sec), Anode=CU, 12-04-98@15:50

FIND: Filter $=99 \mathrm{p}$, Threshold $=3.0 \mathrm{~s}$, Cutoff $=1.0 \%$, 2-Theta $=$ Centroid

Data Generated from Sample Np2141 ICDD-PDF file for $\mathrm{NpO}_{2}$ (cr)

\begin{tabular}{|cccc|c|ccc|c|}
\hline 2-Theta & $\mathrm{d}(\mathrm{A})$ & $\mathrm{I} \%$ & $\mathrm{FWHM}$ & Phase-ID & $\mathrm{d}(\mathrm{A})$ & $\mathrm{l} \%$ & 2-Theta & $\begin{array}{c}\text { Delta } \\
\text { 2-Theta }\end{array}$ \\
\hline 28.445 & 3.135 & 100 & 0.464 & $\mathrm{NpO}_{2}$ & 3.14 & 100 & 28.401 & -0.044 \\
32.987 & 2.713 & 29.3 & 0.431 & $\mathrm{NpO}_{2}$ & 2.717 & 30 & 32.939 & -0.048 \\
47.367 & 1.918 & 40.1 & 0.441 & $\mathrm{NpO}_{2}$ & 1.921 & 50 & 47.279 & -0.088 \\
56.225 & 1.635 & 39.8 & 0.465 & $\mathrm{NpO}_{2}$ & 1.638 & 50 & 56.102 & -0.123 \\
58.966 & 1.565 & 6.6 & 0.508 & $\mathrm{NpO}_{2}$ & 1.568 & 10 & 58.846 & -0.12 \\
69.266 & 1.355 & 4.6 & 0.489 & $\mathrm{NpO}_{2}$ & 1.358 & 10 & 69.113 & -0.153 \\
76.501 & 1.244 & 14.7 & 0.532 & $\mathrm{NpO}_{2}$ & 1.247 & 20 & 76.298 & -0.203 \\
78.884 & 1.212 & 10.2 & 0.523 & $\mathrm{NpO}_{2}$ & 1.215 & 15 & 78.688 & -0.196 \\
88.155 & 1.107 & 11.9 & 0.561 & $\mathrm{NpO}_{2}$ & 1.109 & 20 & 87.986 & -0.168 \\
95.091 & 1.044 & 12.4 & 0.549 & $\mathrm{NpO}_{2}$ & 1.046 & 20 & 94.852 & -0.238 \\
106.817 & 0.959 & 4.1 & 0.528 & $\mathrm{NpO}_{2}$ & 0.961 & 15 & 106.555 & -0.262 \\
114.293 & 0.917 & 19.6 & 0.672 & $\mathrm{NpO}_{2}$ & 0.918 & 25 & 114.087 & -0.205 \\
116.84 & 0.904 & 9.4 & 0.678 & $\mathrm{NpO}_{2}$ & 0.906 & 15 & 116.467 & -0.373 \\
127.656 & 0.858 & 10.4 & 0.663 & $\mathrm{NpO}_{2}$ & 0.859 & 20 & 127.46 & -0.196 \\
137.035 & 0.828 & 8 & 0.696 & $\mathrm{NpO}_{2}$ & 0.829 & 20 & 136.611 & -0.424 \\
140.483 & 0.818 & 6.5 & 0.625 & $\mathrm{NpO}_{2}$ & 0.819 & 15 & 140.276 & -0.207 \\
158.595 & 0.784 & 1.4 & 0.437 & $\mathrm{NpO}_{2}$ & 0.784 & 15 & 158.531 & -0.064 \\
& & & & & & & & \\
\hline
\end{tabular}

@End-Of-List!

Average Delta 2-Theta $=0.183$ 


\section{$\underline{\text { X-ray Absorption Spectroscopy (XAS) }}$}

Following the successful x-ray powder diffraction analysis of sample Np3a, capillary Np3 was shipped from LBNL to the Stanford Synchrotron Radiation Laboratory (SSRL) for examined by x-ray absorption spectroscopy. Efforts were made to measure the sample with two x-ray absorption spectroscopic techniques, both x-ray absorption near edge spectroscopy (XANES) and extended x-ray absorption fine structure (EXAFS) spectroscopy. Measurements of sample Np3 were made simultaneously with reference materials of crystalline $\mathrm{NpO}_{2}$ solid and the aqueous dioxo-neptunium(V) cation, $\mathrm{NpO}_{2}{ }^{+}$.

\section{$\underline{\text { X-ray Absorption Near Edge Spectroscopy (XANES) }}$}

Figure 4-15 shows the neptunium $L_{\text {III }} x$-ray absorption near edge structure for the aqueous dioxo-neptunium(V) cation, $\mathrm{NpO}_{2}^{+}$, (dashed line), crystalline

neptunium(IV) dioxide, $\mathrm{NpO}_{2}$ (solid line), and the solid material obtained in the solubility experiment with a steady-state $\mathrm{pH}$ of 4 (dotted line). Feature "A" in Figure 4-15 is characteristic of the aqueous $\mathrm{NpO}_{2}{ }^{+}$cation and is a result of a multiple scattering effect within the diaxial oxygen atoms that are bound to a central neptunium(V) ion. The XANES of sample Np3 (dotted line) lacks feature "A" and closely resembles the XANES for crystalline $\mathrm{NpO}_{2}$ (solid line). This match indicates that the solid is composed of primarily, at least $85 \%$, crystalline or amorphous neptunium(IV) dioxide. 


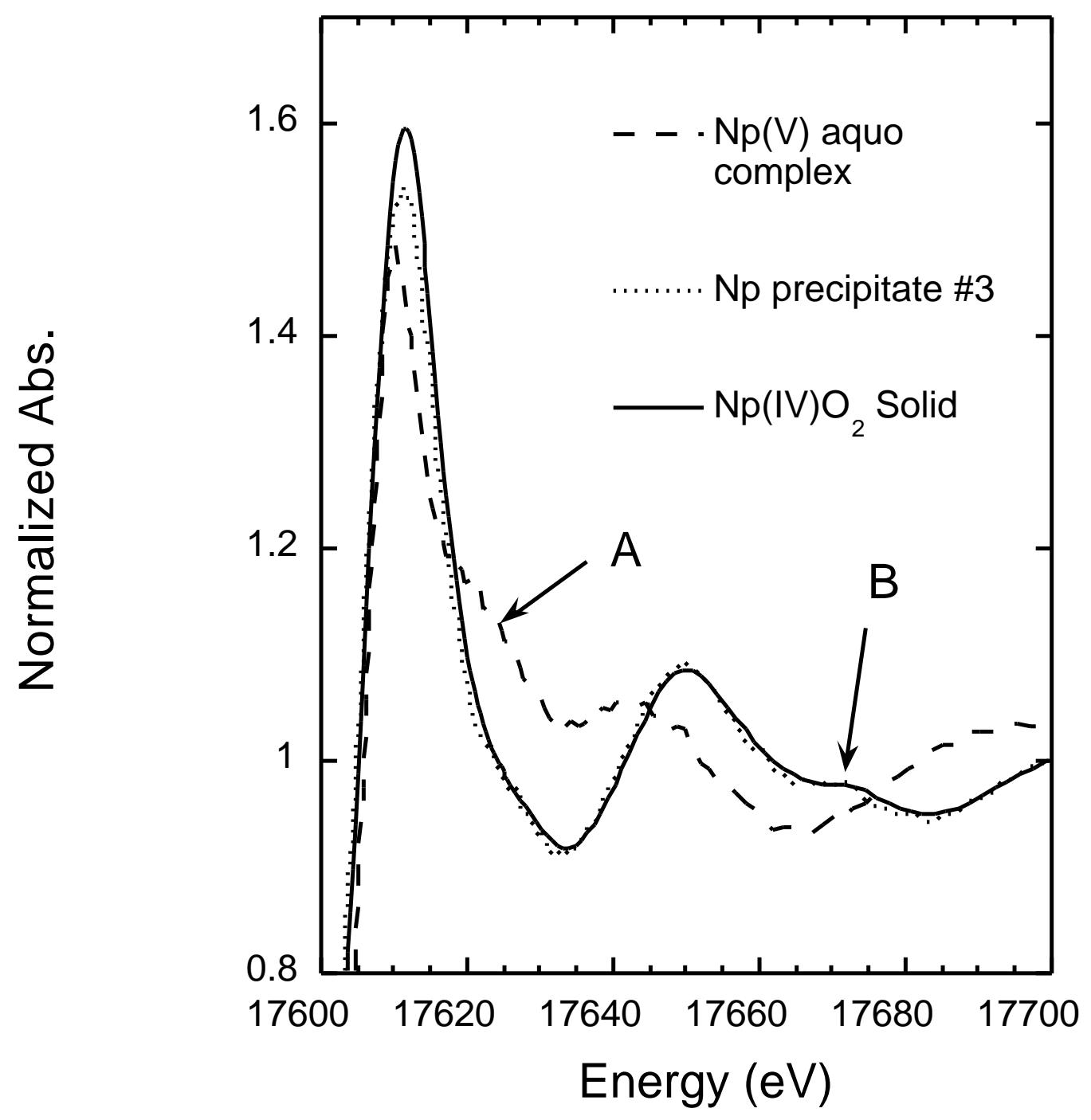

Figure 4-15. The neptunium $\mathrm{L}_{\mathrm{III}} \mathrm{x}$-ray absorption near edge structure for the aqueous dioxo-neptunium $(\mathrm{V})$ cation, $\mathrm{NpO}_{2}^{+}$, (dashed line), crystalline neptunium(IV) dioxide, $\mathrm{NpO}_{2}$, (solid line), and the solid material obtained in the solubility experiment at $\mathrm{pH} 4$ (dotted line). 


\section{Extended X-ray Absorption Fine Structure (EXAFS)}

Figure 4-16 shows the neptunium $\mathrm{L}_{\mathrm{III}}$ extended $\mathrm{x}$-ray absorption fine structure for crystalline neptunium(IV) dioxide, $\mathrm{NpO}_{2}$, (solid line) and the solid material from the solubility experiment at $\mathrm{pH} 4$ (dotted line) at the top of the plot. At the bottom of the plot is the neptunium $\mathrm{L}_{\mathrm{III}}$ extended $\mathrm{x}$-ray absorption fine structure for the aqueous dioxo-neptunium(V) cation, $\mathrm{NpO}_{2}{ }^{+}$, (also a solid line). Fourier transforms are shifted to a lower $\mathrm{R}$ value because of EXAFS phase shifts. There is a strong correspondence in the $\mathrm{Np}-\mathrm{O}$ and $\mathrm{Np}-\mathrm{Np}$ peak positions, or nearest neighbor bond distances, and their resulting amplitudes when comparing the EXAFS results for the reference $\mathrm{NpO}_{2}$ solid and the precipitate obtained in our experiment. This correspondence indicates that the material in sample Np3 has very similar, if not the same, local structure as that of solid $\mathrm{NpO}_{2}$. 


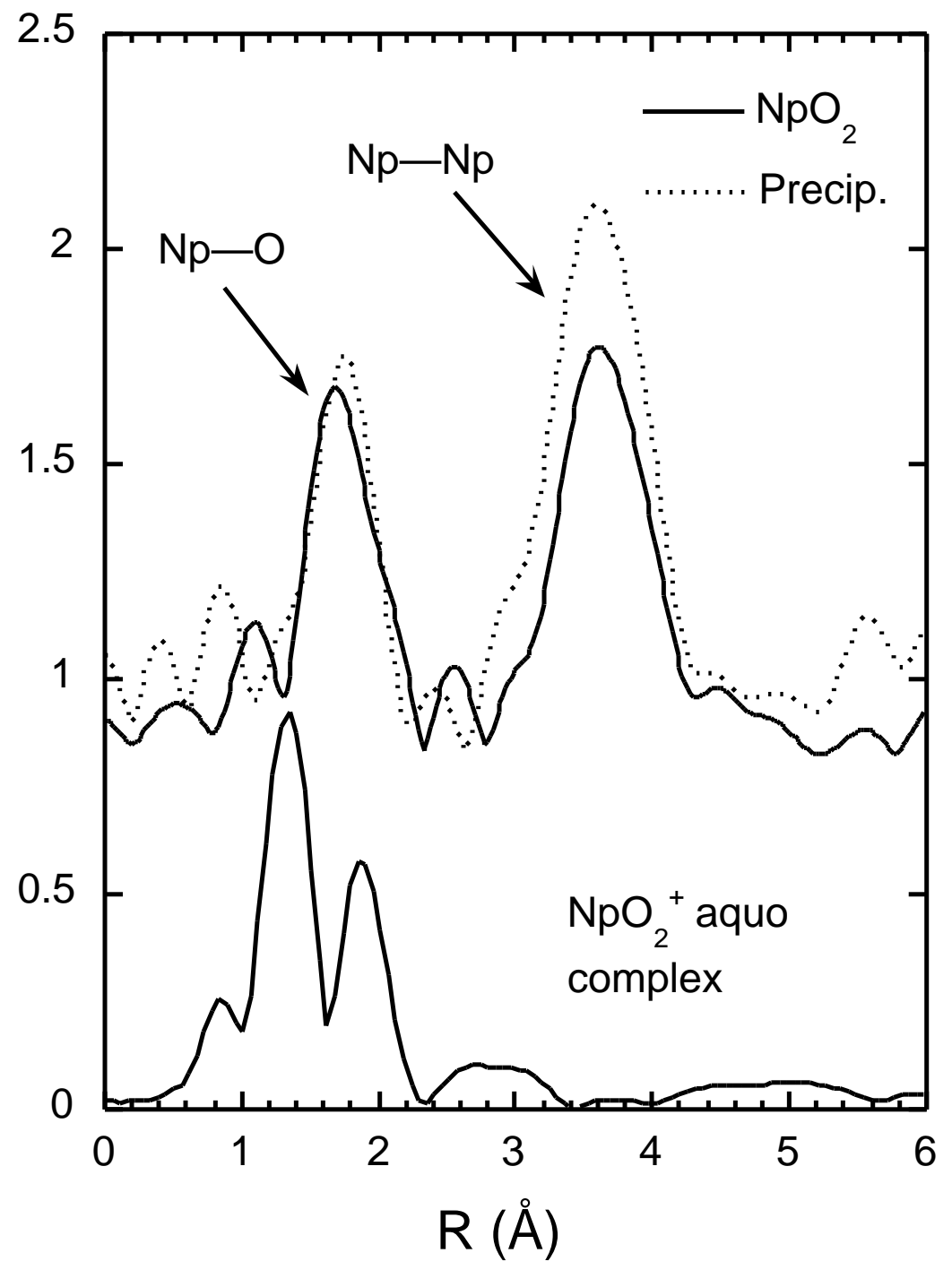

Figure 4-16. The neptunium $\mathrm{L}_{\mathrm{III}}$ extended $\mathrm{x}$-ray absorption fine structure for crystalline neptunium(IV) dioxide, $\mathrm{NpO}_{2}$ (solid line) and the solid material from our experiment (dotted line) are shown at the top of the plot. Also shown in the plot (bottom, solid line) is the neptunium $\mathrm{L}_{\mathrm{III}}$ extended $\mathrm{x}$-ray absorption fine structure for the aqueous dioxo-neptunium(V) cation, $\mathrm{NpO}_{2}{ }^{+}$. 


\section{$\underline{\text { Scanning Electron Microscopy }}$}

After successfully examining the solids by x-ray powder diffraction, capillaries Np3, Np3a, Np4, and Np4a were shipped to Argonne National Laboratory (ANL) for examination by scanning electron microscopy (SEM) by Robert Finch. Analysis by SEM was performed last because the capillaries had to be broken open to expose the material for a direct examination. This prevented any further examination by $\mathrm{x}$-ray powder diffraction or x-ray absorption spectroscopy.

The first two SEM micrographs obtained, Figures 4-17 and 4-18, were of the solid contained in capillary number Np4a. Capillary 4a was placed directly on sticky tape on an aluminum mount and broken open so the solids would spill directly onto the tape. The sample was not coated at first to ensure that no material was lost. It was noted that there were far more particles of titanium than there were of $\mathrm{NpO}_{2}$. This observation agreed with the x-ray powder diffraction results in that the solid material contained in sample Np4a consisted predominantly of titanium metal with a smaller portion of $\mathrm{NpO}_{2}$. Preliminary, qualitative EDS measurements indicated that several of the $\mathrm{NpO}_{2}$ particles were chemically homogenous. The particles were sub-micron agglomerates of small grains of $\mathrm{NpO}_{2}$, and the small grains were at or below the resolution of the instrument. Sample analysis of this material was halted so that a sample with less titanium contamination could be examined. According to Robert Finch, the instrument was being temperamental and the two resulting micrographs were not of the highest quality. 
However, the next series of micrographs, Figures 4-19 through 4-30, were obtained from the solids contained in capillary number Np3a. The first observation was that two forms of $\mathrm{NpO}_{2}$ were present. One form was a flattened type of solid material characterized by Robert Finch as "pancake-like" in structure. Often, the flattened solids were stacked together, many with submicron crystals appearing on one side. Others had surfaces that were smooth at the SEM level of resolution. The other form observed was that of particles or clusters of octahedra. The octahedra ranged in size from submicron to several microns in length, with the majority being of the smaller sizes. Many of the crystals were near perfect octahedral crystals, whereas others showed various imperfections such as near perfect crystals with intergrowths on one or more of the crystal faces.

According to C.B. Finch and G.W. Clark ${ }^{45}$ the structure of crystalline neptunium(IV) dioxide takes on one of two forms of the fluorite structure, cubic or octahedral, depending on the level of impurities contained within the crystal lattice. In their publication, they report on the formation of crystalline neptunium dioxide from "high temperature solutions." In their case, high temperature solutions meant $\mathrm{PbF}_{3}-\mathrm{B}_{2} \mathrm{O}_{3}-\mathrm{NpO}_{2}$ and $\mathrm{Li}_{2} \mathrm{O}-\mathrm{MoO}_{3}-\mathrm{NpO}_{2}$ solutions at $1250-1350^{\circ} \mathrm{C}$ in contrast to this work in aqueous solution at $200^{\circ} \mathrm{C}$. Neptunium dioxide that formed from solutions of $\mathrm{PbF}_{3}-\mathrm{B}_{2} \mathrm{O}_{3}-\mathrm{NpO}_{2}$ took on a cubic (100) growth habit, whereas, the neptunium dioxide that formed from solutions of $\mathrm{Li}_{2} \mathrm{O}-\mathrm{MoO}_{3}-\mathrm{NpO}_{2}$ took on an octahedral (111) growth habit. The authors attributed this difference in habit formation to the level of impurities contained 
within the fluorite structure of the $\mathrm{NpO}_{2}$ that formed. In the case of the $\mathrm{PbF}_{3}$ $\mathrm{B}_{2} \mathrm{O}_{3}-\mathrm{NpO}_{2}$ solution growth of $\mathrm{NpO}_{2}$, levels of contaminant $\mathrm{Pb}$ and $\mathrm{B}$ were on the order of 1000 and $200 \mathrm{PPM}$, respectively. In the case of the $\mathrm{Li}_{2} \mathrm{O}-\mathrm{MoO}_{3}-\mathrm{NpO}_{2}$ solution growth of $\mathrm{NpO}_{2}$, levels of contaminant Mo and Li were on the order of 10 and 2 PPM, respectively. The octahedral growth habit was therefore attributed to the growth of the relative pure form of the $\mathrm{NpO}_{2}$.

With the octahedral habit of the fluorite structure being associated with highpurity crystals of $\mathrm{NpO}_{2}$, it was surprising to find that the solids obtained in these precipitation experiments, aqueous solutions of initially $\mathrm{Np}(\mathrm{V})$ heated to only $200^{\circ} \mathrm{C}$, took on the high-purity, octahedral form. 




Figure 4-17. Scanning electron micrograph of the solid Np4a from the larger scale experiment with a steady-state $\mathrm{pH}$ of 4 . 


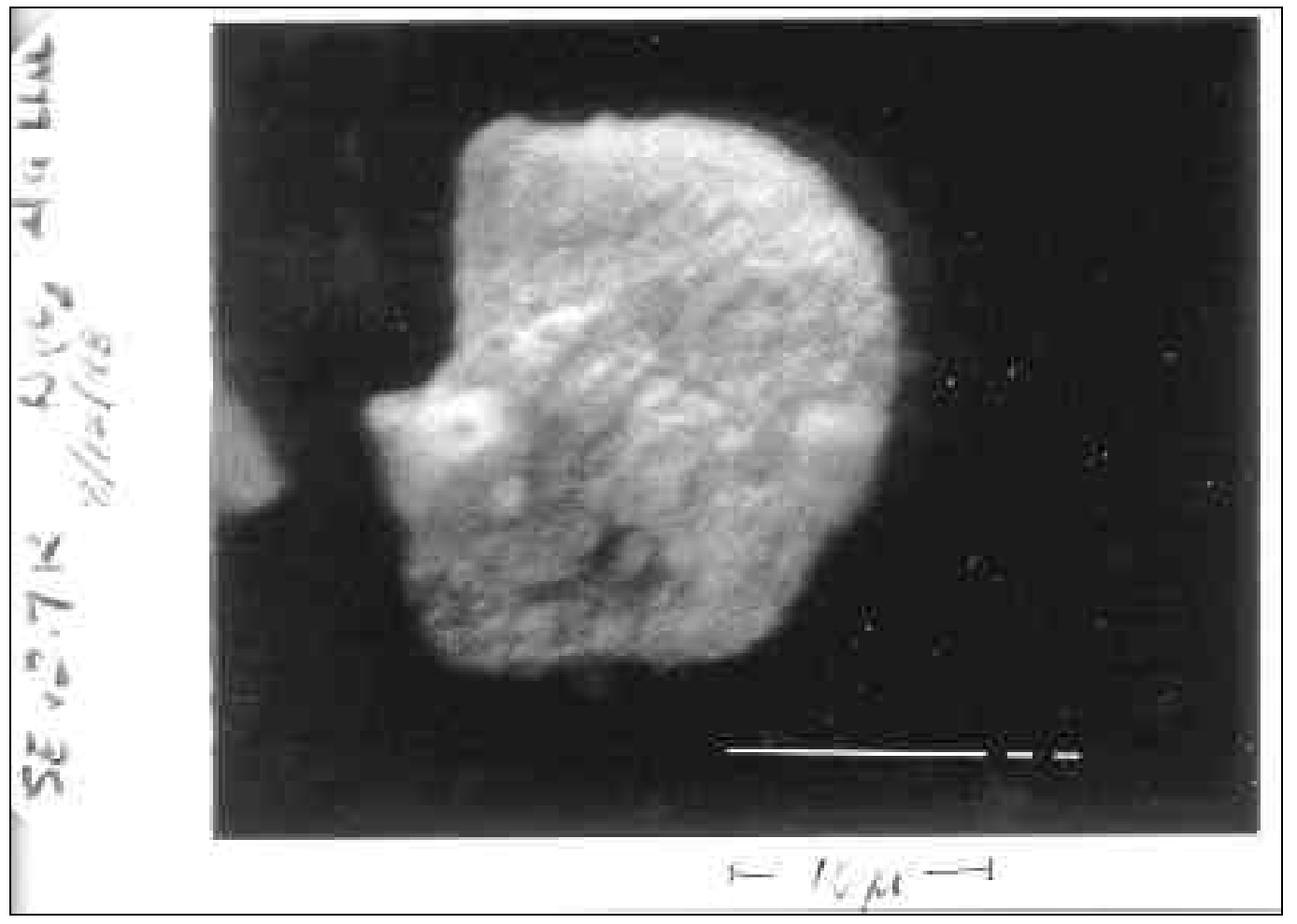

Figure 4-18. Scanning electron micrograph of the solid Np4a from the larger scale experiment with a steady-state $\mathrm{pH}$ of 4 . 




Figure 4-19. Scanning electron micrograph of the solid Np3a from the larger scale experiment with a steady-state $\mathrm{pH}$ of 4 . 


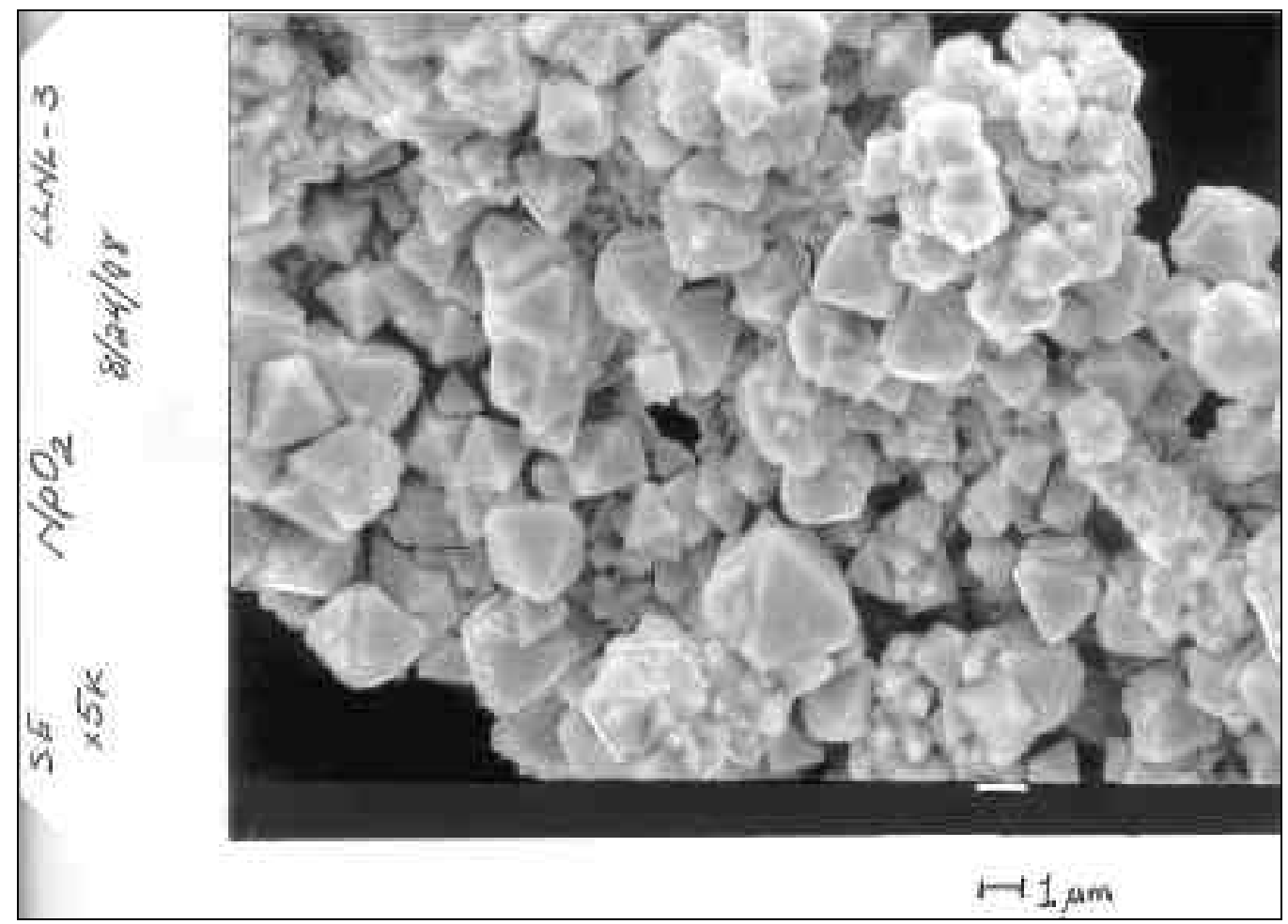

Figure 4-20. Scanning electron micrograph of the solid Np3a from the larger scale experiment with a steady-state $\mathrm{pH}$ of 4 . 


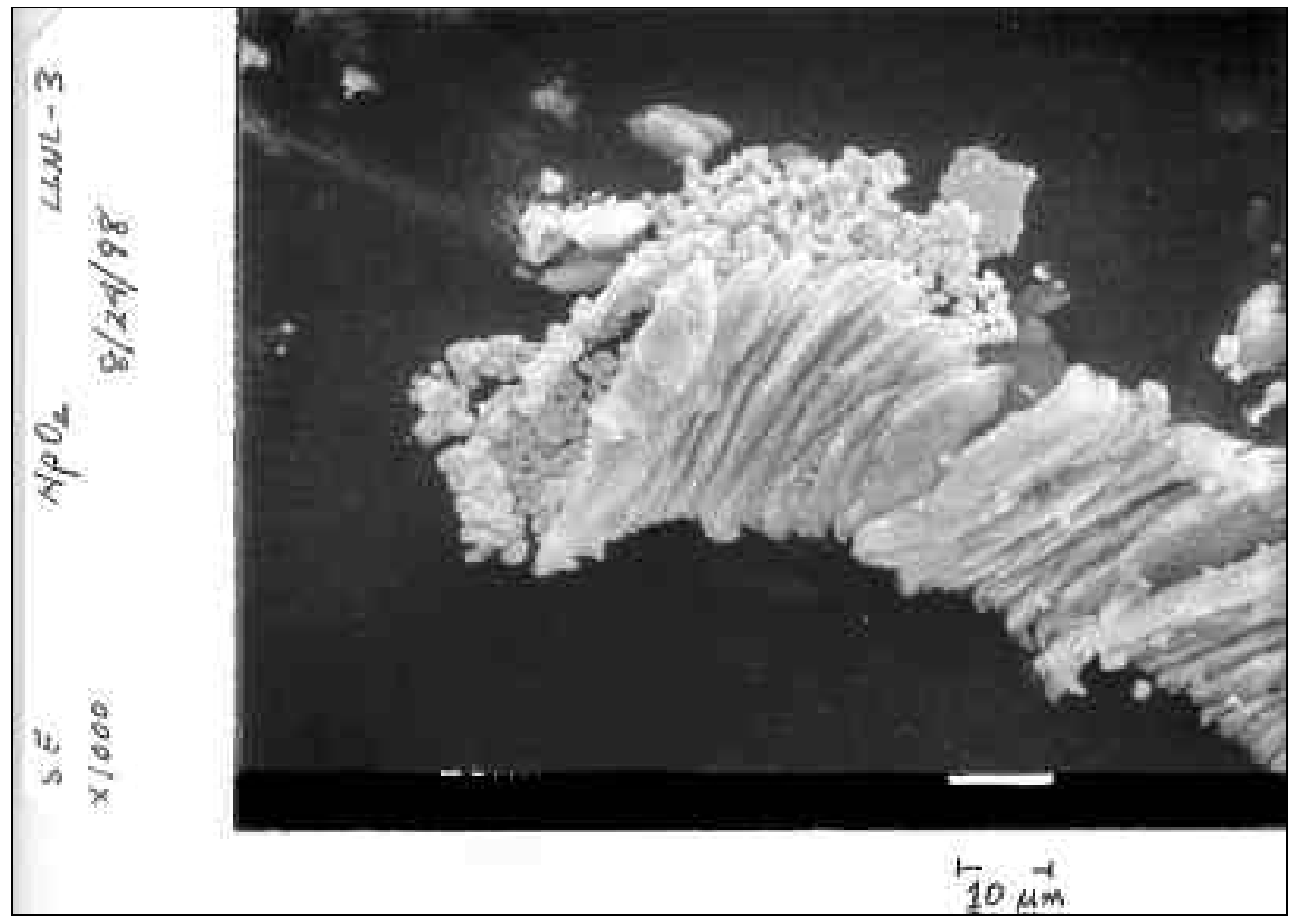

Figure 4-21. Scanning electron micrograph of the solid Np3a from the larger scale experiment with a steady-state $\mathrm{pH}$ of 4 . 


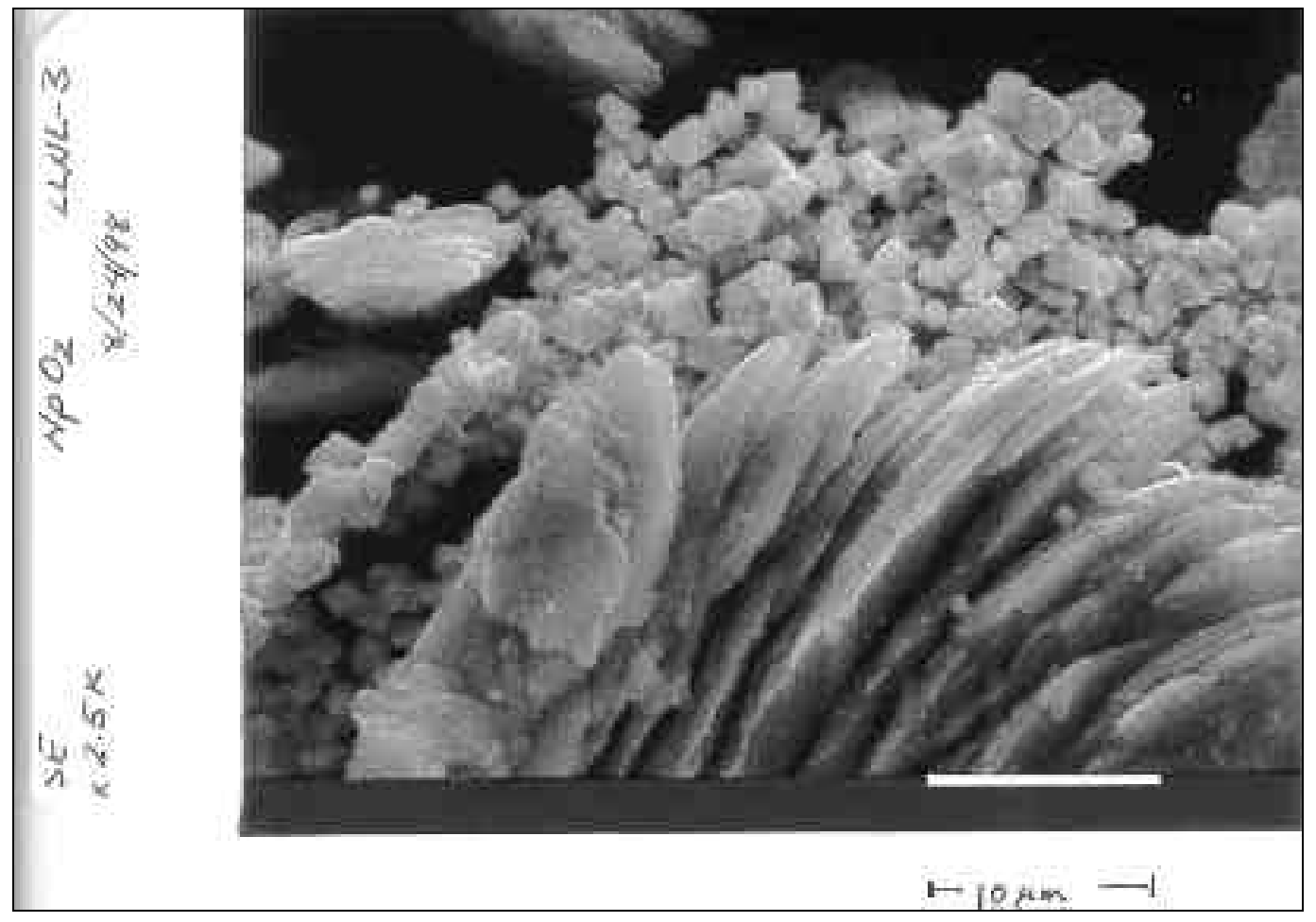

Figure 4-22. Scanning electron micrograph of the solid Np3a from the larger scale experiment with a steady-state $\mathrm{pH}$ of 4 . 


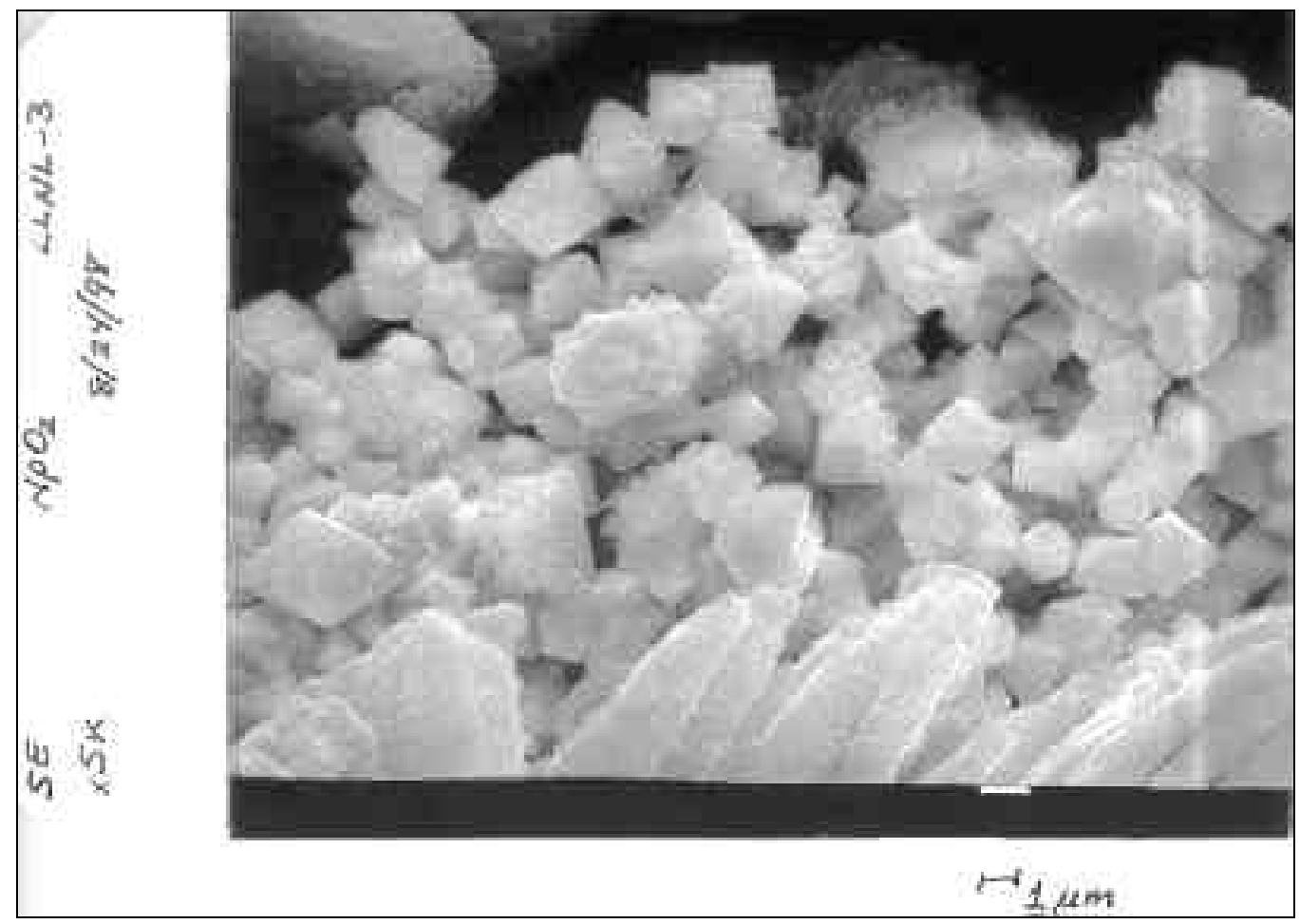

Figure 4-23. Scanning electron micrograph of the solid Np3a from the larger scale experiment with a steady-state $\mathrm{pH}$ of 4 . 


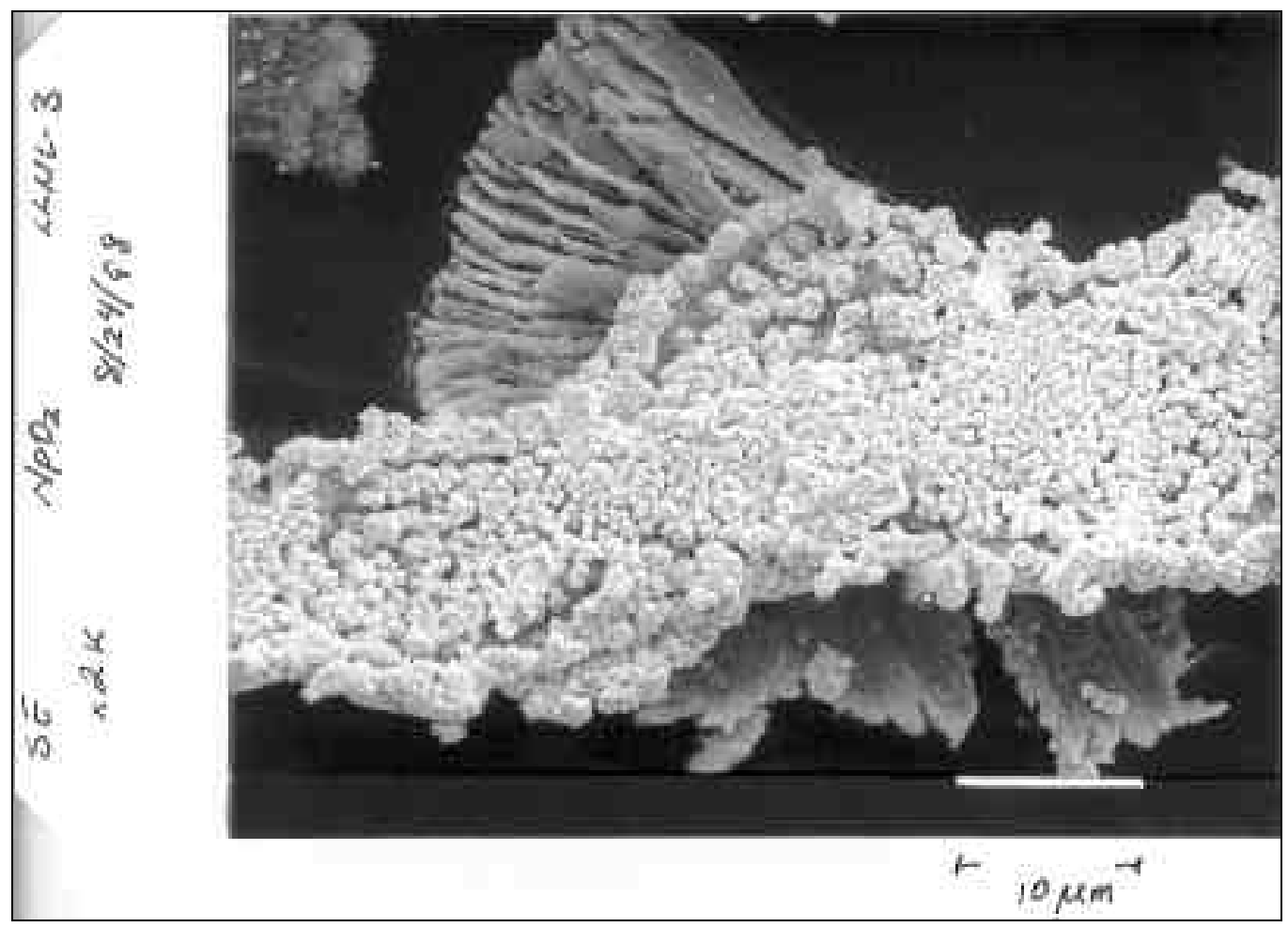

Figure 4-24. Scanning electron micrograph of the solid Np3a from the larger scale experiment with a steady-state $\mathrm{pH}$ of 4 . 


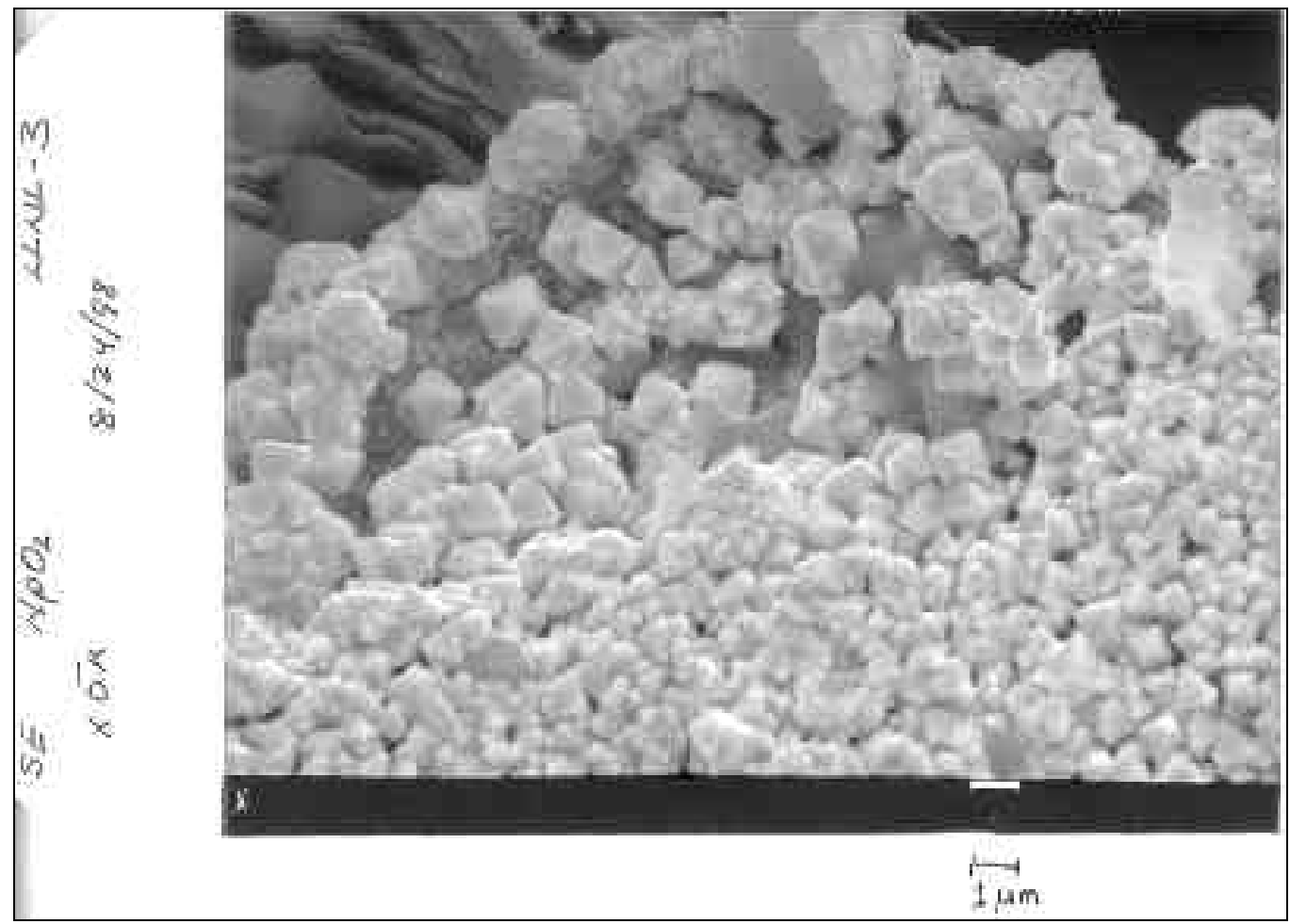

Figure 4-25. Scanning electron micrograph of the solid Np3a from the larger scale experiment with a steady-state $\mathrm{pH}$ of 4 . 


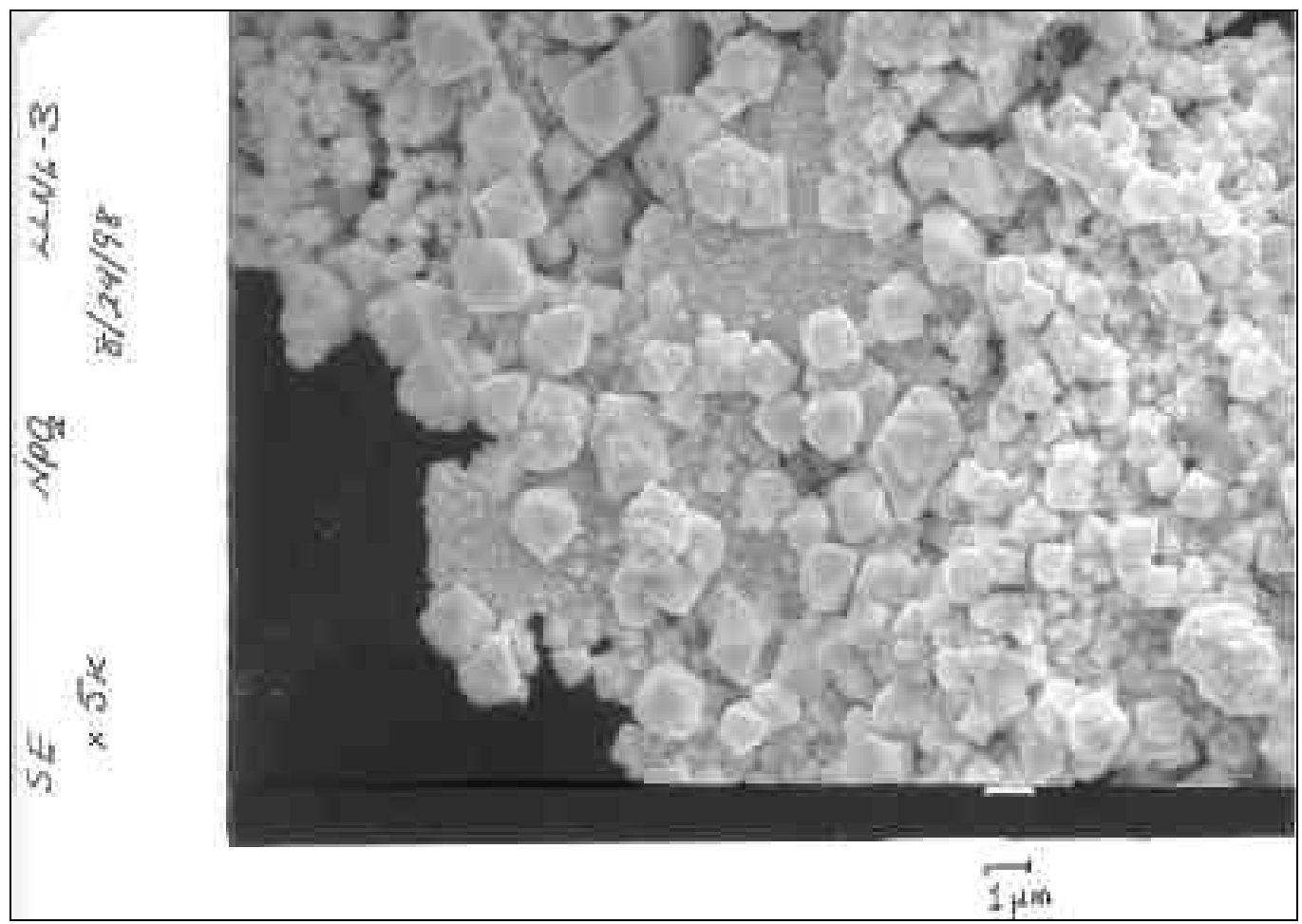

Figure 4-26. Scanning electron micrograph of the solid Np3a from the larger scale experiment with a steady-state $\mathrm{pH}$ of 4 . 


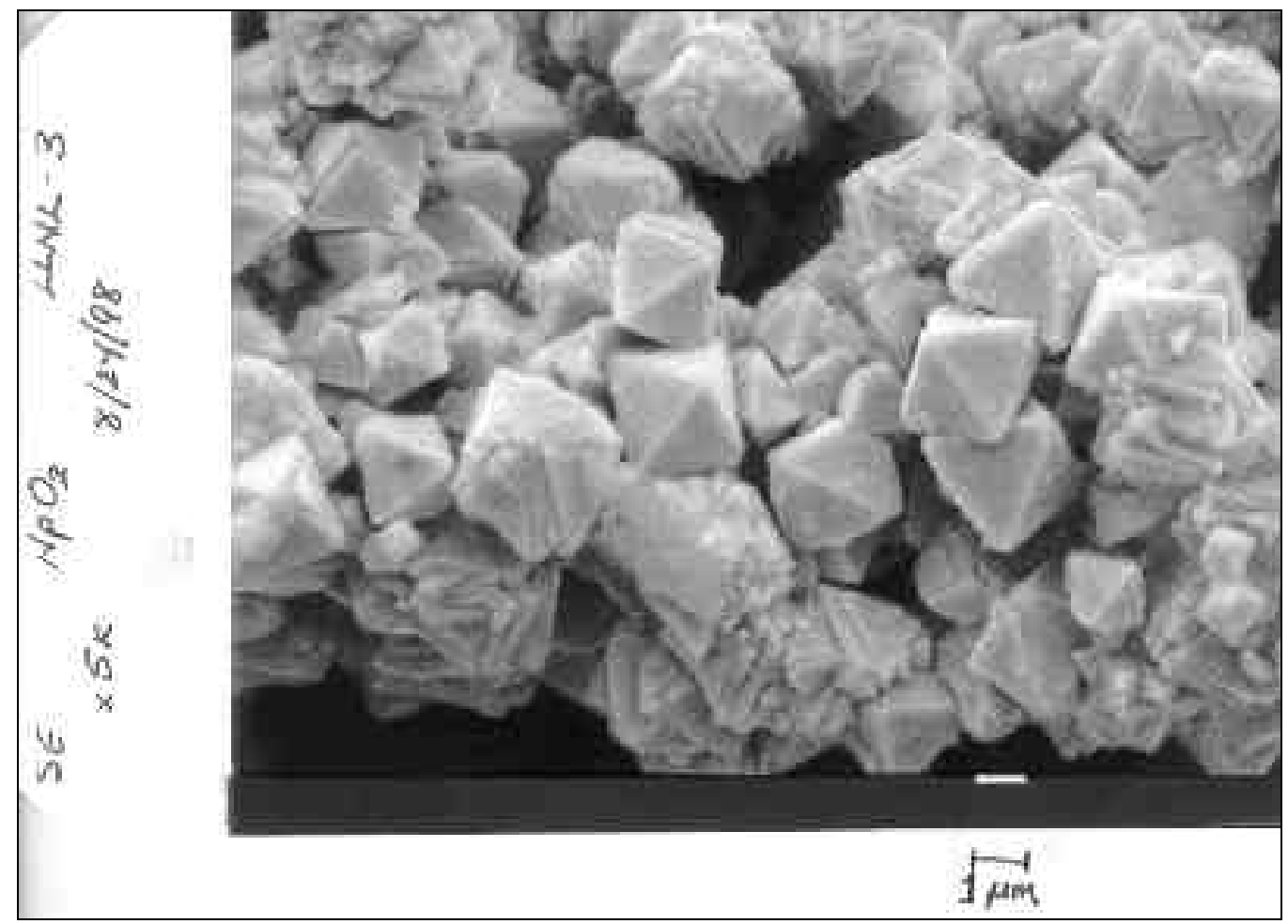

Figure 4-27. Scanning electron micrograph of the solid Np3a from the larger scale experiment with a steady-state $\mathrm{pH}$ of 4 . 




Figure 4-28. Scanning electron micrograph of the solid Np3a from the larger scale experiment with a steady-state $\mathrm{pH}$ of 4 . 


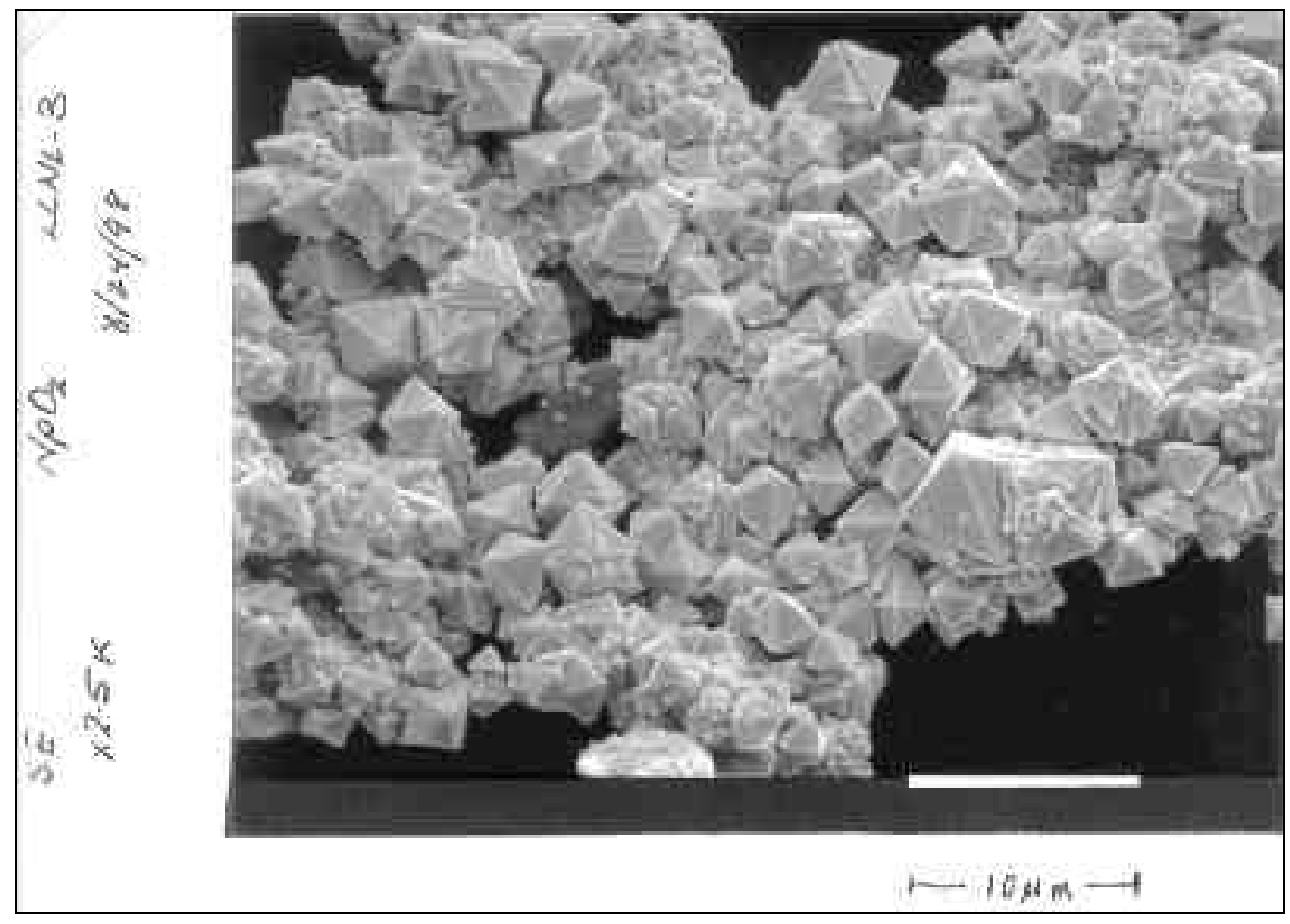

Figure 4-29. Scanning electron micrograph of the solid Np3a from the larger scale experiment with a steady-state $\mathrm{pH}$ of 4 . 


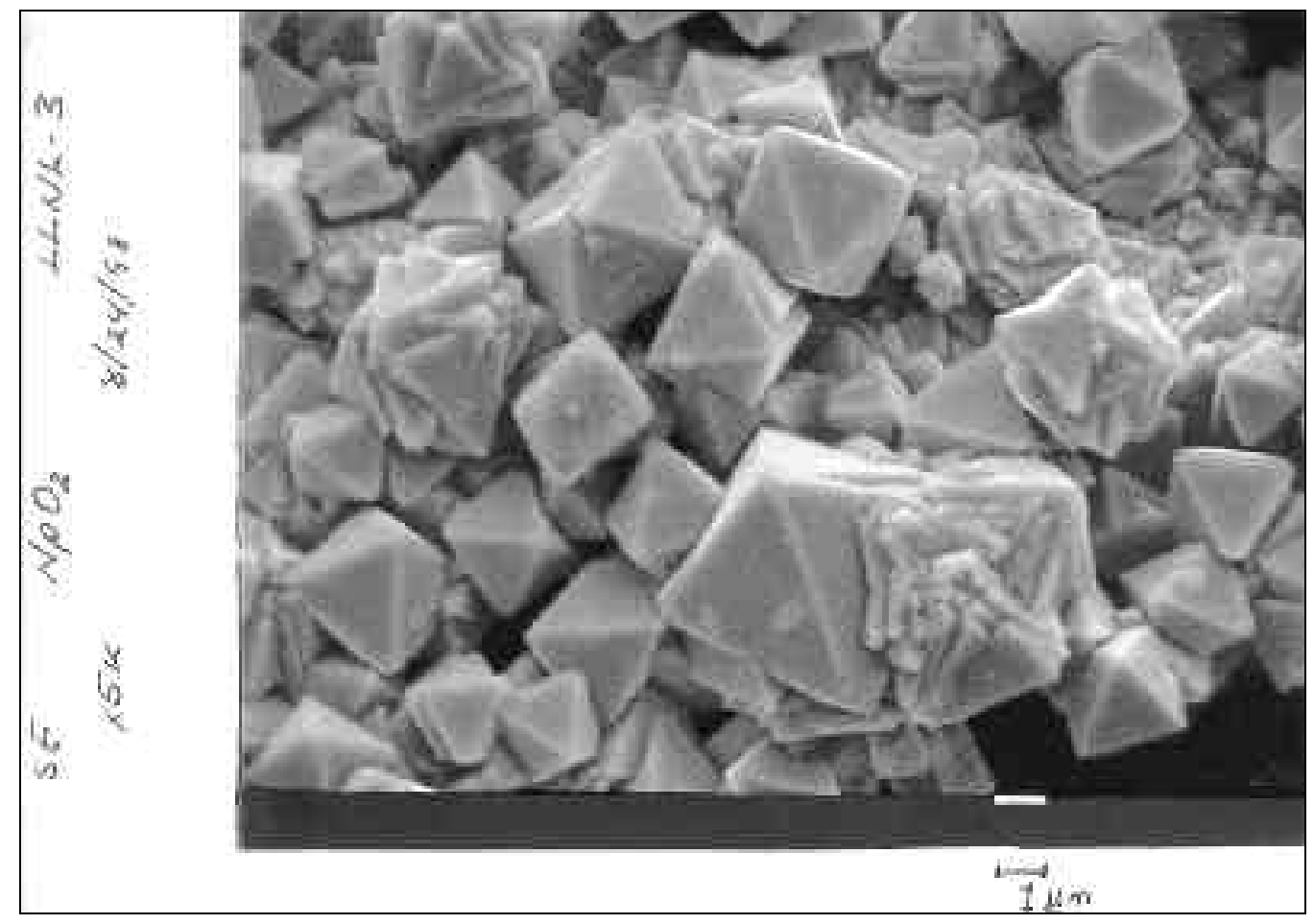

Figure 4-30. Scanning electron micrograph of the solid Np3a from the larger scale experiment with a steady-state $\mathrm{pH}$ of 4 . 


\section{CONCLUSIONS}

Neptunium Solubility

As discussed in the introduction, without exposure to oxygen (or other oxidizing agent), the solubilities of $\mathrm{Np}(\mathrm{IV})$ and $\mathrm{Np}(\mathrm{V})$ are significantly different in aqueous solutions. In the presence of oxygen, the solubility of $\mathrm{Np}$ (IV) solids is increased because of oxidation of the aqueous species to the stable $5+$ oxidation state, but the total aqueous neptunium concentrations are still lower than those observed for the exclusively $N p(V)$ system. Figure 5-1 is the same plot shown in Figure 1-4 but with the addition of the steady-state aqueous neptunium concentrations obtained in the larger scale solubility experiments in this work. The comparison of the data points with the three curves in the plot must be considered only in generalized terms owing to the fact that the curves were calculated for standard state conditions at $25^{\circ} \mathrm{C}$; whereas, the data points were obtained from solutions with a non-zero ionic strength that were allowed to react at $200^{\circ} \mathrm{C}$ for several months. However, generally speaking the solubilities measured in the four elevated temperature experiments most closely resemble the middle, dashed curve. The decrease in the total aqueous neptunium concentration from $\mathrm{pH} 4$ to pH 6 shows a similar linear decrease as observed in the dashed curve. The data points for $\mathrm{pH} 7$ and 9 show an increase in total aqueous neptunium 
concentration most likely because the solutions were in contact with air thus allowing carbonate to enter the aqueous system. Aqueous Np concentrations on the order of $10^{-6} \mathrm{M}$ were below the detection limit of the Guided Wave spectrophotometer; therefore, speciation measurements could not be made at those $\mathrm{pH}$ values. In the absence of carbonate one would expect the same linear decrease with increased $\mathrm{pH}$ as demonstrated by the two acidic data points.

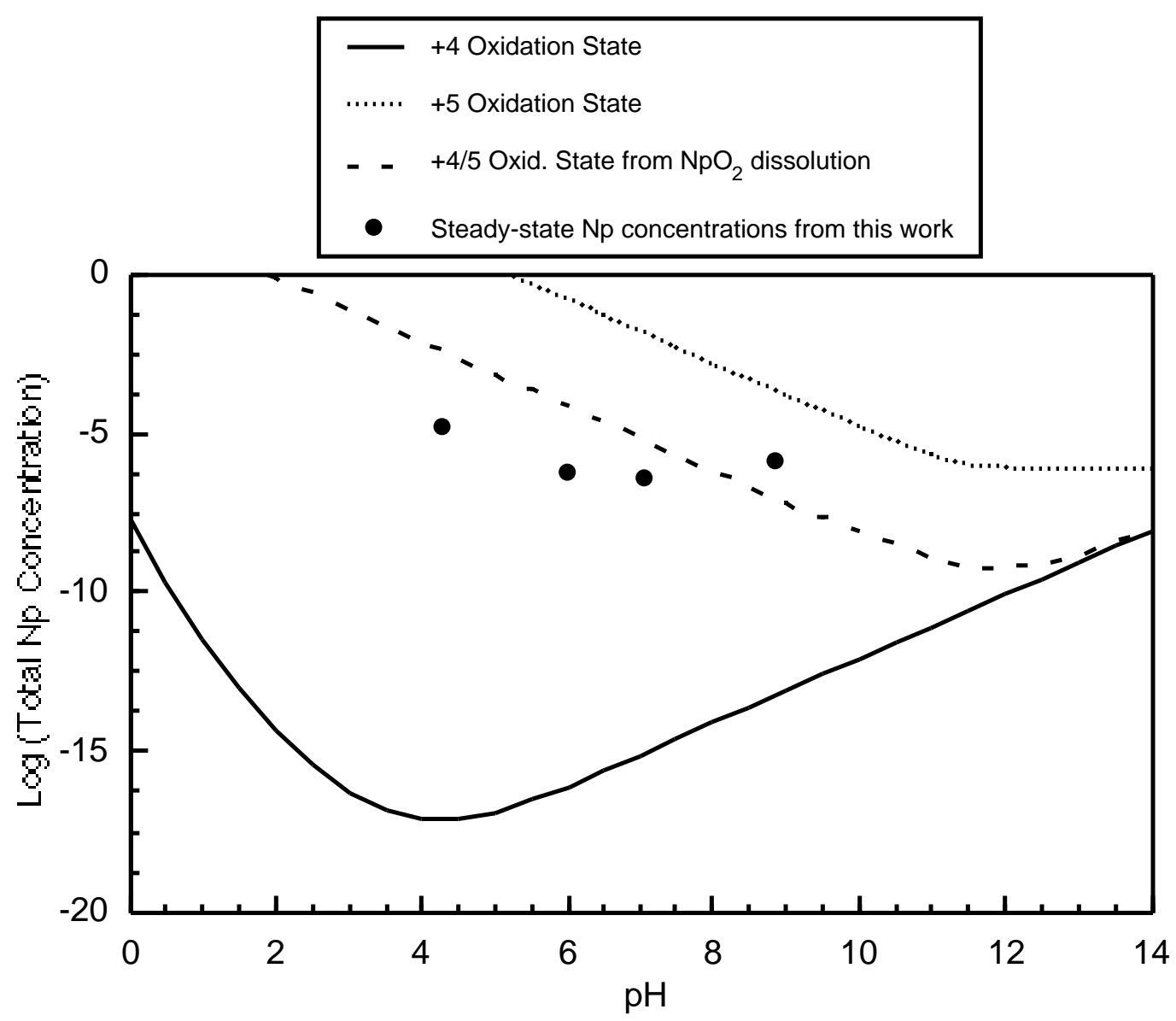

Figure 5-1. The solubility curves for the $\mathrm{Np}(\mathrm{IV}), \mathrm{Np}(\mathrm{V})$, and $\mathrm{Np}(\mathrm{IV}, \mathrm{V})$ system shown are the same as those shown in Figure 1-4. The solid circles are the steady-state aqueous neptunium concentrations obtained in the larger scale experiments. 
The fact that the data resemble the dashed curve is not surprising because of the observed precipitation of crystalline $\mathrm{NpO}_{2}$ from the originally aqueous $\mathrm{NpO}_{2}{ }^{+}$ that was in solution. Had the solids that precipitated been in the 5+ oxidation state, one might expect the solubility curve to more closely resemble the upper, dotted line. However, the initial aqueous neptunium concentration in all of the solubility experiments was $10^{-4} \mathrm{M}$; therefore, precipitation of $5+$ solids would not have occurred until solution $\mathrm{pH}$ values exceeded approximately $\mathrm{pH} 8$ or 9 . Had the aqueous system been of a significantly lower oxidation potential, i.e., in the absence of oxygen, one might expect the data to more closely resemble the lower, solid line.

The difference of approximately two orders of magnitude between the data points and the dashed curve may be due to one or any combination of the following factors. Because the dissolution and/or precipitation of $\mathrm{NpO}_{2}$ appears to be kinetically slow when compared with the 4 hour cooling off time for the vessels before samples were withdrawn, one could argue that the steady-state aqueous neptunium concentrations determined in this work are equilibrium values for the dissolution of $\mathrm{NpO}_{2}$ at $200^{\circ} \mathrm{C}$. Also, at $200^{\circ} \mathrm{C}$, the oxygen content of the aqueous solutions may be significantly lower than at ambient temperatures thereby allowing for less oxidation of the aqueous neptunium in the solutions. Again, the amount of aqueous neptunium available for oxidation is dictated by the slow dissolution of the solid phase. And one must also note that there does exist a difference in ionic strength when comparing the calculated solubility curves with the experimental data points. 
The fact remains that a decrease in total aqueous neptunium was observed in all of the initially $10^{-4} \mathrm{M}$ aqueous $\mathrm{NpO}_{2}{ }^{+}$solubility experiments exposed to $200^{\circ} \mathrm{C}$, and the decrease in total aqueous neptunium was due to the precipitation of crystalline $\mathrm{NpO}_{2}$ solid even with the aqueous solution having been continuously exposed to oxygen with a partial pressure of approximately $0.2 \mathrm{bar}$.

This is the first time that the precipitation of crystalline $\mathrm{NpO}_{2}$ from an aqueous solution of initially $\mathrm{NpO}_{2}^{+}$has been observed experimentally.

\section{Precipitated Neptunium Solids}

Reference powder patterns for other neptunium solids were also obtained from the literature ${ }^{39}$ for comparison with the solid obtained in the elevated temperature experiments. Patterns for $\mathrm{Np}_{3} \mathrm{O}_{8}, \mathrm{~Np}_{2} \mathrm{O}_{5}, \mathrm{NpF}_{3}, \mathrm{NpF}_{4}, \mathrm{NpF}_{5}, \mathrm{NpF}_{6}$, $\mathrm{NaNpO}_{2} \mathrm{CO}_{3}$ are shown in Appendix A. Of these patterns, those of $\mathrm{Np}_{2} \mathrm{O}_{5}$ and $\mathrm{NaNpO}_{2} \mathrm{CO}_{3}$ were of the most interest because they represent what had been observed in previous works involving elevated temperature solubility studies of neptunium(V).4,5,38 A comparison of the patterns obtained from these elevated temperature solubility experiments with those for $\mathrm{Np}_{2} \mathrm{O}_{5}$ and $\mathrm{NaNpO}_{2} \mathrm{CO}_{3}$ clearly shows that these samples do not contain a significant amount of either of these $\mathrm{Np}(\mathrm{V})$ solids. The solid phase $\mathrm{NaNpO}_{2} \mathrm{CO}_{3}$ is of lesser importance because it is unlikely to form under the solution conditions of the current experiments. Significantly higher solution concentrations of both $\mathrm{Na}^{+}$and $\mathrm{CO}_{3}{ }^{2-}$ are needed for 
the precipitation of $\mathrm{NaNpO}_{2} \mathrm{CO}_{3}$ to occur in preference to the precipitation of $\mathrm{Np}(\mathrm{V})$ hydroxides or oxides as stated in the literature by Neck et al. ${ }^{46}$

Also, the patterns obtained in this work do not resemble the powder pattern for $\mathrm{Np}_{3} \mathrm{O}_{8}$ in the ICDD database. ${ }^{39}$ Additionally, the existence of a discrete $\mathrm{Np}_{3} \mathrm{O}_{8}$ solid phase has been discounted. ${ }^{47}$ What had been reported as a unique pattern, the pattern for $\mathrm{Np}_{3} \mathrm{O}_{8}$, appears to be a poorly resolved version for that of $\mathrm{Np}_{2} \mathrm{O}_{5}$. Powder patterns for the fluoride precipitates of neptunium in the $+3,4,5$, and 6 oxidation states were also obtained and are listed in Appendix A. These patterns were obtained in order to rule out the possibility that a fluoride precipitate formed because of the ionic fluoride contamination that resulted from using Teflon reaction vessels. Even though the Teflon vessels released fluoride ions into the experimental solutions to a concentration of approximately $10^{-4} \mathrm{M}$, the precipitate obtained in the very first experiment was not a neptunium fluoride of any kind. The pattern obtained from the solid from the first experiment in a Teflon vessel matched that of crystalline $\mathrm{NpO}_{2}$.

Essentially, all the x-ray powder diffraction patterns obtained from the solids that precipitated in all of these solubility experiments matched that of crystalline $\mathrm{NpO}_{2}$. Using the Jade software to perform a cell refinement to determine the fluorite structure lattice parameter, $\mathrm{a}_{0}$, from the powder patterns, values of 5.426 , $5.431,5.426,5.424,5.424$, and $5.427 \AA$ were obtained from the patterns of precipitates, Np1, Np3a, Np4a, 992b, 2140b, and 2141, respectively. Averaging these values results in a unit cell length of $\left(5.426 \pm 0.003_{1 \sigma}\right) \AA$. The data in the 
ICDD-PDF for $\mathrm{NpO}_{2}$ lists a lattice parameter of $5.433 \AA$ based on the 1970 work of Martinot et al. ${ }^{48}$ A lattice parameter value of $5.425 \AA$ was published in a 1986 comprehensive actinide elements review by Katz et al. ${ }^{49}$ The experimentally determined lattice parameter of $5.426 \AA$ was used to calculate a diffraction pattern for the face centered cubic structure of $\mathrm{NpO}_{2}$ using Ruby version 1.5 software from Materials Data Incorporated, Livermore, California. The resulting pattern is shown in Figure 5-2. The lines shown in the calculated pattern match those in each of the experimentally obtained powder patterns. The inlay in Figure 5-2 shows an expanded 2-theta scale from 110 to 145 degrees. In this region the diffraction peaks are not single peaks but rather doublet peaks that were not resolved in the experimental patterns obtained in this work. However, upon close inspection of the experimentally obtained patterns, one can see that the peaks in this region are actually rather broad, and in some cases a relatively smaller shoulder appears on the right side of the main peak. With a higher resolution diffractometer, resolution of these peaks probably would have been possible.

Ruby software version 1.5 also allows for the creation and visual manipulation of unit cell images for calculated solids. Figure 5-3 shows the "fluorite" unit cell structure for crystalline $\mathrm{NpO}_{2}$ that was calculated with a lattice parameter of $5.426 \AA$. 


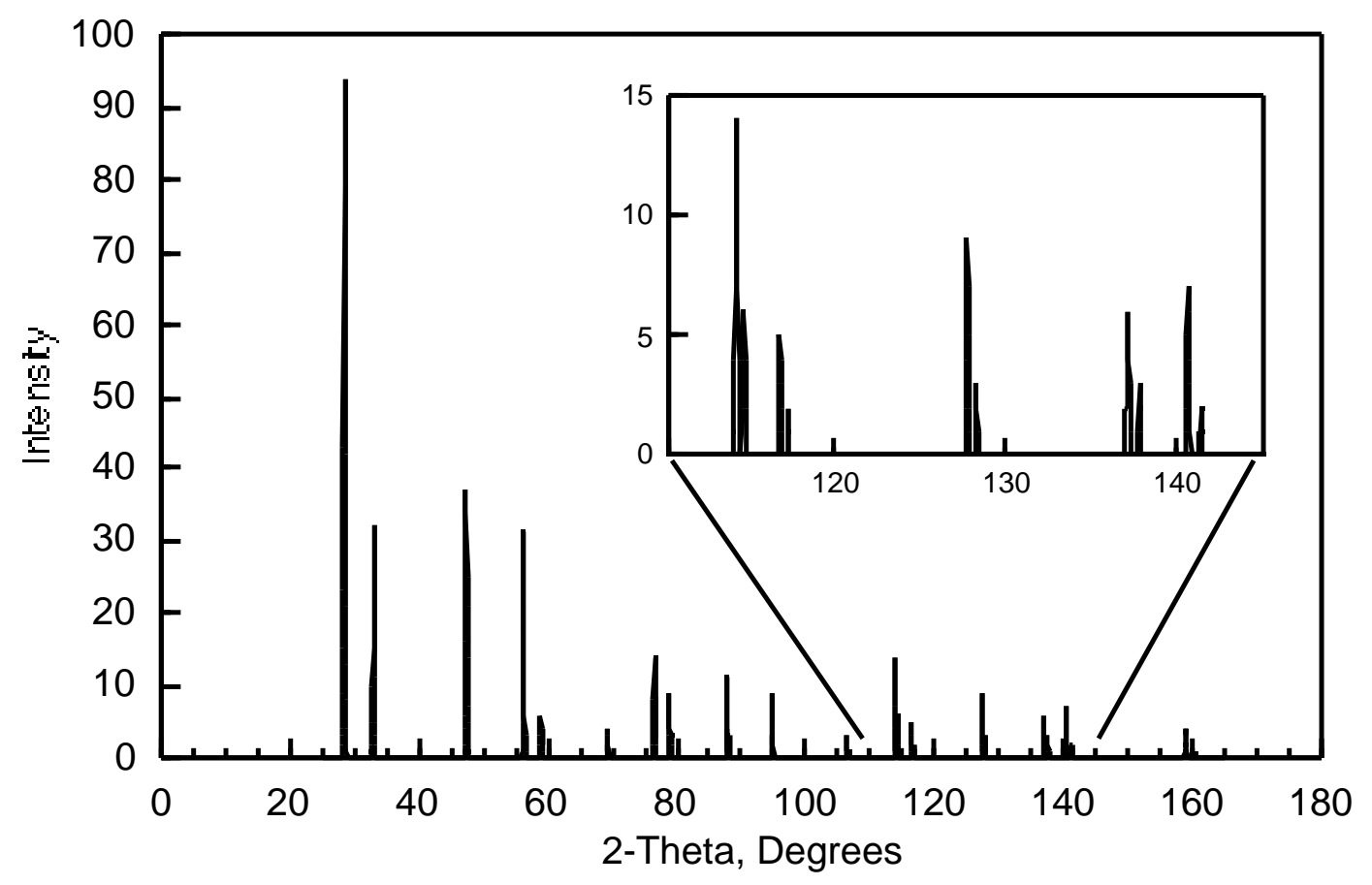

Figure 5-2. X-ray powder diffraction pattern calculated for a face centered cubic unit cell with a experimentally determined lattice parameter of $5.426 \AA$. 




Figure 5-3. Fluorite structure for the unit cell of $\mathrm{NpO}_{2}$. The smaller black spheres are $\mathrm{Np}$ atoms, and the larger white spheres are oxygen atoms.

This software also allows for the manipulation of the structural unit. Upon centering the oxygen atom within the imaged structure and reducing the composite particle size to a spherical enclosure with a $3 \AA$ radius, one obtains a smaller version of what this crystal looks like structurally. Figure 5-4 shows the fluorite structure of $\mathrm{NpO}_{2}$ under such conditions. 


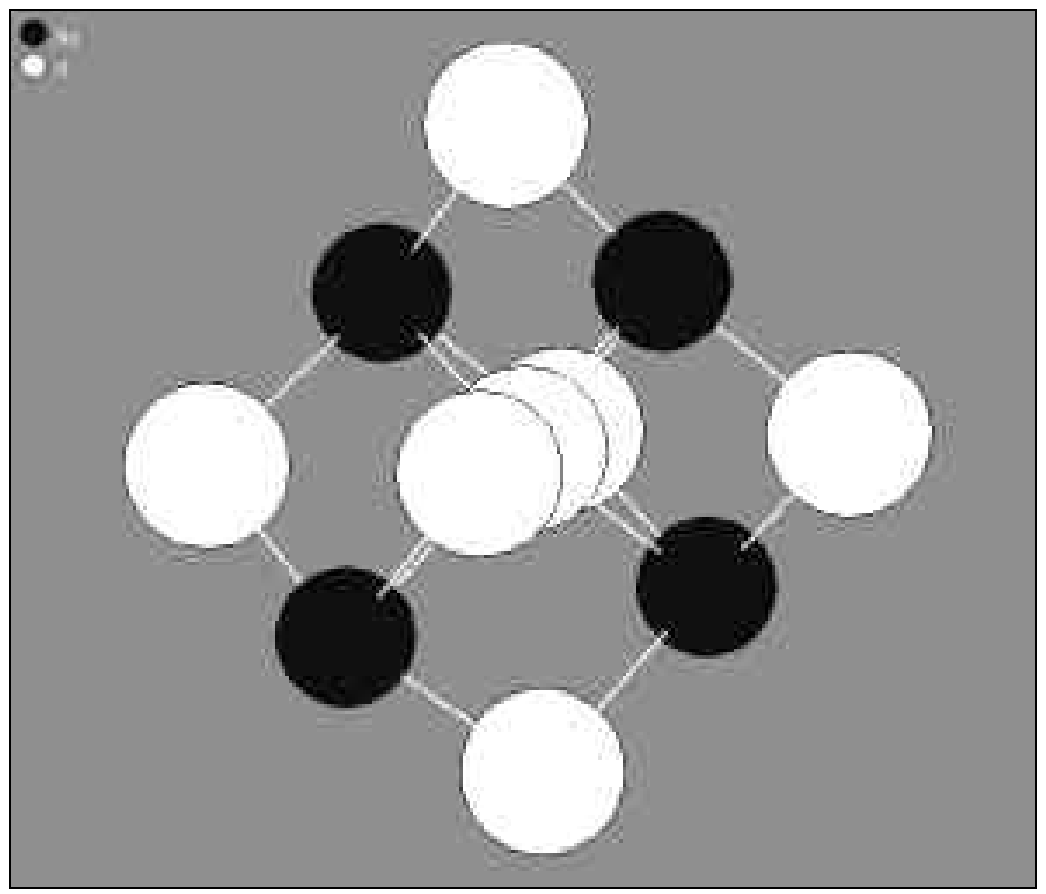

Figure 5-4. Oxygen centered fluorite structure of $\mathrm{NpO}_{2}$ limited to a spherical component with a radius of $3 \AA$. The smaller black spheres are $\mathrm{Np}$ atoms, and the larger white spheres are oxygen atoms.

From this representation of the fluorite structure, one can see how octahedral habits can form when $\mathrm{NpO}_{2}$ precipitates. The oxygen atoms on the left, right, top, bottom, and center are located within the plane of the paper; whereas, the front and rear (with respect to the center oxygen) oxygen atoms line up with the center oxygen perpendicular to the plane of the paper. The six external oxygen atoms make up the six points of the octahedral structure, and the four neptunium atoms form a tetrahedron around the central oxygen atom. Within 
this structure, the $\mathrm{Np}-\mathrm{O}$ and $\mathrm{O}-\mathrm{O}$ bond distances were calculated to be 2.350 and $2.713 \AA$, respectively.

The goal of analyzing the solids by x-ray powder diffraction was to identify what crystalline phase or phases had precipitated from aqueous solution. From the powder patterns quantitative information about the crystal structure was determined for comparison with known data in the literature. The analyses by XAS and SEM were to corroborate, at least qualitatively, the results obtained from x-ray powder diffraction by additional, independent means. The information gained from the XAS and SEM measurements confirmed the result that $\mathrm{NpO}_{2}$ was the precipitate collected at the end of the experiment. Beyond that, the SEM micrographs provide a picture of what the microgram quantities of solid looked like physically, and from this information it was obvious that at least some of the $\mathrm{NpO}_{2}$ that formed was of a very high purity.

The thermodynamic data used to model neptunium solubility appear to be generally correct. The stable solid phase in dilute, aqueous solution appears to be $\mathrm{NpO}_{2}$, at least between $\mathrm{pH} 4$ and 9. This solid precipitated from aqueous solutions of pure $\mathrm{NpO}_{2}{ }^{+}$even when exposed to atmospheric oxygen levels. The thermodynamic data associated with both of the neptunium (IV) and (V) systems however appear to have significant uncertainty associated with them. It would seem prudent to examine these systems systematically in a more precise manner. 
APPENDIX A 


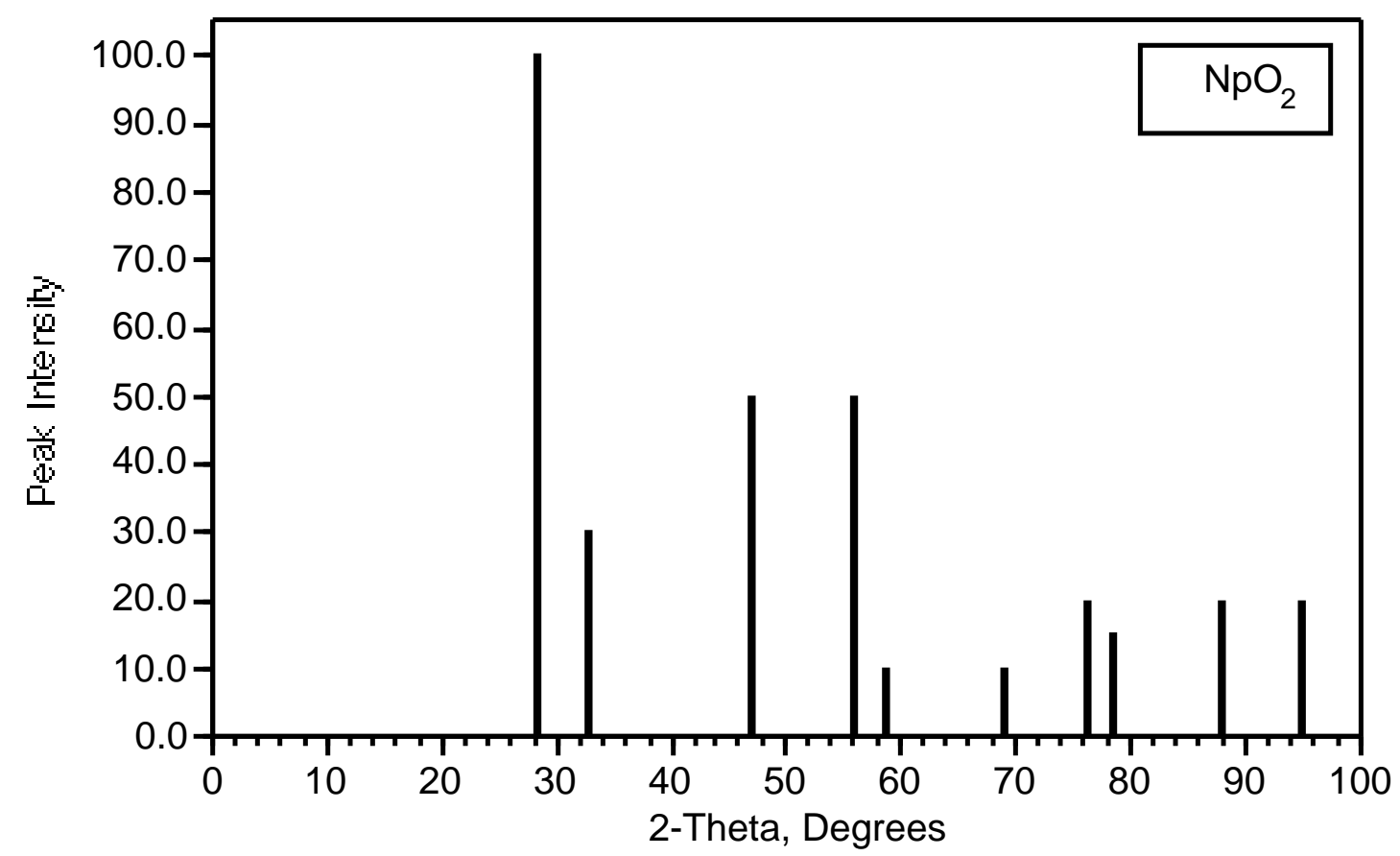

Figure A-1. Reference powder diffraction pattern of $\mathrm{NpO}_{2} \cdot{ }^{39}$

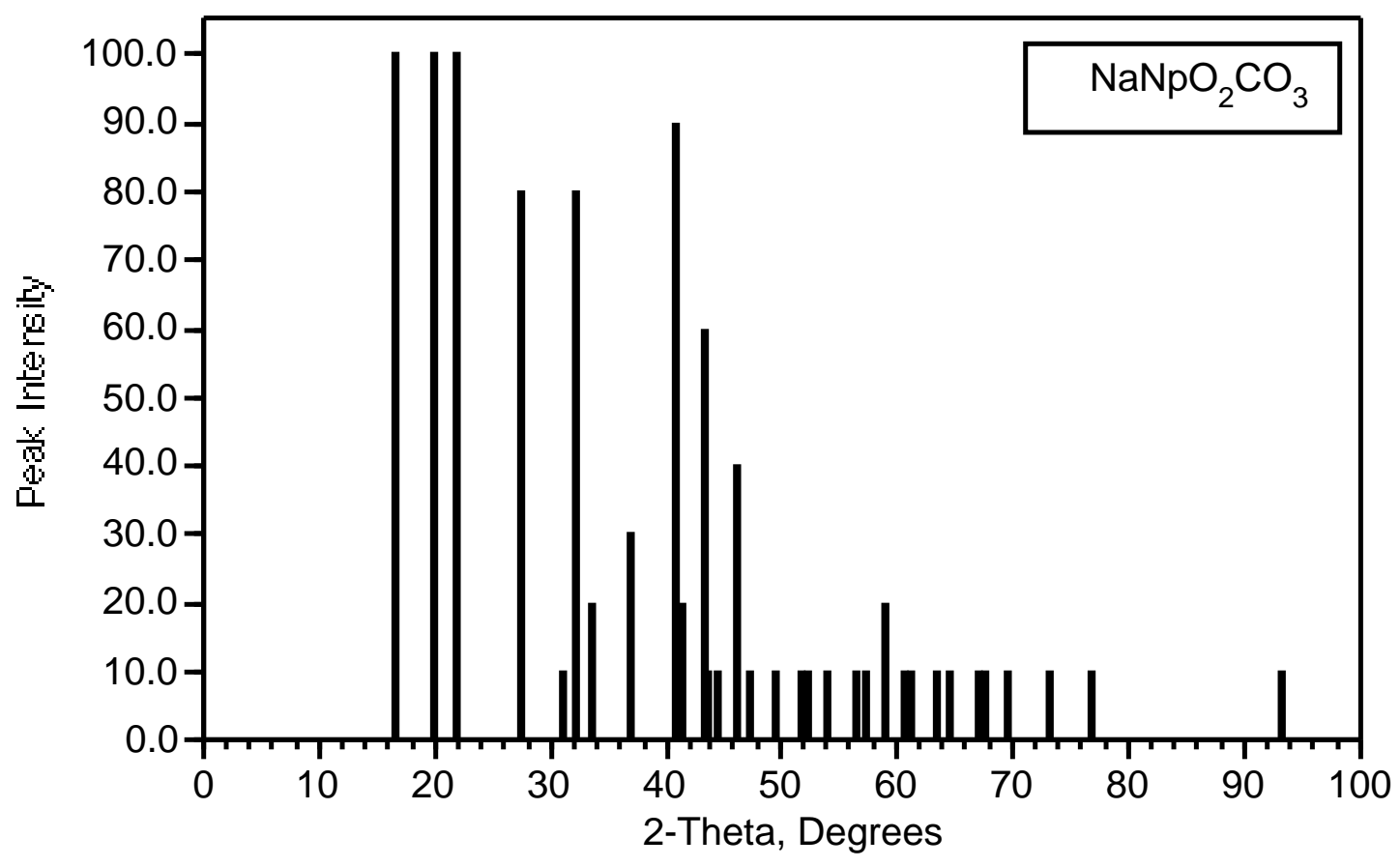

Figure A-2. Reference powder diffraction pattern of $\mathrm{NaNpO}_{2} \mathrm{CO}_{3}{ }^{39}$ 


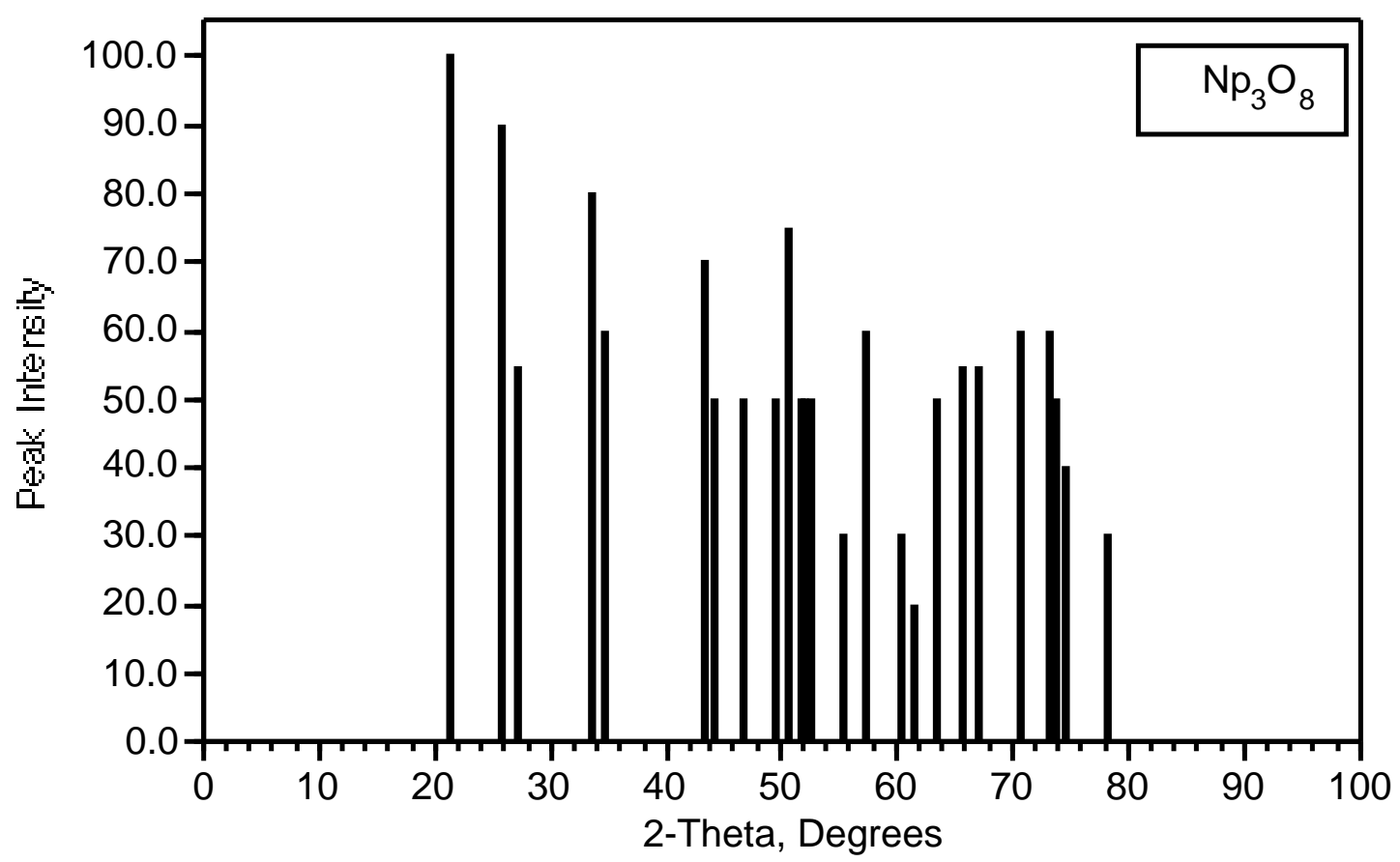

Figure A-3. Reference powder diffraction pattern of $\mathrm{Np}_{3} \mathrm{O}_{8} \cdot{ }^{39}$



Figure A-4. Reference powder diffraction pattern of $\mathrm{Np}_{2} \mathrm{O}_{5} \cdot{ }^{39}$ 


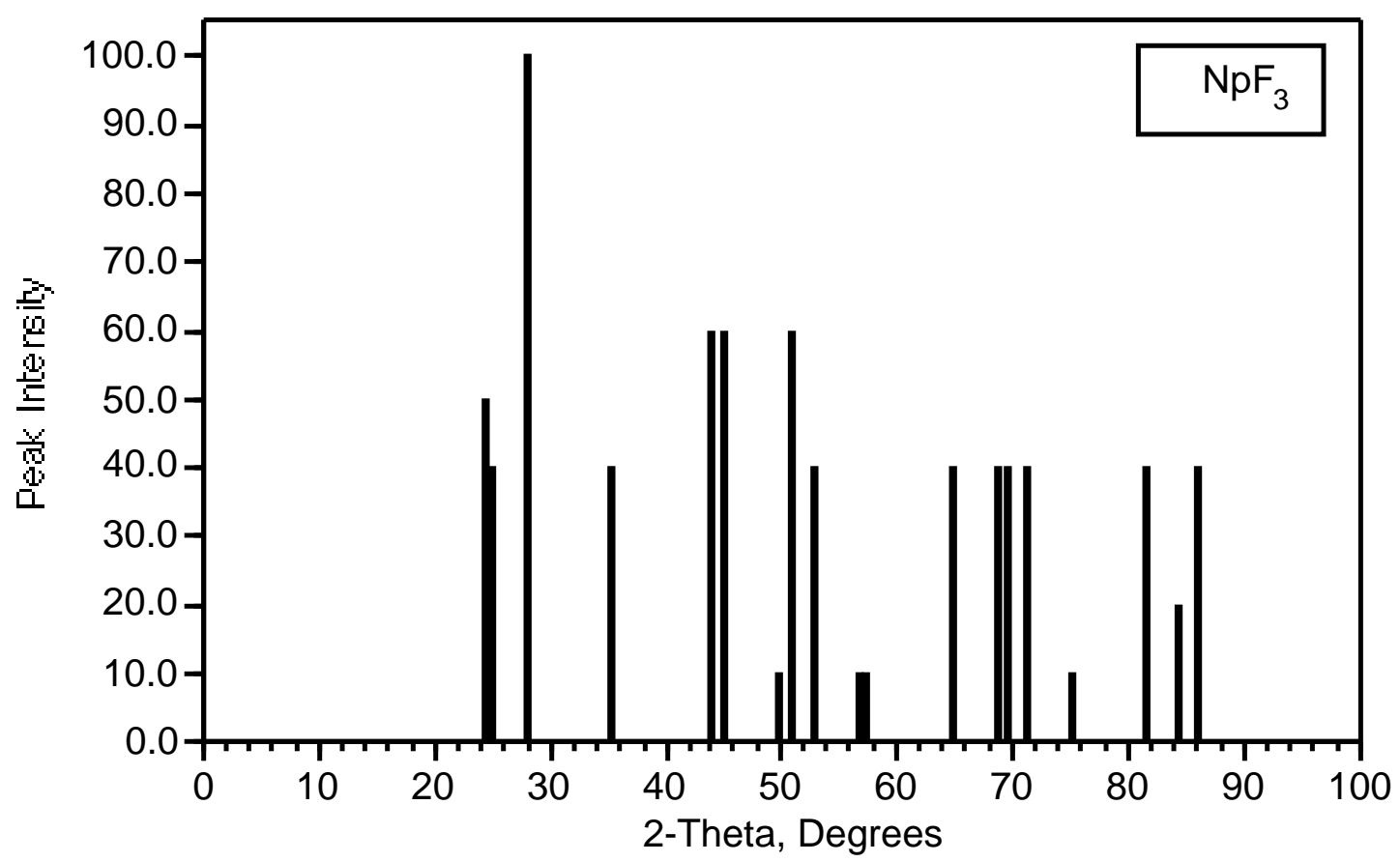

Figure A-5. Reference powder diffraction pattern of $\mathrm{NpF}_{3}{ }^{39}$

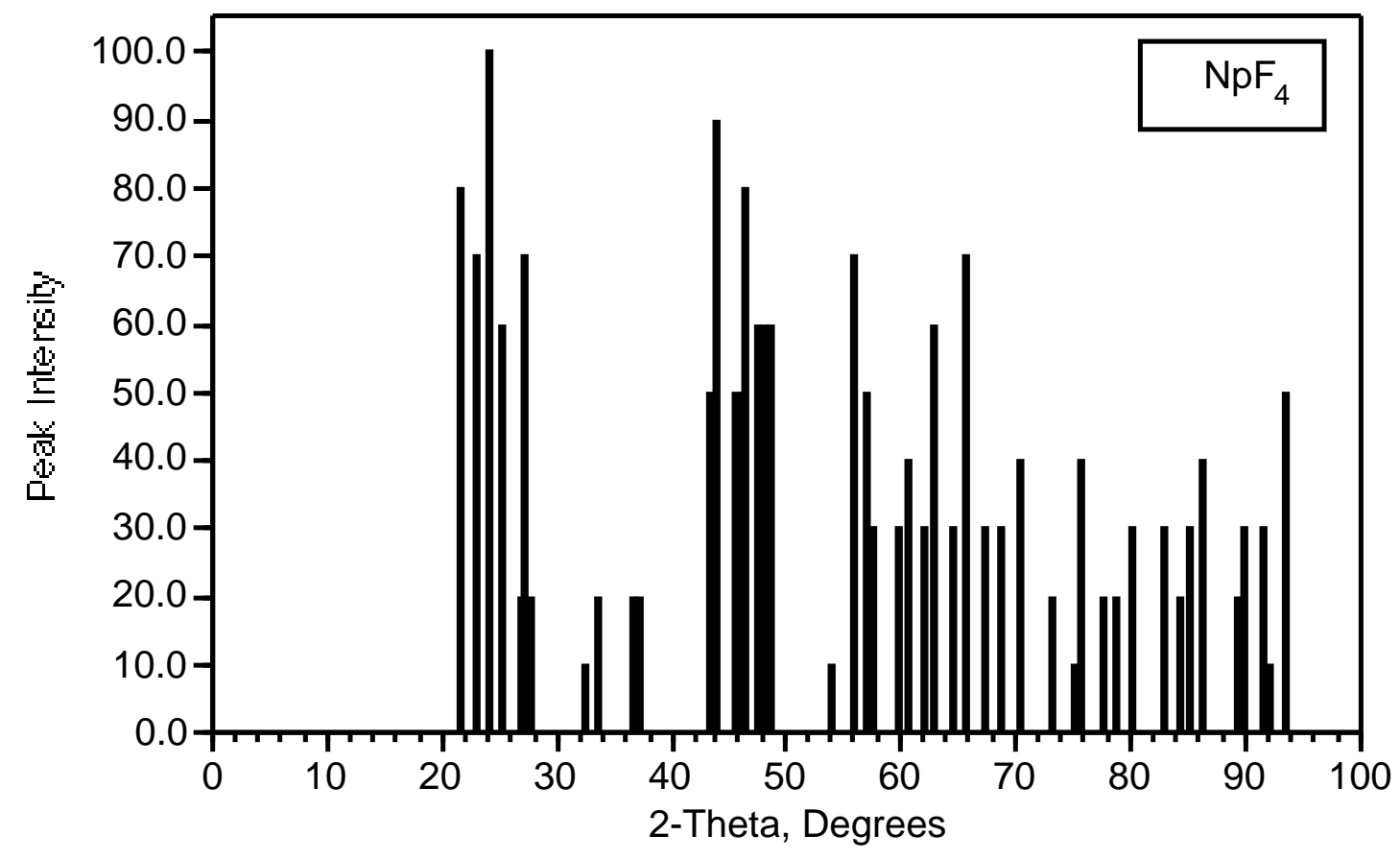

Figure A-6. Reference powder diffraction pattern of $\mathrm{NpF}_{4} \cdot{ }^{39}$ 


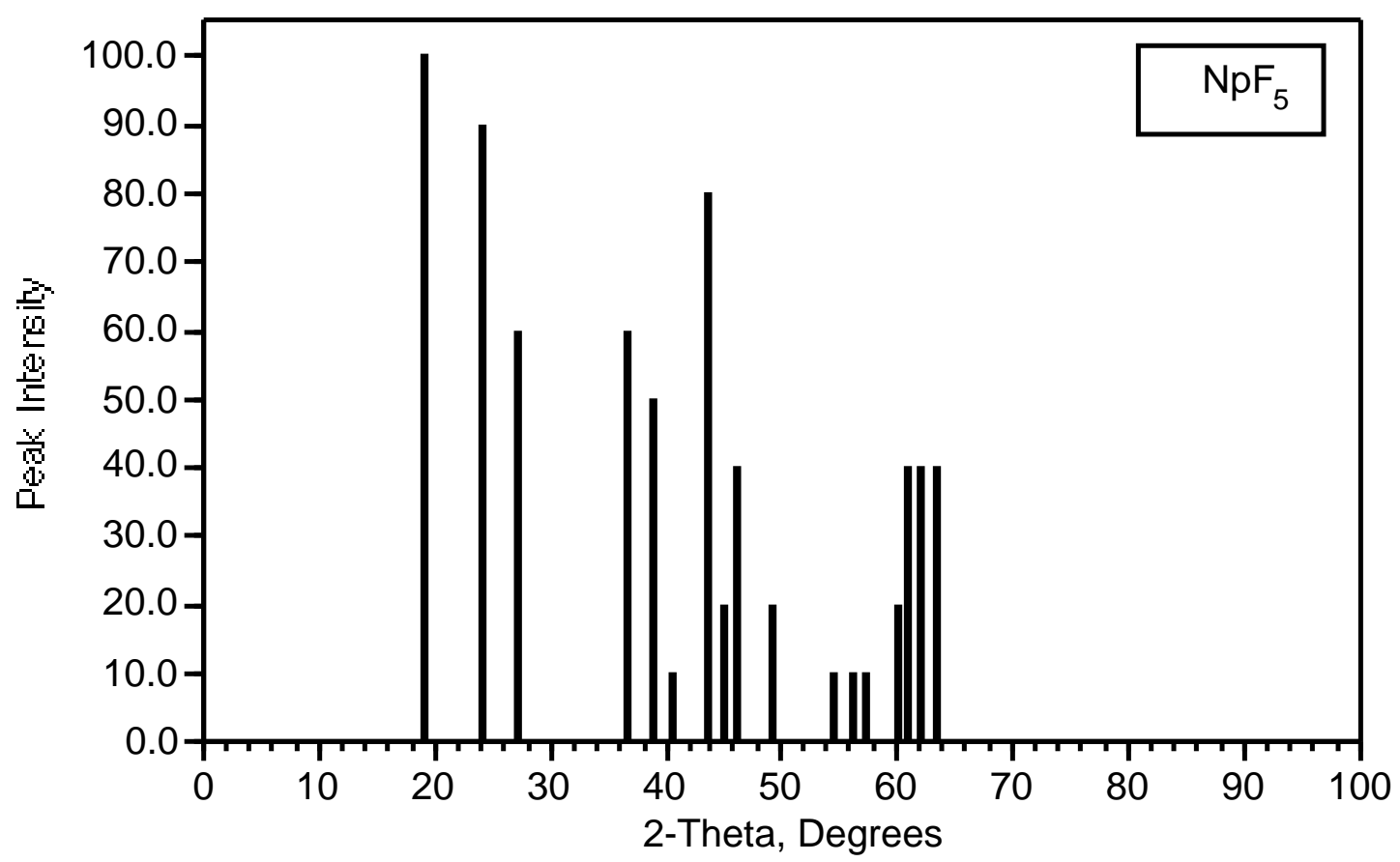

Figure A-7. Reference powder diffraction pattern of $\mathrm{NpF}_{5}{ }^{39}$

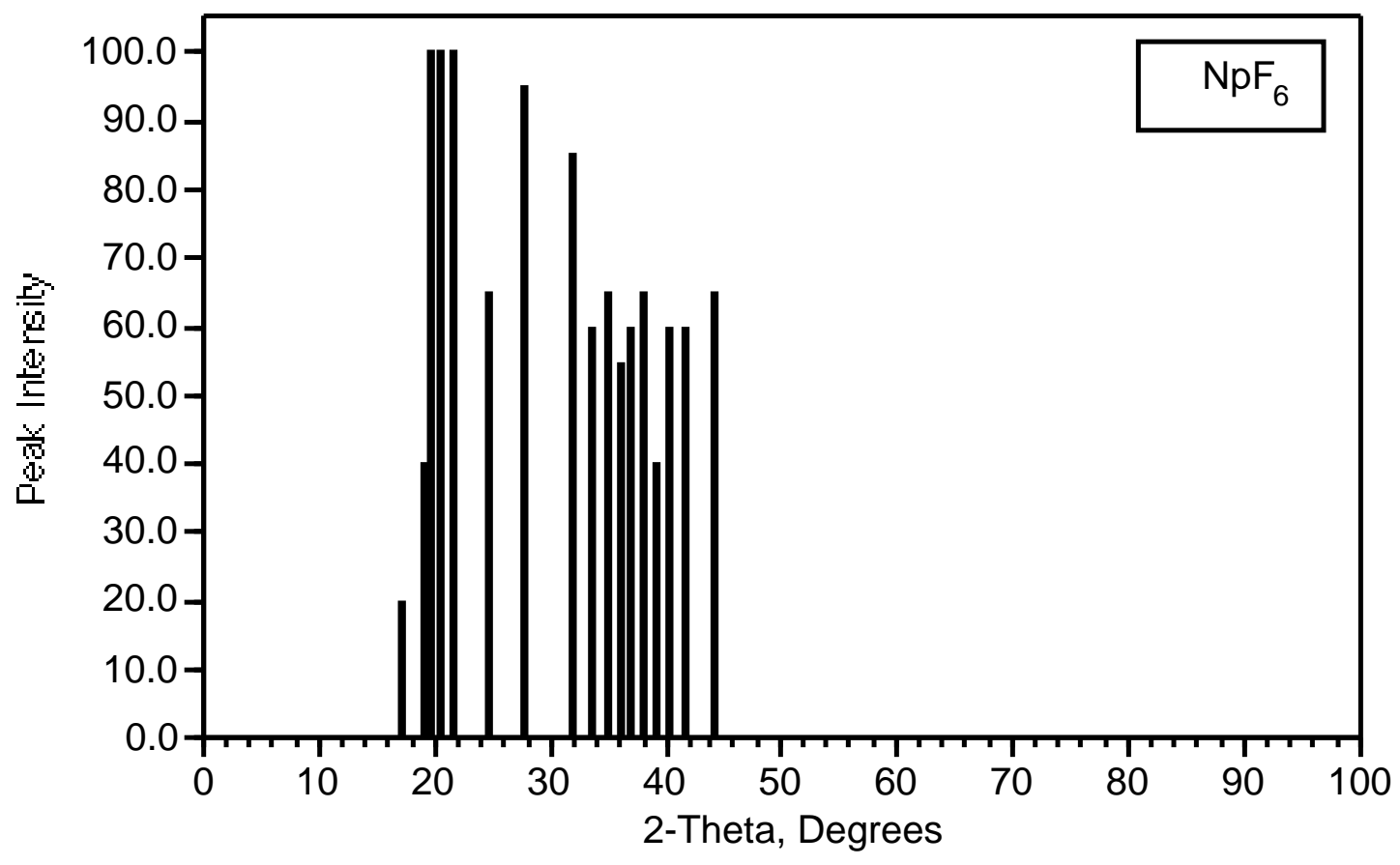

Figure A-8. Reference powder diffraction pattern of $\mathrm{NpF}_{6}{ }^{39}$ 


\section{REFERENCES}

1) Rahn, F. J. A Guide to Nuclear Power Technology : A Resource for Decision Making; Wiley: New York, 1984.

2) Lochbaum, D. A. Nuclear Waste Disposal Crisis; PennWell Books: Tulsa, Okla., 1996.

3) Bodansky, D. Nuclear Energy : Principles, Practices, and Prospects; American Institute of Physics: Woodbury, N.Y., 1996.

4) Nitsche, H.; Gatti, R. C.; Standifer, E. M.; Lee, S. C.; Muller, A.; Prussin, T.; Deinhammer, R. S.; Maurer, H.; Becraft, K.; Leung, S.; Carpenter, S. A. "Measured Solubilities and Speciations of Neptunium, Plutonium, and Americium in a Typical Groundwater (J-13) from the Yucca Mountain Region," Los Alamos National Laboratory, 1993.

5) Nitsche, H.; Roberts, K.; Prussin, T.; Muller, A.; Becraft, K.; Keeney, D.; Carpenter, S. A.; Gatti, R. C. "Measured Solubilities and Speciations from Oversaturation Experiments of Neptunium, Plutonium, and Americium in UE-25p \# 1 Well Water from the Yucca Mountain Region," Los Alamos National Laboratory, 1994.

6) Seaborg, G. T. Electronic Structure of the Heaviest Elements; Seeaborg, G. T., Katz, J. J. and Manning, W. M., Ed.; McGraw Hill: New York, 1949; Vol. 14B, pp 1517-1520.

7) Seaborg, G. T. Nucleonics 1949, 5, 16-36. 
8) Seaborg, G. T. Journal of Chemical Education 1969, 46, 626-634.

9) Seaborg, G. T. Chemical \& Engineering News 1979, 57, 46-52.

10) Seaborg, G. T. Modern Alchemy : Selected Papers of Glenn T. Seaborg; World Scientific: Singapore ; River Edge, N.J., 1994.

11) Seaborg, G. T. The Transuranium Elements; Yale University Press: New Haven,, 1958.

12) Hobart, D. E. Actinides in the Environment: Houston, Texas, 1990, pp 379436.

13) Silva, R. J.; Nitsche, H. Radiochimica Acta 1995, 70-1, 377-396.

14) Nitsche, H. Actinides in the Environment: Houston, Texas, 1997, pp 127-164.

15) McMillan, E. M.; Abelson, P. H. Physical Review 1940, 57, 1185.

16) Magnusson, L. B.; LaChapelle, T. J. Journal of the American Chemical Society $1948,70,3534$.

17) Wahl, A. C.; Seaborg, G. T. Physical Review 1948, 73, 940.

18) Burney, G. A.; Harbour, R. M. Radiochemistry of Neptunium; Technical Information Center Office of Information Services United States Atomic Energy Commission: Oak Ridge, Tenn., 1974.

19) Firestone, R. B.; Shirley, V. S. Table of Isotopes; 8th ed.; Wiley: New York, 1996. 
20) Lemire, R. J. "Assessment of the Thermodynamic Behaviour of Neptunium in Water and Model Groundwaters from 25 to 150 degrees C," Atomic Energy Canada Ltd., 1984.

21) Neck, V.; Kim, J. L.; Kanellakopulos, B. Radiochimica Acta 1992, 56, 25-30.

22) Pan, P. J.; Campbell, A. B. Radiochimica Acta 1998, 81, 73-82.

23) Wolery, T. J.; Jackson, K. J.; Bourcier, W. L.; Bruton, C. J.; Viani, B. E.; Knauss, K. G.; Delany, J. M. Current Status of the EQ3/6 Software Package for Geochemical Modeling; Melchoir, D. C. and Bassett, R. L., Ed.; American Chemical Society: Washington D.C., 1990; Vol. 416, pp 104-116.

24) Wolery, T. J. "A Software Package for Geochemical Modeling of Aqueous Systems," Lawrence Livermore National Laboratory, 1992.

25) Sassani, D. C. "Constraints on Solubility-Limited Neptunium

Concentrations for Use in Performance Assessment Analyses," TRW, 1998.

26) Wilson, P. D. The Nuclear Fuel Cycle : From Ore to Wastes; Oxford University Press: Oxford ; New York, 1996.

27) Rai, D.; Strickert, R. G.; McVay, G. L. Nuclear Technology 1982, 58, 69-76.

28) Barnard, R. W.; Wilson, M. L.; Dockery, H. A.; Gauthier, J. H.; Kaplan, P. G.; Eaton, R. R.; Bingham, F. W.; Robey, T. H. "TSPA 1991: An Initial TotalSystem Performance Assessment for Yucca Mountain," Sandia National Laboratories, 1992.

29) Bruton, C. J.; Shaw, H. F. Geochemical Simulation of the Reaction Between Spent Fuel Waste Form and J-13 Water at $25^{\circ} \mathrm{C}$ and $90^{\circ} \mathrm{C}$; Apted, M. J. and Westerman, R. E., Ed.; Materials Research Society: Pittsburg, 1987; Vol. 112, pp 485-494. 
30) Wilson, C. N.; Bruton, C. J. Studies on Spent Fuel Dissolution Behavior Under Yucca Mountain Repository Conditions; American Ceramic Society, 1989;

Vol. 9, pp 423-441.

31) Wilson, C. N. "Results from NNWSI Series 2 Bare Fuel Dissolution Tests," Pacific Northwest National Laboratory, 1990a.

32) Wilson, C. N. "Results from NNWSI Series 3 Spent Fuel Dissolution Tests," Pacific Northwest National Laboratory, 1990b.

33) Nitsche, H.; Roberts, K.; Prussin, T.; Keeney, D.; Carpenter, S. A.; Becraft, K.; Gatti, R. C. Radionuclide Solubility and Speciation Studies for the Yucca Mountain Site Characterization Project, 1993, pp 1490-5 vol.2.

34) Ogard, A. E.; Kerrisk, J. F. "Groundwater Chemistry Along the Flow Path between a Proposed Repository Site and the Accessible Environment," Los Alamos National Laboratory, 1984.

35) Andrews, R. W.; Dale, T. F.; McNeish, J. A. "Total System Performance Assessment-1993: An Evaluation of the Potential Yucca Mountain Repository," INTERA, INC., 1994.

36) Wilson, M. L.; Gauthier, J. H.; Barnard, R. W.; Barr, G. E.; Dockery, H. A.; Dunn, E.; Eaton, R. R.; Guerin, D. C.; Lu, N.; Martinez, M. J.; Nilson, R.; Rautman, C. A.; Robey, T. H.; Ross, B.; Ryder, E. E.; Schenker, A. R.; Shannon, S. A.; Skinner, L. H.; Halsey, W. G.; Gansemer, J.; Lewis, L. C.; Lamont, A. D.; Triay, I. R.; Meijer, A.; Morris, D. E. "Total System Performance Assessment for Yucca Mountain - SNL Second Iteration (TSPA-1993)," Sandia National Laboratories, 1994.

37) Wolery, T. J.; Palmer, C. E. A.; Knauss, K. "The Neptunium Solubility Problem in Repository Performance Assessment: A White Paper," Lawrence Livermore National Laboratory, 1995. 
38) Efurd, D. W.; Runde, W.; Banar, J. C.; Janecky, D. R.; Kaszuba, J. P.; Palmer, P. D.; Roensch, F. R.; Tait, C. D. Environmental Science E Technology 1998, 32, 3893-3900.

39) Data, I. C. D. D. Powder Diffraction File; PDF-2 Database Sets 1-43; ICDD 1993 Release A6: Newton Square, Pennsylvania, 1993.

40) Allen, P. G.; Bucher, J. J.; Shuh, D. K.; Edelstein, N. M.; Reich, T. Inorganic Chemistry 1997, 36, 4676-4683.

41) Koningsberger, D. C.; Prins, R. X-ray Absorption : Principles, Applications, Techniques of EXAFS, SEXAFS, and XANES; Wiley: New York, 1988.

42) Slowinski, E. J.; Masterton, W. L. Qualitative Analysis and the Properties of Ions in Aqueous Solution; Saunders: Philadelphia, 1971.

43) Hagan, P. G.; Cleveland, J. M. Journal of Inorganic and Nuclear Chemistry 1966, 28, 2905-2909.

44) Roberts, K. E.; Silber, H. B.; Torretto, P. C.; Prussin, T.; Becraft, K.; Hobart, D. E.; Novak, C. F. Radiochimica Acta 1996, 74, 27-30.

45) Finch, C. B.; Clark, G. W. Journal of Crystal Growth 1970, 6, 245-8.

46) Neck, V.; Runde, W.; Kim, J. I. Solid-Liquid Equilibria of Neptunium(V) in Carbonate Solutions of Different Ionic Strengths. II. Stability of the Solid Phases, 1995, pp 295-302.

47) Fahey, J. A.; Turcotte, R. P.; Chikalla, T. D. Journal of Inorganic and Nuclear Chemistry 1976, 38, 495-500.

48) Martinot Bull. Soc. Chim. Belg. 1970, 79, 125. 
49) Katz, J. J.; Seaborg, G. T.; Morss, L. R. The Chemistry of the Actinide

Elements; 2nd ed.; Chapman and Hall: London ; New York, 1986; Vol. 1. 